ZASPiL Nr. 44, Volume 1 - Juni 2006

Proceedings of the Sinn und Bedeutung 10

\title{
Editors:
}

Christian Ebert \& Cornelia Endriss 


\section{Proceedings of the Sinn und Bedeutung 10}

$10^{\text {th }}$ annual meeting of the Gesellschaft für Semantik October 13-15, 2005 Zentrum für allgemeine Sprachwissenschaft, Berlin

Christian Ebert \& Cornelia Endriss (eds.) 


\section{CONTENTS}

\section{Stavros Assimakopoulos}

Cognitive Representation and the Relevance of On-line Constructions. 1

Maria Averintseva-Klisch

The 'Separate Performative' Account of the German Right Dislocation 15

Kata Balogh

Complex Focus Versus Double Focus

Sigrid Beck \& Arnim von Stechow

Dog After Dog Revisited

Adrian Brasoveanu

Temporal Propositional De Se: Evidence from Romanian Subjunctive Mood 55

Ariel Cohen

Bare Nominals and Optimal Inference 71

Paul Dekker

Mention Some of All .85

Ljudmila Geist

Copular Sentences in Russian vs. Spanish at the Syntax-Semantics Interface

Wilhelm Geuder

Manner Modification of States

Wilhelm Geuder \& Matthias Weisgerber

Manner and Causation in Movement Verbs

Elsi Kaiser

Effects of Topic and Focus on Salience. 
Dalina Kallulli

A Unified Analysis of Passives and Anticausatives

Mana Kobuchi-Philip

A Unified Semantics Analysis of Floated and Binominal Each.

Sveta Krasikova \& Ventsislav Zhechev

You Only Need a Scalar Only.

Eric McCready

Functions of English Man

Telmo Móia

On Temporally Bounded Quantification over Eventualities

\section{Karina Veronica Molsing}

The Present Perfect at the Semantics/Pragmatics Interface:

American English and Brazilian Portuguese

Fabrice Nauze

Multiple Modals Construction

Francesca Panzeri

Forking Paths and Polarity Items Licensing

Doris Penka

Almost There: The Meaning of almost

\section{Daniel Rothschild}

The President and the Man on the Street:

Definite Descriptions and Proper Names across Possible Situations 
Florian Schwarz

Presuppositions in Processing: A Case Study of German auch.

Torgrim Solstad

Word-Meaning and Sentence-Internal Presupposition

Stephanie D. Solt

Why $A$ Few? And Why Not *A Many?

Tamina Stephenson

Quantificational Readings of Indefinites with Focused Creation Verbs

Rachel Szekely

Feature-Placing, Localizability, and the Semantics of Existential Sentences 361

Lucia M. Tovena

Dealing with Alternatives 373

Anna Verbuk

Russian Predicate Clefts: Tensions Between Semantics and Pragmatics 389

Matthias Weisgerber

Decomposing Path Shapes: About an Interplay of Manner of Motion and 'The Path' 405

Hedde Zeijlstra

Don't Negate Imperatives! Imperatives and the Semantics of Negative Markers

Hedde Zeijlstra

How Semantics Dictates the Syntactic Vocabulary

Malte Zimmermann

Adverbial Quantification and Focus in Hausa

\section{Eytan Zweig}

When the Donkey Lost its Fleas:

Persistence, Contextual Restriction, and Minimal Situations 469 


\title{
COGNITIVE REPRESENTATION AND THE RELEVANCE OF ON-LINE CONSTRUCTIONS ${ }^{1}$
}

\author{
Stavros Assimakopoulos, \\ University of Edinburgh \\ stavros@ling.ed.ac.uk
}

\begin{abstract}
In this paper, focusing on the relevance-theoretic view of cognition, I discuss the idea that what is communicated through an utterance is not merely an explicature upon which implicature(s) are recovered, but rather a propositional complex that contains both explicit and implicit information. More specifically, I propose that this information is constructed on the fly as the interpreter processes every lexical item in its turn while parsing the utterance in real time, in this way creating a string of ad hoc concepts. While hearing an utterance and incrementally constructing a context, the propositional complex communicated by an utterance is pragmatically narrowed and simultaneously pragmatically broadened in order to incorporate only the set of optimally relevant propositions with respect to a specific point in the interpretation. The narrowing of propositions from the initial context at each stage allows relevant propositions to be carried on to the new level, while their broadening adds to the communicated propositional complex new propositions that are linked to the lexical item that is processed at every step of the interpretation process.
\end{abstract}

\section{Introduction}

In the tradition of linguistics, most investigations tend to equate an utterance's basic proposition with its semantic representation. This perspective although theoretically attractive, can prove to be problematic with respect to its psychological plausibility (Recanati 2004). At the same time, current research in pragmatics can help offer a more realistic alternative that would allow contextual intrusions to influence the basic proposition communicated by an utterance. A suitable pragmatic framework that could provide a rich background in which to investigate propositional content without compromising the account's psychological plausibility is Relevance Theory, which has already developed a realistic approach to cognition.

This paper sets out to examine propositional content as this is constructed during utterance interpretation and in accordance with the relevance-driven comprehension procedure. To begin with, I will present the basic assumptions of the relevance-theoretic framework and, then, move on to a relevance-theoretic description of the aspects of cognition that underline the context-dependent nature of knowledge representations in our cognitive environment when it comes to verbal communication. In this way, I will introduce the basic ideas that motivate the account proposed by this paper. After discussing the relevance-theoretic notion of context, I will present a scenario of how propositional content is derived directly from the cognitive and communicative approach proposed in Relevance itself. In conclusion, I will

\footnotetext{
${ }^{1}$ I am grateful to Ronnie Cann, Robyn Carston, Caroline Heycock, Ruth Kempson and Deirdre Wilson whose invaluable suggestions and extensive comments fine-tuned the contents of this paper and helped me clarify important details of the current account; yet, they are not to be taken responsible for any errors or misinterpretations present here. Many thanks also to the audience, and particularly Jim Hurford and Dan Wedgwood, who commented on a first version of this paper presented at the University of Edinburgh. Finally, I would like to thank the Sinn und Bedeutung 10 organizers and audience as well as the editors of the present volume.
} 
discuss the implications the proposed account carries and suggest directions for future investigations

\subsection{Relevance Theory}

As a framework, Relevance Theory was received with great enthusiasm by researchers across a wide range of fields, since it provided a revolutionizing approach to cognitive pragmatics, by redefining it in terms of characterizations of relevance. In the mid 80s, Sperber and Wilson developed a framework that addresses communication as a process that involves inference in the recovery of meaning to as great a degree as encoding and decoding.

The motivation behind Relevance Theory (Sperber and Wilson 1986, 1987, 1995, Wilson and Sperber 2004) lies in the ground-breaking work of Grice in the field of pragmatics (1957, 1975, 1989). Sperber and Wilson took up Grice's central idea that communication involves not only a single level of coding and decoding - in the Saussurean meaning of semiology (1974), but also an inferential level that is essential in providing the hearer with the speaker's meaning. Grice had laid down a model of utterance comprehension that described the social norms that apply to communication in the shape of a Cooperative Principle and a set of maxims that people attend to when engaging in it: two maxims of truthfulness, two of informativeness, one of relevance and four of clarity.

Relevance Theory, even though highly influenced by Grice's pioneering work, redefines communication as a cognitive exercise. Sperber and Wilson hold that when we engage in communication we do not merely follow social norms that tell us how to communicate, but rather follow a specific cognitive path that makes us communicate efficiently. This path is prescribed solely on the grounds of our expectations of relevance which are "precise and predictable enough to guide the hearer toward the speaker's meaning" (Wilson and Sperber 2004:607).

Now, what makes an utterance or a general input to our cognitive environment relevant depends on a balance of cognitive effects and processing effort. Other things being equal, the more this stimulus changes our cognitive environment in a positive way the more relevant it is, and the less processing effort it demands in doing so the more relevant it is. Sperber and Wilson support the idea that relevance considerations play a central role in the way our whole cognitive system works. This is spelled out in the Cognitive Principle of Relevance they put forward:

Human cognition tends to be geared to the maximization of relevance.

In the same spirit, they also address communication and, especially, a particular form of it, ostensive-inferential communication. As opposed to other forms of communication, ostensive-inferential communication involves two layers of intentionality from the communicator's point of view. In engaging in this sort of communication, she does not only intend to make manifest to her audience some information (informative intention), but she also intends to make it mutually manifest to both her and her audience that she has this informative intention (communicative intention). In other words, the cognitive task of pursuing ostensive communication means that the communicator does not only communicate a set of assumptions, but also her intention to share this information with her audience.

Against this background, Sperber and Wilson propose a second principle of relevance, the Communicative one, which links ostensive communication to expectations of relevance:

Every act of ostensive communication communicates a presumption of its own optimal relevance.

According to this principle, the audience of ostensive-inferential communication always has a right to presume the optimal relevance of the input given to it. This means that it always has a 
right to presume that the stimulus provided is relevant enough to be worth its processing effort, in the sense that it should provide large positive cognitive effects with minimal effort expenditure, and it is the most relevant one compatible with its communicator's abilities and preferences. On the grounds of the definition of relevance and optimal relevance, relevance theorists also suggest that the comprehension procedure follows a prescribed path:

Check interpretive hypotheses in order of their accessibility, that is, follow a path of least effort, until an interpretation which satisfies the expectation of relevance (i.e. yields enough cognitive effects etc.) is found; then stop.

Coming back to Grice with a view to addressing utterance interpretation, another pioneering assumption of his that is important to relevance-theorists is his notion of implicatures. In Grice's work, the explicit meaning of an utterance is basically decoded via a code (i.e. the language system) while what an utterance implies is derived inferentially from the exact decoded content (i.e. literally what is said), after this has been retrieved, in the form of implicatures. In Relevance Theory, decoded and inferred information are not distinguished in this absolute way, since inferential pragmatic enrichment takes place also in the recovery of an utterance's explicit content, that is its explicature(s), like in the case of reference resolution. In instances of verbal communication, the interpreter of an utterance relies on inference to complete all three subtasks that will guide him to recognizing the intended meaning of the speaker's utterance. As Wilson and Sperber suggest, these subtasks involve three levels of construction (2004:615):

a. Constructing an appropriate hypothesis about explicit content (explicatures) via decoding, disambiguation, reference resolution, and other pragmatic enrichment processes.

b. Constructing an appropriate hypothesis about the intended contextual assumptions (implicated premises).

c. Constructing an appropriate hypothesis about the intended contextual implications (implicated conclusions).

All these subtasks involve inferential processing to a great extent, while an important feature of them is that they are not "sequentially ordered: the hearer does not FIRST decode the logical form, THEN construct an explicature and select an appropriate context, and THEN derive a range of implicated conclusions" (ibid.).

This brief introduction to Relevance Theory is by no means exhaustive. Its applications are numerous and further ideas it puts forward will be discussed in the parts to come. What needs to be addressed at this point is what the relevance-theoretic framework has to say about the way mental content is organized and accessed during utterance interpretation.

\section{On the human cognitive system}

This part of the paper addresses the way in which Relevance Theory assumes knowledge is represented in the human cognitive system. In their framework, Sperber and Wilson have sustained a modified Fodorian view of a modular mind (Fodor 1983) ${ }^{2}$ along with his view that our cognitive environment consists of propositions (Fodor 1975); yet, they have, on several

\footnotetext{
${ }^{2}$ Even though this is of little interest for the purposes of this paper, Sperber and Wilson have since 2000 departed quite substantially from Fodor's view of central processes opting for a more modular approach to what Fodor would traditionally treat as central processes (Sperber and Wilson 2002, Wilson 2005). On other occasions, Sperber $(1994,2002)$ has suggested a model of massive modularity that views the mind as modular through and through with modules coming in all sizes and formats, even in the size of a concept.
} 
occasions, criticised Fodor's views on specific cognitive issues, namely his interpretation of the frame problem ${ }^{3}$, something I will come back to later on.

According to Sperber and Wilson, the total of the knowledge represented in our minds partially constitutes our cognitive environment. More specifically, they define an individual's cognitive environment as "the set of all the facts that he can perceive or infer: all the facts that are manifest to him" (Sperber and Wilson 1995:39), in the shape of assumptions that might be either true or false. More specifically, they suggest that "an individual's total cognitive environment is a function of his physical environment and his cognitive abilities. It consists not only of the facts that he is aware of, but also all the facts that he is capable of becoming aware of, in his physical environment". (ibid.)

In this way, Sperber and Wilson manage to capture the idea that our system of thoughts, i.e. mental representations, contains not only the new information we acquire through the processing of a stimulus - might that be anything from a perceivable object in our visual or acoustic environment to an utterance that we are called to interpret, but also the information that we can acquire through the additional processing of a processed stimulus. These extra representations that are derived from originally perceived ones are as important as the latter in mental processing and can potentially be stored in our knowledge database in very much the same way as perceptually-acquired information is ${ }^{4}$. This view of a cognitive environment respects individuality and gives a psychologically indispensable level of subjectivity to the set of assumptions and thoughts that are represented in our mind ${ }^{5}$.

As already mentioned before, Relevance Theory sustains the Fodorian view that our cognitive environment consists of a propositional repertoire. Thoughts, i.e. "conceptual representations", and assumptions, i.e. subjective "thoughts treated by the individual as representations of the actual world" (Sperber and Wilson 1995:2) are logical forms that have an internal structure, in the form of systematically combined conceptual meanings.

\subsection{Concepts}

Right from its emergence, Relevance Theory has taken up a point that is generally undisputable within cognitive science. According to Sperber and Wilson (1995:85), "it seems reasonable to regard logical forms, and in particular the propositional forms of assumptions, as composed of smaller constituents to whose presence and structural arrangements the deductive rules are sensitive. These constituents we will call concepts".

Sperber and Wilson treat concepts as "triples of entries, logical, lexical and encyclopaedic, filed at an address" (1995:92). A concept has a logical entry in the sense of a set of formal deductive rules that apply to logical forms containing the concept at hand and that produce conclusions from a set of premises. The lexical entry of a concept contains "information about the natural-language lexical item used to represent it" (Sperber and Wilson 1995:90). This information is both phonological and grammatical. Finally, the encyclopaedic entry of a

\footnotetext{
${ }^{3}$ Sperber and Wilson (1996) address the Fodorian Frame Problem as wrongly formulated to begin with by claiming that rational central processes would not consider all information provided as modular input, but rather a selected relevant set of them.

${ }^{4}$ A very good example of information that is provided on such grounds is metarepresentational information, information that maps representations over representations in the way discussed by Sperber (2000) and Wilson (2000).

5 Subjectivity in mental representations is deemed indispensable in a psychologically realistic account of cognition because different individuals might store in their minds different assumptions for the same stimuli. As Penco argues (1999) cognitive science seems to favour "the subjective, cognitive representation of the world" (after McCarthy 1993) over "an objective, metaphysical state of affair” (after Kaplan 1989).
} 
concept is the set of extra information that is linked to its denotation. So, for example, if you have the concept APPLE under scrutiny you can schematically represent its entries as follows ${ }^{6}$ :

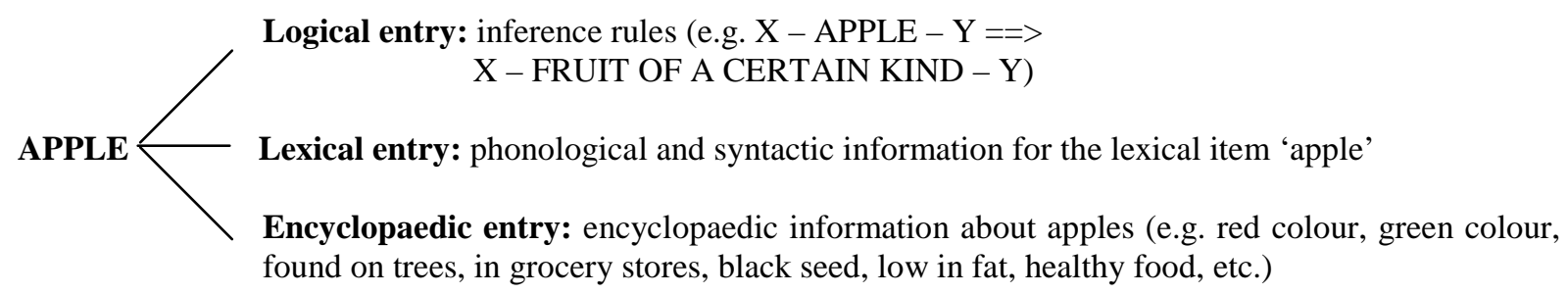

Against this background, most concepts can be represented through their triple entries. Of course, "occasionally, an entry for a particular concept may be empty or lacking" (Sperber and Wilson 1995:92). For example, a concept like BUT would not have an encyclopaedic entry, since it has no extension. Similarly, proper names may lack logical entries. Many concepts even lack lexical entries, like the concept that has UNCLE and AUNT as its subcategories and contains information that is common to both concepts (after Sperber and Wilson 1998).

Relevance Theory distinguishes between the concepts that are stored in our cognitive system and the ones that are communicated through an act of ostensive communication. The former are stable, containing all information linked to the concept in a single conceptual space. However, the concepts that are communicated as parts of, say, the propositional form of an utterance, are rather ad hoc concepts that are constructed on-line during the interpretation process.

The notion of ad hoc conceptual entities was first introduced by Barsalou $(1987,1992)$ in the domain of cognitive science. In his paper 'On the instability of graded structure' (1987), he suggests that individuals tend to produce different sorts of typicality rankings among the same conceptual category members when these are processed in context. Individuals will give different rankings of the same concepts when asked to do so in different situations, like in the case of their own point of view or when judging from the point of view of others. In the same way, people can construct typicality rankings for ad hoc categories (e.g. THINGS THAT CAN FALL ON YOUR HEAD). Through his examples, Barsalou shows that people can easily produce varying representations of the world reflecting context-dependent information they might even have never been processed beforehand in a fast and creative way (Barsalou 1983, 1987, 1993).

Following the experimental research of Barsalou, relevance-theorists suggested that the content of a concept as communicated within a context is constructed ad hoc out of the combination of different parts of encyclopaedic information we have stored in our cognitive system. In other words, relevance-theorists have employed Barsalou's terminology and experiments ${ }^{7}$ to describe the end-product of a process of on-line concept construction during the interpretation process (Carston 2002, 2004, Wilson 2004, Wilson and Sperber 2004). The relevance-theoretic account of lexical meaning suggests that a lexical form maps to a conceptual address in memory, the address that links to the lexical, logical and encyclopaedic entries of a concept, and the context provides the relevant encyclopaedic information that is used with the communicated ad hoc concept in a selective manner. For example, let us consider the following utterance:

\footnotetext{
${ }^{6}$ After Wilson 2002

${ }^{7}$ Barsalou's work has provided evidence mainly for the relevance-theoretic claims of conceptual narrowing that have been present since the beginning of the framework. Later, these claims were generalised to apply to broadening as well (Carston 1996).
} 
The standard relevance-theoretic account would suggest that what is communicated in this utterance is a set of concepts, including an ad hoc concept BACHELOR*. This move is justifiable by certain assumptions communicated along with the utterance in the context of situation. From the point of view of Mary and our knowledge about her the ad hoc concept BACHELOR* refers to unmarried men who are eligible for marriage. In this way, the Pope would not qualify as a bachelor that Mary wants to meet. Similarly, in the situation where Mary is thinking about becoming a nun and is, thus, considering 'unweddedness', she might want to meet bachelors that have also selected to remain unwedded, by becoming God's servants of some sort, and are, therefore, not eligible to marriage.

Relevance Theory makes a clear distinction between already stored concepts that are holistic and contain specific information within interconnected conceptual spaces and concepts that are constructed on-line. What relevance theorists are now dealing with in their work in lexical pragmatics is the way in which these two 'types' of concepts are linked (Wilson 2004). In a nutshell, Relevance Theory suggests that 'the stored lexical concept provides the starting point for the on-line construction of the ad hoc concept which proceeds as part of the utterance comprehension process and so is constrained, as ever, by the search for an optimally relevant interpretation'.

The view that I will be employing in this paper is that all communicated concepts are in effect ad hoc concepts. This move should be justified within the general picture of the relevancetheoretic framework. The linguistically encoded stored concept that is triggered by the utterance of a lexical item points to some space in memory within which the interpreter needs to look for relevant information against the context in which he is processing the utterance. The relevance heuristic should lead him to select the most easily accessible part of this information that will provide adequate cognitive effects. In this way, the information communicated by each lexical item in an utterance does not correspond to the whole of the stored concept's information but is constructed ad hoc by the interpreter in the manner prescribed by the relevance-theoretic comprehension procedure.

\subsection{Propositions}

Having addressed conceptual content, a discussion of propositional content seems indispensable at this point. As already noted above, against the background of Relevance Theory, propositions are logical forms that constitute structured sets of concepts. In light of the previous treatment of concepts, it is clear that when it comes to utterance interpretation, propositional content comprises structured $a d$ hoc concepts ${ }^{8}$.

An important aspect of utterance interpretation that was underlined by Sperber and Wilson in Relevance is that the recovery of explicatures and implicatures occur on the fly. As put forth in the identification of the subtasks involved in the utterance comprehension process, interpretation takes place in a time-linear manner. This should have direct implications for the examination of an utterance's communicated propositional content.

Firstly, the proposition communicated by an utterance is constructed on-line by the hearer. This challenges the traditional view that equates the basic proposition communicated by an utterance with its semantic representation. Taking up the relevance-theoretic account of

\footnotetext{
${ }^{8}$ A point that needs to be put forth here is that there is a distinction between what a proposition is with respect to cognition and what a proposition is with respect to communication. The latter, which is in the centre of attention in this paper, is an outcome of the interpretation process that is constructed on-line, while the former is stored in our cognitive system and has a relatively stable content.
} 
meaning construction makes this basic semantic representation of a given utterance a mere template upon which pragmatic enrichment takes place. In a psychologically plausible account of utterance interpretation, the hearer parses and interprets an utterance in a left-toright time linear way. While the hearer processes the utterance one step at a time, lexical item by lexical item, he is enriching the semantic content of each communicated concept against a context. This occurs dynamically and the hearer would not necessarily wait up to the end of the utterance to engage in any processing. Sperber and Wilson assume that "logical forms, like syntactic forms are trees of labeled nodes" (Sperber and Wilson 1995:205). By parallel arguments to the ones that want syntactic labels to generalize over grammatical categories, logical labels categorise conceptual representations of different types. As Sperber and Wilson argue (1995:206), by association to syntactic anticipatory hypotheses the hearer may make, he can easily make anticipatory hypotheses for the logical categories that are to appear before they $\mathrm{do}^{9}$. Consequently, at any point during interpretation the hearer both entertains specific expectations about what is to follow and can amend his previous choices in constructing the propositional content of an utterance.

Accordingly, in utterance interpretation, explicatures and implicatures are constructed on the fly as well. Inferential processing occurring to this effect takes place at the same time as the decoding of the utterance's content. What is suggested again by this view is that what an utterance communicates is constructed dynamically. Essentially, what a hearer constructs successively in interpreting an utterance is not a basic proposition upon which further conclusions (in the shape of higher-order explicatures or implicatures) are inferred, but rather a propositional complex that contains both explicit and implicit propositions.

In this sense, an utterance's basic proposition is redefined to its pragmatically enriched semantic content. This would ultimately mean that what the hearer has at the end of an utterance's interpretation is a structured set of ad hoc concepts, i.e. an ad hoc basic proposition, which communicates a certain set of additional propositions (thoughts) about the explicit and implicit information conveyed by the utterance.

\section{Communicated propositional content}

Having established the aspects that a psychologically plausible account of communicated propositional content needs to respect, a rather straightforward picture of the way in which propositional content is constructed in utterance interpretation presents itself. A final point that needs to be noted is that the construction of an utterance's propositional content always occurs against a context. So, before moving on to the account of how an utterance's enriched basic proposition is constructed, it is important to introduce the notion of context in Relevance Theory.

\subsection{Context in Relevance Theory}

In Relevance, Sperber and Wilson provide an insightful definition of context that respects its subjective nature and is general enough to accommodate the variety of information context contains in every situation (1995:15-16):

\footnotetext{
${ }^{9}$ Relevance Theory has little to say about this, but a formal account that incorporates relevance-theoretic assumptions in its theoretical premises, Dynamic Syntax (Kempson et.al. 2001), makes extensive use of this idea. Dynamic Syntax holds that when a hearer interprets an utterance, parsing it one lexical item at a time, he entertains specific expectations about what is to follow in the utterance. This is clearly illustrated in cases of routinisation (Purver et.al. to appear):
}

(e.g.) Ruth: What did Alex give to Hugh: Eliot? A teddy-bear. 
A context is a psychological construct, a subset of the hearer's assumptions about the world. It is these assumptions, of course, rather than the actual state of the world, that affect the interpretation of an utterance. A context in this sense is not limited to information about the immediate physical environment or the immediately preceding utterances: expectations about the future, scientific hypotheses or religious beliefs, anecdotal memories, general cultural assumptions, beliefs about the mental state of the speaker, may all play a role in interpretation.

It is clear from this description that, in the relevance-theoretic framework, context is not a metaphysical concept, since it does not contain information about the actual state of the world', but rather information about an individual's representation of the world in the sense of a 'private logbook' or 'an ego-centred map'. In Relevance, Sperber and Wilson discuss context to a considerable extent (1995:132-142). In their discussion, they discard the classical view that in the interpretation of the utterance the context is given and predetermined. In a luminous discussion of what this case would entail, they reach the conclusion that such a view of context would ultimately require the whole volume of our cognitive environment to be the context of the interpretation of a single utterance. Resolving this impossibility they suggest that "the context used to process new assumptions is, essentially, a subset of the individual's old assumptions, with which the new assumptions combine to yield a variety of contextual effects" (1995:132). And this subset is selected on-line while the interpretation takes place. However, even though they have been criticised for not doing so (Chiappe an Kukla 1996), Sperber and Wilson never explicitly discussed the way in which we selectively construct a context when interpreting an utterance.

Against this background, in previous work on context selection (Assimakopoulos 2003), I have entertained the idea that an utterance's context is selected automatically by the same heuristic that mediates the construction of its explicature(s) and implicatures, the relevancedriven comprehension procedure. Within the spirit of the Cognitive Principle of Relevance, I have proposed that relevance considerations mediate the process of selecting a set of assumptions against which an utterance is to be processed and comprehended, a line that will be maintained for the purposes of this paper too.

\subsection{Constructing an utterance's propositional complex}

At this point and in the dynamics discussed in the previous parts, it would be interesting to see how an utterance's basic proposition in the sense endorsed by this paper is constructed on-line as each lexical item ${ }^{10}$ of the utterance is interpreted in turn.

At the outset of the interpretation process there is always an initial context present to the hearer before the utterance is produced. This is a set of propositions that are not tested for cognitive effects with respect to this utterance up to the point when the first lexical item is uttered. In a dialogue this context would minimally be the propositional complex expressed by the previous utterance.

With the utterance of the first lexical item a subset of propositions is selected in a relevancedriven manner from the initial context. Along with this set, more propositions are triggered by the new concept that is introduced and added to the context in which the hearer interprets the utterance. All these propositions will be again tested for relevance as more lexical items are

\footnotetext{
${ }^{10}$ I will assume that a lexical item is a lexical chunk (either a word, an idiom etc) that carries a homogeneous meaning in its premises. "It is clear that we can use and understand far more words (in the morphological sense) than we have learned. As soon as one learns the word stay, the words stayed, staying and stays all come for free" (Bloom 2000:16). For the purposes of this paper I will take up a rather simplistic notion that connects conceptual information with the meaning of a word as a whole. I believe that morphology would have more to say about this, but will not attend to it as of now.
} 
processed in turn. Again, some of these propositions will be abandoned and new ones will be tested for relevance against the context of the utterance up to the point where the utterance ends.

I will try to illuminate what is still a quite blurry picture by use of an example utterance and the propositional complex its production makes the hearer to construct:

(2) John loved the smell of Mary.

To begin with, there is an initial context $S_{i}$ present before the uttering of the first word. This context consists of propositions $T^{11}$ that are linked to whatever provided cognitive effects prior to the hearing of this utterance - that is something in the physical environment or even a previous utterance the hearer just processed.

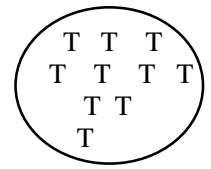

$S_{i}$

Upon hearing the first word, John, the hearer begins his interpretation. The conceptual address for JOHN is, thus, triggered in his mind. The whole set of this concept's information is activated but not yet tested for cognitive effects. The hearer selects the relevant propositions from $S_{i}$ that are likely to be included in the final propositional complex $\left(C_{n}\right)$ denoting the meaning of this utterance. These propositions are relevant since they should provide large cognitive effects with respect to $S_{i}$.

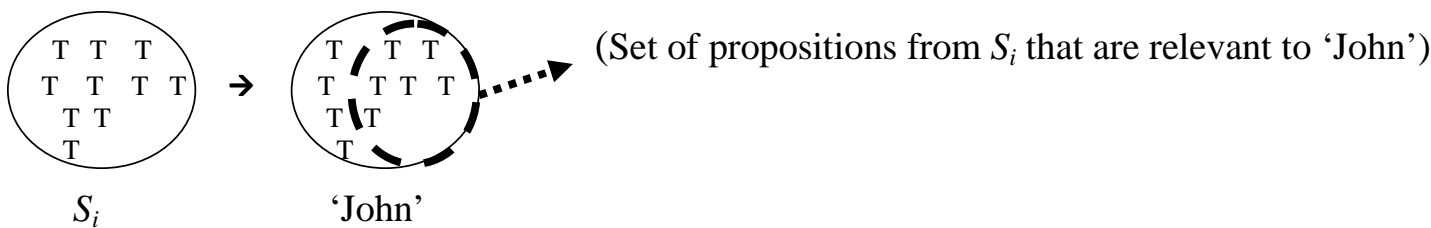

Accordingly, at the same time, new propositions about JOHN that are not included in $S_{i}$, namely contextual information about John that is readily available in the hearer's cognitive environment and can provide rich cognitive effects, get added to the list of propositions that might be intended to get communicated by this utterance $\left(C_{l}\right)$. At the same time, the context in which the utterance is processed is augmented to include these propositions as well. Discarded propositions from $S_{i}$ would be kept in a buffer that would allow their easy reactivation.
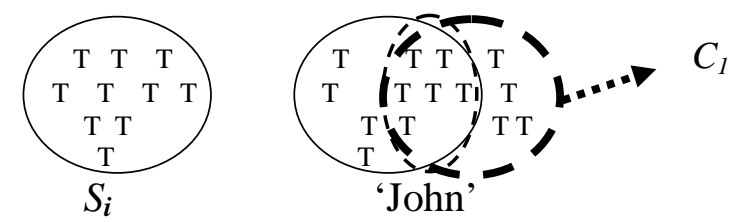

On the hearing of the second word another conceptual address is activated and propositions linked to its content are constructed. In a manner similar to the way $C_{1}$ has been selected, a new complex of relevant propositions $C_{2}$ is constructed. Relevant propositions from the previous context are carried over to $C_{2}$, while new ones triggered by LOVE in the now accordingly augmented context that are deemed relevant are added up to it. In this way an $a d$ hoc concept $\mathrm{JOHN}^{*}$ is constructed. This concept is ad hoc because it contains only the information about John that is relevant to this utterance's interpretation and potentially

\footnotetext{
${ }^{11} \mathrm{~T}$ is used conveniently to represent thoughts, since these are logical trees in light of Sperber and Wilson's suggestion that Dynamic Syntax developed formally.
} 
information that will be included in the final propositional complex that will denote the utterance's meaning.

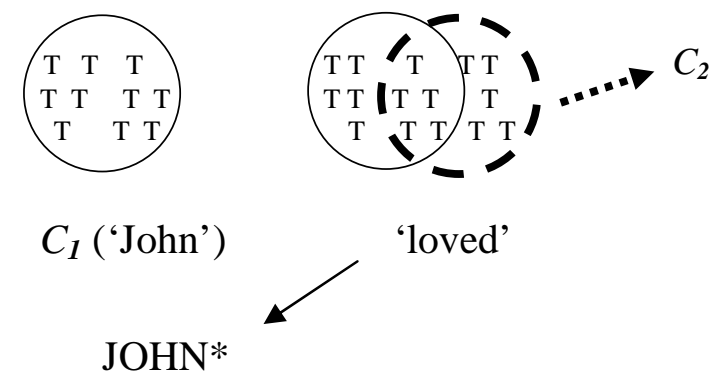

The same scenario applies for all words with conceptual content in the utterance up to the point where the interpretation of the final lexical item occurs and the utterance's explicature(s) and implicatures are fully constructed.

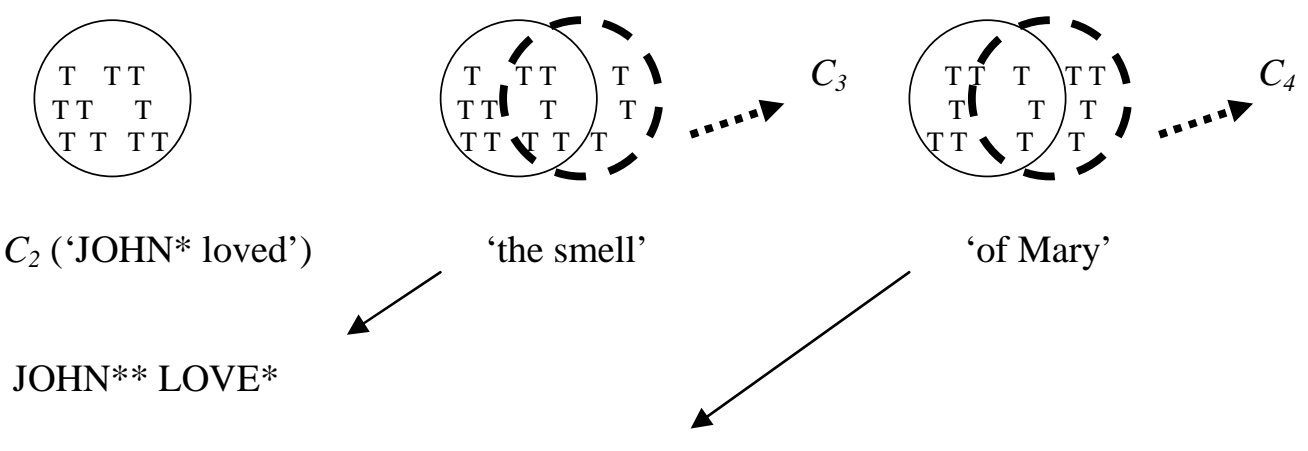

$\mathrm{JOHN}^{* * *} \quad$ LOVE** $^{* *} \quad$ SMELL*

At the end of processing the whole utterance, the concept MARY will again be adjusted to the ad-hoc concept MARY* that communicates the specific property of having a smell that is loved by John. The propositional complex $C_{5}$ ultimately contains the total of the explicature(s) and implicatures the hearer has constructed with respect to utterance (2). In effect, the basic proposition of the utterance is this complex that is communicated by it, which is pragmatically derived.

\subsection{Propositional content adjustment: narrowing and broadening}

It is obvious in this treatment of propositional content that at every stage of its adjustment there are two processes that go on; one of narrowing and one of broadening. After discussing each one, I will entertain the possibility of symmetrifying both of them, by proposing that both processes are processes of narrowing.

As already discussed above, at the beginning of the interpretation and upon hearing the first lexical item of the utterance, the hearer begins his interpretation by selecting from an initial context the propositions that are relevant to the concept communicated by the item just uttered. This selection is the result of narrowing the initial contextual space in the search for relevance. At the same time this selection takes place, another set of propositions appears to the foreground of the processing. This is the set of propositions the utterance of the lexical item introduces. Again these propositions are tested for cognitive effects in search of relevance against the initial context augmenting it. A relevant set of them is again added up to the initial propositional complex that comprises candidates for the utterance's meaning. In 
this way, the potential propositional complex is broadened to accommodate more propositions introduced by the new lexical concept that is communicated.

In the tradition of Carston on concept narrowing (Carston 1996, 2002), I will too suggest that this broadening and narrowing of propositional content illustrates essentially a case of pragmatic narrowing. It is obvious that the heuristic that causes contextual adjustment is relevance. In a way, even if the propositional space in which cognitive effects are searched is large there is always a need to make it as small as possible in order to save effort. So, even when the propositional complex is augmented, the relevance heuristic imposes that not an exceedingly large number of new propositions will be added up to it, which in a sense narrows down the number of potential candidates for inclusion in the complex.

\section{Conclusion}

Any realistic account of communicated meaning is required to take into account the fact that interpretation is a dynamic process that enables pragmatic enrichment to occur automatically along with linguistic decoding. This paper has put forward a cognitive account of the way knowledge is accessed when context-dependent processing of an utterance takes place. The dynamic characteristic of this approach is that it rejects the semantic view of propositional content. Pragmatic enrichment occurs at most levels of cognitive processing and evidence from cases of on-line meaning construction places context-dependency and especially, as expected through the first principle of relevance, relevance considerations to the centre of cognition. While engaging in utterance comprehension, the hearer interprets each lexical item in turn constructing an enriched basic proposition on-line. At the end of an utterance's processing, this basic proposition is a structured set of ad hoc concepts that also contains all the information (thoughts, in the shape of explicatures and implicatures) that is deemed relevant at that stage against the context of the utterance.

No matter how speculative the nature of this system might seem at this point, it manages, along with all the other tenets of Relevance Theory, to provide the starting point for a potential outline of a generative system for pragmatic competence. Contrary to Chomsky's reservations that an attempt to build a theory of pragmatic competence "yields computational systems of hopeless scope, compelling us to try to formulate what amount to "theories of everything' that cannot possibly be the topic of rational inquiry" (Stemmer 1999:399-400), the relevance-theoretic approach to the way contextual constraints mediate cognitive computation seems to succeed in capturing the way mental processing occurs providing the foundations for a generative system of communicative competence.

\section{References}

Assimakopoulos, S.: 2003, Context selection and relevance, paper delivered at the 2003 Theoretical \& Applied Linguistics Postgraduate Conference, University of Edinburgh.

Barsalou, L.: 1983, Ad hoc categories, Memory \& Cognition 11: 211-227.

Barsalou, L.: 1987, The instability of graded structure: Implications for the nature of Concepts, in U. Neisser (ed), Concepts and conceptual development: Ecological and intellectual factors in categorization, Cambridge University Press, pp. 101-140.

Barsalou, L.; 1992, Frames, concepts, and conceptual fields, in E. Kittay and A. Lehrer, (eds), Frames, fields, and contrasts: New essays in semantic and lexical organization, Lawrence Erlbaum, pp. 21-74. 
Barsalou, L.; 1993, Flexibility, structure, and linguistic vagary in concepts: Manifestations of a compositional system of perceptual symbols, in A.C. Collins, S.E., Gathercole and M.A. Conway (eds), Theories of Memory, Lawrence Erlbaum, pp. 29-101.

Bloom, P.: 2000, How children learn the meanings of words. Cambridge, MA: MIT Press.

Carston, R.: 1996, Enrichment and loosening: Complementary processes in deriving the proposition expressed?, UCL Working Papers in Linguistics 8: 205-232.

Carston, R.: 2002, Thoughts and utterances: The pragmatics of explicit communication. Oxford: Blackwell.

Carston, R.: 2004, Relevance theory and the saying/implicating distinction, in L. Horn and G. Ward (eds) Handbook of Pragmatics, Blackwell, pp. 633-656.

Chiappe, D.L. and Kukla, A.: 1996, Context selection and the frame problem, Behavioral and Brain Sciences 19: 529-530.

Fodor, J.: 1975, The language of thought. New York: Thomas Crowell.

Fodor, J.: 1983, Modularity of mind. Cambridge, MA: MIT Press.

Grice, P.: 1957, Meaning, Philosophical Review 66: 377-388

Grice, P.: 1975, Logic and Conversation, in P. Cole and J.L Morgan (eds) Syntax and semantics volume 3: Speech acts, Academic Press, pp. 41-58.

Grice, P.: 1989, Studies in the way of words. Cambridge, MA: Harvard University Press.

Kaplan, D.: 1989, Afterthoughts, in J. Almog, J. Perry and H. Wettstein (eds), Themes from Kaplan, Oxford University Press, pp. 565-614.

Kempson, R., Meyer-Viol, W. and Gabbay, D.: 2001, Dynamic Syntax: The Flow of Language Understanding. Oxford: Blackwell.

McCarthy, J.: 1993, Notes on formalizing context, in IJCAI '93 - Proceedings of the thirteenth international joint conference on Artificial Intelligence. Morgan Kaufman 555560.

Penco, C.: 1999, Objective and cognitive context, in P. Bouquet, L. Serafini, P. Brézillon, M. Benerecetti, and F. Castellani (eds), Modeling and using context: Second international and interdisciplinary conference, CONTEXT'99, Trento, Italy, September 1999, Proceedings, Springer-Verlag, pp. 270-283.

Purver, M., Cann, R. and Kempson, R.: to appear, Grammars as parsers: meeting the dialogue challenge, Research on Language and Computation.

Recanati, F.: 2004 Literal Meaning. Cambridge: Cambridge University Press.

Saussure, F. de: 1974, Course in general linguistics. London: Peter Owen.

Sperber, D.: 1994, The modularity of thought and the epidemiology of representations, in L. Hischfeld and S. Gelman (eds), Mapping the mind: Domain specificity in cognition and culture, Cambridge University Press, pp. 47-57. 
Sperber, D.: 2000, Metarepresentations in an evolutionary perspective, in D. Sperber (ed), Metarepresentations: A Multidisciplinary Perspective, Oxford University Press, pp. 117137.

Sperber, D.: 2002, In defense of massive modularity, in E. Dupoux (ed), Language, brain and cognitive development: Essays in honor of Jacques Mehler, MIT Press, pp. 47-57.

Sperber, D. and Wilson, D.: 1986, Relevance: Communication and cognition. Oxford: Blackwell.

Sperber, D. and Wilson, D.: 1987, Précis of Relevance: Communication and cognition, Behavioral and Brain Sciences 10: 697-710.

Sperber, D. and Wilson, D.: 1995, Relevance: Communication and cognition ( $^{\text {nd }}$ edition with postface). Oxford: Blackwell.

Sperber, D. and Wilson, D.: 1996, Fodor's frame problem and relevance theory, Behavioral and Brain Sciences 19: 530-532.

Sperber, D. and Wilson, D.: 1998, The mapping between the mental and the public lexicon, in P. Carruthers and J. Boucher (eds) Thought and language, Cambridge University Press, pp. 184-200.

Sperber, D. and Wilson, D.: 2002, Pragmatics, modularity and mindreading, Mind and Language 17: 3-23.

Stemmer, B.: 1999, An on-line interview with Noam Chomsky: On the nature of pragmatics and related issues, Brain and Language 68: 393-401.

Wilson, D.: 2000, Metarepresentation in linguistic communication, in D. Sperber (ed), Metarepresentations, Oxford University Press, pp. 411-448.

Wilson, D.: 2002, Issues in pragmatics, UCL lecture notes.

Wilson, D.: 2004, Relevance and lexical pragmatics, UCL Working Papers in Linguistics 16: 343-360.

Wilson, D.: 2005, New directions for research on pragmatics and modularity, Lingua 115: 1129-1146.

Wilson, D. and Sperber, D.: 2004, Relevance Theory, in L. Horn and G. Ward (eds), Handbook of Pragmatics, Blackwell, pp.607-632. 


\title{
The 'Separate Performative' Account OF THE GERMAN RIGHT DISLOCATION*
}

\author{
Maria Averintseva-Klisch, \\ HU Berlin \\ maria.averintseva@rz.hu-berlin.de
}

\begin{abstract}
In my paper, I show that the so-called German right dislocation actually comprises two distinct constructions, which I label 'right dislocation proper' and 'afterthought'. These differ in their prosodic and syntactic properties, as well as in their discourse functions. The paper is primarily concerned with the right dislocation proper (RD). I present a semantic analysis of RD based on the 'separate performative' account of Potts $(2004,2005)$ and Portner (forthc.). This analysis allows a description of the semantic contribution of RD to its host sentence, as well as explaining certain semantic constraints on the kind of NP in the RD construction.
\end{abstract}

\section{Introduction}

In this paper I discuss the construction that is traditionally called 'German right dislocation' (cf. Altmann (1981)). This is a structure consisting of an NP at the end of the clause and a coreferent proform inside the clause, as in (1):

a. Ich mag sie ${ }_{\mathrm{i}}$ nicht, (ich meine) die Serena ${ }_{i}$ I like her not (I mean) the Serena ${ }_{i}$.

b. Und dann passierte das Unglück, (ich meine) dieser schreckliche Autounfall. And then happened the misfortune ${ }_{i}$ (I mean) this terrible traffic-accident $_{i}$.

Traditional analyses of German right dislocation (Altmann (1981), Auer (1991), Selting (1994), Uhmann (1993, 1997), Zifonun et al. (1997)) assume that right dislocation is a strategy of spoken German, which enables the speaker to resolve a (pro)nominal reference that might be unclear to the hearer. This analysis accounts for (1), but is problematic for (2), where pronominal reference is undoubtedly clear:

a. "Ein Taifun!" rief Lukas dem Kapitän zu. "Da ist er!" Ja, da "A typhoon!" called Lukas the captain to. "Here is he!" Yes there war er, der Taifun.

was $_{i}$ the typhoon MASK $_{\text {. }}$.

[M. Ende, Jim Knopf und die Wilde 13: 190]

b. [...] wenn ihnen das Glück nicht den Karpfen Cyprinus zur Hilfe geschickt [...] if them the fortune not the carp Cyprinus for help sent hätte! Ahnungslos kam er dahergeschwommen, der Karpfen Cyprinus. had! suspecting-not came he $e_{i}$ swimming-along the carp $_{\mathrm{MASK}}$ Cyprinus $_{i}$.

[O. Preussler, Der kleine Wassermann: 28]

\footnotetext{
* The research for this paper has been conducted as part of my Ph.D. project, which is financed by the DFG within the graduate school "Ecomony and Complexity in Language" (HU Berlin / Potsdam Univ.). I wish to thank my supervisor Claudia Maienborn for her constant support, Manfred Consten, Mareile Knees and Barbara Schlücker for helpful comments on this paper, as well as the audience of Sinn und Bedeutung 10 for stimulating feedback.
} 
In (2), the function of the right dislocation is not to disambiguate a pronominal reference, as it is not ambiguous at all, but to mark the referent of the right-peripheral NP as being especially important for the succeeding discourse. In other words, the typhoon (2a) and, respectively, the carp (2b) are set as what the following discourse segment is about. In fact, in (2a) the following segment offers a detailed description of the typhoon, and ( $2 b)$ continues describing the carp, its appearance and habits ${ }^{1}$.

It has already been noticed in the literature that right dislocation might have an additional function of "attracting the attention of the addressee" to the right-peripheral NP (Zifonun et al. (1997:548), transl. mine: MA). I argue that disambiguation of a pronominal reference and marking the importance of the discourse referent are not two functions of one construction, but that there are in fact two constructions subsumed under the label of German right dislocation: right dislocation proper (further right dislocation, RD) and afterthought (AT). In the following I will show that RD and AT differ not only with respect to their discourse functions, but also in their prosodic and syntactic features.

The paper is organized as follows: in section 2 the prosodic, syntactic and discoursefunctional properties of RD and AT are briefly introduced. I show that RD is prosodically and syntactically part of its host sentence, whereas AT is an 'orphan' that gets integrated into its host sentence only at the level of the discourse. Then I turn to the main subject of the paper, i.e. to the semantics of RD, or, more precisely, the semantic contribution of RD to its host sentence. In section 3 I introduce the 'separate performative account' (Potts (2004, 2005), Portner (forthc.)). I will show how Portner's account of English topics can be applied to the analysis of RD. Section 4 then discusses how the semantics of RD determines its discourse function of marking the discourse topic referent for the discourse segment following RD. Certain peculiarities of RD concerning the semantic status of the RD-NP are dwelt upon in this context. Finally, in section 5 the results are summed up and some conclusions are drawn.

\section{RD vs. AT: prosodic, syntactic and discourse-functional differences}

In order to concentrate on the semantics of RD I first have to clearly distinguish between RD and AT. Therefore, in this section I will introduce the prosodic and syntactic differences between RD and AT. They all suggest that RD is prosodically and syntactically part of its host sentence, while AT is not. Many of these differences have been already pointed out in Altmann (1981). However, as Altmann does not make any differentiations within right dislocation constructions, his approach is to state a certain prosodic and syntactic pattern for German right dislocation, whereupon he has to allow for numerous exceptions from this pattern. Distinguishing between RD and AT allows us to dispense with most exceptions, and to describe distinct patterns for RD and AT instead. In section 2.2. I will then specify the discourse functions of RD and AT which have been mentioned above.

\subsection{RD vs. AT: prosodic and syntactic differences}

RD is prosodically integrated into its host sentence (3a), i.e. it continues the tone movement of the host sentence and thus does not build a prosodic unit of its own, whereas AT builds a prosodic unit (optionally divided by a pause from the clause) with a tone movement and a clause-like accent of its own, (3b): ${ }^{2}$

\footnotetext{
${ }^{1}$ Moreover, (2) shows that right dislocation is used also in written, and not only in spoken, discourse.

${ }^{2}$ Altmann (1981) observes two distinct prosodic patterns by what he calls "German right dislocation", but does not explain this observation. Selting (1994) differentiates two kinds of "right dislocation" on the basis of their
} 
(3)
a. [Ich MAG sie nicht, die Brigitte $_{\mathrm{i}}$ ].
b. [Ich MAG sie nicht], |[die BriGITte ${ }_{\mathrm{i}}$ ].
I like her not the Brigitte.
(|: pause; [ ]: prosodic unit; CAPITALS: main accent)

Prosodic differences go along with syntactic differences: RD is also syntactically part of its host sentence, whereas AT is an independent unit. The syntactic differences are listed below ${ }^{3}$.

- Strict morphological agreement (in case, gender and number) between the clauseinternal pro-form and the NP is obligatory for RD and optional for AT, cf. (4) vs. (5):
("Der Taifun!"
rief Lukas dem Kapitän zu. "Da
ist er!") Ja, da war
("The typhoon $n_{\mathrm{MASK}}$ !" called Lukas the captain to. "Here is he!") Yes, there was

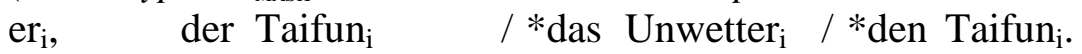
RD
$h e_{\text {NOM_MASK }}$ the typhoon $n_{\text {NOM_MASK }} / *$ the storm $_{\text {NOM_MASK }} / *$ the typhoon ACC_MASK $_{\text {A }}$
a. Der Zwiespalt [...] zerriss
$\mathrm{ihn}_{\mathrm{i}}$
fast: [Fürst
Georg III., der Reformator

The dichotomy [...] tore-apart

him $_{\mathrm{ACC}}$ nearly: prince Georg III [the reformer

von Anhalt-Dessau $]_{i}$.

of Anhalt-Dessau] $]_{\text {Noм. }}$.

[Chrismon 05/2004]

b. Und dann passierte das Unglück, (ich meine) dieser schreckliche And then happened the misfortune NEUTR $_{\text {(I mean) [this terrible }}$ Autounfall. traffic-accident $]_{\text {MASK }}$.

- A subordinate clause between the clause-internal pro-form and the NP is impossible for RD and possible for AT, cf. (6):

a. „Der Taifun“, rief Lukas dem Kapitän zu. „Da ist er!“ Ja, da war "The typhoon!" calledLukas the captain to. "Here is he!" Yes, here was er, *den sie alle gefürchtet haben, der Taifun. $h e_{i} *$ whom they all afraid-of were the typhoon . $^{\text {. }}$

b. So ereilte den TV-Western das, wovor sich der Filmwestern durch So overtook the $T V$-western ACC $_{\text {this }}$ what-of refl the cinema-western through einen stilvollen Selbstmord entzog, der schleichende Tod. AT a classy suicide escaped [the sneaky death] ${ }_{i}$.

[Konkret-Korpus: 289311]

- Optional additions (ich meine ('I mean'), also ('that is'), tatsächlich ('really') etc.) between the clause-internal pro-form and the NP are possible for AT but not for RD, ${ }^{4} \mathrm{cf} .(7)$ :

prosodic difference. In her account, however, prosodic difference is the only important one; functionally, both kinds of "right dislocation" are analysed as a repair strategy. As I show above, RD and AT do not only differ with regard to prosody, but also syntactically as well as in their discourse functions. In a similar way, Fretheim (1995) shows that in Norwegian prosody also helps to distinguish between RD and AT; as in German, prosodically integrated structures are RDs, and prosodically non-integrated ones ATs.

${ }^{3}$ Here I only give a brief listing of syntactic differences, since they are not the main subject of this paper. See Averintseva-Klisch (forthc. a \& b) for more details.

${ }^{4}$ As the examples show, the (im)possibility of additions with RD and AT is not due to the meaning and function of the addition, as one might be tempted to believe in the case of ich meine / also ('I mean' / 'that is'), which are additions explicitly assisting the reference clarifying function of AT. Also additions like natürlich ('of course'), tatsächlich ('really') etc., which are insensitive to the functional difference between RD and AT, are bad with RD and perfectly acceptable with AT. Thus, this difference seems to be a syntactic one. 
a. „Der Taifun“, rief Lukas dem Kapitän zu. „Da ist er!“ Ja, da war "The typhoon!" called Lukas the captain to. "Here is he!" Yes, here was er, (*ich meine / *also / *tatsächlich) der Taifun. he $(* I \quad$ mean /*that-is/*really) the typhoon.

b. (Lisa und Melanie haben sich gestritten.)

(Lisa and Melanie quarrelled.)

Dann ist sie weggelaufen, | (ich meine / also) Lisa.

Then is she run-away (I mean / that-is) Lisa.

- The NP is not bound at the right-peripheral position in the case of AT, but can have a fairly free position in its host sentence, while RD is only possible at the right periphery, cf. (8) vs. (9):

a. Ich habe ihn gestern nur mit Mühe wiedererkannt, | ich meine den PEter. I have him yesterday onlywith effort recognized I mean the Peter.

b. Ich habe ihn, | ich meine den PEter |, gestern nur mit Mühe wiedererkannt. I have him I mean the Peter yesterday onlywith effort recognized.

c. Ich habe ihn gestern, | ich meine den PEter,|nur mit Mühe wiedererkannt. I have him yesterday I mean the Peter only with effort recognized.

I hardly recognized him yesterday, I mean Peter.

(9) a. (Dieser Peter!) Ich kann ihn ${ }_{i}$ nicht leiden, den Peter ${ }_{i}$. (This Peter!) I can him not suffer the Peter

b. (Dieser Peter!) *Ich kann ihn ${ }_{i}$, den Peter ${ }_{i}$, nicht leiden ${ }^{5}$. (This Peter!) I can him the Peter not suffer

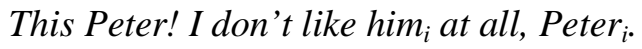

To summarize: there is ample evidence that RD belongs prosodically and syntactically to its host sentence in a much more straightforward way than AT. Prosodically, RD is a part of its host sentence's tone contour. Morphological agreement of the RD-NP with the clause-internal pro-form suggests that NP is part of the clause, as morphological agreement is a sentencebound phenomenon. Moreover, RD occupies a fixed position in the host sentence at its right periphery, and does not allow subordinate clause insertion nor optional additions of any kind between the host sentence and the RD-NP. This leads to the assumption that RD is part of its host sentence, presumably the right adjunct to the IP. An ultimate syntactic analysis of RD would exceed the limits of this paper.

AT, on the contrary, can vary its position in its host sentence. Furthermore, AT does not strictly require morphological agreement between the NP and the clause-internal pronoun, and it allows various insertions between the host sentence and AT-NP. All in all, AT appears to be syntactically fairly free. In this paper I consider AT only as far as it is necessary for delimiting $\mathrm{RD}$ as a separate construction. More details about AT are given in Averintseva-Klisch (forthc. a \& b). I propose to analyze AT as an 'orphan' in terms of Haegeman (1991). An orphan is a unit that is syntactically independent of its host sentence, but gets integrated into it only at the level of the discourse via some discourse relation.

The topic of this paper is the semantics of RD and how it determines the function RD has in the discourse. I first point to the discourse-functional differences between RD and AT. Then I concentrate on RD and its semantics.

\footnotetext{
${ }^{5}$ Here I use the prosodic structure as a diagnostics to distinguish between RD and AT. This means that for cases marked as RD I assume prosodic integration. In other words, (9b) is bad with the RD prosody. It would, however, be perfectly well-formed as an AT construction if the NP builds a prosodic unit of its own.
} 


\subsection{RD vs. AT: discourse-functional differences}

As shown above, RD marks a discourse referent as being the 'theme' for the following discourse segment. ${ }^{6}$ In the following, I name the discourse referent about which a certain discourse segment is 'discourse topic referent'. ${ }^{7}$ RD thus marks a discourse referent ${ }^{8}$ as the discourse topic referent for the segment following the RD, cf. (10):

(10) (Und als der König seine Frau verloren hatte, bedauerte ihn die Dutitre: "Ach ja, für Ihnen is et ooch nich so leicht [...].")

(And when the king lost his wife, Dutitre pitied him: "Dear me, I should say, for you things aren't that easy either [...]).

Sie war ein Original, die Madame Dutitre.

She $_{i}$ was an original the Madame Dutitre . $_{\text {. }}$

(She was somewhat special, that Madame Dutitre.)

(Sie verstand nie, warum man über ihre Aussprüche lachte. Sie war eben echt und lebte, wie alle wirklich originalen Menschen, aus dem Unbewussten. Kein falscher Ton kam deshalb bei ihr auf.)

(She never understood why everybody always laughed at her remarks. She was genuine and lived unconsciously, as all unique people do. She never came across as being artificial.)

[Fischer-Fabian, S. (1959): Berlin-Evergreen: 125]

In (10), RD marks that the following is about Madame Dutitre. Madame Dutitre is thus explicitly set as the discourse topic referent for the segment following the right dislocation. A reference clarification would not be plausible here, as Madame Dutitre is clearly available (and most salient) as the referent for the pronoun sie ('she').

As for AT, its discourse function is to clarify a potentially unclear reference, as in (11):

(11) (Sie [Die Mutter] hat den Wohnzimmerschrank aber auch nicht leiden können,[...], aber mein Vater hat sich auf keine billigen Sachen mehr eingelassen,)

(Mother hated the wardrobe ${ }_{\mathrm{MASC}},[. .$.$] , but my father didn't want to have any more cheap things$ around).

\footnotetext{
${ }^{6}$ I understand discourse segment intuitively as a relatively small span of a discourse (minimally one utterance) that is characterized through a fairly tight thematic contiguity. In written language a discourse segment mostly corresponds to a paragraph (cf. also Goutsos (1997)).

${ }^{7}$ I do not attempt a theoretical solution to the problem of the status of discourse topic, which has been extensively discussed in literature. See e.g. Brown \& Yule (1983/2004), Goutsos (1997) and, more recently, Büring (2003), Asher (2004a \& b), Kehler (2004), Oberlander (2004), Stede (2004) and Zeevat (2004), to name just a few, for the questions of what a discourse topic is (possible answers are: a proposition, a question the discourse answers, an entity etc.) and whether modeling of the discourse needs this concept in the first place. However, the existence of some kind of entity that is most salient at a given stage of the discourse and that is relevant for establishing coherence seems to be uncontroversial; it is for example the common point of the papers in the recent issue of Theoretical Linguistics dedicated to discourse topics. The autors use different terms for the same intuition of "the thing" that "cohesive chunks of text are about" (Asher (2004b: 255)): 'recurring sentence topic' in Oberlander (2004), 'local topics within discourse segments' in Kehler (2004), 'protagonist' in Zeevat (2004) and 'Discourse topic 1' in Stede (2004).

${ }^{8}$ There are certain conditions on the discourse referent here, e.g. it has to be discourse-old in the sense of Prince (1992); see Averintseva-Klisch (forthc. a).
} 


er ist $\mathrm{ihr}$
$\mathrm{He}_{i}$ is for-her f $_{j}$ also too dark been

Here the context suggests that the most plausible referent for the pronoun $\operatorname{er}$ ('he') is the father, and the reference to the wardrobe is explicitly resolved with the help of AT.

To sum up: there is ample prosodic, syntactic and discourse-functional evidence that RD and AT are two different constructions. RD is prosodically and syntactically part of its host sentence, presumably a right IP-adjunct. Its role in the discourse is to mark the discourse topic referent for the following segment. AT is an 'orphan', i.e. it is prosodically and syntactically free. It is used as an explicit clarification of an unclear or ambiguous reference.

In the following I am exclusively concerned with RD. Being a part of its host sentence it is expected to contribute to its semantics. I will investigate the semantic fundamentals of discourse topic referent marking and show how the contribution of the right dislocation to the semantics of the whole sentence arises.

\section{RD as separate performative}

In this section, I first introduce the theoretical framework I use, the 'separate performative account' developed by Potts $(2004,2005)$ and Portner (forthc.), thereafter adapting it to account for the meaning contribution of RD to its host sentence.

\section{1 'Separate performative account': Potts (2004, 2005), Portner (forthc.)}

Potts (2004, 2005) and Portner (forthc.) observe that different constructions such as for example vocatives, NP appositions or topic constructions introduce a special kind of meaning, which they call 'separate performative' or 'expressive content'. ${ }^{10}$ So, besides stating that Amir is from Israel, which is the regular, 'at-issue', meaning of the sentence in (12), a separate performative is introduced: "I assert that Amir is my new neighbour":

(12) Amir, my new neighbour, is from Israel.

at-issue meaning: $\quad$ Amir is from Israel (in a given world w)

separate performative: I thereby assert that Amir is my new neighbour (in w)

This additional content, introduced through the NP apposition, is a separate performative speech act, with which the speaker instructs the addressee as to how the at-issue-meaning has to be integrated in the discourse model. Being a performative, this 'expressive' meaning does not influence the truth conditions of the sentence as it is automatically true when understood. Expressive meaning is non-compositional in its character; this means, it does not contribute in a regular compositional way to the semantics of the sentence, nor is there a complex compositionality of expressive meaning. That is, a sentence might have several expressive meanings, which are then non-compositionally, in a purely additive way "gathered together" to the overall expressive meaning of the sentence. Therefore according to Potts $(2004,2005)$ and Portner (forthc.) expressive meaning constitutes a separate "dimension of meaning" (cf. Portner (2005: 2)). A final meaning of a given sentence $S$ is then a set of two meaning dimensions, cf. (13):

\footnotetext{
${ }^{9}$ I owe this example to Hélène Vinckel, p.c.

${ }^{10}$ A working definition of expressive content is: "Expressive content is non-displaceable, speaker-oriented meaning that is independent of the main semantic content of the sentence in question." [Potts (2003:8)]. Following Potts and Portner, I use the terms "expressive content" and "separate performative" synonymously in my paper.
} 
(13) for a sentence $S$ : final meaning $:\left\langle A_{S}, C_{S}\right\rangle$

$A_{S}$ : at-issue meaning of $S$

$\mathrm{C}_{\mathrm{S}}$ : set of expressive meanings of $\mathrm{S}\left(\mathrm{C}_{\mathrm{S}}:\left\langle\mathrm{C} 1_{\mathrm{S}}, \mathrm{C} 2_{\mathrm{S}} \ldots\right\rangle\right)$

Whereas $A_{S}$ is constituted compositionally, $C_{S}$ is a simple sum of expressive meanings.

Thus, expressive meaning percolates up the tree as a separate set of meanings, cf. (14) (see also Portner (2005: 9)):

(14) Amir, my new neighbour, is from Israel.

$\left[\left[\text { my new neighbour } \mathrm{appos}_{\mathrm{c}}\right]\right]_{\mathrm{c}}=\varnothing$

$\left[\left[\text { my new neighbour }{ }_{\text {appos }}\right]\right]_{\mathrm{c}}^{\mathrm{C}}=[\lambda \mathrm{x} \lambda \mathrm{w} . \mathrm{x}$ is my new neighbour in $\mathrm{w}]$

[[Amir my new neighbour $\left.\left.{ }_{\text {appos }}\right]\right]_{\mathrm{c}}=$ Amir

[[Amir my new neighbour $\left.\left.{ }_{\text {appos }}\right]\right]_{\mathrm{c}}^{\mathrm{C}}=\{[\lambda \mathrm{w}$. Amir is my new neighbour in $\mathrm{w}]\}$

$\left[\left[\text { Amir my new neighbour }{ }_{\text {appos }} \text { is from Israel }\right]\right]_{\mathrm{c}}=[\lambda \mathrm{w}$. Amir is from Israel in w $]$

$\left[\left[\text { Amir my new neighbour }{ }_{\text {appos }} \text { is from Israel }\right]\right]_{c}^{C}=\{[\lambda \mathrm{w}$. Amir is my new neighbour in $w]\}$

interpretation functions: [[ ] ] $]_{c}$ : regular content; [ [ ] $]_{c}^{\mathrm{C}}$ : expressive content

Semantic embedding constitutes strong evidence for separate performatives being a meaning dimension of their own. Potts (2004) argues that expressive meanings are semantically nonembeddable. So, in (15), the expressive meaning introduced by the apposition my new neighbour cannot be contributed to Felix, but only to the speaker of the matrix sentence (see also Potts $(2004,24))$ :

(14) As Felix said, Amir, my new neighbour, is from Israel.

a. $\quad=$ Felix said that Amir is from Israel.

b. $\quad \neq$ Felix said that Amir is my new neighbour.

c. $\quad \neq$ Felix said that Amir is my new neighbour and that he is from Israel.

Portner (forthc.) proposes an analysis of English left dislocation (E-LD; 'topic' in Portner's terminology), according to which its expressive meaning is "speaker's mental representation of $X$ is active (in a given world $w$ )", as in (16):

(16) Mary, I like her a lot.

at-issue meaning: $\quad[\lambda \mathrm{w}$. speaker likes Mary in $\mathrm{w}]$

expressive meaning: $\{[\lambda \mathrm{w}$. speaker's mental representation of Mary is active in $w]\}$

[cf. Portner (2005: 12)]

Portner (forthc.) argues against his own earlier proposal (Portner (2004)), that the expressive meaning of E-LD cannot be an addressee-oriented request "I thereby request that you activate your mental representation of $X$ " (Portner (2004: 9)). He shows that there are theoretical problems with this expressive meaning variant if one takes embedded topics (E-LDs) like (17) into account. These have two possible variants of expressive meaning, the regular one (1) and the embedded one (2):

(17) John said that, as for Maria, she is nice.

at-issue meaning: [ $\lambda \mathrm{w}$. John said that Maria is nice in $w$ ]

expressive meaning (informal): 1 . The speaker says something about Maria in w

2. John says something about Maria in w' (world of the reported speech act) 
In the embedded variant the addressee cannot be defined. That is why Portner (forthc.) dispenses with the addressee-oriented version of the expressive meaning for E-LD, and proposes the version introduced in (16) without explicitly mentioning the addressee.

As Frey (2004a) shows, E-LD formally and functionally corresponds in German to a construction called Hanging Topic $\left(\mathrm{HT}^{11}\right)$, as in (18):

a. Mary, I like her a lot.

E-LD

b. Mary, ich mag sie wirklich sehr.

Mary I like her really very-much.

This suggests that HT has the same expressive meaning as E-LD, cf. (19):

(19) Mary, I like her a lot. / Mary, ich mag sie wirklich sehr.

at-issue meaning: $\quad[\lambda \mathrm{w}$. speaker likes Mary in $w]$

expressive meaning: $\{[\lambda \mathrm{w}$. speaker's mental representation of Mary is active in $w]\}$

$\left[\left[\mathrm{NP}_{\mathrm{HT}}\right]\right]_{\mathrm{c}}^{\mathrm{C}}=\quad\{[\lambda \mathrm{w}$. speaker's mental representation of the referent of the NP is active in $w]$ \}

Frey (2004b) argues that the discourse function of HT in German is to mark the introduction of a new discourse topic referent, ${ }^{12}$ as in (20):

(20) (Hans ist ein richtiger Fan der Berliner U-Bahn. Deshalb reist er oft nach Berlin.)

(Hans is a real fan of the Berlin underground. That's why he rather often goes to Berlin.)

Die Berliner U-Bahn, sie nahm 1902 ihren Betrieb auf. Sie $_{\mathrm{i}}[\ldots]$

The Berlin underground FEMi $_{\text {she }}$ took 1902 her operating on. She $[$ [...]

The Berlin underground, it started operating in 1902. It [...]

[Frey $(2004 b,(57))$ ]

In (20), the discourse topic referent of the first two utterances is Hans, and then it changes to the Berlin underground; this change is explicitly signalled through HT. However, expressive meaning in (19) does not capture this signalling of a change of the discourse topic referent ${ }^{13}$.

11 Altmann (1981) and the following tradition distinguishes between two left dislocation constructions in German, Left dislocation (LD) and Hanging Topic (or 'free theme', HT), cf. (a) and (b):

(a) Den $\mathrm{Hans}_{\mathrm{i}}$, den $\mathrm{i}_{\mathrm{i}}$ mag jeder.

the $_{A K K}$ Hans D-PRON $A K K$ likes everyone

(b) Der / Den Hans, jeder mag ihn.

the $_{N O M}$, the AKK $_{\text {Hans everyone likes him }}$ [FKK (2004 a: 205)]

As shown in Frey (2004 a), LD is prosodically and syntactically integrated into its host sentence; it allows only weak d-pronouns (der, die, das) as clause-internal resumptive forms. The LD-NP resp. the resumptive form is the sentence topic of its host sentence. HT is prosodically and syntactically independent; it allows various resumptive forms, and, being independent, it does not play any syntactic role in its host sentence, but serves to mark the change of the discourse topic.

${ }^{12}$ Frey (2004) uses the term 'discourse topic'; however, his understanding of discourse topic as the "main theme of a Section of a text" (Frey (2004: 217)) corresponds to what I call the 'discourse topic referent' in this paper.

${ }^{13}$ Frey (2004b) argues that HT is not suitable with maintained discourse topic referents, cf. (a):

(a) (A propos Maria: Weißt Du, wen sie in Berlin getroffen hat?)

(As for Maria, do you know whom she met in Berlin?)

\#Maria, sie hat in Berlin Hans getroffen.

Maria she has in Berlin Hans met. (Maria, she met Hans in Berlin.)

[modified after Frey (2004b: 108)]

Thus, the expressive meaning "speaker's mental respresentation of X is active" is too weak for HT (and presumably also E-LD). Besides, one might argue that every mentioning of $\mathrm{X}$ irrespective of a particular construction used signals that the speaker's mental representation of X is active (see also criticism in Potts et al. (2004)). 
Thus it seems to be too weak for HT. Taking the discourse topic change function of HT into account, the expressive meaning of HT is revised in (21):

(21) Maria, ich mag sie wirklich sehr.

$$
\begin{aligned}
& {\left[\left[\mathrm{Maria}_{\mathrm{HT}}\right]\right]_{\mathrm{c}}^{\mathrm{C}}\{[\lambda \mathrm{w} \text {. speaker signals that he is starting to talk about Maria in } \mathrm{w}]\}} \\
& \left.\left[\mathrm{NP}_{\mathrm{HT}}\right]\right]_{\mathrm{c}}^{\mathrm{C}}=\quad\{[\lambda \mathrm{w} \text {. speaker signals that he is starting to talk about the referent of } \\
& \text { the NP in } \mathrm{w}]\}
\end{aligned}
$$

\subsection{Expressive meaning of German RD}

As I argue in Averintseva-Klisch (forthc. b), German RD and HT share one feature in that they both mark the referent of the NP as the discourse topic referent for the following discourse segment. This suggests that RD (as well as HT) introduces the expressive meaning "the speaker signals that he is starting to talk about X', where $\mathrm{X}$ is the referent of the RD-NP, cf. (22) (that is a part of the discourse in (10) above):

$$
\begin{aligned}
& \text { Sie war ein Original, die Madame Dutitre. } \\
& \text { She was an original the Madame Dutitre } \\
& \text { (She was somewhat special, that Madame D.) }
\end{aligned}
$$

at-issue meaning: $\quad[\lambda \mathrm{w}$. Madame Dutitre was somewhat special in $\mathrm{w}]$

expressive meaning: [[Madame Dutitre $\left.\left.{ }_{\mathrm{RD}}\right]\right]_{\mathrm{c}}^{\mathrm{C}}=\{[\lambda \mathrm{w}$. speaker signals that he is starting to talk about Madame Dutitre in w]\}

The at-issue-meaning of (22) does not differ from that of (23):
Madame Dutitre war ein Original.
Madame Dutitre was an original
(Madame D. was somewhat special.)
at-issue meaning: $\quad[\lambda \mathrm{w}$. Madame Dutitre was somewhat special in w]

(22), as well as (23), is true iff Madame Dutitre is somewhat special ${ }^{14}$ in w. The difference between (22) and the unmarked form in (23) is that in (22) Madame Dutitre is explicitly marked as the discourse topic referent for the following segment, whereas in (23) this stays implicit.

However, RD differs from HT in a crucial way: HT always signals a change of the discourse topic referent. For RD, there are two possibilities: one is that the speaker signals the introduction of a new discourse topic referent, as is the case with the discourse-initial RD. As shown in Averintseva-Klisch (forthc. a), RD may be used discourse-initially if the referent in question is presented as being discourse-old, cf. (23): ${ }^{15}$

(23) Es gibt sie noch, die guten Nachrichten aus der deutschen Universität. it gives them yet the good news from the german university

You can still find some - good news coming from German universities. (beginning of a lead)

Otherwise the speaker signals the maintenance of the old discourse topic referent. This is most often the case when the discourse topic referent is maintained in spite of the beginning

\footnotetext{
${ }^{14}$ In this case, a property which has to be defined in the context. I ignore the semantic contribution of the tense for the moment.

${ }^{15}$ I argue that in such cases RD implicitly embeds the beginning discourse into some larger, thematically contiguous setting that is familiar to the author and the recipient of the discourse. In (23) such 'meta-discourse' is a series of articles about the German university system and its future in the weekly German periodical Die ZEIT. The use of a RD is a most economic means of simultaneously introducing a referent, presenting it as being discourse-old and marking it as the discourse topic referent for the following discourse segment (see Averintseva-Klisch (forthc. a) for details).
} 
of a new segment, as in (22) resp. (10). Here the new discourse segment (corresponding to the new paragraph ${ }^{16}$ ) begins, but Madame Dutitre remains the discourse topic referent.

To get to the point: HT always signals the change of the discourse topic referent (cf. Frey (2004a\&b)), whereas RD allows both change and maintenance. Thus, the expressive meaning of (22) should be changed in the following way: "the speaker signals that he is (further on) going to talk about Madame Dutitre":

(24) Sie war ein Original, die Madame Dutitre.

expressive meaning: [[Madame Dutitre $\left.\left.{ }_{\mathrm{RD}}\right]\right]_{\mathrm{c}}^{\mathrm{C}}=\{[\lambda \mathrm{w}$. speaker signals that he is (further on) going to talk about Madame Dutitre in w]

The expressive meaning of RD is thus restated in (25):

(25) $\left[\left[\mathrm{NP}_{\mathrm{RD}}\right]\right]_{\mathrm{c}}^{\mathrm{C}}=\{[\lambda \mathrm{W}$. speaker signals that he is (further on) going to talk about the referent of the NP in $w]\}$

Now, let us have a look at embedded RD, cf. (26):

(26) Hans sagte, dass sie richtig nett ist, die Grete.

Hans said that she really nice is the Grete.

at-issue meaning: $\quad[\lambda \mathrm{w}$. Hans said that Grete is nice in $w]$

expressive meaning: 1 . $\{[\lambda \mathrm{w}$. speaker of the main clause signals that he is (further on) going to talk about Grete in w]

2. * $\{[\lambda \mathrm{w}$. Hans signals that he is (further on) going to talk about Grete in w']\}

In contrast to embedded topics in English (E-LD), there is no embedded reading for RD. ${ }^{17}$ This means, that a slight modification of the expressive meaning of RD is needed. (25) is thus restated as (27):

(27) $\left[\left[\mathrm{NP}_{\mathrm{RD}}\right]\right]_{\mathrm{c}}^{\mathrm{C}}=\{[\lambda \mathrm{W}$. speaker (of the host sentence) signals that he is (further on) going to talk about the referent of the NP in w] $\}^{18}$

In other words, RD adds to the semantics of its host sentence a separate performative explicitly signalling that the speaker is going to talk about the referent of the RD-NP, while it is left open whether he was already talking about this referent or just changed to a new topic.

In the next section I will show how certain semantic peculiarities of RD may be accounted for with the separate performative analysis proposed in (27).

\footnotetext{
${ }^{16}$ The preceding segment gives an example of Madame Dutitre's original sayings; the beginning segment is giving some general information about Madame Dutitre, for which the preceding segment may serve as an illustration.

${ }^{17}$ This means that for RD, contrary to E-LD, it would be possible to have an explicit reference to the addressee. However, this does not seem necessary: intuitively, RD is a strategy that serves to mark the information status of a certain NP that is used by the speaker, and the reference to the speaker making a signal with the RD seems to me to capture this intuition in the best way.

${ }^{18}$ In my paper I consider only NP-RD. Altmann (1981) describes also briefly PP- and CP-'right dislocation' (which he distinguishes from extraposition). It requires further analysis to find out whether these constructions are really RDs or ATs. That is why I state (24) explicitly for NP-RD. However, when needed, (27) can be generalized to $\left[\left[\mathrm{XP}_{\mathrm{RD}}\right]\right]_{\mathrm{c}}^{\mathrm{C}}=\{[\lambda \mathrm{W}$. speaker signals that he is (further on) going to speak about the referent of $\mathrm{X}$ in $\mathrm{w}]\}$.
} 


\section{Consequences of the separate performative account of RD}

The semantic analysis of RD proposed in the previous section accounts for certain restrictions concerning the semantic status of the NP in the RD. Thus, quantificational NPs in general seem not to be possible with RD. Besides, the separate performative account of RD explains the discourse function of the RD in a most straightforward way.

\subsection{Explaining certain semantic constraints on the RD-NP}

It has been noticed that quantified NPs are in general bad with RD, as in $(28)^{19}$ (see also Averintseva-Klisch (forthc. b)):

$\begin{array}{llllll}\text { Peter liebt sie, } & * \text { jede Frau / *keine } & \text { Brünetten } / * \text { zwei } & \text { Frauen. } \\ \text { Peter loves her/them *every } & \text { woman / *no } & \text { brunettes } / * \text { two } & \text { women }^{20} .\end{array}$

This can be accounted for if one assumes that the contribution RD makes to the semantics of its host sentence is an expressive meaning. To show this I first refer to Portner's (forthc.) analysis of vocatives.

Portner (forthc.) notices that quantifiers are in general unable to function as vocatives, cf. (29):

(29) Anna / *Some woman, please, hurry up!

The semantics of vocatives is assumed to be (30) (cf. Portner (forthc.: 9)):

(30) at-issue meaning: $\quad[\lambda x \lambda w$. speaker urges $x$ to hurry up in $w]$

expressive meaning: $\{[\lambda \mathrm{x} \lambda \mathrm{w}$. speaker requests the attention of $\mathrm{x}$ in $\mathrm{w}]\}$

In the expressive meaning formula in (30), $\mathrm{x}$ can be only of type e. Thus, to be able to function as an argument at the level of the expressive meaning, the quantifier some has to raise from the type $\langle e,\langle e, t\rangle\rangle^{21}$ to the type e. In raising to type e, the quantifier changes to the at-issue meaning level, leaving a trace behind at the expressive meaning level. This trace has to be semantically bound by the quantifier (see Heim (1982)). This is, however, not possible. Portner (forthc.) argues that it is impossible to bind "across dimensions of meaning": a quantifier which contributes to at-issue meaning cannot bind a variable which contributes to expressive meaning (see Portner (forthc.) for details).

In a similar way, the impossibility of semantic binding across dimensions accounts for the illformedness of quantificational NPs in RD constructions in (28). The quantifier jede / keine / zwei has to raise to type e to be able to function as an argument of the expressive meaning $\{[\lambda x \lambda w$. speaker (of the host sentence) signals that he is (further on) going to talk about $x$ in $w]\}$; thus it moves to at-issue meaning and cannot bind its trace at the expressive level any more.

\subsection{The semantics of $\mathrm{RD}$ and discourse topic referent}

Besides explaining the impossibility of certain kinds of NPs in RD, the separate performative account provides a straightforward explanation for the contrast in (31):

\footnotetext{
${ }^{19}$ Grewendorf (2002) notices the same for LD. I do not attempt any explanation of this fact here.

${ }^{20}$ Note that these sentences are well-formed without RD:

(b) Peter liebt jede Frau / keine Brünetten / zwei Frauen. Peter loves every woman / no brunettes / two women

${ }^{21}$ This being the semantic type of this kind of quantifier, cf. Heim and Kratzer (1997).
} 
a. "Ein Taifun!" rief Lukas dem Kapitän zu. "Da ist er!"" Ja, da war "A typhoon!" called Lukas the captain to. "Here is he!" Yes, here was er, der Taifun. Ein hellblauer Blitz fuhr zischend vom he the typhoon $_{\text {MASK. }}$ A light-blue lightning went whizzing from-the Himmel nieder [...] sky downwards [...]

[M. Ende, Jim Knopf und die Wilde 13: 190]

b. "Ein Taifun!" rief Lukas dem Kapitän zu. "Da ist er!" \#Er lief zum "A typhoon!" called Lukas the captain to. "Here is he!" He ran to-the Steuer, der Lukas. Ein hellblauer Blitz fuhr zischend vom steering-wheel the Lukas. A light-blue lightning went whizzing from-the Himmel nieder [...] sky downwards $[\ldots]^{22}$

Here, RD is only possible with the NP der Taifun; no other NP, as der Lukas as in (31b) might be right-dislocated, even if the corresponding referent is discourse-old and also otherwise complies with the requirements on the RD-NP. This changes, however, as soon as the following discourse segment is adapted so that its discourse topic referent corresponds to the referent of the RD-NP: RD is perfectly well-formed, cf. (32):

$$
\begin{aligned}
& \text { "Ein Taifun!" rief Lukas dem Kapitän zu. "Da ist er!" Er lief zum } \\
& \text { "A typhoon!" called Lukas the captain to. "Here is he!" He ran to-the } \\
& \text { Steuer, der Lukas. Dort angekommen, riss er sein Hemd runter und band } \\
& \text { steering-wheel the Lukas. There arrived tore he his shirt down and bound } \\
& \text { damit das Steuerrad fest. } \\
& \text { with-it the steering-wheel firmly. }
\end{aligned}
$$

That means that RD is suitable with a NP referring to the discourse topic referent; otherwise only AT is possible. This follows directly from the expressive meaning that RD contributes to the semantics of its host sentence: with a RD the speaker signals that he is going to talk about the referent of the RD-NP. And it is pragmatically unsound first to mark a referent as being what one is going to talk about, and then to change the subject.

\section{Summary and conclusions}

In my paper, I have shown that what is traditionally subsumed under the label of German right dislocation are in fact two different constructions: right dislocation proper and afterthought. RD and AT differ in their formal and functional properties. AT is an 'orphan' that gets integrated into its host sentence only at the discourse level. Its discourse function is to resolve a potentially unclear (pro)nominal reference. RD is prosodically and syntactically a part of its host sentence. Its function is to mark the discourse topic referent for the following discourse segment.

The main goal of this paper was to show that RD adds a separate performative (an 'expressive meaning') to the semantics of the sentence. This performative is "the speaker (of the host sentence) signals that he is (further on) going to talk about $X$ ", with $\mathrm{X}$ being the referent of the RD-NP. This account of the RD explains certain constraints on the semantic status of the RD-NP: only NPs of the type e are possible here. This corresponds to ontological constraints on the discourse topic referent: only definite individual nominal referents are possible.

Furthermore, I argue that the discourse function of RD is to mark the discourse topic referent, as follows directly from the semantics of RD. I believe that for an approach to the otherwise highly elusive pragmatic category of the discourse topic it is a prerequisite to have a look at

\footnotetext{
${ }^{22}$ (33b) is thouroughly acceptable as AT, with the corresponding prosody, but not as RD.
} 
explicit linguistic means of referring to it. In this sense RD in its function of marking the discourse topic referent is an explicit means revealing something of how the discourse model is built up.

\section{References}

Altmann, H.: 1981, Formen der 'Herausstellung' im Deutschen: Rechtsversetzung, Linksversetzung, Freies Thema und verwandte Konstruktionen. Tübingen: Niemeyer.

Asher, N. and Lascarides, A.: 2003, Logics of Conversation. Cambridge: CUP.

Asher, N.: 2004 a, Discourse topic, Theoretical Linguistics 30, 163-201.

Asher, N.: 2004 b, Troubles with topics: comments on Kehler, Oberlander, Stede and Zeevat, Theoretical Linguistics 30, 255-262.

Auer, P.: 1991, Vom Ende deutscher Sätze, Zeitschrift für Germanistische Linguistik 19, 139157.

Averintseva-Klisch, M.: forthc. a, Anaphoric properties of the German right dislocation, in M. Schwarz-Friesel, M. Consten and M. Knees (eds.), Anaphors in Text.

Averintseva-Klisch, M.: forthc. b, German Right Dislocation and Afterthought in Discourse, in C. Sassen, A. Benz and P. Kühnlein (eds.), Constraints in Discourse.

Brown, G. and Yule, G.: 2004, Discourse analysis. Cambridge: CUP [reprinted from original of 1983].

Fretheim, T.: 1995, Why Norwegian Right-Dislocated Phrases are not Afterthoughts, Nordic Journal of Linguistics 18, 31-54.

Frey, W.: 2004a, Notes on the syntax and pragmatics of the German Left Dislocation, in H. Lohnstein and S. Trissler (eds.), The Syntax and Semantics of the Left Periphery, Mouton de Gruyter, pp. 203-233.

Frey, W.: 2004b, Pragmatic properties of certain German and English left peripheral constructions. Linguistics 43/1, 89-129.

Goutsos D.: 1997, Modeling Discourse Topic: Sequential Relations and Strategies in Expository Text. Norwood: Ablex (= Advances in Discourse Processes LIX).

Grewendorf, G.: 2002, Minimalistische Syntax. Tübingen / Basel: A. Francke (= UTB 2313).

Haegeman, L.: 1991, Parenthetical adverbials: The radical orphan approach, in S. Chiba et al. (eds), Aspects of modern English linguistics: Papers presented to Masatomo Ukaji on his 60th birthday. Kaitakusha, pp. 232-254.

Heim, I.: 1982, The Semantics of Definite and Indefinite Noun Phrases. Ph.D. Thesis, MIT.

Heim, I. and Kratzer, A.: 1997, Semantics in Generative Grammar. Oxford: Blackwell.

Kehler, A.: 2004, Discourse topics, sentence topics, and coherence, Theoretical Linguistics 30, 227-240. 
Oberlander, J.: 2004, On the reduction of discourse topic, Theoretical Linguistics 30, 213225.

Portner, P.: 2004, Vocatives, Topics and Imperatives, handout for IMS Workshop on Information Structure, Bad Teinach, URL: http://www.georgetown.edu/faculty/ portnerp/

Stuttgart_handout.pdf.

Portner, P.: forthc, Instructions for Interpretation as Separate Performatives, in K. Schwabe and S. Winkler (eds.), On Information Structure, Meaning and Form. Amsterdam: Benjamins.

Potts, Ch.:2003, The performative nature of expressive content, handout, URL http://wwwunix.oit.umass.edu/ potts/potts-expressives-uconn-rochester.pdf.

Potts, Ch.: 2004, Conventional implicatures, a distinguished class of meanings, in G. Ramchand and Ch. Reiss (eds.), The Oxford Handbook of Linguistic Interfaces. OUP, pp. 187-198.

Potts, Ch. , Schwarz, F. and Kawahara, Sh.: 2004, Comments on Paul Portner's 'Instructions for Interpretation as Separate Performatives', handout for Harvard-MIT-UConn Indexicality Workshop Nov. 20, 2004, URL http://www-unix.oit.umass.edu/ potts/talks/pottsschwarz-kawahara-cmts-on-portner.pdf.

Potts, Ch.: 2005, The Logic of Conventional Implicature. Oxford: OUP.

Prince, E.: 1992, The ZPG Letter: Subjects, Definiteness, and Information-Status, in W. Mann and S. Thompson (eds.), Discourse Description. Diverse linguistic analyses of a fundraising text. Amsterdam: Benjamins, pp. 295-325.

Selting, M.: 1994, Konstruktionen am Satzrand als interaktive Ressource in natürlichen Gesprächen, in B. Haftka (ed.), Was determiniert Wortstellungsvariation?, Westdeutscher Verlag, pp. 299-318.

Shaer, B. and Frey, W.: 2004, 'Integrated' and 'Non-integrated' Left-Peripheral Elements in German and English, in B. Shaer, W. Frey and C. Maienborn (eds.), Proceedings of the Dislocated Elements Workshop, ZAS Berlin, November 2003. ZAS Papers in Linguistics 35, 465-502.

Stede, M.: 2004, Does discourse processing need discourse topics?, Theoretical Linguistics 30, 241-253.

Uhmann, S.: 1997, Grammatische Regeln und konversationelle Strategien. Fallstudien aus Syntax und Phonologie. Tübingen: Niemeyer.

Ward, G. and Birner, B.: 1996, On the Discourse Function of Rightward Movement in English, in A. Goldberg (ed.), Conceptual Structure, Discourse and Language. Stanford Center for the Study of Language and Information Publications, pp. 463-479.

Zeevat, H.: 2004, Asher on discourse topic, Theoretical Linguistics 30, 203-211. 


\title{
Complex Focus Versus Double Focus \\ INVESTIGATIONS OF MULTIPLE FOCUS INTERPRETATIONS IN HUNGARIAN
}

\author{
Kata Balogh \\ Universiteit van Amsterdam \\ k.balogh@uva.nl
}

\begin{abstract}
The main aim of this paper is to point out several problems with the semantic analysis of Hungarian focus interpretation and 'only'. For current semantic analyses the interpretation of Hungarian identificational/exhaustive focus and 'only' is problematic, since in classical semantic analyses 'only' is identified with an exhaustivity operator. In this paper I will discuss multiple focus constructions and question-answer pairs in Hungarian to show that such a view cannot be applied to Hungarian exhaustive focus. Next to this I will discuss possible interpretations of Hungarian sentences containing multiple prosodic foci: complex focus versus double focus. My claim is that in order to interpret multiple focus (in Hungarian) we have to take into consideration the different intonation patterns, the occurrence of 'only', and the syntactic structure as well.
\end{abstract}

In my paper I discuss multiple focus constructions and their interpretations based on Hungarian data. Sentences containing two prosodical foci have two possible interpretations. First, the complex focus meaning (Krifka 1991), where we have semantically one focus: an ordered pair; and second, the double focus meaning, where the first focus takes scope over the second one. The paper investigates three main topics: (1) the multiple focus interpretations, (2) complex focus vs. double focus disambiguation and (3) the interpretation of 'only' in Hungarian. My main claims are the following:

(a) 'only' is not responsible for exhaustive meaning and 'only' and exhaustification are distinct in Hungarian contrary to the analysis of the classical theories (Groenendijk and Stokhof 1984, Groenendijk and Stokhof 1991, Krifka 1991);

(b) in order to interpret multiple focus constructions we have to take into consideration the occurrence of 'only', the intonation pattern and the syntactic structure as well.

The paper is organized as follows. As an introduction, in section 1.1 we will see the main attributes of Hungarian focus and in 1.2 we briefly discuss the classical semantic analyses of focus and exhaustivity. In section 2 we investigate the problem of 'only' and exhaustivity in multiple focus constructions and I propose a pragmatic analysis of 'only'. Section 3 provides further evidence of a pragmatic analysis of 'only' via Hungarian question-answer pairs. Section 4 deals with the disambiguation between complex focus and double focus interpretations and the role of intonation, syntax and the appearance of 'only'. Section 5 gives the conclusions and introduces some further work on scalar readings and scope relations.

\section{Introduction}

\subsection{Focus in Hungarian}

Hungarian - like Basque, Catalan, Greek, Finnish and many other languages - belongs to the family of discourse-configurational languages (É. Kiss 1995). A main property of these languages is that some discourse-semantic information is mapped into the syntactic structure of the 
sentences as well. Hungarian has special structural positions for topics, quantifiers and focus. The special structural position for focused elements in Hungarian is the immediate pre-verbal position. The constituent in this position is assigned a pitch accent and receives an exhaustive interpretation.

In "neutral sentences" like (1a) the immediate pre-verbal position is occupied by the verbal modifier (VM) whereas in focused sentences like $(1 \mathrm{~b})$ this position is occupied by the focused element, and the verbal modifier is behind the finite verb.

(1) a. Anna felhívta Emilt.

(Anna VM-called Emil.acc)

'Anna called Emil.'

b. Anna Emilt hívta fel.

(Anna Emil.acc called VM)

'It was Emil whom Anna called.'

É. Kiss (1998) distinguishes two types of focus: identificational focus and information focus. Her main claims are that these two types are different both in syntax and semantics, and that identificational focus is not uniform across languages. The main differences in Hungarian according to É. Kiss are the following: a) identificational focus: expresses exhaustive identification, certain constituents are out, it takes scope, involves movement and can be iterated; b) information focus: merely marks the unpresupposed nature, is nonrestricted, does not take scope, does not involve movement and can project. For example, we can answer the question 'Where were you last summer?' with (2a), which has identificational focus, or with (2b), which has information focus. From these two answers only (2a) gets exhaustive interpretation.

(2) a. ANGLiÁBAN voltam.

(England.loc was.1sg)

'It is England where I went.' [and nowhere else]

b. Voltam ANGLIÁBAN.

(was.1sg England.loc)

'I went to England.' [among other places]

The pre-verbal focus in Hungarian falls under the category of identificational focus, whereas the status of the information focus in Hungarian is rather questionable (see e.g. Szendrôi 2003). In the following we will concentrate on the pre-verbal (identificational) focus to point out several problems with the exhaustive meaning and 'only'. In Hungarian 'only' (csak) is always associated with identificational focus, see (3).

(3) a. Csak ANGLiÁBAN voltam.

(only England.loc was.1sg)

'I went only to England.'

b. *Voltam csak ANGLí́BAN.

(was.1sg only England.loc)

Since in Hungarian both 'only' (csak) and identificational focus indicate exhaustivity, the question arises whether both contribute to semantics or one has only pragmatic function. English data suggest that the interpretation of 'only' is on the semantic part and the interpretation of focus is pragmatics. The Hungarian data I will discuss in the following sections will lead us to a different view.

\footnotetext{
${ }^{1}$ Here and further on small capitals indicate pitch accent.
} 


\subsection{Classical analyses of focus and exhaustivity}

In this section I will briefly introduce two classical semantic analyses of focus and exhaustivity: the Partition Semantics (Groenendijk and Stokhof 1984, 1991) and the Structured Meaning Account (Krifka 1991, among others). In both theories, 'only' is identified with an exhaustivity operator. Later on in the paper we will see that this view cannot be applied to some multiple focus constructions and the exhaustive focus in answers in Hungarian.

Krifka proposes a structured meanings account of questions and the focusation of answers. This theory is also called a functional approach, because the basic idea is that the meaning of a question is a function, which when applied to the meaning of a congruent answer, yields a proposition. Next to the function, its domain is given and together they form an ordered pair.

(4) $[[$ Who called Emil? $]]=\langle\lambda x[\operatorname{called}(x$, Emil $)], P E R S O N\rangle$

Correspondingly, a sentence with focus is represented as a focus-background pair $\langle F, B\rangle$ where if we apply the background to the focus $B(F)$ we get the ordinary interpretation.

(5) $\left[\left[\right.\right.$ ANNA $_{F}$ called Emil. $\left.]\right]=\langle$ Anna, $\lambda x[\operatorname{called}(x$, Emil $)]\rangle$ $\lambda x[\operatorname{called}(x$, Emil $)]($ Anna $)=\operatorname{called}($ Anna, Emil $)$

In this theory the focus sensitive particle 'only' is analysed as an operator which takes a focusbackground structure. The meaning rule for 'only' (simple version) is the following:

$$
[[\text { only }]](\langle F, B\rangle)=B(F) \wedge \forall X \in A l t(F)[B(X) \rightarrow X=F]^{2}
$$

In order to get the right interpretation for Hungarian exhaustive focus in this framework we have to introduce an exhaustivity operator that applies to the focus-background structure and has the same interpretation as 'only':

$$
E X H(\langle F, B\rangle)=B(F) \wedge \forall X \in A l t(F)[B(X) \rightarrow X=F]
$$

With this exhaustivity operator we get the right interpretation for sentences like (1b) or (2a). In this way sentences with identificational focus and sentences with 'only' will get the same interpretation, since the interpretation of 'only' and the exhaustivity operator are the same. We will see in section 3 that this view can be problematic for Hungarian.

Similar facts hold for the question analysis of (Groenendijk and Stokhof 1984, 1991). For the semantics of linguistic answers they define an answer formation rule introducing an exhaustivity operator, which gives the minimal elements from a set of sets.

(8) a. the rule of answer formation: if $\alpha^{\prime}$ is the interpretation of an n-place term, and $\beta^{\prime}$ is the relational interpretation of an n-constituent interrogative, the interpretation of the linguistic answer based on $\alpha$ in the context of the interrogative $\beta$ is $\left(E X H^{n}\left(\alpha^{\prime}\right)\right)\left(\beta^{\prime}\right)$, where $E X H^{n}$ is defined as follows (generalized rule):

b. $E X H^{n}=\lambda \mathcal{R}^{n} \lambda R^{n}\left[\mathcal{R}^{n}\left(R^{n}\right) \wedge \neg \exists S^{n}\left[\mathcal{R}^{n}\left(S^{n}\right) \wedge R^{n} \neq S^{n} \wedge \forall \vec{x}\left[S^{n}(\vec{x}) \rightarrow R^{n}(\vec{x})\right]\right]\right]$

In this model, if we give the answer 'Anna.' to the question 'Who called Emil?', then it is interpreted as 'Only Anna called Emil.':

(9) $(\operatorname{EXH}(\lambda P . P($ Anna $)))(\lambda x$.called $(x$, Emil $))=$ $\lambda P \forall x[P(x) \leftrightarrow[x=$ Anna $]](\lambda x$.called $(x$, Emil $))=$ $\forall x[\operatorname{called}(x$, Emil $) \leftrightarrow[x=$ Anna $]]$

\footnotetext{
${ }^{2} A l t(F)$ is the set of the natural alternatives of the focused element.
} 
So the interpretation is that Anna called Emil and nobody else (from the relevant) domain called Emil.

\section{Multiple focus interpretations}

\subsection{Two readings}

This section focuses on two readings of multiple focus constructions. In case of sentences containing two (or more) prosodic foci there are two possible interpretations. The two foci can form an ordered pair like in (10). Here semantically a pair of constituents is in focus. Krifka (1991) calls this type complex focus to distinguish it from other multiple focus constructions.

(10) (Csak) AnNA hívta fel EmILT.

((only) Anna called VM Emil.acc)

'It is the Anna, Emil pair of whom the first called the second.'

(11) John only introduced BILL to SuE. (from Krifka 1991)

reading: the only pair of persons such that John introduced the first to the second is $\langle$ Bill, Sue $\rangle$

The other type is one involving real multiple foci (Krifka 1991). In this case there are two focus operators and the first focus takes scope over the second one. See the following examples:

(12) Csak AnNA hívta fel csak EMILT.

(only Anna called VM only Emil.acc)

'Only Mary called only Peter.' [the others nobody or more persons]

(13) Even $_{l} \mathrm{JOHN}_{l}$ drank only 2 WATER$_{2}$. (from Krifka 1991)

A similar distinction can be found in Hungarian multiple constituent questions. In multiple wh-questions there are two possible word orders that lead to two different meanings.

a. Ki kit hívott fel?

(who whom called VM)

'Who called whom?' (pair-list)

b. Ki hívott fel kit?

(who called VM whom)

'Who called whom?' (complex)

(14a) requires a pair-list answer, while (14b) is a restricted question where both the questioner and the answerer already know that there is only one pair of whom the "call-relation" holds. The question can have a strict and a loose meanings (Lipták 2000). In the case of the strict meaning there are two specific individuals - e.g. Anna and Bea - under discussion, and the question is just about the theta-roles of the individuals: $\langle a, b\rangle$ or $\langle b, a\rangle$. In the case of the loose meaning there is a specific set of pairs of individuals, and the questions wants one element from this set. In our examples the interpretation of question (14b) corresponds to the complex focus reading in (10), in both cases there is one pair of individuals of whom the "call-relation" holds.

In the following I will use a bit more informative terminology for these two types: pair-reading for the complex focus and scope-reading for the double focus/real mutiple foci.

The above examples show that these two different readings are present in Hungarian. However, interestingly, example (15) can have both readings: the scope-reading $(15 \mathrm{a})$ and the pair-reading (15b). 
(15) Csak Anna hívta fel csak Emilt. (=12

(only Anna called VM only Emil.acc)

a. 'Only Mary called only Peter.' [the others nobody or more persons]

b. 'It is the Mary, Peter pair of whom the first called the second.'

One of the main questions of this paper is to find out how to analyze example $(15 \mathrm{~b})$, where a pair of constituents is in focus but there are two 'only's. This case is rather problematic for the classical theories, since they analyze 'only' as an exhaustivity operator but here we have only one operator applied to the pair of constituents.

\subsection{Analyses}

In example (10) exhaustivity applies to pairs, which is exactly what Groenendijk and Stokhof's $(1984,1991)$ generalized definition of exhaustivity (8b) gives us. In our examples there are two terms, so the interpretation runs as follows:

$$
\begin{aligned}
& \left(E X H^{2}(\lambda R[R(a, e)])\right)(\lambda x \lambda y . c a l l e d(x, y))= \\
& \lambda R \forall x \forall y[R(x, y) \leftrightarrow[x=a \wedge y=e]](\lambda x \lambda y . \operatorname{called}(x, y))= \\
& \forall x \forall y[\operatorname{called}(x, y) \leftrightarrow[x=a \wedge y=e]]
\end{aligned}
$$

Krifka (1991) also gives an elegant analysis of multiple focus constructions in a compositional way. He gives a recursive definition of extended application for Focus-Background structures $17]^{3}$ and defines the syntactic-semantic rules as follows (we give here only the relevants ones for our examples).

(17) $\alpha(\beta)$ functional application

$\langle\alpha, \beta\rangle(\gamma)=\langle\lambda X .[\alpha(X)(\gamma)], \beta\rangle$

$\gamma(\langle\alpha, \beta\rangle)=\langle\lambda X . \gamma(\alpha(X)), \beta\rangle$

$\langle\alpha, \beta\rangle(\langle\gamma, \delta\rangle)=\langle\lambda X \bullet Y .[\alpha(X)(\gamma(Y))], \beta \bullet \delta\rangle$

(18) $\mathrm{S} \rightarrow \mathrm{NP} \mathrm{VP} ;\left[\left[{ }_{S} \mathrm{NP} \mathrm{VP}\right]\right]=[\mathrm{NP}]([\mathrm{VP}])$

$\mathrm{VP}_{t r} \rightarrow \mathrm{V} \mathrm{NP} ;[[v P t r \mathrm{~V} \mathrm{NP}]]=\lambda S \lambda T \lambda x \cdot T(\lambda y \cdot S(x, y))([V])([N P])$

$\mathrm{C} \rightarrow \mathrm{C}_{F} ;\left[\mathrm{C}_{F}\right]=\langle\lambda X . X,[C]\rangle$

$\mathrm{C} \rightarrow \mathrm{FO} \mathrm{C} ;[[C \mathrm{FO} \mathrm{C}]]=\lambda\langle X, Y\rangle \lambda O[\lambda Z . O(\langle X, Z\rangle)(Y)]([C])([F O])$

$X \bullet Y$ is defined by Krifka as a list, but practically it is an ordered tuple (in our case here: a pair). $F O$ stands for the focus sensitive operator ('only'). According to this system the interpretation of $(10)$ is as follows:

(19) $\operatorname{Emil}_{F}:\langle\lambda T . T, e\rangle$

called Emil $_{F}:\langle\lambda T \lambda x . T(\lambda y . c a l l e d(x, y)), e\rangle$

Anna $_{F}:\langle\lambda T . T, a\rangle$

Anna $_{F}$ called Emil E $_{F}:\langle\lambda X \bullet Y[X(\lambda x . Y(\lambda y$.called $(x, y))], a \bullet e\rangle$

only Anna $F$ called Emil :

$\operatorname{called}(a, e) \wedge \forall x \bullet y[[x \bullet y \in \operatorname{Alt}(a \bullet e) \wedge \operatorname{called}(x, y)] \rightarrow(x \bullet y=a \bullet e)]$

These examples (16, 19) show us that both theories can easily deal with prosodically multiple foci that express semantically one focus, a pair. Both theories take an operator ( $\mathrm{exh} /$ 'only') that applies to an ordered pair. This way we get the intended meaning that it was the Anna, Emil

\footnotetext{
${ }^{3}$ To make it simpler we give the rules without types. For more details see (Krifka 1991).
} 
pair of whom the first called the second and there are no other pairs in the domain of which the call-relation holds. The problem of identifying 'only' with the exhaustivity operator is not yet visible here, because the interpretation results are correctly the same for (20a) and (20b), both have a pair-reading.

a. AnNA hívta fel EMILT. (Anna called VM Emil.acc)

b. Csak AnNA hívta fel EMILT. (only Anna called VM Emil.acc)

for both: 'It is the Anna, Emil pair of whom the first called the second.'

The problem arises if we try to get the interpretation $(15 \mathrm{~b})$ according to the classical theories. In Groenendijk and Stokhof's $(1984,1991)$ framework the two 'only's are the operators that exhaustify the phrases 4 . Following this the interpretation of 15 goes as follows:

$$
\begin{aligned}
& (\operatorname{EXH}(\lambda P . P(a)))((\operatorname{EXH}(\lambda P . P(e)))(\lambda x \lambda y . \text { called }(x, y)))= \\
& (\lambda P \forall y[P(y) \leftrightarrow y=a])((\lambda P \forall x[P(x) \leftrightarrow x=e])(\lambda x \lambda y . \text { called }(x, y)))= \\
& \forall y[\forall x[\lambda y . \text { called }(x, y) \leftrightarrow x=a] \leftrightarrow y=e]
\end{aligned}
$$

It says that only Anna is such that she called only Emil, so we get the 'scope-reading' (15). Exhaustifying the terms separately we cannot get the complex focus interpretation (15b).

The same problem arises for the interpretation in Krifka's (1991) analysis, where the two 'only's are applied to the two focused constituents respectively. In this framework as well, for (15) we get the 'scope-reading' (15) but not the 'pair-reading' $(15 \mathrm{~b})$.

$$
\begin{aligned}
& \text { only } \operatorname{Emil}_{F}: \lambda P[P(e) \wedge \forall y[(y \in \operatorname{Alt}(e) \wedge P(y)) \rightarrow y=e] \\
& \text { called only } \operatorname{Emil}_{F}: \lambda x[\text { called }(x, e) \wedge \forall y[y \in \operatorname{Alt}(e) \wedge \text { called }(x, y) \rightarrow y=e]] \\
& \text { only Anna } F: \lambda P[P(a) \wedge \forall x[(x \in \operatorname{Alt}(a) \wedge P(x)) \rightarrow x=a]] \\
& \text { only } \text { Anna }_{F} \text { called only Emil } F \text { : } \\
& \lambda P[P(a) \wedge \forall x[x \in \operatorname{Alt}(a) \wedge P(x) \rightarrow x=a]]\left(\lambda x \left[\operatorname{call}^{\prime}(x, e) \wedge\right.\right. \\
& \left.\left.\forall y\left[y \in \operatorname{Alt}(e) \wedge \operatorname{call}^{\prime}(x, y) \rightarrow y=e\right]\right]\right)= \\
& \operatorname{called}(a, e) \wedge \forall y\left[y \in \operatorname{Alt}(e) \wedge \operatorname{call}^{\prime}(a, y) \rightarrow y=e\right] \wedge \forall x\left[x \in \operatorname { A l t } ( a ) \wedge \left(\operatorname{call}^{\prime}(x, e) \wedge\right.\right. \\
& \left.\left.\forall y\left[y \in \operatorname{Alt}(e) \wedge \operatorname{call}^{\prime}(x, y) \rightarrow y=e\right]\right) \rightarrow x=a\right]
\end{aligned}
$$

\subsection{Proposal}

A possible solution to solve the above problem is to suppose that in the case of the complex focus meaning of $(12 \mathrm{~b})$ semantically there is only one operator. This can give rise to a suggestion that 'only' here is a resumptive operator and we have a kind of concord. However, I want to avoid this idea because of the fact that dropping the second 'only' from the sentence does not lead to ungrammaticality but gives the same meaning, see example (20a) and 20b).

Rather we suppose that 'only' and the exhaustivity operator are different, and in this case there is one exhaustivity operator that applies to the pair of the arguments, and the two 'only's work pragmatically saying that only Anna calling somebody and that only Emil being called by somebody were both unlikely or against the expectations.

\footnotetext{
${ }^{4}$ An alternative might be that next to the exhaustification of the 'only's the exhaustification of the identificational focus comes on the top of it. It might be the case that exhaustification of the pair of exhaustified terms does not lead to scopal meaning. The question if this alternative might be correct is left for further research.
} 
As for the double focus meaning where the first focus takes scope over the second one we suppose two separate exhaustivity operators, but on different points of the discourse. At the point of the discourse when the sentence is uttered the second focused expression comes as old information and happens to be in the scope of the first focus, which constitutes new information. This way the two focused expressions are apart and there is no way for them to form a pair.

Q: Ki hívta fel csak EMILT?

(who called VM only Emil.acc)

'Who called only Emil?'

A: Csak Anna hívta fel csak EmiLt.

(only Anna called VM only Emil.acc)

'Only Anna called only Emil.' (scope-reading)

\#'It is the Anna, Emil pair of whom the first called the second.' (pair-reading)

\section{A pragmatic analysis of 'only'}

As we saw in section 1.2 the Structured Meaning Account and the Partition Semantics both treat 'only' and exhaustivity as identical. In this way we cannot account for examples of constituent questions and answers in Hungarian where the occurence of 'only' makes a significant difference, as in example 25.

In section 2 I suggested a pragmatic account of 'only' in multiple focus constructions where a pair-reading comes together with two 'only's. With the following examples we obtain another argument for a pragmatic analysis of 'only' in Hungarian. Consider the following examples:

a. Ki hívta fel Emilt?

(who called VM Emil.acc)

'Who called Emil?'

b. ANNA hívta fel Emilt.

(Anna called VM Emil.acc)

'It is Anna who called Emil.'

c. Csak AnNA hívta fel Emilt.

(only Anna called VM Emil.acc)

'Only Anna called Emil.'

(25) a. Kik hívták fel Emilt?

(who.pl called.pl VM Emil.acc)

'Who called Emil?'

b. \#AnNA hívta fel Emilt.

(Anna called VM Emil.acc)

'It is Anna who called Emil.'

c. Csak Anna hívta fel Emilt.

(only Anna called VM Emil.acc)

'Only Anna called Emil.'

For the question in 24a the answers with or without 'only' 24b and 24c are semantically equivalent, saying that Anna and nobody else called Emil. The focus in (24b) expresses exhaustive identification, thus the interpretation is as follows: 


$$
\operatorname{called}(a, e) \wedge \forall x \in \operatorname{Alt}(a)[\operatorname{called}(x, e) \rightarrow x=a]
$$

Therefore it seems that the appearance of csak 'only' in (24c) does not make any difference, since it is interpreted as (26), too. But consider example (25) where we pose the same question in plural, so we make an expectation explicit of more persons calling Emil. Question (25a) cannot be answered with a simple identificational focus, but (25c) - with 'only' - is felicitous. Considering the above example I propose that it is not the 'only' that is responsible for the exhaustive meaning. What 'only' does here is simply cancelling the expectation, and therefore I claim, that 'only' in answers has a pragmatic rather than a semantic function. This idea is similar to Zeevat's (to appear) proposal about 'only'. In his examples 'only' seems to be superfluous and he concludes that the function of 'only' is less semantic and more pragmatic than was assumed before. He suggests two possible ways to solve this problem. The first one is that 'only' has a pragmatic function to cancel the expectation of the questioner, and the second one is that 'only' makes exhaustivity stronger in the sense that it expands the extension of the restriction on the hidden wh-phrase in the topic. Considering the Hungarian data I prefer the first solution. In the following I will discuss some examples of Hungarian focus and 'only'-sentences and present my proposal to try and solve the above problems.

To explain what is going on in (24) and (25) I use Groenendijk and Stokhof's (1984, 1991) theory of questions and answers. In this theory the meaning of an interrogative determines what its possible complete semantic answers are. The semantic interpretation of an interrogative is an equivalence relation over the set of possible worlds, thus an interrogative sentence denotes a partition of logical space. Every block of the partition induced by ? $\phi$ contains the possible worlds where the extension of $\phi$ is the same, thus the meaning of a question is a set of propositions, the set of complete semantic answers to the question.

$$
[[? \vec{x} \phi]]=\left\{(w, v) \in W^{2} \mid[[\lambda \vec{x} \phi]]^{w}=[[\lambda \vec{x} \phi]]^{v}\right\}
$$

For example, if we have a relevant domain $D=\{$ Anna,Rena,Tomi $\}$ who might have called Emil then the question 'Who called Emil?' (=24a) expresses an eight-block partition:

\begin{tabular}{|c|}
\hline$\lambda w . \neg \exists x$. called $(x, e)(w)$ \\
\hline$\lambda w . \forall x . c a l l e d(x, e)(w) \leftrightarrow x=a$ \\
\hline$\lambda w . \forall x . c a l l e d(x, e)(w) \leftrightarrow x=r$ \\
\hline$\lambda w . \forall x . c a l l e d(x, e)(w) \leftrightarrow x=t$ \\
\hline$\lambda w . \forall x$. called $(x, e)(w) \leftrightarrow[x=a \vee x=r]$ \\
\hline$\lambda w . \forall x$. called $(x, e)(w) \leftrightarrow[x=a \vee x=t]$ \\
\hline$\lambda w . \forall x$. called $(x, e)(w) \leftrightarrow[x=r \vee x=t]$ \\
\hline$\lambda w . \forall x . c a l l e d(x, e)(w)$ \\
\hline
\end{tabular}

\begin{tabular}{|c|}
\hline nobody \\
\hline anna \\
\hline rena \\
\hline tomi \\
\hline anna and rena \\
\hline anna and tomi \\
\hline rena and tomi \\
\hline everybody \\
\hline
\end{tabular}

The question in example (24) is equated with the partition in (28). The focus expresses exhaustive identification, thus it contains an implicit exhaustivity $(E X H)$ operator (along Groenendijk $\&$ Stokhof, 1984, 1991). Consequently, the proposition that a sentence with identificational focus denotes is one of the propositions in the partition induced by the underlying question; the answer with identificational focus is a complete semantic answer ${ }^{5}$. Thus identificational focus selects one block from the partition, or equivalently, it eliminates all blocks but one from the partition. In case of $24 \mathrm{~b}$ ) the focus selects the block containing the proposition only Anna called Emil.

\footnotetext{
${ }^{5}$ For the simple cases.
} 
(29)

\begin{tabular}{|c|c|}
\hline nobody & anna and rena \\
\hline anna & $a n n a$ and tomi \\
\hline rena & rena and tomi \\
\hline tomi & everybody \\
\hline
\end{tabular}

Question (25) has an explicit expectation from the questioner's side: (s)he thinks that there was more than one person (from the relevant domain) who came. This expectation should be interpreted as a restriction on the partition:

$P \nrightarrow$\begin{tabular}{|c|c|}
\hline nobody & anna and rena \\
\cline { 1 - 2 } & anna and tomi \\
\hline rena & rena and tomi \\
\hline tomi & everybody \\
\hline
\end{tabular}

For the identificational focus only the restricted area (dashed lines) is accessible to select a block. Therefore we cannot reply to (25a) with $(25 \mathrm{c})$, because the block where the proposition is only Anna called Emil is not among the available ones, but we can reply with (31). It follows from this that it is not the case that the exhaustive focus is out as an aswer for plural questions.
ANNA és TOMI hívta
fel Emilt.
(Anna and Tomi called.3sg VM Emil.acc)
'It is Anna and Tomi who called Emil.'

Thus the answer with an identificational focus is a complete semantic answer and also a complete pragmatic answer.

In fact, for question (25a) it is not excluded to give an answer that expresses that Anna and nobody else called Emil, but in case of (25a) we need csak 'only' to go explicitly against the previous expectation of the questioner. Thus csak 'only' cancels the restriction, whereby the blocks which were excluded before "pop-up" again, so they become accessible for the identificational focus to select one of them. It follows that the exhaustive identification - namely selecting a block from the partition - is the function of the identificational focus, and csak 'only' has a pragmatic effect on the domain restriction.

Given these observations we may wonder 'What is happening in (24c)?' In question (24a) the questioner does not have any expectation about how many people came, but we can answer with an 'only'-sentence. I claim that in this case the use of 'only' in the answer gives information about the answerer's previous expectations, namely the answerer expected more people to come. But according to the questioner's information state this additional information is irrelevant. Nevertheless, it shows, too, that $(24 b)$ and $(24 c)$ are slightly different and the use of 'only' in (24c) is not redundant.

The main idea outlined above can also be applied to multiple constituent questions and their answers with multiple foci. As we saw in example (14), in Hungarian there are two possible structures for questions containing two wh-phrases, and these two different structures have a different meaning.

a. Ki kit hívott fel? (=14a pair-list)

(who whom called VM)

'Who called whom?' 
b. \#ANnA hívta fel EMILT.

(Anna called VM Emil.acc)

'It is the Anna, Emil pair of whom the first called the second.'

c. Csak AnNA hívta fel EmiLt.

(only Anna called VM Emil.acc)

'It is the Anna, Emil pair of whom the first called the second.'

a. Ki hívott fel kit? (=14b; complex $)$

(who called VM whom)

'Who called whom?

b. AnNA hívta fel EMILT.

(Anna called VM Emil.acc)

'It is the Anna, Emil pair of whom the first called the second.'

c. \#Csak AnNA hívta fel EMILT.

(only Anna called VM Emil.acc)

'It is the Anna, Emil pair of whom the first called the second.'

Example (32) perfectly fits in the previous picture; the explanation is the same as it was for (24). Over a domain of three persons $D=\{$ Anna,Emil,Tomi $\}$ the partition determined by (32a) has 512 blocks 6 , and since (32a) is a pair-list question, we have an expectation that there were more calls, that restricts us to the blocks containing more than one pair.

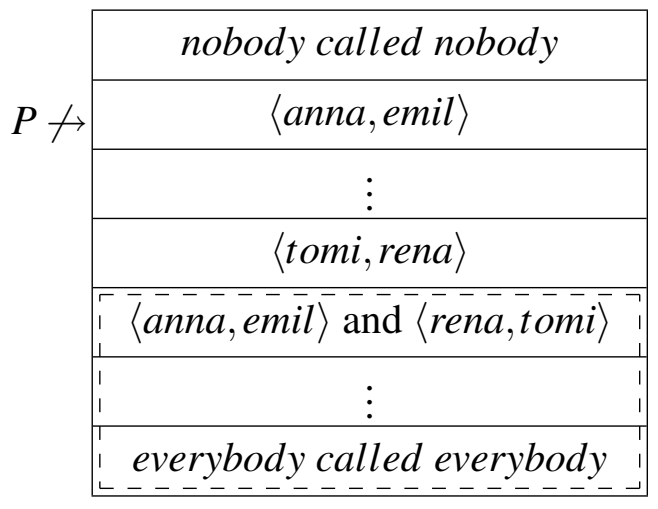

For (32a) the answer (32b) is infelicitous, we cannot simply select the block where there is only the $\langle$ Anna,Emil $\rangle$ pair. It is not accessible because of the expectation (restriction) of the questioner, we need 'only' again to go against the expectation. (32c) is felicitous, because the restriction is cancelled, so the identificational focus can select the block where there is only one pair: Anna and Emil.

Example (33) is a bit different, since here both the questioner and answerer already know that there is only one pair of persons of whom the call-relation holds. The question in 33a) denotes a partition where the blocks contain one pair.

\footnotetext{
${ }^{6}$ Assuming that people can call themselves.
} 
(35)

Loose meaning:

\begin{tabular}{|c|}
\hline$\langle$ anna, emil $\rangle$ \\
\hline$\langle$ anna, tomi $\rangle$ \\
\hline$\vdots$ \\
\hline$\langle$ tomi, anna $\rangle$ \\
\hline$\langle$ tomi, emil $\rangle$ \\
\hline
\end{tabular}

Strict meaning:

\begin{tabular}{|c|}
\hline$\langle$ anna,emil $\rangle$ \\
\hline$\langle$ emil, anna $\rangle$ \\
\hline
\end{tabular}

The complex focus can select one of the blocks, but (33c) is out. The explanation is that in this case both the questioner and answerer know that there is one pair, thus there is no expectation from both sides, so for 'only' there is nothing to cancel, therefore the use of 'only' in this context is out.

\section{Multiple focus readings}

Example (12) raises the question what linguistic factors play a role to disambiguate between the two meanings. In this section we will discuss these factors: intonation, syntactic structure, appearance of 'only' and information structure. Our claim is that in order to interpret multiple foci we have to take into consideration all these factors. First of all we discuss intonation, which seems to have a very important role here. For sentence (12) two different intonation patterns lead to two meanings.

Csak AnnA hívta fel csak EMILT. (=12)

a. Csak Anna hívta fel csak Emilt.

$\mathrm{H}^{*}$-L L $\quad \mathrm{L}-\mathrm{H} \% \quad \mathrm{H}^{*}$-L $\Longrightarrow$ pair-reading / *scope-reading

'It is the Anna, Emil pair of whom the first called the second.'

b. Csak Anna hívta fel csak Emilt. $\Longrightarrow$ *pair-reading / scope-reading

$\mathrm{H}^{*}$-L L $\quad \mathrm{L} \quad \mathrm{L} \quad \mathrm{H}^{*}-\mathrm{L}$

'Only Anna called only Emil. [the others more or nobody]'

In (36a) both focussed constituents get pitch accent, before the second focused element there is a little stop (end of an intonation phrase) and just before this break there is a rising intonation. This intonation pattern gives us the complex focus (pair) reading. In $(\sqrt{36} \mathrm{~b})$ all words between the focussed constituents are deaccented and there is no break 7 . This pattern gives the double focus (scope) reading. Intonation has the role to yield the intended meaning, however, there is no one-to-one correspondence between intonation patterns and meanings, since for (10) and (20b) the pair-intonation leads to the pair-reading, but the scope-intonation leads either to the pair-reading again or ungrammaticality. Interestingly only for structure (12) we can get the scope-reading, for structures $(10)$ and $(20 \mathrm{~b})$ the scope-reading is out.

Csak AnNA hívta fel EMiLt. (=20b

a. Csak Anna hívta fel Emilt.

$\mathrm{H}^{*}$-L L $\quad \mathrm{L}-\mathrm{H} \% \mathrm{H}^{*}-\mathrm{L} \Longrightarrow$ pair-reading / *scope-reading

b. Csak Anna hívta fel Emilt.

$\mathrm{H}^{*}-\mathrm{L} \mathrm{L} \quad \mathrm{L} \quad \mathrm{H}^{*}-\mathrm{L} \Longrightarrow$ *pair-reading /*scope-reading

(38) AnNa hívta fel EMILT. (=10)

\footnotetext{
${ }^{7}$ I will not discuss here the question whether the second focused phrase here is deaccented as well or gets pitch accent. There are different opinions on this topic, according to my intuitions the second focus is not deaccented.
} 

a. Anna hívta fel Emilt.
$\mathrm{H}^{*}$-L L $\quad \mathrm{L}-\mathrm{H} \% \mathrm{H}^{*}$-L $\Longrightarrow$ pair-reading / *scope-reading
b. Anna hívta fel Emilt.
$\mathrm{H}^{*}-\mathrm{L} \mathrm{L} \quad \mathrm{L} \quad \mathrm{H}^{*}-\mathrm{L} \Longrightarrow$ *pair-reading / *scope-reading

This suggests that the scope-reading is only possible with 'only'-phrases. We cannot even ask Who is that, who called Emil and nobody else? by using (39a), but we can by using (39b). Thus it seems that to express scope-meaning without 'only' we need a special syntactic structure.
a. *Ki hívta fel EMILT?
(who called VM Emil.acc)
'Who called Emil (and nb. else)?'
b. Ki hívta EmiLt fel?
(who called Emil.acc VM)
'Who called Emil (and nb. else)?'

É. Kiss (1998) proposes an elegant syntactic analysis of multiple focus constructions. She claims that $\mathrm{F}$ (ocus) $\mathrm{P}$ (hrase) (Bródy 1990) iteration is possible. According to this analysis, the second focused constituent also moves to an FP position, while the verb moves to the first Fhead going through the second one. This syntactic analysis supports the cases where we have semantically two focused elements, hence two focus/exhaustivity operator where the first takes scope over the second one.

(40) Csak AnNA hívta csak EMilt meg.

(only Anna called only Emil.acc VM)

'Only Anna called only Emil. [the others more or nobody]'

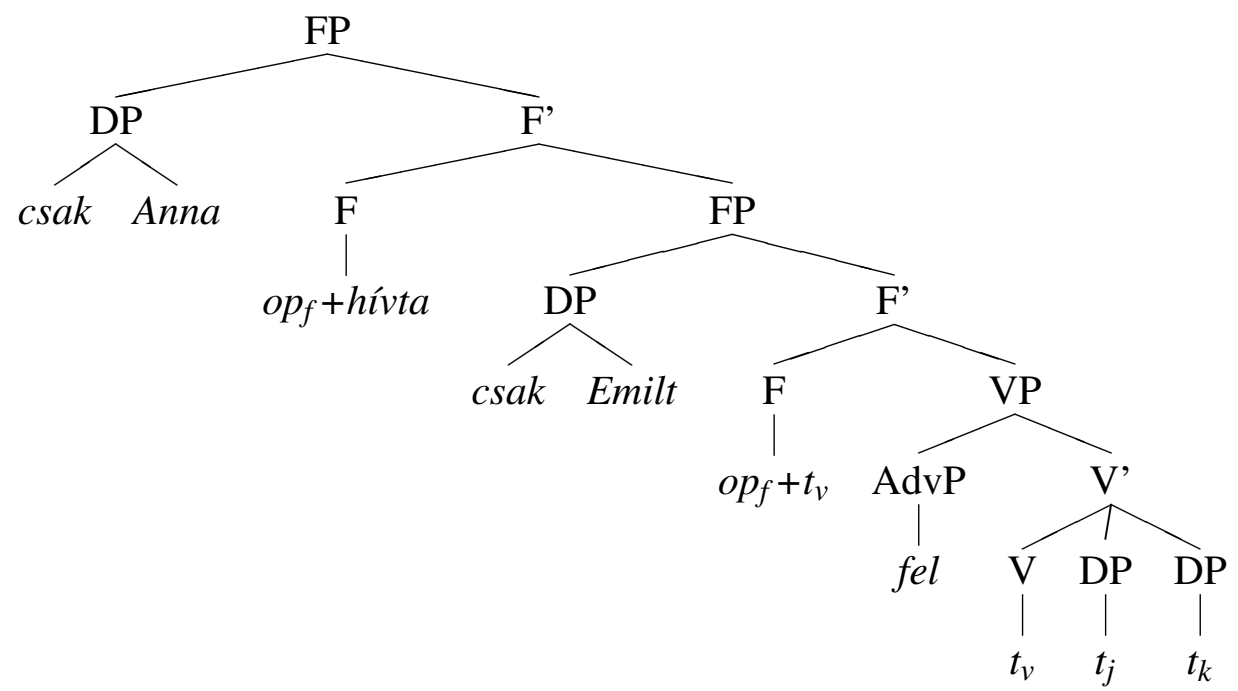

Alberti and Medve (2000) gives a different syntactic structure for the pair-reading which they call "mirror focus" 41) construction versus the "double focus" construction from É. Kiss.

(41) (Csak) AnNA hívta fel (csak) EMILT.

((only) Anna called VM (only) Emil.acc)

'It is the Anna, Emil pair of whom the first called the second.'

$\ldots\left[F P\left[V P \ldots t_{k} t_{u} \mathrm{XP} t_{l} \ldots\right]_{i}\left[F^{\prime} \mathrm{F}+\left(\mathrm{V}+\mathrm{V}_{k}\right)_{s}\left[V P t_{s} t_{i} t_{u} \mathrm{XP}_{l} \ldots\right] t_{i}\right]\right]$

The advantage of this analysis is that it assigns a different syntactic structure for the complex focus, where there is only one focus phrase and consequently only one focus/exhaustivity operator which is applied to an ordered pair of arguments. The disadvantage is that these analyses 
suggest a correspondence between the readings and the structures respectively. However, the picture is not as simple as that, since it can be the case that structure (40) gets the pair reading or structure (41) gets the scope reading. Consider, for example, the following example with the same word order as in (40), but with the strong intonation pattern we can get the complex focus reading.

\section{(42) AnNa hívta EMilt fel.}

(Anna rescued Emil.acc VM)

a. Anna hívta Emilt fel.

$\mathrm{H}^{*}$-L L-H\% $\mathrm{H}^{*}$-L L\% $\Longrightarrow$ pair-reading

b. Anna hívta Emilt fel.

$\mathrm{H}^{*}$-L L $\quad \mathrm{H}^{*}$-L L\% $\Longrightarrow$ scope-reading

There are at least three factors that play a role in the interpretation of multiple focus constructions: the use of different intonation patterns, different word order and the occurence of 'only'.

\section{Conclusion and further issues}

The paper presented some investigations on Hungarian focus interpretation concentrating on the multiple (double) focus constuctions. We saw that the interpretation of Hungarian exhaustive focus and 'only' is problematic for the current semantic analyses in several cases like $(12 \mathrm{~b}$ ) where we have two 'only's but a complex focus reading; and also in the answers of singular and multiple wh-questions. On the basis of these examples we claim that exhaustivity operators and 'only' are distinct (in Hungarian) and 'only' in Hungarian has a strong pragmatic nature which goes against expectation. In section 4 we saw several linguistic considerations that give the "complex focus" or double/real multiple focus reading of multiple focus constructions. On the one hand there is a strong intonation pattern which gives the complex focus reading, but there is no one-to-one correspondence between intonation and interpretation 8 , since word order or the appearance of 'only' can modify it. Thus, the main claim is here that for the disambiguation between these two readings, intonation, syntactic structure and 'only' work together.

In the research on exhaustivity, 'only' and multiple foci, there is another important issue: the scalar reading. According to Hungarian data scalar 'only' and non-scalar 'only' behave differently in scope-relations.

(43) Csak HÁROM FIÚ tud befogni csak ÖT CSIKÓT.

(only three boys can hitch only five foals.acc)

'Only three boys can hitch only five foals.'

Example (43) allows for four possible readings in principle: 1) the first 'only'-phrase (OP) is scalar and the second OP is non-scalar/exhaustive, 2) the first OP is scalar and the second OP scalar, 3) the first OP is exhaustive and the second OP is scalar, and 4) the first OP is exhaustive and the second OP is exhaustive. However, from these four possible readings the ones where the first 'only'-phrase gets a scalar interpretation are ungrammatical. This suggests the following generalization: if we have two only-phrases where the first takes scope over the second one, then the first one cannot be scalar, but has to be exhaustive and distributive. However, this does not mean that scalar 'only'-phrase cannot take wide scope. There are examples where the second focus phrase is without 'only', and the first focus phrase with 'only' can have both a scalar and non-scalar reading (with different underlying questions).

\footnotetext{
${ }^{8}$ The same conclusion is drawn by Šafárová's (to appear) work.
} 


\section{References}

Bródy, M.: 1990, Some remarks on the focus field in hungarian, UCL Working Papers in Linguistics 2.

É. Kiss, K.: 1998, Identificational focus versus information focus, Language 74:2.

É. Kiss, K. (ed.): 1995, Discourse Configurational Languages, Oxford University Press, New York/Oxford.

Groenendijk, J. and Stokhof, M.: 1984, Studies on the Semantics of Questions and the Pragmatics of Answers, $\mathrm{PhD}$ thesis, University of Amsterdam, Amsterdam.

Groenendijk, J. and Stokhof, M.: 1991, Partitioning Logical Space, Annotated handout at the 2nd ESSLLI, Leuven.

Krifka, M.: 1991, A compositional semantics for multiple focus constructions, in J. Jacobs (ed.), Informationsstruktur und Grammatik, Sonderheft der Linguistische Berichte.

Lipták, A.: 2000, Multiple relatives as relatives of questions, in I. Kenesei and G. Alberti (eds), Approaches to Hungarian 7., JATEPress, Szeged.

Šafářová, M.: to appear, Nuclear rises in update semantics, in M. Aloni, A. Butler and P. Dekker (eds), Questions in Dynamic Semantics. CRiSPI Series, Elsevier, Amsterdam.

Szendrői, K.: 2003, A stress-based approach to the syntax of hungarian focus, The Linguistic Review 20:1.

Zeevat, H.: to appear, Exhaustivity, questions and plurals in update semantics, in M. Aloni, A. Butler and P. Dekker (eds), Question in Dynamic Semantics. CRiSPI Series, Elsevier, Amsterdam. 


\title{
DOG AFTER DOG REVISITED
}

\author{
Sigrid Beck \& Arnim von Stechow, \\ Universität Tübingen \\ sigrid.beck@uni-tuebingen.de, arnim.stechow@uni-tuebingen.de
}

\begin{abstract}
This paper presents a compositional semantic analysis of pluractional adverbial modifiers like 'dog after dog' and 'one dog after the other'. We propose a division of labour according to which much of the semantics is carried by a family of plural operators. The adverbial itself contributes a semantics that we call pseudoreciprocal.
\end{abstract}

\section{Introduction}

The topic of this paper is the semantic analysis of the sentences in (1). (1a,b) contain the adverbial modifiers 'one after the other' and 'dog after dog', respectively, which add to the simple (1') information on how the overall event of the dogs entering the room is to be divided into subevents based on a division of the group of dogs into individual dogs. We call these adverbials pluractional adverbials, following e.g. Lasersohn's (1995) use of the term pluractionality for the division of larger eventualities into subeventualities.

(1) a. These three dogs entered the room one after the other.

b. They entered the room dog after $\mathbf{d o g}$.

These three dogs entered the room.

The type of situation described by (1a) (and also by (1b) if the referent of 'they' is the same as the referent of 'the three dogs') is depicted informally in (2). We will aim to derive this fact by associating with $(1 \mathrm{a}, \mathrm{b})$ (roughly) the truth conditions in (3); that is, we will propose a compositional semantics for $(1 \mathrm{a}, \mathrm{b})$ that derives approximately the truth conditions in (3), and (3) serves to capture our intuitions about the situations in which $(1 \mathrm{a}, \mathrm{b})$ would be considered true.

(2) a. These three dogs entered the room one after the other.

b. $\quad$ D3 $\rightarrow$ D2 $\rightarrow$ D1 $" x \rightarrow y "=x$ enters the room after $y$

(3) These three dogs entered the room, and the entering can be divided into a sequence of subevents in each of which one of the dogs enters, and the dogs can be divided into a sequence of individual dogs each of which entered in one of the subevents.

While we largely concentrate on the particular examples in (1), the phenomenon as such is of course more general. Other examples of reduplicative adverbials like 'dog after dog' are given in (4), and other examples of the 'one ... the other' type are provided in (5). These data were collected informally from the web.

(4) a. This mystery offers puzzle within puzzle.

b. She laid book upon book and built a staircase long enough to climb up and look over the wall.

c. The Wall of Tears is a very big wall that was built, stone over stone by the prisoners when Isabela was a penal colony back in 1946. 
(5) a. Because life's interaction is like a series of boxes one within the other, ecological studies are organized in hierarchical levels

b. In storing textiles, rugs, or other large-sized weavings, these should never be folded and piled one upon the other .

c. My grandmother had on not just one skirt, but four, one over the other.

There have of course been earlier approaches to these or related phenomena. The most relevant ones to our knowledge are the following: Moltmann (1995), who proposes an analysis of 'piece by piece' adverbials; Stockall (2001), who analyses 'dog after dog' type adverbials; and Zimmermann (2002), who proposes a refinement of Stockall's analysis. Our goal in this paper is not so much to develop a compositional semantics of (1), but rather to develop such an analysis in the framework of plural predication developed in Beck (2001). The earlier proposals just mentioned do not have that aim.

We will first introduce the background on plural predication that we assume, in section 2. In section 3 we analyse the 'one ... the other' type of adverbial in this system. We take a closer look at the internal make-up of the modifier in section 4 and propose a semantics we call pseudoreciprocal. We go on to suggest that a certain kind of apparent reciprocal had better receive an analysis in terms of pseudoreciprocity. Section 5 concludes the paper.

\section{Background}

Besides individuals (type $\left\langle\mathrm{e}>\right.$ ) we use eventualities (type $\langle\mathrm{v}\rangle$ ). We assume that both $\mathrm{D}_{\mathrm{e}}$ (the denotation domain of individuals - count and mass) and $\mathrm{D}_{\mathrm{V}}$ (the denotation domain of eventualities) have a mereological structure:

$$
\begin{aligned}
& \text { For any set } \mathrm{M} \subseteq \mathrm{D}_{\sigma}, \Sigma \mathrm{M} \in \mathrm{D}_{\sigma} \quad \text { (Lewis, 1991) } \\
& \text { where } \sigma=\mathrm{e} \text { or } \sigma=\mathrm{v} \text { and } \Sigma \mathrm{M} \text { is the mereological fusion of the elements of } \mathrm{M} \text {. } \\
& \mathrm{x}+\mathrm{y}=\Sigma\{\mathrm{x}, \mathrm{y}\} \\
& \text { the fusion of those individuals that are parts of } \mathrm{x} \text { or } \mathrm{y} \text { or overlap with } \mathrm{x} \text { and } \mathrm{y} \\
& \text { a. } \quad \text { part of relation } \leq \text { : } \\
& \text { b. } \quad \text { o primitive relation between individuals: antisymmetric, reflexive, transitive } \\
& \quad \mathrm{x} \text { o y iff } \exists \mathrm{z}[\mathrm{z} \leq \mathrm{x} \& \mathrm{z} \leq \mathrm{y}]
\end{aligned}
$$

We assume that basic predicates can be pluralized in order to apply to groups (or generally entities with a part-whole structure). For this purpose we use a family of operators of various types, beginning with Link's (1983) * operator for the pluralization of <e,t> predicates, and moving on to operators pluralizing relations (compare in particular Sternefeld (1998), also Beck (2001)). The relevant case for our present purposes is an operator $* *$ that pluralizes predicates of type $\langle\mathrm{e},\langle\mathrm{v}, \mathrm{t}\rangle\rangle$. The pluralized relation is true of all the things that the original relation was true of, plus all the part-whole structures that can be built from them.

Cumulation operator $* *$

Let $\mathrm{R}$ be a relation of type $\langle\mathrm{e},\langle\mathrm{v}, \mathrm{t}\rangle\rangle$. Then $\left[{ }^{* *} \mathbf{R}\right]$ is the smallest relation $\mathrm{R}$ ' such that the condtions in (a) and (b) are satisfied.

(a) $\quad \mathrm{R} \subseteq \mathrm{R}^{\prime}$

(b) for all $\langle x, e\rangle$ and $\left\langle y, e^{\prime}\right\rangle$ :

If $\langle\mathrm{x}, \mathrm{e}\rangle \in \mathrm{R}^{\prime}$ and $\left\langle\mathrm{y}, \mathrm{e}^{\prime}\right\rangle \in \mathrm{R}^{\prime}$, then $\left\langle\mathrm{x}+\mathrm{y}, \mathrm{e}+\mathrm{e}^{\prime}\right\rangle \in \mathrm{R}^{\prime}$

We further assume that all such pluralization is sensitive to a contextually given division of entities into subparts. We concretely follow Schwarzschild (1996) who suggests that the context provides a cover of the universe of discourse (compare also once more Moltmann (1995)). The covers relevant for our purposes will all be partitions (defined in (11a). (11b,c) 
define two useful bits of notation: the constraint that the cover be a partition of an entity $\mathrm{x}$ in (11b), and in (11c) the part of the cover that pertains to an entity $x$.

\section{(10) Cover (mereological version)}

$\mathrm{C}$ is a cover of $\mathrm{x}$ iff $\mathrm{C}$ is a set such that $\Sigma \mathrm{C}=\mathrm{x}$.

(11) a. A cover $\mathrm{C}$ is a partition iff for any $\mathrm{x}, \mathrm{y} \in \mathrm{C}: \mathrm{x}$ and $\mathrm{y}$ don't overlap.

b. $\quad \operatorname{PART}(\mathbf{C}, \mathbf{x}):=1$ iff $\mathrm{C}$ is a partition (and a cover) of $\mathrm{x}$.

c. $\quad \operatorname{Cov}[\mathrm{x}]=\{\mathrm{y}: \mathrm{y} \in \operatorname{Cov} \& \Sigma \mathrm{y} \leq \mathrm{x}\}$

We implement these suggestions through syntactic pluralization operations such as (12) for pluralization of type $\langle\mathrm{e},\langle\mathrm{v}, \mathrm{t}\rangle\rangle$ predicates; (12) combines the $* *$ operator with the requirement that the division into subparts be into the contextually relevant ones, plus the presupposition that the contextually provided cover be a partition of the entities considered.

$$
\begin{aligned}
{[[\mathbf{P L}]]=} & \lambda \operatorname{Cov} \cdot \lambda \mathrm{R}<\mathrm{e},\langle\mathrm{v}, \mathrm{t}>>\cdot \lambda \mathrm{x} \cdot \lambda \mathrm{e}: \operatorname{PART}(\operatorname{Cov}, \mathrm{e}+\mathrm{x}) . \\
& * *\left[\lambda \mathrm{x}^{\prime} \cdot \lambda \mathrm{e}^{\prime} \cdot \operatorname{Cov}\left(\mathrm{e}^{\prime}\right) \& \operatorname{Cov}\left(\mathrm{x}^{\prime}\right) \& \mathrm{R}\left(\mathrm{x}^{\prime}\right)\left(\mathrm{e}^{\prime}\right)\right](\mathrm{x})(\mathrm{e})
\end{aligned}
$$

The use of PL is illustrated in the example in (13). A predicate of type $\langle\mathrm{e},\langle\mathrm{v}, \mathrm{t}\rangle\rangle$ is created through movement of the object NP. The PL operator together with its cover restriction is adjoined to that predicate. If the presupposition triggered by PL is met, the result will be the predicate of events in (13c). (13c) is true of an event e iff e and the cake can be divided into relevant parts $\mathrm{x}$ and $\mathrm{e}$ ' that stand in the relation 'John ate $\mathrm{x}$ in $\mathrm{e}$ ". The cake and the big event $\mathrm{e}$ can be divided in this way just in case (13d) is true: each relevant part of the cake was eaten by John in a relevant subevent, and each relevant subevent has John eating a relevant part of the cake in it. Thus (13a) is true of an event that can be divided into smaller events of eating parts of the cake; a sample situation would be (14).

(13) a. John ate the cake.

b. [ [the cake] [PLCov $[\langle\mathrm{e},\langle\mathrm{v}, \mathrm{t}\rangle\rangle \lambda 1[\mathrm{John}$ ate $\mathrm{t} 1]]]]$

c. $\quad \lambda \mathrm{e} .\langle\mathrm{e}, \mathrm{C}\rangle \in * *\left[\lambda \mathrm{x} \cdot \lambda \mathrm{e}^{\prime} \cdot \operatorname{Cov}(\mathrm{x}) \& \operatorname{Cov}\left(\mathrm{e}^{\prime}\right) \& \mathrm{~J}\right.$ eat $\mathrm{x}$ in $\left.\mathrm{e}^{\prime}\right]$

d. $\forall \mathrm{x}\left[\mathrm{x} \leq \mathrm{C} \& \operatorname{Cov}(\mathrm{x})->\exists \mathrm{e}^{\prime}\left[\mathrm{e}^{\prime} \leq \mathrm{e} \& \operatorname{Cov}\left(\mathrm{e}^{\prime}\right) \& \mathrm{~J}\right.\right.$ eat $\mathrm{x}$ in $\left.\left.\mathrm{e}^{\prime}\right]\right] \&$ $\forall \mathrm{e}^{\prime}\left[\mathrm{e}^{\prime} \leq \mathrm{e} \& \operatorname{Cov}\left(\mathrm{e}^{\prime}\right)->\exists \mathrm{x}\left[\mathrm{x} \leq \mathrm{C} \& \operatorname{Cov}(\mathrm{x}) \& \mathrm{~J}\right.\right.$ eat $\mathrm{x}$ in $\left.\left.\mathrm{e}^{\prime}\right]\right]$

(14) a. $\mathrm{g}(\mathrm{Cov})[\mathrm{C}+\mathrm{e}]=\{\mathrm{c} 1, \mathrm{c} 2, \mathrm{e} 1, \mathrm{e} 2\}$ with $\mathrm{e}=\mathrm{e} 1+\mathrm{e} 2$ and $\mathrm{C}=\mathrm{c} 1+\mathrm{c} 2$

b. $\quad \llbracket$ eat $\rrbracket=\{\langle\mathrm{J}, \mathrm{c} 1, \mathrm{e} 1\rangle,\langle\mathrm{J}, \mathrm{c} 2, \mathrm{e} 2\rangle\}$

It is not obvious that such an analysis in terms of pluractionality is needed for (13). In (15), however, with the adverbial 'piece by piece', it is clear that the truth conditions of the sentence imply a division of the overall event of eating the cake into subevents depending on a division of the cake into pieces. This is reflected in the truth conditions described in (15'). The adverbial 'piece by piece' seems to be an instantiation of a version of the PL operator with a cover of the cake into pieces. We will not worry here too much about how to implement this idea; one possibility is given in (16). The resulting truth conditions (16c) correspond closely to the ones in (13c,d): (16c) is true of an event e iff e and the cake can be divided into relevant parts $y^{\prime}$ and e' such that $y^{\prime}$ is a piece and John are $y^{\prime}$ in e'. That is, each piece of the cake was eaten by John in some relevant subevent, and each relevant subevent was John eating a piece of the cake.

(15) John ate the cake piece by piece.

$\left(15^{\circ}\right)(15)$ is true of an event e iff the relevant division of the cake is into pieces, and each piece was eaten by John in a relevant subevent of e, and each relevant subevent of e is an eating of one of the pieces by John. 
(16) a. [ [the cake] [ piece by pieceCov $[\langle\mathrm{e},\langle\mathrm{v}, \mathrm{t}\rangle\rangle\rangle 2[\mathrm{John}$ ate $\mathrm{t} 2]]]]$

b. $\quad[[$ piece by pieceCov $]]=\lambda \mathrm{R}<\mathrm{e}<\mathrm{v}, \mathrm{t}>>. \lambda \mathrm{y} . \lambda \mathrm{e}$ : $\operatorname{PART}(\operatorname{Cov}, \mathrm{e}+\mathrm{y})$.

$* *\left[\lambda \mathrm{y}^{\prime} . \lambda \mathrm{e}^{\prime} . \operatorname{Cov}\left(\mathrm{y}^{\prime}\right) \& \operatorname{Cov}\left(\mathrm{e}^{\prime}\right) \& \mathrm{y}^{\prime}\right.$ is a piece $\left.\& \mathrm{R}\left(\mathrm{y}^{\prime}\right)\left(\mathrm{e}^{\prime}\right)\right](\mathrm{y})(\mathrm{e})$

c. $\quad \lambda$ e. $\left\langle e, C>\in * *\left[\lambda y^{\prime} . \lambda e^{\prime} . \operatorname{Cov}\left(y^{\prime}\right) \& \operatorname{Cov}\left(e^{\prime}\right) \& y^{\prime}\right.\right.$ is a piece $\&$ John ate $y^{\prime}$ in $\left.e^{\prime}\right]$

\section{One after the Other}

We can now return to the problem that interests us, repeated below. We approach it by first considering more standard occurrences of the modifier 'after NP' and extending their analysis to 'after the other'.

(2) These three dogs entered the room one after the other.

D3 -> D2 -> D1

(3) These three dogs entered the room, and the entering can be divided into a sequence of subevents in each of which one of the dogs enters, and the dogs can be divided into a sequence of individual dogs each of which entered in one of the subevents.

\subsection{The Modifier 'after NP'}

Our baseline will be the contribution of 'after NP' suggested in (17') for (17). This leads to the semantics in (17") for 'after Katie': it modifies a relation of type $\langle\mathrm{e},\langle\mathrm{v}, \mathrm{t}\rangle\rangle$ and adds the information that the relation held between Katie and the immediately preceding event. We rely on the notion of the relevant predecessor of an event, which is the event whose running time is immediately before the running time of the event considered.

(17) Min entered the room (immediately) after Katie.

$\left(17^{`}\right) \lambda$ e. Min enters the room in e \& Katie enters the room in pred(e)

$\operatorname{pred}(\mathrm{e})$ : the immediate predecessor of $\mathrm{e}$

$\left(17^{*}\right) \quad[[$ after Katie $]]=\lambda \mathrm{R}<\mathrm{e},\langle\mathrm{v}, \mathrm{t}>>. \lambda x . \lambda \mathrm{e} . \mathrm{R}(\mathrm{x})(\mathrm{e}) \& \mathrm{R}(\operatorname{Katie})(\operatorname{pred}(\mathrm{e}))$

$$
\operatorname{pred}(\mathrm{e})=1 \mathrm{e}^{\prime}: \tau\left(\mathrm{e}^{\prime}\right)<\tau(\mathrm{e}) \& \forall \mathrm{e}^{\prime \prime}\left[\tau\left(\mathrm{e}^{\prime \prime}\right)<\tau(\mathrm{e})->\mathrm{e}^{\prime \prime}=\mathrm{e}^{\prime} \text { or } \tau\left(\mathrm{e}^{\prime \prime}\right)<\tau\left(\mathrm{e}^{\prime}\right)\right]
$$

A generalized verison of this idea is given in (19) and (20). There is an ordering relation on events based on temporal precedence. We can identify the predecessor according to that order.

(19) ordering relation on events:

e is before $\mathrm{e}^{\prime}: \quad \quad \mathrm{e} \angle \mathrm{e}^{\prime}$ iff $\tau(\mathrm{e})<\tau\left(\mathrm{e}^{\prime}\right)$

(20) the immediate predecessor of $\mathrm{e}$ :

$\operatorname{pred}(\mathrm{e})=\mathrm{ee}^{\prime}: \mathrm{e}^{\prime} \angle \mathrm{e} \& \forall \mathrm{e}^{\prime \prime}\left[\mathrm{e}^{\prime \prime} \angle \mathrm{e}->\mathrm{e}^{\prime \prime}=\mathrm{e}^{\prime}\right.$ or e" $\left.\angle \mathrm{e}^{\prime}\right]$

\subsection{The 'Other' Dog}

The instance of the 'after'-modifier that we are confronted with is 'after the other'. The key to our analysis of pluractional 'one after the other' lies in our understanding of the meaning of 'the other' in this construction. We suggest that for each dog, the relevant other dog is always the immediately preceding one. That is, we propose that there is an ordering on the individuals that is derived from the ordering of events, as in (21). The predecessor of an individual can be defined on the basis of that derived order. 
(21) ordering relation on individuals:

$\mathrm{x} \angle \mathrm{y}$ iff $\exists \mathrm{e}\left[\mathrm{x}\right.$ is in e and $\forall \mathrm{e}^{\prime}\left[\mathrm{y}\right.$ is in $\left.\left.\mathrm{e}^{\prime}->\mathrm{e} \angle \mathrm{e}^{\prime}\right]\right]$

$\mathrm{x}$ is before $\mathrm{y}$ iff $\mathrm{x}$ occurs in a relevant event before $\mathrm{y}$ does

(22) the immediate predecessor of $x$ :

$\operatorname{pred}(\mathrm{x})=\mathrm{ty}: \mathrm{y} \angle \mathrm{x} \& \forall \mathrm{z}[\mathrm{z} \angle \mathrm{x}->\mathrm{z}=\mathrm{y}$ or $\mathrm{z} \angle \mathrm{y}]$

Finding the predecessor for each dog requires that the dogs can successfully be ordered into a sequence. (23) defines the notion of sequence: the cover has to have this property so that its members can be ordered. In our example, we would have (24).

(23) $\operatorname{Cov}[x]$ is a sequence iff

$\operatorname{Cov}[\mathrm{x}]=\left\{\mathrm{x}_{1}, \ldots, \mathrm{x}_{\mathrm{n}}\right\}$ and for any $\mathrm{x}_{\mathrm{i}}, \mathrm{x}_{\mathrm{i}+1}: \mathrm{x}_{\mathrm{i}} \angle \mathrm{x}_{\mathrm{i}+1}$

$\operatorname{Cov}[\mathrm{e}]=\left\{\mathrm{e}_{1}, \ldots, \mathrm{e}_{\mathrm{n}}\right\}$ such that for any $\mathrm{e}_{\mathrm{i}}, \mathrm{e}_{\mathrm{i}+1}$ : $\mathrm{e}_{\mathrm{i}} \angle \mathrm{e}_{\mathrm{i}+1}$

$\operatorname{Cov}[$ these $3 \mathrm{dogs}]=\left\{\mathrm{x}_{1}, \ldots, \mathrm{x}_{\mathrm{n}}\right\}$ such that for any $\mathrm{x}_{\mathrm{i}}, \mathrm{x}_{\mathrm{i}+1} \mathrm{x}_{\mathrm{i}} \angle \mathrm{x}_{\mathrm{i}+1}:=\{\mathrm{D} 1, \mathrm{D} 2, \mathrm{D} 3\}$

If the appropriate sequence is given, then the truth conditions of our example (1) can be stated as in (25) below. From (25a) we get (25b). The overall truth conditions we propose are paraphrased in (26).

(25) a. $\quad<3 \mathrm{D}, \mathrm{e}>\in^{* *}\left[\lambda \mathrm{x} \cdot \lambda \mathrm{e}^{\prime} . \operatorname{Cov}(\mathrm{x}) \& \operatorname{Cov}\left(\mathrm{e}^{\prime}\right) \& \mathrm{x}\right.$ enters the room in $\mathrm{e}^{\prime} \&$ $\operatorname{pred}(\mathrm{x})$ enters the room in $\left.\operatorname{pred}\left(\mathrm{e}^{\prime}\right)\right]$

b. $\quad \forall \mathrm{x}\left[\mathrm{x} \leq 3 \mathrm{D} \& \operatorname{Cov}(\mathrm{x})->\exists \mathrm{e}^{\prime}\left[\mathrm{e}^{\prime} \leq \mathrm{e} \& \operatorname{Cov}\left(\mathrm{e}^{\mathrm{c}}\right) \& \mathrm{x}\right.\right.$ enters the room in $\mathrm{e}^{\prime} \&$ $\operatorname{pred}(\mathrm{x})$ enters the room in $\left.\left.\operatorname{pred}\left(\mathrm{e}^{\prime}\right)\right]\right] \&$

$\forall \mathrm{e}^{\prime}\left[\mathrm{e}^{\prime} \leq \mathrm{e} \& \operatorname{Cov}\left(\mathrm{e}^{\prime}\right)->\exists \mathrm{x}\left[\mathrm{x} \leq 3 \mathrm{D} \& \operatorname{Cov}(\mathrm{x}) \& \mathrm{x}\right.\right.$ enters the room in $\mathrm{e}^{\prime} \&$ $\operatorname{pred}(\mathrm{x})$ enters the room in $\left.\left.\operatorname{pred}\left(\mathrm{e}^{\prime}\right)\right]\right]$

(26) e can be divided into a sequence of subevents, and

the three dogs can be divided into a sequence of individual dogs, such that

each dog entered the room in a relevant subevent, and its predecessor entered in the preceding subevent, and

each subevent was one of one of the dogs entering, and the preceding event was one of the predecessor of that dog entering.

These truth conditions can be derived straightforwardly from the Logical Form in (27). The subject is raised, with the movement binding an anaphor contained in the NP 'the other'; the relevant pluralization operator is attached to the modified relation (the predicate created by the movement). We propose a version of our PL operator that incorporates the constraint on the cover that the cover of the relevant entity and event be a sequence. And we suggest a semantics for the modfier 'one after the other' that is essentially a combination of what we found out about 'after NP' in (17") and the idea that the NP here contributes, for each dog, the predecessor of that dog. With this, (27) will give rise to the truth conditions in (26).

(27) these 3 dogs $\left[\mathrm{PL}^{\mathrm{seq}} \mathrm{Cov} \lambda \mathrm{x}[\langle\mathrm{v}, \mathrm{t}\rangle \mathrm{x}[\langle\mathrm{e},\langle\mathrm{v}, \mathrm{t}\rangle\rangle\right.$ entered the room] [one after the other $\left.\mathrm{x}]]\right]$

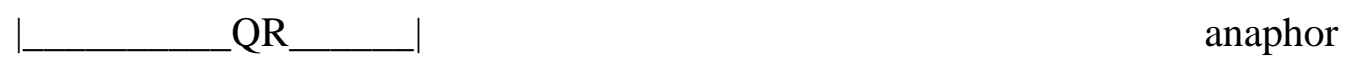

(28) $\llbracket$ one after the other $\mathrm{x} \rrbracket^{\mathrm{g}}=\lambda \mathrm{R} \cdot \lambda \mathrm{y} \cdot \lambda \mathrm{e} \cdot \mathrm{R}(\mathrm{y})(\mathrm{e}) \& \mathrm{R}(\operatorname{pred}(\mathrm{g}(\mathrm{x})))(\operatorname{pred}(\mathrm{e}))$

(29) $\quad\left[\left[\mathbf{P L}^{\mathbf{S e q}} \mathbf{C o v}\right]\right]=\lambda \mathrm{R} \cdot \lambda z \cdot \lambda \mathrm{e} \cdot \operatorname{Cov}[\mathrm{e}]$ is a sequence and $\operatorname{Cov}[\mathrm{z}]$ is a sequence $\&$

$$
* *\left[\lambda z^{\prime} . \lambda e^{\prime} . \operatorname{Cov}\left(z^{\prime}\right) \& \operatorname{Cov}\left(e^{\prime}\right) \& R\left(z^{\prime}\right)\left(e^{\prime}\right)\right](z)(e)
$$




\subsection{The First Dog}

The observant reader will no doubt have noticed that the truth conditions in (26) suffer from a problem: We require that for each dog, that dog enter after its predecessor. But the first dog in the sequence does not have a predecessor. So (26) as such could never be true.

We propose to embrace this prediction - so our compositional semantics will derive these truth conditions. There must then be a pragmatic process that allows us to ignore the first dog, and thus makes it possible for (26) to be true. We suggest that essentially the same process is at work in (30) and (31) below. In (31) for instance, we must subtract Arnim from the domain of quantification and understand 'everyone' to mean here 'everyone but Arnim'; else the sentence could never be true. Likewise we subtract the first sentry in the row from the domain that 'each' quantifies over.

(30) 20 Wachposten sind so in einer Reihe aufgestellt, dass jeder den vorherigen sehen kann.

20 sentries are standing in a row such that each can see the one before him.

(31) Everyone has a faster computer than Arnim.

Thus we think that it is generally possible to reinterpret a quantificational statement that could not come out true by subtracting the problematic indivdual from the domain of quantification. This process will also have to apply to our examples in (1).

\subsection{Similar Cases: One above/within the Other}

In this subsection, we indicate how the analysis proposed for 'one after the other' extends to similar instances of pluractional adverbials with different prepositions. Some examples are given below. We will focus on (32a) with 'above'.

(32) a. These three children sleep one above/ next to the other.

b. She laid the books bundle beside/ upon bundle on the porch.

Our starting point is once more a regular occurrence of the modifier, (33a). The semantics in (33b) leads to the meaning in (34) for the modifier. Like our earlier example 'after NP', the PP modifies a relation. In this case, this is a relation between an individual and a place. It adds to the original relation the information that the relation also holds between the referent of the NP and the relevant preceding place, which is the place immediately below.

(33) a. Hans sleeps above Fritz.

b. $\quad \lambda$ p. Hans sleeps at $\mathrm{p} \&$ Fritz sleeps at bel(p)

$\operatorname{bel}(\mathrm{p})=$ the place immediately below $\mathrm{p}$

$$
[[\text { above Fritz] }]=\lambda R \cdot \lambda x \cdot \lambda p . R(x)(p) \& R(\text { Fritz })(\operatorname{bel}(p))
$$

Once more, then, we have an ordering relation, this time based on the meaning of the preposition 'above'. A place is smaller than another one according to that ordering if it is below it. We then also have the notion of the immediately preceding place.

\section{ordering relation on places:}

$\mathrm{p} \angle \mathrm{p}^{\prime}$ iff $\mathrm{p}$ is below $\mathrm{p}^{\prime}$

$$
\begin{aligned}
& \text { the immediate predecessor of p: } \\
& \operatorname{bel}(\mathbf{p})=\mathrm{t} \mathrm{p}^{\prime}: \mathrm{p}^{\prime} \angle \mathrm{p} \& \forall \mathrm{p}^{\prime \prime}\left[\mathrm{p}^{\prime \prime} \angle \mathrm{p}->\mathrm{p}^{\prime \prime}=\mathrm{p}^{\prime} \text { or } \mathrm{p}^{\prime \prime} \angle \mathrm{p}^{\prime}\right]
\end{aligned}
$$

In order to find a denotation for the NP 'the other' in the pluractional adverbial 'one above the other', we again suppose that there is a derived ordering of individuals based on the one of places (as defined in (37)), which will permit us to define the predecessor of an individual according to the scale introduced by 'above' (cf. (38)). 
(37) ordering relation on individuals:

$\mathrm{x} \angle \mathrm{y}$ iff $\exists \mathrm{p}[\mathrm{x}$ is in $\mathrm{p}$ and $\forall \mathrm{p} "[\mathrm{y}$ is in $\mathrm{p} "->\mathrm{p} \angle \mathrm{p} "]]$

$\mathrm{x}$ is below $\mathrm{y}$ iff $\mathrm{x}$ is in a place that is below any place that $\mathrm{y}$ is in.

$$
\begin{aligned}
& \text { the immediate predecessor of } \mathbf{x} \\
& \operatorname{bel}(\mathbf{x})=\mathrm{ty}: \mathrm{y} \angle \mathrm{x} \& \forall \mathrm{z}[\mathrm{z} \angle \mathrm{x}->\mathrm{z}=\mathrm{y} \text { or } \mathrm{z} \angle \mathrm{y}]
\end{aligned}
$$

The rest of the analysis is quite parallel to the analysis of the 'after' example. We must be able to divide both the place and the plural individual into a sequence. Given that, we propose the analysis in terms of the ** in (40) which amounts to the truth conditions in (41). The resulting truth conditions are described roughly in (42).

\section{$\operatorname{Cov}[\mathrm{p}]=\left\{\mathrm{p}_{1}, \ldots, \mathrm{p}_{\mathrm{n}}\right\}$ such that for any $\mathrm{p}_{\mathrm{i}}, \mathrm{p}_{\mathrm{i}+1}: \mathrm{p}_{\mathrm{i}} \angle \mathrm{p}_{\mathrm{i}+1}$}

$\operatorname{Cov}[$ these 3 children $]=\left\{\mathrm{x}_{1}, \ldots, \mathrm{x}_{\mathrm{n}}\right\}$ such that for any $\mathrm{x}_{\mathrm{i}}, \mathrm{x}_{\mathrm{i}+1}: \mathrm{x}_{\mathrm{i}} \angle \mathrm{x}_{\mathrm{i}+1}$

$$
\begin{aligned}
& \langle 3 \mathrm{C}, \mathrm{p}\rangle \in * *\left[\lambda \mathrm{x} . \lambda \mathrm{p}^{\prime} . \operatorname{Cov}(\mathrm{x}) \& \operatorname{Cov}\left(\mathrm{p}^{\prime}\right) \& \mathrm{x} \text { sleeps in } \mathrm{p}^{\prime} \& \operatorname{bel}(\mathrm{x}) \text { sleeps in bel}\left(\mathrm{p}^{\prime}\right)\right] \\
& \forall \mathrm{x}[\mathrm{x} \leq 3 \mathrm{C} \& \operatorname{Cov}(\mathrm{x})-> \\
& \left.\left.\exists \mathrm{p}^{\prime}\left[\mathrm{p}^{\prime} \leq \mathrm{p} \& \operatorname{Cov}\left(\mathrm{p}^{\prime}\right) \& \mathrm{x} \text { sleeps in } \mathrm{p}^{\prime} \& \operatorname{bel}(\mathrm{x}) \text { sleeps in bel( } \mathrm{p}^{\prime}\right)\right]\right] \text { \& } \\
& \forall \mathrm{p}^{\prime}\left[\mathrm{p}^{\prime} \leq \mathrm{p} \& \operatorname{Cov}\left(\mathrm{p}^{\prime}\right)->\right. \\
& \left.\left.\exists x\left[x \leq 3 C \& \operatorname{Cov}(x) \& x \text { sleeps in } \mathrm{p}^{\prime} \& \operatorname{bel}(\mathrm{x}) \text { sleeps in bel( } \mathrm{p}^{\prime}\right)\right]\right]
\end{aligned}
$$

(42) The place $\mathrm{p}$ can be divided into a sequence of subplaces,

and the three children can be divided into a sequence of individual children such that:

each child sleeps above the one immediately below,

and each place has a child sleeping in it (...).

The compositonal derivation of these truth conditions is based on the Logical Form in (43) and uses the PL operator in (44) - the same one as before adapted to talk about places instead of events.

(43) these 3 children [PL ${ }^{\text {seq }} \operatorname{Cov} \lambda x[\mathrm{x}[[$ sleep] [one above the other $\mathrm{x}]]]$

(44) $\quad\left[\left[\mathbf{P L}^{\mathbf{S e q}} \mathbf{C o v}\right]\right]=\lambda R \cdot \lambda z \cdot \lambda p . \operatorname{Cov}[\mathrm{p}]$ is a sequence and $\operatorname{Cov}[\mathrm{z}]$ is a sequence $\&$

$$
* *\left[\lambda z^{\prime} . \lambda p^{\prime} \cdot \operatorname{Cov}\left(z^{\prime}\right) \& \operatorname{Cov}\left(p^{\prime}\right) \& R\left(z^{\prime}\right)\left(p^{\prime}\right)\right](z)(p)
$$

Other prepositions occuring in the structure 'one Preposition the other' would give rise to different orderings, but be otherwise parallel to the examples discussed.

\section{Pseudoreciprocity}

In this section we will take a closer look at the internal structure of the modifier 'one...the other' and propose a more detailed analysis. We then extend that analysis to certain cases of apparent reciprocals, namely Dalrymple et al.'s (1998) Inclusive Alternative Ordering reciprocals.

\subsection{Pseudoreciprocal 'One ... the Other'}

The overt material in (45a) suggests an internal structure of the modifier as in (45b). We assume that in addition there is covert structure in the form of the anaphor $\mathrm{x}$ and $\mathrm{a}$ contextually given relation that will constrain us to the relevant other individual. A hidden anaphor in the expression 'other' has been suggested e.g.in Heim et al. (1991) on the basis of data like (46): 'another' here means 'a shirt different from this shirt'. The expression 'another' 
thus includes an anaphoric reference to 'this shirt'. The difference between (46) and our data (as well as reciprocal pronouns) is that the anaphor is bound in the latter case.

(45) a. The dogs entered the room one after the other.

b. [one [ after [ the [other]]]]

c. [one [ after [ the [ R other $\mathrm{x}]]]]$

(46) I don't like this shirt, bring me another.

In (47) we recall the desired semantics for 'the other', argued for in the previous section. We can achieve this result if the hidden relation variable is assigned by the context the value in (48a) (this must come from the preposition), and compositional interpretation proceeds as in (48b). We end up with the meaning 'that $\mathrm{y}$ which is not $\mathrm{x}$ and immediately preceeds $\mathrm{x}$ ' - the predecessor of $\mathrm{x}$ according to the 'after' relation.

$$
\begin{aligned}
\mathbb{I} \text { the } \mathrm{R} \text { other } \mathrm{x}]^{\mathrm{g}} & =\operatorname{pred}(\mathrm{g}(\mathrm{x})) \\
& =\mathrm{ty}: \mathrm{y} \text { immediately precedes } \mathrm{g}(\mathrm{x}) \\
& =\mathrm{ty}: \mathrm{y} \angle \mathrm{g}(\mathrm{x}) \& \forall \mathrm{z}[\mathrm{z} \angle \mathrm{g}(\mathrm{x})->\mathrm{z}=\mathrm{y} \text { or } \mathrm{z} \angle \mathrm{y}]
\end{aligned}
$$

(48) a. $\mathrm{g}(\mathrm{R})=$ immediately precede

b. $\quad[[$ the $[N P<e, t>[<e,<e, t>>R$ other $] \mathrm{x}]]]]^{\mathrm{g}}$

$$
=\text { ty: } \mathrm{y} \neq \mathrm{g}(\mathrm{x}) \& \mathrm{~g}(\mathrm{R})(\mathrm{g}(\mathrm{x}))(\mathrm{y})=\operatorname{pred}(\mathrm{g}(\mathrm{x}))
$$

The referential NP needs to combine with 'after' in the same way as the referential NP 'Katie' would in the simpler case, repeated in (49). The 'after' from (50b) is combined with the meaning of 'the other' in (51). The actual modifier we see also includes 'one'. We propose that that provides an additional constraint on the individual argument of the relation, namely that that be a singular individual. The meaning of 'one after the other' is then as in (52).

(49) a. Min entered the room after Katie.

b. $\quad \lambda$ e. Min enters the room in e \& Katie enters the room in pred(e)

(50) a. $\quad \llbracket$ after Katie $\rrbracket=\lambda P . \lambda x . \lambda e . P(x)(e) \& P(K a t i e)(\operatorname{pred}(e))$

b. $\quad \llbracket$ after $\rrbracket=\lambda z . \lambda P . \lambda x . \lambda e . P(x)(e) \& P(z)(\operatorname{pred}(e))$

(51) $\quad \llbracket$ after the $\mathrm{R}$ other $\mathrm{x} \rrbracket \mathrm{g}=\lambda \mathrm{P} . \lambda \mathrm{y} . \lambda \mathrm{e} . \mathrm{P}(\mathrm{y})(\mathrm{e}) \& \mathrm{P}(\operatorname{pred}(\mathrm{g}(\mathrm{x})))(\operatorname{pred}(\mathrm{e}))$

(52) $\llbracket$ one after the R other $\mathrm{x} \rrbracket \mathrm{g}=\lambda \mathrm{P} \cdot \lambda \mathrm{y} \cdot \lambda \mathrm{e} \cdot \mathrm{P}(\mathrm{y})(\mathrm{e}) \&$ one $(\mathrm{y}) \& \mathrm{P}(\operatorname{pred}(\mathrm{g}(\mathrm{x})))(\operatorname{pred}(\mathrm{e}))$

We believe that $(53 a, b)$ are equivalent. Hence we suggest that the two modifiers make the same semantic contribution. One way to derive this would be to have an underlying form (54a) from which both are derived as different surface forms.

(53) a. She washed them dog after dog.

b. She washed them one (dog) after the other.

(54) a. one dog after the other dog

b. one dog after the other dog

c. ene dog after dog

It is relatively obvious how to derive 'one after the other' from (54a), namely, through a process of $\mathrm{N}$-deletion. This is not obligatory, at least not for the first $\mathrm{N}$ to be deleted, cf. (55). (It is far less obvious how (54c) would be derived, and in fact some issues remain open regarding the internal structure that might suggest that one would not always trace reduplicative adverbials to the same source as 'one ... the other' adverbials. We will put this aside for the moment.) 
(55) a. She put the books one bundle beside the other (bundle) on the porch.

b. She examined the wine one bottle after the other (bottle).

The above considerations lead to a final revision for the internal semantics of the modifier which yields (56): we add the information that the relevant predecessor as well as the individual argument of the relation are Ns.

a. $\quad$ II [the $[[[\mathrm{R}$ other $] \mathrm{x}] \mathrm{N}]]]^{\mathrm{g}}=$ ly: $\mathrm{y} \neq \mathrm{g}(\mathrm{x}) \& \mathrm{~g}(\mathrm{R})(\mathrm{g}(\mathrm{x}))(\mathrm{y}) \& \mathbb{\mathbb { N }} \rrbracket(\mathrm{y})=\operatorname{pred}(\mathrm{g}(\mathrm{x}))$

b. $\quad[$ one $\mathrm{N}$ after [the $\mathrm{R}$ other $\mathrm{x} \mathrm{N}] \rrbracket \mathrm{g}=$ $\lambda P . \lambda y . \lambda e . P(y)(e) \&$ one $(y) \& \llbracket N \rrbracket(y) \& P(\operatorname{pred}(\mathrm{g}(\mathrm{x})))(\operatorname{pred}(\mathrm{e}))$

We call these modifiers pseudoreciprocal. They are reminiscent of reciprocals formally in the use of 'other', and semantically in talking about a different member of the same group. But they are not reciprocal pronouns formally. Moreover, the NP in the modifier is a singular. By contrast, a reciprocal pronoun introduces a second plurality of individuals (Beck (2001)).

\subsection{IAO Reciprocals as Pseudoreciprocals}

Finally, we will explore the possibility of extending our analysis of pseudoreciprocals to certain apparent reciprocals, namely those that have an Inclusive Alternative Odering (IAO) interpretation. Some examples of such reciprocals are given in (57). The interpretation of (57a) according to Dalrymple et al. is paraphrased in (58). The general schema of an IAO interpretation is given in (59). The data in (57) are all taken to have such a weak semantics.

(57) a. The children sleep above each other.

b. The three dogs came into the room after one another /

The three dogs followed each other into the room.

(58) IAO: Each child sleeps above or below some other child.

(59) a. Schema of an elementary reciprocal sentence:

$\begin{array}{lll}\text { A } & \mathrm{R} & \text { each other. } \\ \text { antecedent } & \text { relation } & \text { reciprocal pronoun }\end{array}$

b. IAO: $\forall \mathrm{x}[\mathrm{x} \leq \mathrm{A}->\exists \mathrm{y}[\mathrm{y} \leq \mathrm{A} \& \mathrm{xRy}$ or $\mathrm{yRx}]]$

We suggest instead that the data in (57) (and IAO reciprocals in general) have a pseudoreciprocal semantics. That is, (57a) really amounts to (60a). The semantics we assign to (60a), and by assumption then also to (57a), entails (60b).

(60) a. The children sleep one above the other.

b. $\quad$ Each child sleeps above some other child

(namely, her "predecessor" relative to the 'below'- relation).

Why do we pursue this idea? There are three kinds of facts that motivate us. The first is that the IAO truth conditions are very weak indeed, and intuitively too weak for example for (57b). The IAO truth conditions for (57b) are given in (61a). These truth conditions predict the sentence to be true in the situation depicted in (61b). This doesn't accord with intuitions. By contrast, our truth conditions will render (57b) equivalent to (61c) and correctly predict that the sentence is false in a situation like (61b).

(61) a. Each dog came into the room after or before some other dog.

b. D3+D2 $\rightarrow$ D1

c. The dogs entered the room one after the other. 
A second problem for IAO reciprocals is the fact that an IAO interpretation is only possible with a restricted set of relations. See Beck (2001) and references therein for discussion. As an illustration, notice that (62a) with the relation 'on top of' is acceptable under an IAO interpretation while (62b) with 'outnumber' is unacceptable and cannot have an IAO reading (which would be made true by the fact that the Smiths are more numerous than the Johnsons, for instance). If IAO were a regular interpretation for reciprocal sentences, why should it not be generally available?

(62) a. The plates are stacked on top of each other.

b. * The Smiths and the Johnsons outnumber each other.

A third and final problem with IAO is noted in Beck (2001): IAO reciprocals are restricted to local reciprocal relations while other reciprocals are not. To illustrate what is meant by a nonlocal reciprocal relation, consider (63). The sentence is judged true if (63'a) is the case. This can be derived from the truth conditions in $\left(63^{\prime} \mathrm{b}\right)$ : the reciprocal relation 'want to kill' holds between non-identical members of the antecedent group 'Tracy and Joe'. (63) is an example of a regular reciprocal interpretation, weak reciprocity. The reciprocal relation 'want to kill' is non-local in that it is not a relation that exists as the meaning of a surface constituent.

(63) Tracy and Joe want to kill each other.

(63') a. Tracy wants to kill Joe and Joe wants to kill Tracy.

b. $\quad\langle\mathrm{T} \& \mathrm{~J}, \mathrm{~T} \& \mathrm{~J}>\in * * \lambda \mathrm{x} \lambda \mathrm{y}: \mathrm{x} \neq \mathrm{y}$. $\mathrm{x}$ wants to kill $\mathrm{y}]$

We should contrast (63) with (64). The sentence can be understood as in (65) - Tracy and Joe agree that they want to sleep above each other rather than, say, beside each other. It cannot be understood as in (66), which would be made true by the fact that Tracy wants to sleep above Joe. (66) would be a non-local IAO interpretation with the reciprocal relation 'want to sleep above'. Clearly, this is not possible. Only a local reading inside the embedded clause in (65) is acceptable.

(64) Tracy and Joe want to sleep above each other.

(65) Tracy and Joe both have the following desire: we sleep above each other.

(66) For each $x, x$ one of Tracy and Joe: either $x$ wants to sleep above the other one of Tracy and Joe, or the other one of Tracy and Joe wants to sleep above $\mathrm{x}$.

The pair in (67) makes the same point: in (67a) a non-local interpretation is possible in which the different members of the antecedent group 'these people' were introduced by different linguists. A similar interpretation is not available in (67b); the same apprentice magician has to line up the glasses.

(67) a. These people were introduced to each other by a linguist.

b. The glasses were lined up behind each other by an apprentice magician.

The two constraints on the availability of IAO interpretations (limited set of relations, and local interpretation only) are quite unexpected as long as one thinks of IAO as a regularly available interpretation of reciprocal pronouns. This is additional motivation then, besides the problem mentioned above with inappropriately weak truth conditions, for looking for an alternative analysis of the phenomenon of IAO. We propose that IAO reciprocals only appear to be reciprocals, and are really pseudoreciprocals:

(68) above each other $==>$ (one) above the other

That is, the example in (69a) should really be interpreted as (69b). 
(69) a. Tracy and Joe want to sleep above each other.

b. Tracy and Joe want to sleep one above the other.

The truth conditions we predict are the ones of pseudoreciprocals, which seems right to us. As for the unexpected constraints on the relations that participate in an IAO interpretation, we have nothing concrete to offer. One may suppose that whatever process relates (69a) and (69b) is somehow restricted and cannot apply to every relation. For all we know, the connection may be lexical. But no concrete predictions arise regarding which relations can participate.

We do have something to say about the fact that apparent IAO reciprocals - now reanalysed as pseudoreciprocals - only receive a local interpretation. In $(64)=(69)$, for instance, the whole '(one) above the other' is an adverbial that can only modify the embedded predicate 'sleep' (whishes cannot plausibly be above each other). And since there is no further potentially scope bearing element in this modifier ('the other' being a singular), there is no process that could generate a non-local interpretation.

A final comment: there are cases of IAO reciprocals for which our pseudoreciprocal truth conditions might be thought too strong. (70b) is a case in point. Dalrymple et al. point out that such a sentence can be considered true in a situation with two bunk beds each of which sleeps two children. This is different from (70a), our pseudoreciprocal. We speculate that (70b) permits a partition of the children into two groups of two, on which its interpretation with the bunk beds is based. This is excluded by the overt element 'one' in (70a) which tells us that the partition of the children is into singletons.

(70) a. These four children sleep one above the other.

b. These four children sleep above each other.

\section{Conclusions}

To summarize, we subscribe to the view that all pluralization is sensitive to a division of pluralities into appropriate subparts. Pluractionals make this visible; in our cases with 'piece by piece' and 'dog after dog', they tell us which units are contained in the cover. They also show that natural language has pluralization of $\langle\mathrm{e},\langle\mathrm{v}, \mathrm{t}\rangle\rangle$ predicates, i.e. simulataneous pluralization of an event- and an individual-argument slot. Adverbials 'one ... the other' are a case of such pluractionals which gives rise to a sequence interpretation that we have called pseudoreciprocal.

If IAO reciprocals are reanalyzed as pseudoreciprocals (i.e. pluractional 'one ... the other'), this may explain some peculiarities that otherwise set apart IAO reciprocals from better behaved reciprocals. Pseudoreciprocals would be different from regular reciprocals in not introducing a plurality of type $\langle\mathrm{e}\rangle$. Rather, they are a modifier containing a singular 'the other' NP.

Let us also point out what is still missing from the discussion here. One caveat is empirical. Not all 'Noun Preposition Noun' modifiers share the pseudoreciprocal semantics proposed here for 'one ... the other'. One ought to relate the semantic contribution of modifiers like 'leaf by leaf', 'two and two', 'side by side' to our pluractionals.

The other omission is a detailed comparison of our analysis to related proposals. Let us briefly explain how we perceive the relation of our analysis to Moltmann (1995) on the one hand and Stockall/Zimmermann on the other. Moltmann suggests a semantics for pluractional 'one at a time' (extendable to 'piece by piece'-type adverbials) which is based on simultaneous division of events into subevents and entities into subparts. She thus anticipates this aspect of our analysis. It is, however, embedded into a different architecture, in that her views of the syntax-semantics interface and pluralization operations in particular, are incompatible with 
our own. The same is true of Stockall/Zimmermann's analysis of 'dog after dog'. Like Moltmann, they hold the adverbial itself and/or its composition within its local structure responsible for all of the specific semantics of the construction. Our analysis has been guided by the idea that we have a system of plural predication in place independently which includes plural operators of various types plus a restriction on relevant part-whole structures. Thus the adverbial has a very slim semantics, with much of the burden to be carried by the pluralization operation. A more thorough discussion that includes an empirical comparison with other works must wait until a future occasion.

\section{References}

Beck, Sigrid. 2001. Reciprocals are Definites. Natural Language Semantics 9:69-138.

Dalrymple, Mary et al. 1998. Reciprocal Expressions and the Concept of Reciprocity. Linguistics and Philosophy 21:159-210.

Fiengo, R., and Lasnik, H. 1973. The Logical Structure of Reciprocal Sentences in English. Foundations of Language 9:447-468.

Heim, Irene, Lasnik, Howard, and May, Robert. 1991. On "Reciprocal Scope". Linguistic Inquiry 22:173-192.

Lasersohn, P. 1995. Plurality, Conjunction and Events. Boston: Kluwer Academic Publishers.

Lewis, David. 1991. Parts of Classes. Oxford: Basil Blackwell.

Link, G. 1983. The Logical Analysis of Plurals and Mass Terms: A Lattice-Theoretical Approach. In Meaning, Use, and Interpretation of Language, eds. R. Bäuerle, C. Schwarze and A. v. Stechow, 302-323. Berlin: de Gruyter.

Moltmann, Friederike. 1995. Parts and Wholes in Semantics. Oxford: Oxford University Press.

Schwarzschild, R. 1996. Pluralities: Studies in Linguistics and Philosophy. Dordrecht: Kluwer.

Sternefeld, Wolfgang. 1998. Reciprocity and Cumulative Predication. Natural Language Semantics: 303-337.

Stockall, L. 2001. Pluriactionality and Prepositions in Germanic. The Syntax and Semantics of [NP-P-NP]s. In ConSole X. Leyden.

Zimmermann, Malte. 2002. Boys Buying Two Sausages Each. On the Syntax and Semantics of Distance-Distributivity, Universiteit van Amsterdam: Dissertation. 


\title{
Temporal and Propositional De Se: Evidence from Romanian SUBJUNCTIVE MOOD ${ }^{1}$
}

\author{
Adrian Brasoveanu, \\ Rutgers University and University of Frankfurt \\ abrsvn@eden.rutgers.edu
}

\begin{abstract}
The paper investigates the interpretation of the Romanian subjunctive B (subjB) mood when it is embedded under the propositional attitude verb crede (believe). SubjB is analyzed as a single package of three distinct presuppositions: temporal de se, dissociation and propositional de se. I show that subjB is the temporal analogue of null PRO in the individual domain: it allows only for a de se reading. Dissociation enables us to show that subjB always takes scope over a negation embedded in a belief report. Propositional de se derives this empirical generalization. The introduction of centered propositions (generalizing centered worlds), together with propositional de se, dissociation and the belief 'introspection' principles, derives the fact that subjB belief reports (unlike their indicative counterparts) are infelicitous with embedded probabil.
\end{abstract}

\section{Introduction}

This paper is a systematic exploration of the interpretation of the Romanian subjunctive B mood when it is embedded under the propositional attitude verb crede (believe) ${ }^{2}$. Subjunctive B - traditionally labeled 'conditional-optative' - is one of the two subjunctive (i.e. nonindicative finite) moods in Romanian. As the example in (1) below shows, it is morphologically realized as an auxiliary verb that agrees in person and number with the subject.

$$
\text { Maria crede că ar fi în pericol. }
$$

Mary believe.ind.pres.3s that subjB.3s be in danger.

Mary believes that she is in danger.

I analyze subjunctive $\mathrm{B}$ as a bundle of three distinct presuppositions: (a) temporal de se, (b) dissociation and (c) propositional de se. Consider example (1) above: temporal de se means that the reported belief of being in danger is temporally located at the internal now of the believer, i.e. at the time which Mary (correctly or not) takes her 'present' to be. Dissociation basically means that the speaker dissociates herself from the reported belief, i.e. as far as the

\footnotetext{
${ }^{1}$ Acknowledgements: I am greatly indebted to Maria Bittner, Sam Cumming, Hans Kamp, Oana SăvescuCiucivara, Roger Schwarzschild, Adam Sennet, Magdalena Schwager, Matthew Stone and Ede Zimmermann for extensive discussion of the issues addressed here. I want to thank the Sinn und Bedeutung 10 abstract reviewer(s) for their very helpful comments. I am also indebted to the following people for discussion: Agnes Bende-Farkas, Alexandra Cornilescu, Veneeta Dayal, Carmen Dobrovie-Sorin, Donka Farkas, Kai von Fintel, Jane Grimshaw, Nathan Klinedinst, Angelika Kratzer, Cécile Meier, Jessica Rett, Uli Sauerland, Oana Săvescu-Ciucivara, Philippe Schlenker, Ted Sider, Satoshi Tomioka, Violeta Vazquez-Rojas Maldonado, Hong Zhou, Eytan Zweig and the SURGE (Sept. 2005), GK Frankfurt Colloquium (Oct. 2005) and Sinn und Bedeutung 10 (Oct. 2005) audiences. I want to thank Carmen Dobrovie-Sorin, Andreea Grigorean, Simona Herdan, Mihai Ignat, Cristian Lupu and Oana Săvescu-Ciucivara for the Romanian judgments and Sam Cumming, Jessica Rett, Roger Schwarzschild and Adam Sennet for the English judgments. The support of a DAAD grant during the last stages of this investigation is gratefully acknowledged. The usual disclaimers apply.

${ }^{2}$ There seem to be dialectal differences in the use of subjB with the verb crede: one of the native speakers I have consulted does not readily accept sentences like (1) above.
} 
speaker is concerned, it could be the case that Mary is not in danger, even though Mary herself thinks that she is.

Finally, propositional de se means that the believer has an attitude towards a 'self-referential' kind of content similar to the self-referential experience contents proposed by Searle $(1983)^{3}$. For example, the content of my visual experience of seeing a yellow station wagon is that: (a) there is a yellow station wagon there and (b) the fact that there is a yellow station wagon there is causing this very visual experience. This 'self-referentiality' is the expression of the common sense intuition that having an experience or an attitude is assuming a particular point of view / perspective on the content of the experience or of the attitude.

Intuitively, a belief report with subjunctive $\mathrm{B}$ mood is propositionally de se insofar it explicitly encodes in the believed content this perspectival component inherent in any attitude; the form of such a report is basically: $x$ has a belief $p$ that the embedded clause is true and $x^{\prime} s$ belief $p$ is such that the proposition expressed by the embedded clause is true in any world $w$ in $p$. This makes a subjunctive B report 'self-referential' in Searle's sense and also redundant, since the commitment of the attitude holder to the proposition expressed by the embedded clause is stated twice. However, the redundancy is crucial in deriving two unexpected empirical generalizations: (a) if the believed proposition has a negative form, e.g. $x$ believes that not $q$, then subjunctive $\mathrm{B}$ has to have wide-scope with respect to negation; this is a consequence of the fact that, on the narrow-scope reading, the subjunctive B report is contradictory: it has the form $x$ believes that not $q$ (on the one hand) and $q$ is what $x$ believes (on the other hand); (b) moreover, subjunctive B reports with probabil (probably) of the form $x$ believes that probably $q$ are not felicitous, unlike their indicative counterparts; this is due to the fact that subjunctive B requires complete commitment to proposition $q$, while probably implicates that there is at most a partial commitment.

The structure of the paper is the following. In section 2, I argue that the contrast between indicative and subjunctive B in Romanian is parallel to the contrast between overt pronouns (e.g. John hopes that he will win) and null PRO (e.g. John hopes to win) in the individual domain. As Chierchia (1989) and Schlenker (2003) observe, overt pronouns are compatible with both the de se and non-de se readings, while null PRO allows only for a de se reading. The proposal is that subjunctive $\mathrm{B}$ is parallel to PRO in that it requires a temporally de se reading, while indicative is parallel to overt pronouns because it can, but does not have to receive such a reading.

In section 3, I expand on the brief observation in Farkas (1992) that subjunctive B has a dissociation component. I argue that dissociation is a presupposition (as opposed to e.g. a conventional implicature) based on its projection behavior in negative contexts and 'stacked' attitude reports of the form $x$ wants $y$ to believe that $p$. I end the section with the generalization that sets the stage for propositional de se: subjunctive $\mathrm{B}$ always has wide-scope with respect to an embedded negation, e.g. in belief reports of the form $x$ believes that not $p$, the speaker always dissociates herself from not $p$ and never from $p$, despite the fact that, on the surface, the subjunctive B morpheme is always placed between not and $p$.

Section 4 proposes a semantic solution to the wide-scope problem (as opposed to syntactically stipulating the wide-scope and attempting to justify the syntactic assumption on independent grounds): subjunctive $\mathrm{B}$ is propositional de se in the sense suggested above. This solution extends the de se vs. non-de se contrast between subjunctive $\mathrm{B}$ and indicative from the temporal to the modal domain and thus makes for an attractive overall analysis: we extend the parallel between pronouns, tenses and moods, pursued in Partee (1973), Abusch (1997), Stone (1999) and Schlenker (2003) among others, to de se readings. The propositional de se hypothesis also derives the incompatibility between subjB and probably if we assume the

\footnotetext{
${ }^{3}$ Matthew Stone suggested this parallel (p.c.).
} 
belief introspection principles ${ }^{4}$, which effectively reduce iterated belief ( $x$ believes that $x$ believes that $p$ ) to non-iterated belief ( $x$ believes that $p$ ).

The concluding section 5 briefly discusses whether the three components of the subjunctive B interpretation are independent.

\section{Subjunctive $B$ as temporal de se}

In this section, I first review de se and de re beliefs in the individual domain and sketch the way Lewis (1979) analyzes them. In particular, I focus on the contrast between overt pronouns and null PRO in non-de se 'mistaken identity' scenarios, which was noticed in Chierchia (1989) and Schlenker (2003) among others (2.1). Based on a 'mistaken temporal identity' scenario, I establish that the Romanian subjunctive B mood has to be interpreted temporally de se, just like PRO has to be interpreted individually de se (2.2).

\subsection{De se and de re belief in the individual domain}

The Kaplanian sentence in (2) below can receive two distinct interpretations.

Neo believes that his pants are on fire.

Under the first - de se - interpretation, Neo is saying to himself "My pants are on fire" and he is therefore very likely to run for the fire extinguisher.

To see the second - non-de se - interpretation, consider the following scenario: Neo is looking in a mirror without realizing it. He is seeing a man whose pants are on fire, which is in fact Neo himself, but he does not realize that either; (2) can be truthfully asserted in this situation, but it receives a different interpretation, as witnessed by Neo's possibly different behavior: if Neo is in a particularly mean mood, he might very well just stand there and enjoy the show (at least until the situation gets hot enough for him to realize his misunderstanding).

Under the de se interpretation, (2) reports Neo's belief that someone's pants are on fire, where that someone is the belief-internal self, i.e. whoever Neo takes himself to be. Under the nonde se (but de re) interpretation, (2) reports Neo's belief that someone's pants are on fire, where that someone is the guy that Neo is looking at, whoever that may be.

The analysis of de se and de re belief in Lewis (1979) involves three ingredients: (a) centered worlds: the believed content is not a proposition, i.e. a set of worlds (as the standard analysis would have it $^{5}$ ), but a property, or, equivalently, a set of centered worlds ${ }^{6}$; a centered world is a pair $\left(w, x^{\text {self }}\right)$, where $w$ is a world and $x^{\text {self }}$, the center of world $w$, is the unique individual that Neo takes himself to be in $w$, i.e. the belief-internal 'self'; (b) self ascription: the verb believe is interpreted as a relation between an individual and a set of centered worlds (and not as a relation between an individual and a proposition); that is, we replace the function $\boldsymbol{d o x}_{w^{*}, x^{*}}$ that returns a set of worlds (the set of $x^{*}$ 's doxastic alternatives to $w^{*}$ ) with a function self_ascribe $w_{w^{*}, x^{*}}$, which returns a set of centered worlds $\left(w, x^{\text {self }}\right)$; (c) acquaintance relations: the reported belief is about an individual with whom the belief-internal 'self' is acquainted in a particular way; in the de se case, the acquaintance relation is the most intimate relation the belief-internal 'self' can have with any individual whatsoever, namely the identity relation; in the non-de se (but de re) case, the acquaintance relation is the causal relation established between the belief-internal 'self' and whoever it is that he is looking at (see Lewis (1979): 539).

\footnotetext{
${ }^{4}$ See Hintikka (1962) for an early discussion.

${ }^{5}$ See for example Hintikka (1969).

${ }^{6}$ See for example Creswell \& von Stechow (1982) for more discussion.
} 
Thus, independently of other presuppositional features like gender or number, the pronoun his in (2) is triply context dependent: (a) it presupposes access to an acquaintance relation; (b) it is anaphoric to the real individual that the believer is acquainted to in the actual world; (c) it is dependent on the internal 'self' of the believer.

The de re but non-de se reading of (2) is given in (3) below.

(3) De re (non-de se): Neo's centered belief worlds $\left(w, x^{\text {self }}\right)$ are such that, given the unique individual $x$ the belief-internal 'self' (i.e. $x^{\text {self }}$ ) is looking at, $x^{\prime}$ s pants are on fire in $w$.

The de se reading of (2) is given in (4) below.

(4) De se: Neo's centered belief worlds $\left(w, x^{\text {self }}\right)$ are such that, given the unique individual $x$

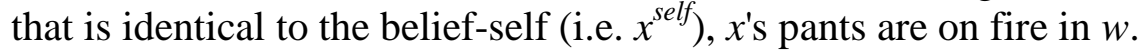

Moreover, as Chierchia (1989) and Schlenker (2003) (among others) observe, the morphological form of the pronoun can distinguish between the two readings: overt pronouns like he in (5a) below are compatible with both the de se and non-de se readings, while the null PRO in (5b) allows only for a de se reading ${ }^{7}$.

a. Neo hopes that he will win.

b. Neo hopes PRO to win.

To see this, consider the following de se and non-de se scenarios (based on Schlenker (2003)): (a) de se: young Neo participates in a singing competition; after his performance, he tells one of his friends: "I hope I'll win"; (b) non-de se 'mistaken identity' scenario: young Neo participates in a singing competition; after his performance, he relaxes with one too many glasses of wine; accidentally, he listens to a recording of his own performance but doesn't realize that and he says: "I hope this guy will win". Both the overt pronoun in (5a) and PRO in (5b) are felicitous in the de se context, but only the overt pronoun in (5a) is felicitous in the non-de se context.

\subsection{De se and non-de se belief in the temporal domain}

In this section, I show that the contrast between subjunctive B (subjB) and indicative (ind) in Romanian is the temporal analogue ${ }^{8}$ of the contrast between PRO and overt pronouns in the individual domain. SubjB is the temporal analogue of PRO, since it requires a de se interpretation, in contrast to indicative, which, like an overt pronoun, can but does not have to receive a de se interpretation. Consider the 'mistaken temporal identity' scenario in (6) below.

(6) John is a very gullible tabloid reader: whatever a tabloid says, he believes. A Monday tabloid said that the Martians were going to invade Bucharest on Thursday, i.e. three days later. On Thursday, the day of the invasion, John and I talked about this issue. But John was confused: he thought it was Wednesday when, in fact, it was Thursday.

In this context, the indicative report in (7a) is (more or less) felicitous, while the subjB report in $(7 b)$ is not.

(7) Cînd m-am întîlnit cu el, Ion (de fapt) credea că...

When I met him, John (in fact) believed that...
a. ?marţienii
invadează
Bucureștiul în ziua aceea.
Martians.the
invade.ind.pres Bucharest.the in day that.

\footnotetext{
${ }^{7}$ For more discussion, see Chierchia (1989): 14 et seqq.

${ }^{8}$ Lewis (1979): 530-531 already observes that there is such a thing as a temporally de se attitude.
} 


\section{b. \#marțienii ar invada Bucureştiul în ziua aceea. \\ Martians.the subjB invade Bucharest.the in day that. \\ the Martians were invading Bucharest that day.}

The scenario in (6) and the examples in (7) are parallel to the individual de se 'mistaken identity' scenarios and examples because, just as Neo hopes that he will win without realizing that his hopes are about himself - in which case the overt pronoun he is acceptable, but PRO is not - , John believes that the Martian invasion happens the very day of the conversation, without actually realizing the imminence of the alien takeover - in which case indicative is acceptable, while subjunctive $B$ is not.

The analysis of temporal de se / de re is parallel to the analysis of individual de se / de re. Just as in Abusch (1997), we extend centered worlds with a variable for time: the individual john is self-ascribing in world $w^{*}$ at time $t^{*}$ a set of centered worlds $\left(w, x^{\text {self }}, t^{\text {now }}\right)$, where $x^{\text {self }}$ is the unique individual that john takes himself to be in $w$ and $t^{\text {now }}$ is the unique time that john takes its internal 'now' to be in $w$. Moreover, we will have acquaintance relations relative to time intervals: for example, in (7a) above, John has a non-de se acquaintance relation to the following Thursday as "the day the tabloid said the Martians would invade Bucharest" ${ }^{\text {9 }}$ and, in (7b), a de se acquaintance relation with the day of his internal now, which he believes is a Wednesday (while in the actual world it is in fact Thursday).

The two readings of the belief report in (7) are given in (8) and (9) below.

(8) Non-de se: John's centered belief worlds $\left(w, x^{\text {self }}, t^{\text {now }}\right)$ are such that, given the unique day $t$ that the tabloid specified in $w$, the Martians are invading Bucharest at $t$ in $w$.

De $s e^{10}:$ John's centered belief worlds $\left(w, x^{\text {self }}, t^{\text {now }}\right)$ are such that, given the unique day $t$ that is the day of $t^{\text {now }}$ in $w$, the Martians are invading Bucharest at $t$ in $w$.

Since the indicative in (7a) can receive the interpretation in (8), the belief report is felicitous, while the subjunctive $\mathrm{B}$ report in $(7 \mathrm{~b})$ is not, because subjunctive $\mathrm{B}$ can receive only the de se interpretation in (9), which is false in the given context. Thus, we discovered that the temporal de se vs. non-de se contrast is mirrored in the morphology of belief reports just as the individual de se vs. non-de se contrast is ${ }^{11}$.

\footnotetext{
${ }^{9}$ But not exactly de re, if we assume that de re relations have to involve causal connections: how can John be causally acquainted on a Monday with the following Thursday? See Abusch (1997) for some discussion.

${ }^{10}$ Note that temporal de se belief is belief under the acquaintance relation of inclusion (the day of $t^{\text {now }}$ is the day in which $t^{\text {now }}$ is included), unlike individual de se, where the acquaintance relation is that of identity.

${ }^{11}$ The hypothesis that subjB is temporally de se seems to be contradicted by the fact that subjB can be part of constructions of the form subjB + auxiliary $\mathrm{BE}+$ past participle of the verb - which receive a perfective reading - in addition to the constructions mentioned above of the form subjB + bare verb, as shown in (i) below.

(i) Ion tocmai şi - a terminat de scris lucrarea de licență.

John has just finished writing his undergrad thesis.

Maria crede că Ion ar fi scris o capodoperă.

Mary believe.ind.pres.3s that John subjB.3sg BE written a masterpiece.

Mary believes that John wrote / has written a masterpiece.

We can maintain that subjB is temporally de se if we analyze the construction BE+ppart similarly to the way Kamp \& Reyle (1993): 556 et seqq. analyze the English perfective have written: the auxiliary BE contributes an eventuality of its own (a state, but not a result state as the English have) which is temporally located at the internal now of the attitude; the completed eventuality contributed by the lexical verb is temporally located before the state contributed by BE. An independent argument for the subjB+BE+ppart construction being temporally de se is provided by present attitude reports towards a future eventuality: as the examples in (iia) and (iib) below show, the indicative anterior future is felicitous in such situations, but not subjB+BE+ppart.

(ii) Ion a plecat ieri în Australia. Maria crede că în şase luni ...
}

John left for Australia yesterday. Mary believe.ind.pres.3s that in six months...

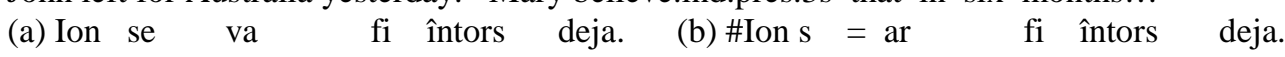
John SE ind.fut.3s $B E$ returned already. John $\mathrm{SE}=\operatorname{subjB} .3 \mathrm{~s} B E$ returned already. Mary believes that in six months John will have already come back. 


\section{Subjunctive B: dissociation}

In this section, we turn to the second presuppositional component of subjunctive $\mathrm{B}$, namely dissociation, which was first noticed in Farkas (1992): $82^{12}$. Dissociation means that in a report of the form $x$ believes that $p$, where $p$ is marked with subjunctive $\mathrm{B}$, the speaker dissociates herself from $p$, i.e. the speaker has reason to believe that $p$ might be false. In general, a speaker $a$ dissociates herself from a proposition $p$ iff there is at least one world $w$ among $a$ 's doxastic alternatives in which $p$ is false. Thus, dissociation simply means that the speaker and the attitude holder do not agree on proposition $p$ and not the stronger requirement that the speaker believes not $p$. In 3.1, I provide several diagnostics for dissociation and briefly indicate how dissociation is represented. In 3.2, I argue that dissociation is presuppositional based on its projection behavior in negative contexts and 'stacked' attitude reports of the form $x$ wants $y$ to believe that $p$ (the projection facts in conditionals are omitted for space reasons). Finally, in 3.3, I establish the generalization that sets the stage for propositional de se: subjB always has wide-scope with respect to embedded negation.

\subsection{Diagnostics for dissociation}

Once again, we contrast indicative and subjunctive B.

(10) Ion îşi scrie lucrarea de licență. Maria crede că ...

John is writing his undergrad thesis. Mary believes that...
a. Ion scrie
o capodoperă. $\sqrt{ }$ IND
b. Ion ar scrie o capodoperă. $\sqrt{ }$ SUBJB John write.ind.pres a masterpiece. John subjB write a masterpiece.

The indicative report in (10a) is neutral with respect to the speaker's attitude, while the subjB report in (10b) expresses, in addition to what (10a) does, that the speaker does not also believe John's thesis to be a masterpiece, i.e. as far as the speaker is concerned, it could be a piece of junk (although the speaker does not necessarily believe that it is junk).

This intuition is supported by the fact that first-person belief reports with indicative are felicitous, while subjB reports are not. This contrasts with the third-person reports in (10) above, where both indicative and subjB are felicitous ${ }^{13}$.
Cred
că Maria este
/ \# ar fi
bolnavă. IND / \#SUBJB
Believe.ind.pres.1s that Mary be.ind.pres / \#subjB be sick.
I believe that Mary is sick.

Another argument for dissociation is the infelicity of subjunctive B with factive verbs like şti (know) or regreta (regret), as shown by (12) below.
Ion ş̧ie / regretă că Maria este
/ \#ar
fi bolnavă. VIND / \#SUBJB
John knows / regrets that Mary be.ind.pres / \#subjB be sick.

Dissociation is supported by the infelicity of subjB with factive verbs because factive verbs presuppose that the reported belief is true throughout the current Context Set (see Stalnaker

\footnotetext{
12 "In Romanian, in the case of declaratives, the conditional is used to indicate 'speaker reservation' with respect to the truth of the complement [...] Note that the use of a non-indicative in the complements of declaratives does not commit the speaker to a negative valuation of the propositional content of the complement; the nonindicative mood simply stresses that the speaker is not committed to a positive valuation. The complement is therefore not counterfactual, but rather 'afactual' as far as the speaker is concerned." (Farkas (1992): 82)

${ }^{13}$ First-person belief reports with subjunctive B are felicitous in the following kind of context: I am trying to objectively present a debate between me and John to a third party, e.g. to an audience of people asked to judge for themselves whether the Romanian subjunctive B is de se or not. In that case, I can utter:

(i) Ion crede că subjonctivul B în română nu ar fi de se, dar eu cred că ar fi de se.

John believes that the Romanian subjunctive B is (subjB) not de se, but I believe it is (subjB) de se.
} 
(1978) for this notion) and the speaker belief-worlds are always a subset of the Context Set since all the propositions in the Common Ground have already been accepted by all participants in the conversation. Therefore, if the speaker already accepted the proposition that Mary is sick, she cannot dissociate herself from it, as the subjB in (12) requires ${ }^{14}$.

Finally, dissociation is supported by the distribution of indicative and subjB in the three kinds of contexts listed in (13) below; (13a) says that, in a context in which $\neg p$ is true, we can felicitously assert $x$ believes $p$, where $p$ is marked with either indicative or subjB - and the same goes for (13b), where the Context Set endorses neither $p$ nor $\neg p$. The only context that distinguishes between indicative and $\operatorname{subjB}$ is the one in (13c): if $p$ is true throughout the Context Set (hence, the speaker also believes $p$ ), only the indicative report is felicitous.
a. $\neg p$;
$x$ believes $p$
$\sqrt{ } \mathbf{I N D} ; \quad \sqrt{ } \mathbf{S U B J B}$
b. $\operatorname{possible}(p) \& \operatorname{possible}(\neg p) ; \quad x$ believes $p$
$\sqrt{I N D} ; \sqrt{\text { SUBJB }}$
c. $p$
$x$ believes $p$
$\sqrt{ }$ IND; \#SUBJB

I give the actual data only for the last case.

(14) (Eu cred că) Maria este urîtă. Ion crede că Maria este / \#ar fi urîtă. VIND / \#SUBJB (I believe that) Mary is ugly. John believes that Mary is ugly.

I represent dissociation as a condition $w \notin p$, i.e. there is at least one witness world $w$ among the speaker belief worlds - hence, among the current Context Set worlds - such that the reported belief $p$ is not true in $w$. The tree in (15) below gives the basic structure of the logical form for (1): subjB requires there to be at least one world $w$ in CS (the Context Set) in which $p$ is false and this requirement 'percolates' all the way to the top of the tree.

Mary believes that she is (subjB - dissociation) in danger.

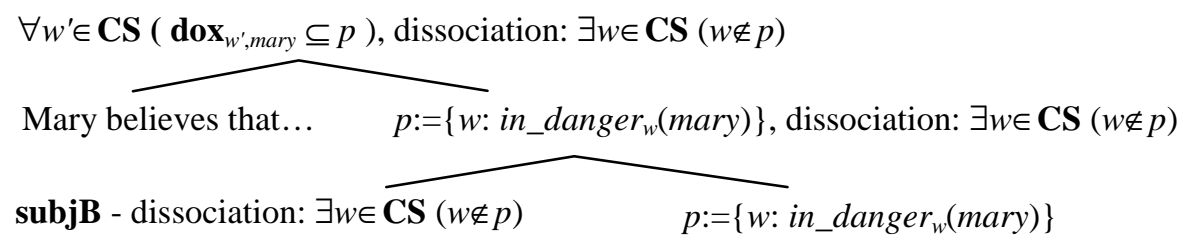

The 'percolation' of the dissociation requirement $\exists w \in \mathbf{C S}(w \notin p)$ to the top of the tree is consistent with the presuppositional nature of dissociation, to which we now turn.

\subsection{Dissociation is presuppositional}

The fact that dissociation is presuppositional is shown by its projection behavior in negative contexts, conditionals and 'stacked' attitude reports of the form $x$ wants $y$ to believe that $p$ (for space reasons, I do not provide the data for conditionals). A negative expression of the form $N u$ este adevărat că... (It is not the case that...), when added on top of a subjB belief report of the form $x$ crede că $p$ ( $x$ believes that $p$ ) is transparent, i.e. a 'hole', for dissociation.

\footnotetext{
${ }^{14}$ It follows from these observations that matrix declarative sentences marked with subjB are infelicitous. In fact, they are not - but a subjB matrix clause like the one in (i) below can be interpreted only: (a) as expressing Mary's desire to go to the movies or (b) as the consequent of a covert conditional (hence the traditional labeling of subjunctive B as 'conditional-optative'). Either way, (i) cannot be interpreted as asserting the proposition that Mary is going to the movies - as its indicative counterpart does.

(i) Maria ar merge la film.

Mary subjB go to movie.

Mary would like to go to the movies / [If the theater weren't that far], Mary would go to the movies.
} 
(16) $\neg p$; it is not the case that $x$ believes $p$

$\sqrt{\text { SUBJB }}$

Maria nu este în pericol. (Şi) Nu este adevărat că Maria crede că ar fi în pericol.

Mary is not in danger. (And) It is not the case that Mary believes that she is in danger.

$p$; it is not the case that $x$ believes $p$

\#SUBJB

Maria este în pericol. \#(Dar) Nu este adevărat că Maria crede că ar fi în pericol.

Mary is in danger. \#(But) It is not the case that Mary believes that she is in danger.

Finally, the projection behavior of dissociation in 'stacked' attitude reports of the form $x$ wants $y$ to believe that $p$ also shows that dissociation is presuppositional: unlike conventional implicatures ${ }^{15}$, the dissociation requirement does not have to be resolved relative to the speaker belief-worlds, but can be resolved relative to the belief-worlds of the higher attitude holder, e.g. $x$ 's belief-worlds in the 'stacked' report $x$ wants $y$ to believe that $p^{16}$. Thus, the initial characterization of dissociation as a speaker-oriented requirement is an oversimplification, which I have upheld for expository reasons. Consider the scenario in (18).

(18) Both Mary and Helen like John and they are jealous of each other. A couple of days ago, Helen suddenly decided to leave LA for a trip - and she left that very day.

In this context, the discourse in (19), in particular the subjB report in $\left(19^{2}\right)$, is felicitous.
${ }^{1}$ Maria crede în mod greșit că...
Elena este încă în LA,
Mary mistakenly believes that...
Helen is (ind) still in LA,
${ }^{2}$ dar vrea ca Ion să creadă că...
Elena nu ar fi în LA.
but she wants John to believe that... Helen is (subjB) not in LA.

(IND)

$\sqrt{ }$ SUBJB

Since the speaker knows that Helen is not in LA, the dissociation triggered by the subjB in $\left(19^{2}\right)$ cannot be resolved relative to the speaker's belief-worlds. However, subjB is felicitous because Mary's belief worlds can satisfy the dissociation requirement ${ }^{17}$.

\subsection{The relative scope of subjunctive $B$ and embedded negation}

The dissociation requirement allows us to pinpoint the relative scope of subjB with respect to embedded negation and embedded negative quantifiers. We have distinct dissociation presuppositions if subjB has wide scope with respect to negation ( $\mathbf{s u b j B}>>\mathbf{n o t}>>p$ ) and if subjB has narrow scope (not $>>\mathbf{s u b j B}>>p$ ). In the wide-scope case, subjB dissociates from not $p$, i.e. for some $w$ in the Context Set, $w \notin \neg p$; in the narrow-scope case, subjB dissociates from $p$, i.e. for some $w$ in the Context Set, $w \notin p$. Only the wide-scope dissociation is empirically attested - despite the overt surface form, in which negation precedes (and has to precede) the subjB morpheme. The data is provided in (20) and (21) below.

$p ; x$ believes not $p$.

${ }^{1}$ Maria este în pericol. ${ }^{2}$ (Dar) Maria crede că

$\checkmark$ SUBJB

Mary is in danger.

(But) Mary believes that

nu ar fi în pericol.

not subjB be in danger.

\footnotetext{
${ }^{15}$ For the distinction between presuppositions and conventional implicatures, see Potts (2004).

${ }^{16}$ Propositional attitude verbs like want, fear etc. are filters for the presuppositions of the embedded sentence: they have to be satisfied by the belief-worlds of the attitude holder (in the given local context). As Heim (1992): 183, following Karttunen, puts it, "if $\sigma$ is a verb of propositional attitude, then a context c satisfies the presuppositions of ' $\alpha \sigma \varphi$ ' only if $\mathrm{B}_{\alpha}(\mathrm{c})$ satisfies the presuppositions of $\varphi$; where ' $\mathrm{B}_{\alpha}(\mathrm{c})$ ' stands for the set of beliefs attributed to $\alpha$ in c". For example, John wants the king of France to get bald does not presuppose that John wants it to be the case that there is a unique king of France, but that John believes that there is a unique king of France.

${ }^{17}$ As expected, if we embed first-person belief reports in structures like the one in (19), they are also felicitous:
}

(i) ${ }^{1}$ Maria crede în mod greşit că... $\quad$ Elena este încă în LA,

Mary mistakenly believes that... Helen is (ind) still in LA,

${ }^{2}$ dar vrea ca eu să cred că... $\quad$ Elena nu ar fi în LA.

(IND)

but she wants me to believe that... Helen is (subjB) not in LA. 
(21) $\quad \operatorname{not} p ; x$ believes not $p$.

\#SUBJB

${ }^{1}$ Maria nu este în pericol. ${ }^{2}$ \#(Şi) Maria crede că nu ar fi în pericol.

Mary is not in danger. \#(And) Mary believes that not subjB be in danger.

In a context in which $p$ is true (as in (20)), the wide-scope dissociation from not $p$ is satisfied - hence subjB is felicitous; in a context in which not $p$ is true (as in (21)), the narrow-scope dissociation from $p$ is satisfied - but subjB is not felicitous. SubjB has to have scope not only over the embedded sentential negation, but also over preverbal negative quantifiers in subject position like nimeni (no one) or nici un student (no student) ${ }^{18}$ in examples of the form $x$ believes no $F$ is $G$; due to space limitations, I do not provide the actual data.

\section{Subjunctive $B$ as propositional de se}

In this section, I propose a semantic solution to the problem of deriving the fixed wide-scope of $\operatorname{subjB}$, as opposed to syntactically stipulating the wide-scope and attempting to justify the syntactic assumption on independent grounds. In particular, I assume that subjB can freely scope with respect to negation and I propose that subjB has a third presuppositional component, besides temporal $d e s e^{19}$ and dissociation, which rules out the narrow scope: subjB is also propositional de se, i.e. it presupposes that the proposition expressed by the embedded clause is true in the centered worlds self-ascribed by the attitude holder.

Intuitively, an individually de se report is about an individual that is identical to the beliefinternal 'self' and a temporally $d e$ se report is about a time that includes the belief-internal 'now'. A propositionally de se report is about a proposition that includes the belief-internal 'actually', where the belief-internal 'actually' is the set of worlds self-ascribed by the believer.

The resulting analysis is theoretically appealing because it extends the parallel between pronouns, tenses and moods to de se readings, following the research program of Partee (1973), Abusch (1997), Stone (1999) and Schlenker (2003) among others.

\subsection{Deriving the 'only wide scope' generalization}

The basic idea is that subjB takes wide scope with respect to negation much like the pronominal tense takes wide scope with respect to negation in the well-known example from Partee (1973) I didn't turn off the stove. As Partee (1973): 602 observes, "... such a sentence clearly does not mean that [...] there exists no time in the past at which I turned off the stove". That is, subjB 'goes proxy' for, i.e. it must be bound by, the centered world variable contributed by the attitude verb. This makes it parallel to null PRO, which has to be bound by the belief-internal 'self' variable $x^{\text {self }}$ and to the temporal de se presupposition, which 'goes proxy' for the belief-internal 'now' variable $t^{\text {now }}$.

The basic structure of a propositional de se report is given in (22) below: $w^{*}$ stands for the actual world; in an expression of the form $\lambda w: \phi . \psi, \phi$ is the presupposition and $\psi$ is the assertion; given that we are focusing on the modal coordinate, I use dox instead of self_ascribe and omit the variables $x^{\text {self }}$ and $t^{\text {now }}$ for simplicity.

\footnotetext{
${ }^{18}$ Under the assumption that nimeni (no one) and nici un student (no student) are negative quantifiers exhibiting negative concord with the sentential negation $n u$ and not negative polarity items.

${ }^{19}$ De se interpretations are in general presupposed because they require the presence of a pronominal, hence anaphoric / presuppositional, element - either in the individual or the temporal domain.
} 
Mary believes that she is ( $\operatorname{subjB}-$ propositional de se) not in danger. $\sqrt{ }$ subjB $>>$ not

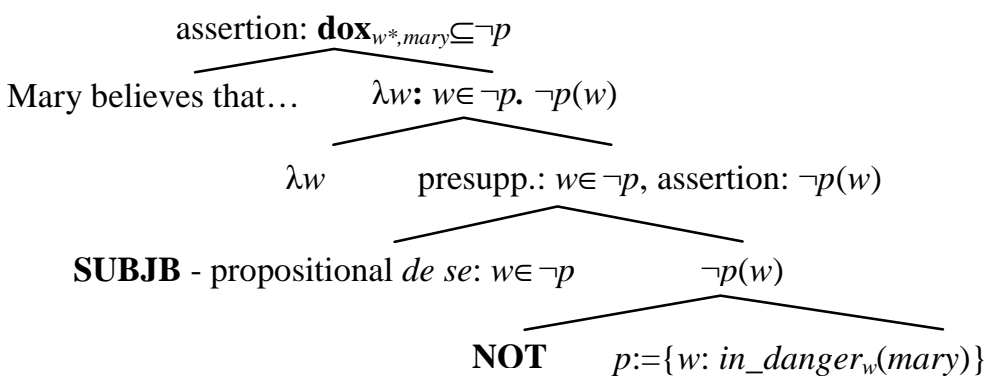

The de se presupposition redundantly iterates the asserted part of the embedded clause. But, as shown in (23) below, the same presupposition yields a contradiction if subjB has narrowscope with respect to negation - thus we derive the 'only wide scope' generalization.

(23) Mary believes that she is (subjB - propositional de se) not in danger. \#not $>>$ subjB



At the embedded clause level, we presuppose that Mary's centered worlds satisfy $p$ and we assert that they do not. But no possible world can satisfy such a condition, hence the belief report ascribes to Mary the empty set of centered worlds which, under the assumption that Mary's beliefs are consistent, is impossible.

It is important to represent and compute the de se presupposition at the level of the embedded clause and not at the matrix clause level, e.g. as the contradiction between the assertion that Mary believes she is not in danger (see $\mathbf{d o x}_{w^{*}, \text { mary }} \subseteq \neg p$ in (22) above) and a presupposition of the form Mary believes she is in danger, i.e. $\mathbf{d o x}_{w^{*}, \text { mary }} \subseteq p$. Representing the presupposition at the matrix level would not make any difference for the embedded negation in (23) above (we still derive a contradiction), but it would predict that a matrix negation is also unacceptable, e.g. in a sentence like It is not the case that Mary believes that $p$, with $p$ marked with subjB. Such a sentence asserts $\neg \mathbf{d o x}_{w^{*}, \text { mary }} \subseteq p$ and, if we represented the de se presupposition at the matrix level, we would have $\mathbf{d o x}_{w^{*}, \text { mary }} \subseteq p$, thus contradicting the assertion. But we know that subjB reports with a matrix negation are felicitous (see (16) above), so we have to represent and bind the propositional de se presupposition locally at the embedded clause level.

The local binding of the presupposition at the embedded clause level is a consequence of the presupposition resolution procedure itself: the de se presupposition contains the bound world variable $w$ and this variable has to still be bound when the presupposition is resolved ${ }^{20}$.

A final observation: the present account of the 'only wide scope' generalization is not entirely appealing insofar the propositional de se presupposition is basically identical to the assertion, which should yield infelicity if we assume something like Stalnaker's non-redundancy constraint on context update (see Stalnaker (1978)). I do not have anything to say about this except to point out that the felicitous sentence The queen of Netherlands exists exhibits a

\footnotetext{
${ }^{20}$ For more discussion, see van der Sandt (1992): 363-366.
} 
similar kind of redundancy: the definite description presupposes the existence of the queen of Netherlands, which is exactly what the sentence asserts ${ }^{21}$.

\subsection{The incompatibility between subjunctive $B$ and probabil}

The contrast between subjB and indicative belief reports with probabil is exemplified in (24).

(24) $x$ believes that probably $p$

VIND; \#SUBJB

Cînd m-am întîlnit cu el, Ion credea că... (When I met him, John believed that...)

a. marțienii probabil invadează Bucureştiul. the Martians probably invade.ind.pres Bucharest.

b. \#marțienii probabil ar invada Bucureştiul. the Martians probably subjB invade Bucharest. ...the Martians were probably invading Bucharest.

\#SUBJB

Intuitively, subjB is incompatible with probabil reports precisely because, being propositionally de se, subjunctive $\mathrm{B}$ expresses that the attitude holder is completely committed to the believed proposition, while probably implicates that there is at most a partial commitment.

To make this intuition precise, we need to look more closely at how probably is interpreted. Imagine that Mary utters the sentence in (25) below while walking through a bad neighborhood late at night. I will represent this sentence as shown in (26).

(25) I'm probably in danger. (26) MOST $\left(\left\{w: w \in \mathbf{d o x}_{w^{*}, \text { mary }}\right\}\right)(\{w:$ in_danger $(\operatorname{mary})\})$

The adverb probably is an epistemic modal quantifier, i.e. it quantifies over Mary's doxastic alternatives $\mathbf{d o x}_{w^{*}, \text { mary }}$ (where $w^{*}$ is the actual world). In fact, we consider only a subset of $\mathbf{d o x}_{w^{*}, \text { mary }}$, namely the worlds that are ideal - or close enough to being ideal - with respect to a stereotypical ordering source ('in view of what Mary takes the normal course of events to $\mathrm{be}^{\prime 22}$ ), but for simplicity I will assume that (25) is true iff most of Mary's doxastic alternatives $w$ are such that Mary is in danger in $w$. Since probably is a 'MOST'-type quantification, it has a 'ᄀEVERY'-type scalar implicature, i.e. $\neg \operatorname{EVERY}\left(\mathbf{d o x}_{w^{*}, m a r y}\right)\left(\left\{w\right.\right.$ : in_danger in $\left.\left.\left._{\text {mary }}\right)\right\}\right)$,

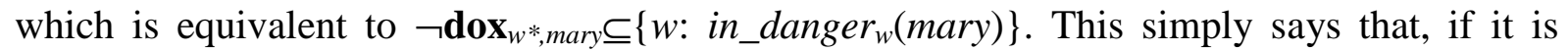
probable that $p$, then it is not certain that $p$.

The goal is to derive a contradiction between the propositional de se presupposition, which requires the complete commitment of the attitude holder, and the implicature triggered by probabil / probably, which denies the complete commitment. At a first glance, pursuing this strategy does not seem to take us too far: even if we were able to derive a contradiction, we would expect the implicature to be canceled since, by definition, implicatures are only default inferences. However, implicatures of this kind, i.e. which contradict presuppositions, always yield infelicity, despite their otherwise undisputed cancelability. This is shown by the pairs of sentences in (27)-(28), (29)-(30) and (31)-(32) below: the presuppositions triggered by stop in (27) and (29) and by the fact that the quantifier restrictor itself is presupposed in (31) contradict the implicatures of probably and most, making the examples unacceptable.

(27) \#The students that stopped smoking had probably smoked before.

(28) VThe students that stopped smoking had smoked before.

(29) \#Most students that stopped smoking had smoked before.

(30) $\sqrt{ }$ Every student that stopped smoking had smoked before.

\footnotetext{
${ }^{21}$ I am grateful to Philippe Schlenker (p.c.) for pointing out this type of examples.

${ }^{22}$ See Kratzer (1991): 643-645.
} 
(31) \#Most dolphins are dolphins.

(32) $\sqrt{\text { Every dolphin is a dolphin }}{ }^{23}$.

Now consider (33) below and assume for the moment that subjB scopes under probabil.

(33) \#Mary believes that she probably is (subjB - propositional de se) in danger.

The 'subjB narrow-scope' reading is interpreted as shown in (34) below. Just as in (23) above, subjB contributes a propositionally de se presupposition. Then, we have the asserted probably quantification. Finally, the formula following the semi-colon is the probably implicature. Generally, in an expression of the form $\lambda w: \phi . \psi ; \xi, \phi$ is the presupposition, $\psi$ is the assertion and $\xi$ is the implicature. Following the observations in Chierchia (2001): 5 et seqq., we compute the scalar implicature at the embedded clause level.

\section{believe $_{w^{*}}\left(\right.$ mary, $\lambda w:$ in_danger ${ }_{w}($ mary $)$.}

$\operatorname{MOST}\left(\mathbf{d o x}_{w, \text { mary }}\right)\left(\left\{w^{\prime}:\right.\right.$ in_danger $_{w^{\prime}}($ mary $\left.\left.)\right\}\right) ; \neg \mathbf{d o x}_{w, \text { mary }} \subseteq\left\{w^{\prime}:\right.$ in_danger $_{w^{\prime}}($ mary $\left.\left.)\right\}\right)$

There is no intuitively plausible way to derive a contradiction between the presupposition and the implicature in (34). Quite the contrary: the presupposition that Mary is in danger in $w$ (i.e. in_danger $($ mary $)$ ) and the implicature that it is not the case that Mary believes in $w$ that she is in danger (i.e. $\neg \mathbf{d o x}_{w, m a r y} \subseteq\left\{w^{\prime}:\right.$ in_danger $_{w}\left(\right.$ mary $\left.\left._{\text {a }}\right\}\right)$ can very well be compatible - people often refuse to believe things that are actually true. Intuitively however, we should be able to derive a contradiction between the presupposition and the implicature: we presuppose that all of Mary's doxastic alternatives satisfy the proposition $p:=\left\{w^{\prime}:\right.$ in_danger $_{w^{\prime}}\left(\right.$ mary $\left._{\text {) }}\right\}$ (this is what the formula believe $w^{*}($ mary $, \lambda w: p(w)$... says) and we implicate that they do not.

\subsection{Propositional de se all the way: centered propositions}

To solve the probabil - subjB puzzle, I propose to replace centered worlds with centered propositions, i.e. triples of the form $\left(p, f^{\text {self }}, g^{\text {now }}\right)$, where $f^{\text {self }}$ is an individual concept (type $s e$ ) and $g^{\text {now }}$ is a time-interval concept (type $\left.s \tau\right)$. Intuitively, for any $w \in p, f^{\text {self }}(w)$ is the beliefinternal 'self' in $w$ and $g^{\text {now }}(w)$ is the belief-internal 'now' in $w$. It is a natural assumption that there is a unique 'self' and a unique 'now' per belief-world $w$, although they can vary from world to world as in, for example, Heimson believes that he is Hume or Napoleon.

Note that we independently need centered propositions to account for cross-sentential propositional anaphora in examples like (35) below.
${ }^{1}$ Maria crede că Ion ar fi chipeş.
${ }^{2}$ Ar avea ochi frumoşi.
Mary believes that John is (subjB) handsome. He has (subjB) beautiful eyes.

The subjB sentence $\left(35^{2}\right)$ has to be interpreted as a further elaboration of Mary's beliefworlds $^{24}$ and cannot be interpreted as stating that John has beautiful eyes in the actual world.

The core idea of the centered-propositions analysis is that, in a belief report of the form $x$ believes + embedded clause, the matrix clause $x$ believes sets up the context for the interpretation of the embedded clause by contributing a centered proposition relative to which the embedded clause is interpreted. Of course, as (35) above shows, a subsequent matrix clause can also be interpreted relative to the same centered proposition. The matrix clause basically introduces a centered proposition discourse referent (more exactly, three suitably related discourse referents - for $p, f^{\text {self }}$ and $g^{\text {now }}$ ), which is anaphorically accessed by the embedded clause. For simplicity, we will represent this via static existential quantification

\footnotetext{
${ }^{23}$ I am grateful to Roger Schwarzschild for suggesting the examples in (31) and (32).

${ }^{24}$ We can even have modal subordination, as shown in (i) below.

(i) Maria crede că ar fi vampiri în LA. $\quad{ }^{2} \mathbf{A r}$ intra noaptea în case şi ar ataca oamenii în somn. Mary believes that there are (subjB) vampires in LA. They break (subjB) into houses at night and attack (subjB) people in their sleep.
} 
over a propositional variable $p$ that is contributed by the attitude verb (we systematically ignore $f^{\text {self }}$ and $g^{\text {now }}$ ). For example, a simple report like Mary believes that she is in danger is represented as shown in (36) below.

$$
\begin{aligned}
& \left.\exists p \text { (believe } w^{*}(\text { mary, } p) \& \text { in_danger }(\text { mary })\right) \text {, where: }
\end{aligned}
$$

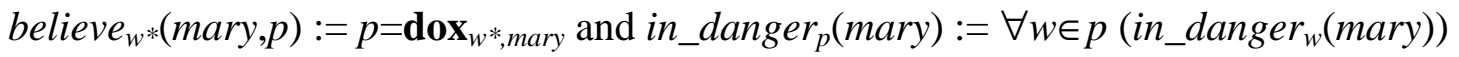

The first conjunct equates the proposition $p$ with Mary's doxastic alternatives in the actual world $w^{*}$. The second conjunct simply says that for any world $w$ in the proposition $p$, Mary is in danger in $w$. This technique of encapsulating modal quantification was first proposed in Stone (1999) and it is independently motivated by the analysis of modal subordination.

A propositional de se report is interpreted as in (37) below. The second conjunct is the propositional de se presupposition contributed by subjB. For simplicity, I do not distinguish between the status of assertions and presuppositions or implicatures. Just as in (36), the third conjunct is the assertion contributed by the embedded clause.

$$
\begin{aligned}
& \text { Mary believes that she is (subjB - propositional de se) in danger. } \\
& \exists p\left(p=\mathbf{d o x}_{w^{*}, \text { mary }} \& p \subseteq\{w: \text { in_danger }\right. \\
& \text { (mary) }\} \text { \& in_danger } \\
& \text { (mary }))
\end{aligned}
$$

The solution to the 'only wide-scope' problem in $\mathbf{4 . 1}$ above is easily reformulated in terms of centered propositions. Negation is interpreted as: $\operatorname{not}_{w}\left(p^{\prime}\right):=w \notin p^{\prime} ; \operatorname{not}_{p}\left(p^{\prime}\right):=\forall w \in p\left(w \notin p^{\prime}\right)$. That is, negation is interpreted as any other lexical predicate (e.g. in_danger) modulo the fact that it has a propositional argument. We give only the interpretation of the contradictory narrow-scope subjB (not>>subjB): the second conjunct (the propositional de se presupposition) contradicts the third conjunct (the assertion).

(38) Mary believes that she is (subjB - propositional de se) not in danger.

$$
\exists p\left(p=\operatorname{dox}_{w^{*}, \text { mary }} \& p \subseteq\left\{w: \text { in_danger }{ }_{w}(\text { mary })\right\} \& \operatorname{not}_{p}\left(\left\{w: \text { in_danger }_{w}\left(\text { mary }_{)}\right\}\right)\right)\right.
$$

Moreover, since the existential quantification over the variable $p$ is contributed by the attitude verb believe, we are still locally representing and binding the propositional de se presupposition, ruling out the narrow-scope of subjB with respect to the embedded negation while at the same time allowing for felicitous matrix negation examples like (16) above.

\subsection{Deriving the incompatibility between subjunctive $B$ and probabil}

Finally, we return to the probabil problem, i.e. to ruling out the 'subjB narrow-scope' reading (probabil >>subjB) of (33) above. This is interpreted as shown in (39).

$$
\begin{aligned}
\exists p( & p=\mathbf{d o x}_{w^{*}, \text { mary }} \& p \subseteq\{w: \text { in_danger }(\text { mary })\} \& \\
& \forall w^{\prime} \in p\left(\operatorname{MOST}\left(\mathbf{d o x}_{w^{\prime}, m a r y}\right)\left(\left\{w: \text { in_danger }{ }_{w}(\text { mary })\right\}\right)\right) \& \\
& \left.\forall w^{\prime} \in p\left(\neg \mathbf{d o x}_{w^{\prime}, m a r y} \subseteq\left\{w: \text { in_danger }{ }_{w}(\text { mary })\right\}\right)\right)
\end{aligned}
$$

The second conjunct is the propositional de se presupposition, the third conjunct is the probably assertion and the last conjunct is the probably implicature. The advantage of using centered propositions instead of centered worlds is that now we have access to the first conjunct contributed by the attitude verb when we compute the contradiction between the presupposition and the implicature. Given the equality in the first conjunct, the presupposition is equivalent to the formula in (40a) below and the implicature with the formula in (40b).

$$
\begin{aligned}
& \text { a. presupposition: } \mathbf{d o x}_{w^{*}, \text { mary }} \subseteq\{w: \text { in_danger } \\
& \text { b. implicature: } \forall w^{\prime} \in \mathbf{d o x}_{w^{*}, \text { mary }}\left(\neg \mathbf{d o x}_{w^{\prime}, \text { mary }} \subseteq\left\{w: \text { in_danger }_{w}(\text { mary })\right\}\right)
\end{aligned}
$$


To derive the contradiction between (40a) and (40b), we only need the (fairly uncontroversial) belief 'introspection ${ }^{\prime 25}$ principles in (41a) and (41b) below. The 'introspection' principles are equivalent to the formula in (41c), which exhibits the internal structure of the dox function that is enforced by these principles.

$$
\begin{aligned}
& \text { a. Positive 'Introspection': bel }(x, p) \rightarrow \text { bel }(x, \text { bel }(x, p)) \\
& \text { b. Negative 'Introspection': } \neg \text { bel }(x, p) \rightarrow \text { bel }(x, \neg \text { bel }(x, p))^{26} \\
& \text { c. } \forall w \forall x \forall w^{\prime} \in \mathbf{d o x}_{w, x}\left(\mathbf{d o x}_{w^{\prime}, x}=\mathbf{d o x}_{w, x}\right)^{27}
\end{aligned}
$$

Among other things, the 'introspection' principles derive the intuitive equivalence between sentence (25) above when uttered by Mary and the belief report Mary believes that she is probably in danger, when probably is interpreted relative to Mary's doxastic alternatives.

It is easily checked that, based on (41c), we can derive a contradiction between the formulas in (40a) and (40b) above. To derive the incompatibility between subjunctive B and probabil, we also need to rule out the 'wide scope' reading $\mathbf{s u b j B}>>$ probabil. I propose that this is due to the fact that dissociation yields a contradiction in this case. The dissociation presupposition is provided in (42a) below and the corresponding assertion in (42b).

\#Mary believes that she probably is (subjB - dissoc.) in danger. \#subjB >>probabil

a. dissociation: $\exists w \in \mathbf{C S}\left(\neg \operatorname{MOST}\left(\mathbf{d o x}_{w, \text { mary }}\right)\left(\left\{w^{\prime}:\right.\right.\right.$ in_danger $_{w^{\prime}}($ mary $\left.\left.\left.)\right\}\right)\right)$

b. assertion: $\forall w^{\prime \prime} \in \mathbf{C S}\left(\mathbf{d o x}_{w^{\prime \prime}, \text { mary }} \subseteq\left\{w^{\prime \prime \prime}: \operatorname{MOST}\left(\mathbf{d o x}_{w^{\prime \prime}, \text { mary }}\right)\left(\left\{w^{\prime}:\right.\right.\right.\right.$ in_danger $_{w^{\prime}}($ mary $\left.\left.\left.\left.)\right\}\right)\right\}\right)$

Take a witness world $w^{*} \in \mathbf{C S}$ that satisfies the dissociation requirement; hence, we have that $\neg \operatorname{MOST}\left(\operatorname{dox}_{w^{*}, \text { mary }}\right)(p)$, where $p$ is the proposition $\left\{w^{\prime}:\right.$ in_danger $w^{\prime}\left(\right.$ mary $\left.\left.^{\prime}\right)\right\}$. This world should also satisfy the assertion, i.e. $\operatorname{dox}_{w^{*}, \text { mary }} \subseteq\left\{w^{\prime \prime \prime}: \operatorname{MOST}\left(\mathbf{d o x}_{w^{\prime \prime \prime}, \text { mary }}\right)(p)\right\}$. The latter formula is equivalent to $\forall w^{\prime \prime \prime} \in \mathbf{d o x}_{w^{*}, \text { mary }}\left(\operatorname{MOST}\left(\mathbf{d o x}_{w^{\prime \prime}, \text { mary }}\right)(p)\right)$. By the introspection postulate in (41c), this formula is equivalent to $\operatorname{MOST}\left(\operatorname{dox}_{w^{*}, \text { mary }}\right)(p)$, which contradicts the dissociation requirement. A final observation: the dissociation-based analysis of the infelicity of the widescope structure subjB>>probabil makes the prediction that, if subjB dissociates from a set of worlds that is different from the worlds in which the belief is reported, we will not get a contradiction between assertion and dissociation - hence, in such belief reports, there should be no contrast between indicative and subjB and the latter should be compatible with embedded probabil. As the example in (43) below shows, this prediction is borne out.

Maria nu încearcă să îl pună pe Ion în umbră şi nu vrea ca Ion să creadă că...

Mary is not trying to disadvantage John and she doesn't want John to believe that...

probabil ar încerca să facă asta.
probably subjB try subjA do this.
she is probably trying to do this.

\section{Conclusion}

I have analyzed the Romanian subjB as a single package of three distinct presuppositions: temporal de se, dissociation and propositional de se. The subjB - indicative contrast is the temporal analogue of the PRO - overt pronoun contrast in the individual domain. The dissociation presupposition enabled us to show that subjB always takes scope over the

\footnotetext{
${ }^{25}$ The scare quotes are meant to suggest that the one should not understand the introspection principles as psychological principles; for more discussion, see Hintikka (1962): 56-57 et seqq, who prefers the less psychological term of 'self-intimating'.

${ }^{26}$ The logic of belief is usually assumed to be the modal system KD45, where positive 'introspection' is Axiom 4 $\left(B_{x} \phi \rightarrow B_{x} B_{x} \phi\right)$ and negative 'introspection' is Axiom $\mathbf{5}\left(\neg B_{x} \phi \rightarrow B_{x} \neg B_{x} \phi\right)$.

${ }^{27}$ The de se version of the introspection postulate is given in (i) below. We use the simpler dox-based version.

(i) $\forall w, x, t \forall\left(w^{\prime}, x^{\prime}, t^{\prime}\right) \in$ self_ascribe $_{w, x, t}\left(\right.$ self_ascribe $_{w^{\prime}, x^{\prime}, t^{\prime}}=$ self_ascribe $\left._{w, x, t}\right)$.
} 
embedded negation. The propositional de se presupposition derives this generalization. The move to centered propositions (generalizing centered worlds) in combination with propositional de se, 'introspection' principles and dissociation conspire to derive the fact that subjB reports (unlike their indicative counterparts) are infelicitous with embedded probabil.

There are at least two directions for future research. First, we need to investigate the distribution and interpretation of subjB and its contrast with indicative when the two moods are embedded under other attitude verbs, e.g. spune (say), zice (say), pretinde (claim) and se indoi (doubt). Moreover, following Farkas (1992), we need to extend the investigation to the Romanian subjunctive A and the ways it contrasts with indicative and subjB. Second, we need to examine the cross-linguistic typological predictions that the present analysis of subjB suggests. An important question is whether the three components of the subjB interpretation are truly independent; if so, we expect to encounter languages with items that have only one or two of the three presuppositions. A possibly relevant mood is the English infinitive: it is compatible with verbs like hope or promise, which suggests that it is not temporally de se, and it is incompatible with probably (\#Mary believes herself to probably be in danger vs. Mary believes that she is probably in danger), which might indicate that it is propositionally de se.

\section{References}

Abusch, D.: 1997. Sequence of Tense and Temporal De Re, in Linguistics \& Philosophy 20, $1-50$.

Chierchia, G.: 1989. Anaphora and Attitudes De Se, in Semantics and Contextual Expression, R. Bartsch et al. (eds.), Foris, 1-31.

Chierchia, G.: 2001. Scalar Implicatures, Polarity Phenomena, and the Syntax/Pragmatics Interface, U. of Milan - Bicocca ms., May 2001.

Cresswell, M.J. and A. von Stechow: 1982. De Re Belief Generalized, in Linguistics and Philosophy 5, 503-535.

Farkas, D.: 1992. On The Semantics of Subjunctive Complements, in Romance Languages and Modern Linguistic Theory, P. Hirschbühler et al (eds.), Benjamins, 69-104.

Heim, I.: 1992. Presupposition projection and the semantics of attitude verbs, in Journal of Semantics 9, 183-221.

Hintikka, J.: 1962. Knowledge and Belief, Cornell University Press.

Hintikka, J.: 1969. Semantics for Propositional Attitudes, in Philosophical Logic, J.W. Davis et al (eds.), 21-45.

Kamp, H. \& U. Reyle: 1993. From Discourse to Logic, Kluwer.

Kaplan, D.: 1989. Demonstratives, in Themes from Kaplan, P. Almog et al (eds.), OUP, 481563.

Kratzer, A.: 1991. Modality, in Semantik/Semantics, A. von Stechow et al (eds.), de Gruyter, 639-650.

Lewis, D.: 1979. Attitudes De Dicto and De Se, in The Philosophical Review 88:4, 513-543. 
Partee, B.: 1973. Some Structural Analogies between Tenses and Pronouns in English, in Journal of Philosophy 70, 601-609.

Potts, C.: 2004. Conventional Implicatures, A Distinguished Class of Meanings, to appear in The Oxford Handbook of Linguistic Interfaces, G. Ramchand et al (eds.), OUP.

Schlenker, P.: 2003. A plea for monsters, in Linguistics and Philosophy 26, 29-120.

Searle, J.: 1983. Intentionality. An Essay in the Philosophy of Mind, Cambridge.

Stalnaker, R.: 1978. Assertion, in Syntax and Semantics 9, 315-332.

Stone, M.: 1999. Reference to Possible Worlds, RuCCS Report 49, Rutgers University NB.

Van der Sandt, R.: 1992. Presupposition Projection as Anaphora Resolution, in Journal of Semantics 9, 333-377. 


\title{
BARE NOMINALS AND OPTIMAL INFERENCE ${ }^{*}$
}

\author{
Ariel Cohen, \\ Ben-Gurion University of the Negev \\ arikc@bgu.ac.il
}

\begin{abstract}
In this paper I discuss four type of bare nominal, and note that, in some sense, all of them appear to imply stereotypicality. I consider an account in terms of Bidirectional Optimality Theory: unmarked (bare) forms give rise to unmarked (stereotypical) interpretations. However, it turns out that, while the form of bare numerals is unmarked, the interpretation sometimes is not. I suggest that the crucial notion is not unmarkedness, but optimal inference: unmarked forms give rise to interpretations that are best used for drawing inferences. I propose a revision of Bidirectional Optimality Theory to reflect this.
\end{abstract}

\section{Stereotypical Interpretations of Bare Nominals}

\subsection{Generic Bare Plurals}

What does a generic sentence like (1) mean?

(1) Ravens are black.

Clearly, this is not a universal, since the existence of the odd albino raven does not render (1) false. But what, then, does it mean? The meaning of a generic is a hotly debated topic, and I am not going to address it here. ${ }^{1}$ At a pretheoretic level, however, a reasonable approximation of the meaning of the sentence is that it makes a statement not about all ravens, but about stereotypical ravens. Since an albino raven is not stereotypical, it does not count an an exception, and does not falsify (1).

Note that I am not advocating here that the truth conditions of (1) are captured by an appeal to stereotypicality_indeed, I will argue against such a claim. ${ }^{2}$ All I am saying is that when (1) is interpreted, there is a "feeling" that stereotypicality is involved. Nothing more than this rather weak and, I believe, non-controversial claim is necessary for the purposes of this paper, as we shall see.

\subsection{Existential Bare Plurals}

Existential bare plurals are usually supposed to express nothing more than a simple existential claim. They are certainly rarely associated with notions of stereotypicality. And yet, stereotypicality does appear to play a role in their interpretation (Cohen 2005a).

Consider the following examples:

(2) a. This tractor has wheels.

\footnotetext{
* I would like to thank Manfred Krifka for helpful comments and suggestions.

${ }^{1}$ See Cohen $(1996 ; 1999)$ for my take on this question.

${ }^{2}$ Though some researchers, e.g. Geurts (1985) and Declerk (1986), argue for precisely this claim.
} 
b. This tractor has some wheels.

Suppose the tractor in question has only two wheels. Then (1a) would be odd, but (1b) would be fine. Sentence (2a), but not (2b), suggests that the tractor has four wheels, suitably arranged: two large ones in the rear, two smaller ones in front. In other words, (1a) implies that the tractor has the stereotypical arrangement of wheels.

For another example, consider the following pair, suggested by Tova Rapoport (pc):

a. John has playing cards.

b. John has Victorian playing cards.

Sentence (3a) suggests that John has the stereotypical set of cards, i.e. a full deck. Sentence (3b), on the other hand, may be felicitously uttered even if John has only a few Victorian cards; in the context of this sentence, John is most probably a collector of Victorian cards, and there is no specific set of cards that would be considered stereotypical for collecting purposes.

Even the "classic" example of an existential reading of a bare plural, namely the subject of available, may give rise to stereotypicality. Suppose we wish to send a spaceship to the moon. We contact NASA, and get the following response:

(4) Astronauts are available.

Sentence (4) says more than simply that there exist some available astronauts. Rather, it implies that there is a set of available astronauts that is stereotypical, in terms of its size, the training of its members, etc., in the context of our mission: there are, say, three astronauts, who have the respective roles of Command Module Pilot, LEM Pilot, and Mission Commander.

Note that this feeling of stereotypicality is perceived by the hearer, who may felicitously respond to it as if it were explicitly made:

(5) A: This tractor has wheels.

B: So where do you want to go with it?

(6) A: John has playing cards.

B: Great, let's start a game.

(7) A: Astronauts are available.

B: But the mission cannot go ahead, because the rocket is still malfunctioning.

B's response in (5a) relates to the implied claim that the tractor has a set of wheels suitable for the purpose of riding it; in (6b), B responds to A's implication that John has a set of playing cards suitable for playing; and in (7b), B understands A's purpose to indicate that the mission is ready (and the set of available astronauts is the appropriate stereotypical set).

\subsection{Incorporated Bare Nouns}

Carlson (2005) discusses a number of studies of incorporation in various languages. While the languages and the theoretical approaches differ substantially, all these works seem to converge on some sort of stereotypical interpretation of incorporated nouns.

Thus, for example, Borthen (2003) proposes:

A bare indefinite can occur in Norwegian if it is... selected as a complement by a predicate and together with this predicate (and possibly other selected elements) designates a conventional situation type... A conventional situation type is a property, state, or activity 
that occurs frequently or standardly in a given contextual frame (e.g. in the macro social frame) and has particular importance or relevance in this frame as a recurring property, state, or activity type (p. 160).

Similarly, Axelrod (1990) suggests that "incorporation provides the lexicalized version of a typical activity". Mithun (1984) relates the typicality implication of incorporation to frequency: "some entity, quality, or activity is recognized sufficiently often to be considered nameworthy." Mulder (1994) follows suit: "Noun incorporation in Sm'algyax occurs when a habitual activity toward an object is expressed." Similarly, de Reuse (1994) suggests that the incorporated form "refers to habitual, permanent, chronic, specialized, characteristic or unintentional activities or states, or localized events".

\subsection{Bare Goal Arguments}

Horn (1993) considers sentences with bare goal arguments:

$$
\text { My brother went to }\left\{\begin{array}{l}
\text { church } \\
\text { jail } \\
\text { school }
\end{array}\right\} \text {. }
$$

Horn notes that (8) implies that my brother went to church (jail, school) for the purpose of performing the stereotypically associated function (praying, being incarcerated, studying). In this its meaning is different from (9), which means simply that my brother changed his location to the specified location — the church (the jail, the school).

$$
\text { My brother went to a }\left\{\begin{array}{l}
\text { church } \\
\text { jail } \\
\text { school }
\end{array}\right\} \text {. }
$$

It appears, then, that four different kinds of bare nominal, which differ on their syntax, semantics, and pragmatics, share a stereotypical "flavor". Surely this cannot be mere coincidence: there must be something about bare nominals that contributes to this interpretation. How can we explain this fact?

\section{Unmarked Forms and Interpretations}

\subsection{The basic idea}

An idea that goes as far back as Atlas and Levinson (1981) and Horn (1984) can be expressed succinctly by the following well known slogan: unmarked forms receive unmarked interpretations.

The underlying notion is simple: both speaker and hearer want to minimize their effort. Unmarked (shorter) forms are easier for the speaker to produce; unmarked (stereotypical) meanings are easier for the hearer to understand. Hence, unmarked forms are preferred to marked forms, and unmarked interpretations are preferred to marked interpretations.

\subsection{Bidirectional Optimality Theory}

This notion has been formalized by Blutner $(1998 ; 2000)$ in his Bidirectional Optimality Theory. Blutner considers pairs of form and interpretation: $\langle A, \tau\rangle$ means that $\tau$ is the interpretation of $\mathrm{A}$. Blutner proposes a partial order ' $\succ$ 'on such pairs. Intuitively, $\left\langle\mathrm{A}^{\prime}, \tau\right.$ ' $\rangle \succ$ $\langle\mathrm{A}, \tau\rangle$ means that $\left\langle\mathrm{A}^{\prime}, \tau\right\rangle$ is preferred to $\langle\mathrm{A}, \tau\rangle$. A pair $\langle\mathrm{A}, \tau\rangle$ is superoptimal iff it satisfies the following two principles: 
Q principle: $\tau$ is a possible interpretation of $A$ and there is no other pair $\left\langle A^{\prime}, \tau\right\rangle$ satisfying the I principle s.t. $\left\langle\mathrm{A}^{\prime}, \tau\right\rangle \succ\langle\mathrm{A}, \tau\rangle$

I principle: $\tau$ is a possible interpretation of $A$ and there is no other pair $\langle A, \tau$ ' $\rangle$ satisfying the $\mathrm{Q}$ principle s.t. $\langle\mathrm{A}, \tau\rangle\rangle\langle\mathrm{A}, \tau\rangle$

At first sight, the combination of these two principles might appear circular, since the definition of the Q principle refers to the I principle, and the definition of the latter refers back to the former. However, this circularity is not vicious, and, in fact, the principles can predict successfully a number of phenomena.

For an example, consider the following minimal pair, from McCawley (1978):

a. Black Bart killed the sheriff.

b. Black Bart caused the sheriff to die.

McCawley notes that while (10a) implies that Black Bart killed the sheriff in a direct way (i.e. shot him), (10b) implies some indirect way of killing, e.g. sabotaging the sheriff's own gun so that it backfires.

Bidirectional Optimality Theory can account for this difference, under the plausible assumption that the stereotypical manner of killing is direct rather than indirect.

Note that the form-meaning pair <kill, direct killing> is superoptimal, since both its form (short) and its meaning (stereotypical) are preferred. But the form-meaning pair < cause to die, indirect killing $>$ is also superoptimal. This is the case, although there are pairs that are preferred to it. For example, <kill, indirect killing> is preferred (its form is shorter), but it doesn't satisfy the I-principle, because the pair <kill, direct killing $>$ is better than it. Similarly, although <cause to die, direct killing> is preferred (its meaning is stereotypical), it doesn't satisfy the Q-principle, since the pair <kill, direct killing> is better than it. Thus, we get the desired result: unmarked forms pair with unmarked meanings, and marked forms pair with marked interpretations.

It appears that Bidirectional Optimality Theory would straightforwardly account for the facts about bare nominals discussed above, provided we make two assumptions:

1. The meaning of bare nominals is unmarked (stereotypical)

2. The form of bare nominals is unmarked (shorter, easier to produce)

These assumptions appear quite reasonable; but are they tenable?

\section{Non-stereotypicality}

Let us first reconsider the claim that bare nominals receive stereotypical interpretations. We will see that this does not hold in general, in any of the four phenomena we have considered.

\subsection{Generic Bare Plurals}

It is quite easy to show that generics do not, in general, express stereotypicality. Take (11), for example:

??Mammals are placental mammals.

The stereotypical mammal is certainly a placental mammal. Hence, if generics expressed statements about stereotypes, (11) ought to be unproblematically true; but the fact is that it is quite bad. 
It might be argued that the problem with is simply the fact the same word, mammals, occurs in both subject and predicate. Perhaps this is what makes the sentence awkward. To see that this is not the case, consider the following examples:
a. ??Primary school teachers are female.
b. ??People are over three years old.

Although the stereotypical primary school teacher is female, (12a) is bad, and although the stereotypical person is an adult, (12b) is very odd.

Elsewhere (Cohen 1996; 1999; 2004) I account for such facts by proposing that generics carry a homogeneity presupposition. The generic $\operatorname{gen}(\psi, \varphi)$ presupposes that its domain, $\psi$, is homogeneous, in the following sense: for any psychologically salient criterion by which $\psi$ may be partitioned into subsets, the conditional probability of $\varphi$ ought to be roughly the same given every such subset of $\psi$. That is to say, the domain of a generic may not have "chunks" where there are significantly more $\varphi s$ or significantly fewer $\varphi s$ than there are in the rest of $\psi$.

Homogeneity corresponds rather well to the pretheoretical notion of what a generic sentence means. For example, suppose a friend is coming to Israel for a visit, and is worried about whether she will be able to manage, speaking only English. We reassure her by saying

\section{(13) Israelis speak English.}

Observe that (13) means more than simply that if you meet an Israeli, he or she is likely to speak English; in addition, the sentence requires that, wherever you go in Israel, whichever group of Israeli society you associate with, a member of this community will be likely to speak English. Indeed, suppose the friend spent all her visit in a town where nobody spoke English, or with members of some group of Israeli society where English was rarely spoken. In such a case, she would be justified in accusing us of misleading her.

Homogeneity can explain the oddness of examples (11-12) above. Partition according to biological group violates homogeneity: one subset (the placental mammals) satisfies the property, another (marsupials) does not. Hence, (11) is bad.

Sentence is (12a) is odd because partition according to sex violates homogeneity: one subset (the females) satisfies the property, another (the males) does not. And (12b) is bad because partition according to age violates homogeneity: some subsets (adults) satisfy the predicated property, others (babies and toddlers) do not.

Why do generics have this requirement? In Cohen (1996) I suggest that homogeneity is useful for inference. If the domain is homogeneous, we are safe from local minima. That is to say, we will not find ourselves in a situation where, because of bad luck, we happen to find ourselves dealing with a subset of the domain where all our inferences are wrong.

For example, consider (1) again, repeated below:

Ravens are black.

This sentence is acceptable and true, despite the existence of albino ravens. Why? The reason is that albino ravens are homogeneously distributed throughout the raven community-there are no colonies of albino ravens. Hence, if, whenever we encounter a raven, we infer that it is black, this inference will be justified. It might not always prove correct-sometimes we will encounter the odd albino raven - but it will not be repeatedly wrong.

Hence, I suggest that the crucial notion which prefers an interpretation of a bare nominal is not whether the interpretation is stereotypical as such, but whether it provides information that is useful for inference. Thus, a generic implies that inferences about its domain are generally reliable. Of course, one of the ways to aid inference is stereotypicality; indeed, this is arguably why we have stereotypes. But it is not the only way: another one is homogeneity. 


\subsection{Existential Bare Plurals}

We have seen above that existential bare plurals often imply stereotypicality. Indeed, stereotypicality can aid inference. For example, the hearer of (2a), repeated below, can draw inferences about the tractor (e.g. that it can run).

(15) This tractor has wheels.

However, existential bare plurals are not always interpreted stereotypically. Consider the following sentence:

(16) In this forest, trees are dying.

The stereotypical, indeed the common situation where trees are dying is where the trees are concentrated in some area, the location that was first infected. However, in such a case, where only a single grove out of the forest is dying, (16) would be quite odd. Rather, (16) seems to indicate that the dying trees are homogeneously distributed throughout the forest. ${ }^{3}$

As in the case of generics, so in the case of existential bare plurals, homogeneity serves as an aid to inference. The hearer of (16a) can draw inferences about the forest (e.g. that it is sick), which would not be possible if only a single grove were infected.

For further examples of existential bare plurals that express homogeneity, consider the following sentences, after Greenberg (1994):

(17) a. (Although it is winter now, in our country...) lakes are dry.

b. (Wellington's army has won a great victory today, but...) soldiers are tired.

c. (It is New Year's Eve, and...) restaurants are full.

Note that if only lakes located in a specific geographical region, or only salt-water lakes were dry, (17a) would be odd; rather, the sentence implies that throughout the country, lakes are dry. Similarly, (17b) would be bad if only the young soldiers, or only the soldiers in a specific platoon were tired; its acceptability requires that soldiers from a variety of ages, units, etc. be tired. As for $(17 \mathrm{c})$, if only Italian restaurants, or only restaurants on a specific street were full, it would be odd; (17c) implies that various types of restaurant, throughout town, are full.

\subsection{Incorporated Bare Nouns}

We have seen that incorporation often implies stereotypicality. What is the role of stereotypicality? Asudeh and Mikkelsen (2000), discussing syntactic noun incorporation in Danish, propose that it is subject to the following constraint:

the resulting predicate must denote an action that is 'institutionalized'

(Rischel, 1983). In other words, the denotation of the incorporated verb phrase must be an action or event which is conventionally associated with a certain structure or set of activities (pp. 5-6)

Asudeh and Mikkelsen present the following pair (phonological phrasing is indicated by square brackets):

$$
\begin{aligned}
& \text { a. Min nabo [p købte hus] sidste år } \\
& \text { My neighbor bought house last year }
\end{aligned}
$$

\footnotetext{
${ }^{3}$ Or, at least, that the disease is spreading, and that the dying tress will be homogeneously distributed in the near future.
} 
'My neighbour did house-buying last year.'

b. \#Min nabo [p købte blyant] igår

My neighbor bought pencil yesterday.

Why is (18a) fine, while (18b) is bad? Borthen (2003) explains: "there are presumably more conventionally associated activities connected to buying a house than buying a pen, which is in accordance with the fact that in Danish, the action of buying a house can be expressed with a sentence that contains a bare singular referring to the house, whereas the action of buying a pen cannot" (p. 94).

Incorporated mominals, however, do not always denote a stereotypical activity. Just like with generic and existential bare plurals, incorporated nominals sometimes indicate homogeneity.

In his discussion of verbal incorporation in Chukchi, Dunn (1999) notes that:

the stem qora-nm-at - 'slaughter reindeer'... refers to something which, in Chukchi culture, is a unitary activity and is exceptionally nameworthy as a focus of ritual activity and the high point of a day... this incorporation... only refers to reindeer-killing in its traditional Chukchi cultural context, i.e. killing of a domestic meat reindeer with a knife in the prescribed manner with all attendant ritual" (p. 223, my emphasis).

This traditional manner of killing reindeer is unitary, i.e. presumably homogeneous, and gives rise to a number of inferences (e.g. about the fact that the animal is domestic, that the killing is done with a knife, etc.), which anyone familiar with the Chukchi culture may draw.

\subsection{Goal Arguments}

We have seen that bare goal arguments imply stereotypicality. This cannot, however, be the only factor. If it were, we would expect sentences like (19) to be fine, and to imply that my brother went to the beach to perform the stereotypically associated activity (bathing).

*My brother went to beach

The fact is, however, that (19) is bad. Why, then, is (8), repeated below, good?

$$
\text { My brother went to }\left\{\begin{array}{l}
\text { church } \\
\text { jail } \\
\text { school }
\end{array}\right\} \text {. }
$$

The explanation I propose is that churchgoers, prison inmates, and school children are fairly homogeneous groups, and many inferences can be made about them. If we learn that the speaker's brother belongs to one of these groups, there is a fair amount of information we can infer about him. In contrast, this is not the case for beachgoers. What inference can we draw about the speaker's brother on the basis of his going to the beach?

\subsection{Dutch Predicate Nominals}

Perhaps the clearest case of bare nominals that give rise to an implication of homogeneity is provided by Dutch predicate nominals, studied by de Swart, Winter, and Zwarts (2004). For example, (21a), which uses a bare nominal, implies that being a manager is Henriëtte's job. In contrast, (21b) merely says that Henriëtte has administrative duties.

(21) a. Henriëtte is manager.

'Henriëtte is manager' 
b. Henriëtte is een manager.

'Henriëtte is a manager'

The class of managers is a much more homogeneous group that than of people with administrative duties. Hence, from (21a), but not from (21b), we can infer all sorts of facts about Henriëtte; this is why (21a) uses a bare nominal, while (21b) does not.

To give another example, (22a) implies that Marie's husband is literally a dictator, while (22b) merely expresses the statement that he behaves in a dictatorial fashion.

(22) a. Maries echtgenoot is dictator.

'Marie's spouse is dictator.'

b. Maries echtgenoot is een dictator.

'Marie's spouse is a dictator.'

Again, we can draw many more inferences about Marie's husband if we know that he belongs to the homogeneous group of country leaders who are dictators; we can tell much less about him just on the basis of his dictatorial behavior.

One more example is provided by the sentences in (23).

(23) a. hij is visser

'He is a fisherman'

b. hij is een visser

'He is fishing'

While (23a) says that he belongs to the rather homogeneous group of people whose profession is fishing, (23b) merely says that he is fishing at the time of utterance. Clearly, we can infer much more from the former than from the latter interpretation.

The phenomenon of class qualifiers provides evidence that what is at issue here really is homogeneity. These are qualifiers that are used when the predicate is taken to indicate that the argument belongs to a certain class. Significantly, such qualifiers are possible with the bare form of the predicate nominal, but not with the explicit indefinite form:

a. Jan is $\left\{\begin{array}{l}\text { advocaat van beroep } \\ \text { Belg van nationaliteit } \\ \text { christen van religie }\end{array}\right\}$.

b. * Jan is een $\left\{\begin{array}{l}\text { advocaat van beroep } \\ \text { Belg van nationaliteit } \\ \text { christen van religie }\end{array}\right\}$.

Jan is $\left\{\begin{array}{l}\text { a lawyer by profession } \\ \text { of Belgian nationality } \\ \text { of the Christian faith }\end{array}\right\}$. 
Thus, the predicate nominal indicates that Jan belongs to the group of professional lawyers, Belgian nationals, or religious Christians; all these groups are perceived (rightly or wrongly) to allow the hearer to draw some inferences about Jan.

Compare the above to Borthen's characterization of the type of cases that allow bare singular objects in Norwegian. She notes that the bare singular is fine in sentences like those in (25), but bad in sentence such as those in (26).

(25) a. Hun er kontorist.

she is clerk

'She is a clerk.'

b. Hun er bellonamedlem.

she is Bellona-member

'She is a Bellona member.'

(26) a.??Per er liten gutt.

Per is little boy

'Per is a little boy.'

b. */??Han er kjernekar.

he is splendid-chap

'He is a splendid chap.'

Borthen's explanation of these facts notes that the properties predicates in (25) denote homogeneous groups, whereas those in (26) do not. In her own words:

One particularly prominent and frequently relevant contextual frame for humancommunication, is the macro social frame. For Norwegian, this means the Norwegian society. In this frame, human beings are categorized relative to certain properties. Job, political affiliation, and religion, for instance, are all important properties of individuals because the society or community is organized in terms of these properties; rules make reference to them, money is being distributed according to them, and people are listed and kept track of according to them. On the other hand, being or not being-let's say—a splendid chap, a little boy, or a boring woman, for instance, might be of importance to these individuals' friends, but in the macro social frame these properties are irrelevant; no rules refer to them, no money is being distributed according to them, and presumably no lists of splendid chaps, little boys, or boring women exist anywhere in the system (p. 126).

\subsection{Inference and Preference}

It should be emphasized that homogeneity and stereotypicality are quite distinct concepts. While it might be argued that stereotypicality is the unmarked interpretation, no such argument can be made for homogeneity. Indeed, there is no reason to assume a-priori that the domain of inference is homogeneous-in most cases, this will not be so. Hence, the implication of homogeneity is actually quite informative, and is therefore not simply the unmarked reading. 
I propose, then, that the crucial notion is not unmarkedness, but aid to inference. We prefer an interpretation not on the basis of how easy it is to assume it, but on the basis of its potential to support inference.

Using the notation of Bidirectional Optimality Theory, this means that

$\langle\mathrm{A}, \tau\rangle \succ\langle\mathrm{A}, \tau$ ' $\rangle$ if $\tau$ aids inference, by either:

1. being more stereotypical, or

2. by implying that the domain of inference is homogeneous.

At this point, I ought to clarify what I am not saying. It is not my claim that every stereotypical or homogeneous statement is expressed using bare nominals. Clearly, there are other ways to express these notions. However, I am claiming the converse: namely, that every use of bare nominals implies that inferences are facilitated, either because the interpretation is stereotypical, or because the domain of inference is homogeneous.

\section{Is the Form Unmarked?}

We have seen that the preferred interpretation is not necessarily the unmarked one, as claimed by Bidirectional Optimality Theory, but the one that best supports inferences. What about the form? Is the preferred form the unmarked one? Or does an alternative factor apply here as well?

\subsection{The Data}

Bare nominals are, in a sense, underspecified: they leave out the determiner. There is some reason to believe that underspecified interpretations are preferred (Krifka 2002). But what about underspecified forms?

Obviously, a bare nominal is shorter than a full DP. It is therefore arguably easy to produce. We could therefore say that bare nominals are preferred, because it takes less effort to produce them.

There is, however, a problem with this idea: what is expressed by a bare nominal in one language, is expressed by a definite determiner in another. We can see this in all four forms of bare nominal we have considered.

\section{(i) Generic plurals}

While generic plurals are bare in English, they are explicitly definite in Romance. Thus, the translation of (1) into Spanish is:

(27) Los cuervos son negros.

'The ravens are black'.

\section{(ii) Existential plurals}

In Romance, existential plurals that imply stereotypicality/homogeneity are not bare, but rather definite. Thus, the translation of (2a) into Italian is:

(28) Questo trattore ha le ruote (G. Longobardi, pc)

'This tractor has the wheels'.

\section{(iii) Incorporated nominals}

Carlson (2005) notes that incorporated nominals are often translated into English as definites:

a-urapá-pirár (Tupinambá-Mithun 1984) 
I-bow-open

'I draw my bow'

(30)

Nej-Ek 'ElE-lgE-g'i (Chukchi-Polinsky 1990)

hill-LOC snow-melt-3SG.S

'On the hill, the snow melted.'

\section{(iv) Goal arguments}

In Spanish, instead of bare nominal goal arguments, we have definites. Thus, the translation of (8) is:

$$
\begin{gathered}
\text { Mi hermano fue a la }\left\{\begin{array}{l}
\text { iglesia } \\
\text { carcel } \\
\text { escuela }
\end{array}\right\} . \\
\text { 'My brother went to the jail }
\end{gathered}
$$

\subsection{Definites as a Last Resort}

It appears that we can draw the following generalization: languages that can use a bare nominal in the constructions we have discussed, do so. Languages that cannot, use a definite, rather than an indefinite, instead. While it makes sense to assume that a bare nominal is easier to produce than an overt indefinite, could we also argue that a definite is easier to produce than an indefinite?

I would like to offer a speculative affirmative answer to this question. Definites are obviously more prominent than indefinites on the definiteness hierarchy (Comrie 1989). This hierarchy has considerable explanatory power, and has been correlated with other prominence hierarchies. For example, subjects are more prominent than objects, and animate individuals are more prominent than inanimate ones. It turns out that subjects are more likely to be definite, while objects are more likely to be indefinite. This, indeed, has been seen as an explanation for the phenomenon of Differential Object Marking: "the most natural kind of transitive construction is one where the [subject] is high in animacy and definiteness, and the [object] is lower in animacy and definiteness; and any deviation from this pattern leads to a more marked construction" (Comrie 1989, p. 128). Hence, some languages have a special way of marking definite objects (sometimes in addition to specific indefinite objects), contrasting them with indefinite ones.

If definites are higher on the prominence scale than indefinites, they may be more easily accessible, hence easier to produce. Let us see how we can use this principle to account for the distribution of definites in the cases discussed here:

\section{(i) Generic plurals}

In Romance, BPs cannot denote kinds (Longobardi 2001). ${ }^{4}$ Elsewhere (Cohen 1996; 2005b), I argue that all generic readings, whether characterizing generics or direct kind predication, require reference to kinds. If this is granted, then Romance BPs cannot get generic readings. Consequently, a different construction is required to express genericity. Since definites are higher on the prominence scale than indefinites, they are chosen.

\footnotetext{
${ }^{4}$ Chierchia (1995) claims that this is not the case, but his arguments are rather weak; see Cohen (2005b) for discussion.
} 


\section{(ii) Existential plurals}

Although existential bare plurals are not topical (Cohen and Erteschik-Shir 2002), when they express stereotypiality or homogeneity, they are typically deaccented. Indeed, when stressed, they can only be read contrastively:
a. THIS tractor has wheels.
b. This tractor HAS wheels.
c. ?This tractor has WHEELS.

Thus, it is easy to accommodate a context where (32a) is acceptable (e.g. when comparing this tractor with some other, wheeless tractor). It is also easy to accommodate such a context for (32b) (e.g. when it is uttered as a response to someone who claimed the absence of wheels on the tractor). In contrast, (32c) is somewhat odd, and it is hard to think of a context where it would be acceptable-perhaps when used to correct another speaker's utterance that the tractor has, say, legs.

It is well known that Romance languages disprefer pragmatic deaccenting; hence, producing a bare nominal would not be so easy after all, since it would carry the cost of deaccenting. Consequently, definite plurals are actually easier. Since they are also easier than indefinites, being higher on the prominence scale, they are selected for production.

\section{(iii) Incorporated nominals}

English does not allow verbal incorporation. The most natural translation of an incorporated noun may be as a bare singular; however, English usually does not allow bare singulars in argument positions either. Hence, because of the prominence hierarchy, the best remaining option is to use definite singulars instead.

\section{(iv) Goal arguments}

Since Romance does not allow bare singulars in argument position, and since definites are more prominent than indefinites, a definite singular is produced instead.

\section{Conclusion}

We can conclude that the preferred forms are those that are easier to produce, and the preferred interpretations are those that aid inference. Applying the machinery of Bidirectional Optimality Theory, this results in the desired superoptimal form-interpretation pairs.

For example, with respect to the sentences in (2), the superoptimal pairs are:

1 <wheels, stereotypical interpretation>

2. <some wheels, non-stereotypical interpretation>

An interpretation can aid inference, hence be preferred, by either providing stereotypical information, or by indicating that the domain is homogeneous.

A form is preferred if it is easier to produce: this means that it is the shortest expression that is consistent with the constraints of the specific language spoken.

Plugging these constraints into Bidirectional Optimality Theory, it follows that bare nominals receive interpretations that are optimal for inference.

\section{References}

Asudeh, A.and L.H. Mikkelsen.(2000) .'Incorporation in Danish: Implications for interfaces.' In Cann,R.,C.Grover,and P.Miller (eds.): A Collection of Papers on Head-driven Phrase Structure Grammar. Stanford University. 
Atlas, J. and S.C. Levinson (1981) 'It-clefts, informativeness, and logical form: Radical pragmatics (revised standard version)', in P. Cole (ed) Radical Pragmatics. New York: Academic Press, 1-61.

Axelrod, M. (1990). 'Incorporation in Koyukon Athapaskan'. International Journal of American Linguistics 56(2), 179-195.

Blutner, R. (1998) 'Lexical pragmatics.’ Journal of Semantics 15(2): 115-162.

Blutner, R. (2000): 'Some aspects of optimality in natural language interpretation'. Journal of Semantics 17:189-216.

Borthen, K. (2003). Norwegian Bare Singulars. Doctoral Dissertation, Norwegian University of Science and Technology, Trondheim.

Carlson, G. (2005) 'The meaningful bounds of incorporation.' Talk presented at the Conference Indefinites and Weak Quantifiers, Brussels.

Chierchia. G (1995) 'Individual predicates as inherent generics.' In: G. N. Carlson and F. J. Pelletier (eds.): The generic book, 176-223. Chicago: University of Chicago Press

Cohen (1996) Think Generic! The Meaning and Use of Generic Sentences. Doctoral Dissertation, Carnegie-Mellon University. Published 1999, CSLI, Stanford.

Cohen, A. (1999) 'Generics, frequency adverbs, and probability. Linguistics and Philosophy 22: 221-253.

Cohen, A. (2004) 'Generics and mental representation'. Linguistics and Philosophy, 27(5), 529-556.

Cohen (2005a) 'More than bare existence: an implicature of existential bare plurals'. Journal of Semantics. 22: 389 - 400

Cohen, A. (2005b) 'The meaning of bare plurals: evidence from Italian.' Talk presented at the Conference Indefinites and Weak Quantifiers, Brussels.

Cohen, A.and N. Erteschik-Shir (2002). 'Topic, focus, and the interpretation of bare plurals.' Natural Language Semantics 6:339-405.

Comrie, B. (1989) Language Universals and Linguistic Typology, 2nd ed., University of Chicago Press, Chicago.

Declerk, R. (1986) `The manifold interpretations of generic sentences’ Lingua 68:149-188.

Dunn, M. (1999). A Grammar of Chukchi. Ph.D. dissertation, Australian National University, Canberra.

Greenberg, Yael: 1994, Hebrew nominal sentences and the stage/individual level distinction., Master's thesis, Bar-Ilan University.

Geurts B., (1985): 'Generics.' Journal of Semantics 4, 247-55. 
Horn, L. R.: (1984), 'Toward a new taxonomy for pragmatic inference: Q-based and R-based implicature', in D. Schiffrin (ed.), Meaning, Form, and Use in Context: Linguistic Applications, pp. 11-42. Georgetown University Press, Washington.

Horn, L. R.: (1993), 'Economy and redundancy in a dualistic model of natural language', in S. Shore and M. Vilkuna (eds.) SKY 1993: 1993 Yearbook of the Linguistic Association of Finland, pp. 33-72. The Linguistic Association of Finland, Turku.

Krifka, M. (2002) 'Be brief and vague! And how Bidirectional Optimality Theory allows for verbosity and precision.' In Sounds and systems: studies in the structure and change. A Festschrift for Theo Vennemann, eds. David Restle and Dietmar Zaefferer, 439-458. Berlin / New York: Mouton de Gruyter.

Longobardi, G. (2001) 'How comparative is semantics? A unified parametric theory of bare nouns and proper names' Natural Language Semantics 9, 335-369.

McCawley, J.D. (1978). 'Conversational implicature and the lexicon'. In: Syntax and Semantics 9: Pragmatics (P. Cole, ed.), pp. 245-259. Academic Press, New York.

Mithun, M. (1984). `The evolution of noun incorporation'. Language 62, 847-94.

Mulder, J. G. (1994). Ergativity in Coast Tsimshian (Smíalgyax). Universiry of California Press: Berkeley.

Polinsky, M. (1990). 'Subject incorporation: evidence from Chukchee.' In: Dziwirek et al. (eds.): Grammatical Relations: A Cross-Theoretical Perspective. Stanford: CSLI, 349364.

de Reuse, W. (1994) 'Noun incorporation in Dakota (Siouan).' International Journal of American Linguistics 60(3), 199-260.

Rischel, J. (1983) 'On unit accentuation in Danish - and the distinction between deep and surface phonology.' Folia Linguistica 17:51-97.

de Swart, H., Y. Winter and J. Zwarts (2004) 'The interpretation of bare predicate nominals in Dutch'. Unpublished ms. 


\title{
Mention Some of AlL*
}

\author{
Paul Dekker, \\ ILLC, Universiteit van Amsterdam
}

p.j.e.dekker@uva.nl

\begin{abstract}
In the interpretation of natural language one may distinguish three types of dynamics: there are the acts or moves that are made; there are structural relations between subsequent moves; and interlocutors reason about the beliefs and intentions of the participants in a particular language game. Building on some of the formalisms developed to account for the first two types of dynamics, I will generalize and formalize Gricean insights into the third type, and show by means of a case study that such a formalization allows a direct account of an apparent ambiguity: the 'exhaustive' versus the 'mention some' interpretation of questions and their answers. While the principles which I sketch, like those of Grice, are motivated by assumptions of rationality and cooperativity, they do not presuppose these assumptions to be always warranted.

Key words: natural language interpretation, dynamic semantics, semantics-pragmatics interface, Gricean pragmatics, epistemic logic, decision theory.
\end{abstract}

In the interpretation of natural language one may distinguish three types of dynamics, which, though obviously related, can be studied relatively independently. Firstly, there are the acts or moves that are made, assertions, questions and answers, commands and permissions, etc. The first two categories have been studied by Stalnaker, Groenendijk and Stokhof, Heim and Veltman, to name a few. Secondly, the strict interpretation of these moves are interrelated in that there are structural relations between subsequent moves such as anaphoric dependencies, ellipsis configurations, and discourse relations, all of which have to be resolved. The work on these subjects is so numerous that it is even impossible to mention here only the most important ones. While this second type of dynamics is of an arguably 'local' nature, which can be studied by focusing on move-pairs, or small sequences, I will argue that the third type of dynamics requires one to take a 'global' perspective, which takes into account (assumptions about) the beliefs and intentions of the participants in a language game. I will generalize and formalize Gricean insights into these subjects, and show by means of one case study that such a formalization allows a direct account of an apparent ambiguity: the 'exhaustive' versus the 'mention some' interpretation of questions and their answers. While the principles which I sketch, like those of Grice, are motivated by assumptions of rationality and cooperativity, they do not presuppose these assumptions to be always warranted. In this small paper I will not provide much technical details, but confine myself to sketching and illustrating the main ideas.

I will proceed as follows. In the first two sections I present the basic concepts of the semantics of declaratives and interrogatives, and of the dynamics of questions and their answers. I present

\footnotetext{
*Various versions of this paper have been presented at the UCLA Linguistics Department in 2003, the 5-th LLC Symposium in Tbilisi 2003, Sinn und Bedeutung VIII in Frankfurt 2003, the ILLC Amsterdam in 2004, the IKP in Bonn 2004, LoLa8 in Debrecen 2004, the workshop Sémantique et Modélisation in Paris 2005, and of course Sinn und Bedeutung $\mathrm{X}$ in Berlin 2006. I thank the audiences for constructive criticisms and inspiring comments. The work reported on has been funded by a grant from the Netherlands Organization for Scientific Research (NWO) for the project Formal Language Games, which is gratefully acknowledged.
} 
the main ideas only, and only the main concepts to be used later, as they can be deemed quite classical and because they are defined and discussed at length at various other places. In section 3 I present the notion of an 'optimal discourse', a reinterpretation of Grice's conversational maxims which does not serve as a set of categorial imperatives, but as a measure to explain other people's discourse moves, and to motivate those of one's own. In section 4 it is shown how this notion can be used to explain, on the basis of the exhaustive semantics from the first two sections, the non-exhaustive interpretation of questions and answers in specific cases. Section 5 sums up the results and establishes directions for future work.

\section{The Semantics of Declaratives and Interrogatives}

According to a long and widely respected tradition, the spirit of which can be traced back to the work of Gottlob Frege, the meanings of declarative sentences can be equated with their truth-conditions. As Wittgenstein has put it: "Einen Satz verstehen, heißt, wissen was der Fall ist, wenn er wahr ist." ("To understand a proposition means to know what is the case, if it is true," Tractatus Logico-Philosophicus, Satz 4.024.) Declarative sentences are used to convey information about the world, and if you know what the world ought to be like in order for such a sentence to be true, you grasp what the world is like if someone sincerely asserts such a sentence, and is not misguided. It is important to emphasize that one does not need to know whether such a sentence is true, because then an assertion of it would hardly be informative; the main point of asserting declarative sentences resides in communicating information which has not been established before.

This idea can be fleshed out in a Tarskian fashion by a recursive definition of a satisfaction relation $\models$ which defines truth of a formula relative to a model and/or world, and a number of parameters relevant to the interpretation of the formula, such as those that determine the interpretation of overt or covert pronouns, and that of, slightly more technically, free variables. In the remainder of this paper such a satisfaction relation is taken for granted.

The meanings of interrogative sentences can be understood in a similar fashion. According to the classical doctrine, set out by Hamblin, Karttunen, and Groenendijk and Stokhof, knowing the meaning of an interrogative sentence equals knowing the conditions under which it is answered, so that the meanings of interrogatives can be equated with their answerhood-conditions. Again, one does not need to be taken to know, in order to understand a question, what is the full and true answer to it, what is relevant is that one knows, what, in various circumstances, counts as a full and true answer. A uniform and perspicuous implementation of this idea has been given in (Groenendijk and Stokhof 1984), where a question is conceived of as a function, which in each circumstance or world defines the full and true answer to the question in that world, and effectively this cuts up logical space into a partition in which worlds are grouped together iff they define the same full and true answer; in turn this corresponds to an equivalence relation over the set of possibilities such that two possibilities are taken as equivalent for the question iff the same full and true answer holds there, and relevantly different iff not. Before I illustrate this notion of the meaning of a question, it must be emphasized that it is a purely semantic, if one wants Fregean or Platonic, notion. More pragmatic notions of answerhood have been presented in terms of this notion already in Groenendijk and Stokhof's work, and a more fine-tuned practical interpretation of actual answers given will be discussed below.

Questions can be understood, in general, as querying the values of a (possibly empty) list of variables. In case the list is empty, we are dealing with a polar, or 'yes'/'no'-question like ? $p$ ("Does it rain in California now?"). The answers will be the singleton set containing the empty sequence (the truth value 1) in case it is indeed raining in California, or the empty set (the truth 
value 0) in case it is not. This cuts up the space of possibilities in two blocks, one block of possibilities in which it rains in California, and one block of those in which it doesn't. More structure is generated by constituent, or Wh-questions. Consider the following question, with associated gloss:

Who will come to the banquet? $(? x C x)$

A full and true answer specifies, in each possibility, all of those whom come in that possibility, and, moreover, that nobody else comes. Effectively, this renders possibilities equivalent iff exactly the same persons come to the banquet in those possibilities, and if at least one person comes in one possibility and not in another, then they are rendered distinct. If, for the purpose of exposition, we assume the domain contains only two relevant individuals, $a$ and $b$, the meaning of the question can be displayed as follows:

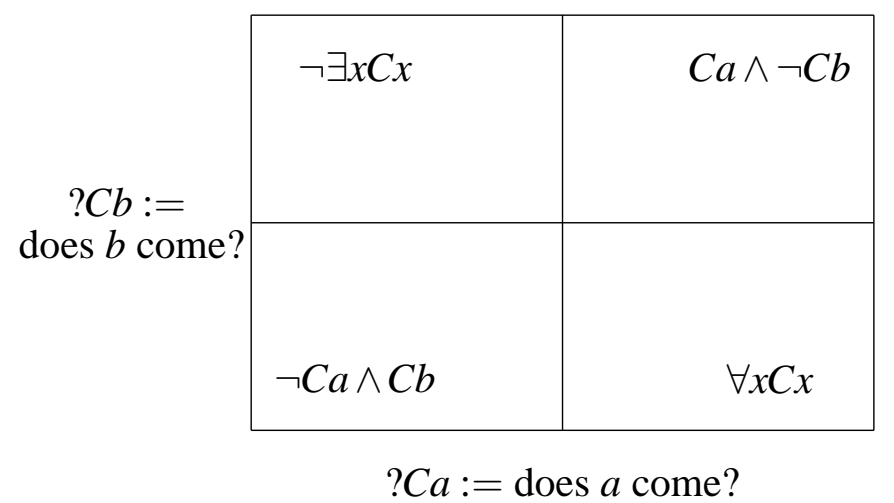

The question queries, for each individual, i.e., $a$ and $b$, whether that individual comes. The conjunction of the questions whether $a$ comes and whether $b$ comes cuts up logical space into four parts: one block of possibilities in which both answers are negative (none come), two blocks of possibilities in which only one of them comes (only $a$ and only $b$, respectively), and one block of possibilities in which both come. Once one knows in which of these blocks the actual world resides, one knows the full and true answer. This approach generalizes to multiple Wh-questions like:

(2) Who gave what to whom? (?xyz Gxyz)

This question asks for a specification of the give-relation; in any possibility it will have to specify the full set of triples which stand in the give-relation, together with the specification that no other triple stands in that relation.

As may be clear from this exposition, the semantics of questions is taken to be an exhaustive one. The various (semantic) answers to a question are exhaustive answers in that they specify the full and exact set of values of a given predicate or relation. (This is the same in case of polar questions, but then there is only one possible value: the empty sequence.) As we will see below, this does not mean that actual answers given need to be understood this way-they can be felicitous when they only partially answer a question, and even questions themselves can be felicitously understood as querying only a partial specification. For now, however, it is more important to observe three things. Firstly, this semantic notion of answerhood underlies a uniform notion of entailment in terms of $\subseteq$, also indicated by means of $\models$, which corresponds to logical entailent if it relates two declaratives, which corresponds to answerhood if it relates a declarative and an interrogative, and which corresponds to question subsumption if it relates two interrogatives. That is, all of the following are valid: 


$$
\begin{aligned}
& \forall x C x \models C a \\
& \forall x(C x \leftrightarrow x=a) \models ? x C x \\
& ? x C x \models ? C a
\end{aligned}
$$

Secondly, as observed by van Rooij (2003), a partition theory of questions naturally links up with decision theory, both intuitively, as well as technically. That is, an agent's decision problem may also be modeled by a partition of logical space, to the effect that the blocks in the partition correspond one to one to the alternative actions the agent has to choose from. In the example above, our protagonist may be wondering whether or not go to the banquet, and whether or not to advise Kata to go there. If none of $a$ and $b$ come it might be good to go together; if only $a$ comes, I might better go alone and if only $b$ comes Kata might better go alone; if both $a$ and $b$ come, Kata and me might better stay home both of us. Once I have a full answer to the semantic question displayed above, I know in this case what to do.

The very same situation can be used to make the third and final point. If my question indeed is whether or not to go to the banquet, and whether Kata should go there, the relation between the question meaning and my decision problem is mediated by a number of assumptions, for instance that it is fine for me to go there with $a$ only, and not for Kata, and that it is no good for me to be there with only $b$, while this is no problem for Kata, etc. My predicament therefore better be displayed as follows:

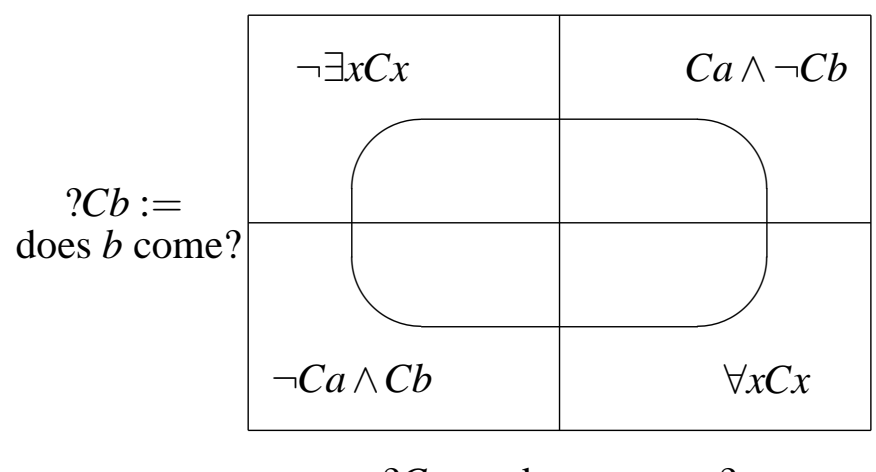

$? C a:=$ does $a$ come?

where the oval distinguishes the possibilities I conceive of as maybe actual from those I have already excluded. If it so happens that the actual world lies, say, in the left bottom block outside of the oval, and you know it, you might truly and rightfully answer that only $b$ comes; however, this might not appropriately solve my decision problem, because this might be one of these worlds I have mistakenly excluded because it is one in which indeed it is a problem for Kata to be with only $b$ and not for me. For the remainder it is important that questions faced ("Will I go the banquet? Should Kata go as well?") are not literally the same as those posed ("Who come to the banquet?"); yet, against the background of my information, it is assumed that the latter entails the first, according to the notion of $\models$ sketched above.

\section{The Dynamics of Questions and Answers}

Stalnaker (1978) presents it as two of four 'truisms' that the content of an assertion can be dependent on the context in which it occurs, and that assertions affect, and are intended to affect, this context. The interpretation of pronouns, for instance depends on the specific contexts in which they are used, and certain presuppositions may or may not be acceptable as a consequence of the information available in the context in which they are triggered. The context next, will be altered to the effect that the interlocutors can take it for granted that a certain assertion has been made, and, if no objections are made, that its contents are added to the stock of com- 
mon knowledge. Although, it seems, Stalnaker regards these as observations belonging to the realm of pragmatics (Stalnaker 1998), they have been taken up in indeed quite of few formal systems of interpretation: Kamp's discourse representation theory, Heim's file change semantics, Groenendijk and Stokhof's dynamic predicate logic, and Veltman's update semantics, to name but a few. Whereas in each of the mentioned systems the concept of a context is adapted to their various purposes, they all implement the idea that the interpretation of discourse resides in a step-wise update of information.

Interrogatives have been accommodated into this picture as well, in various ways. The idea is that, while it is assumed that indicatives are used to add information to the context, interrogatives are used to add questions, in the semantic sense described in the previous section (Ginzburg 1996, Groenendijk 1999, Hulstijn 2000, Jäger 1996, Roberts 1996). The general idea, the first type of dynamics sketched above, thus consists of conceiving of the interpretation of a discourse as a step-wise update of a 'common scoreboard' (Lewis) with information and questions, and under the assumption that, in general, the information provided resolves the questions asked.

The second type of dynamics is of an, arguably, more instrumental nature. Questions and their subsequent answers may hang together in a more structural manner than one can account for according to the platonistic view sketched in the previous section. This already holds for two assertions by the way. Most of the mentioned dynamic theories of interpretation expand upon the fact that the use of a certain type of term (a name, a definite or indefinite description) may be associated with a witness as its value which can be referred back to by means of a pronoun in a subsequent assertion-while this does not (need to) hold for a truth-conditionally equivalent assertion which does not employ such a term. One of the arguments of a structured meanings approach to questions (von Stechow 1991, Krifka 1991), as against the propositional one sketched above, is that something similar holds for question-answer pairs.

Consider the following two questions:

Is it raining?

Is it not raining?

Besides some clearly pragmatic overtones, these questions are equivalent on the propositional approach, since their propositional answers are "It is raining." and "It is not raining." They are not fully equivalent, though, since an elliptical answer like "Yes." ("No.") to the first may mean something different than when it answers the second. Similarly:

Who is coming to the banquet?

Who is not coming to the banquet?

can both be taken to ask for a full specification of who is, and who is not coming to the banquet. Yet, a constituent reply like "Susanne and Wilfrid." will be interpreted differently in response to these two questions. These facts have also been observed by Groenendijk and Stokhof and they already submitted that, for a proper interpretation of these questions and their elliptical answers, one needs to have access to the abstracts associated with these questions, precisely the moral advocated on the structured meanings approach. Roughly, the idea is that example (1) queries that set of individuals coming, and example (6) the set of individuals not coming. Even though either set determines the extension of the other, they are obviously not the same, and thus they can help to characterize the relevant difference between the above two pairs of examples. 
These observations have been implemented in an update semantics in (Aloni, Beaver and Clark 1999) and (Dekker 2003). While the papers only provide for a minor structural extension of the semantics of questions, they allow one to deal with the dynamics of question-answer pairs as indicated above, and in principle also of a kind of topical restriction like we find in the following examples. As Jäger (Jäger 1996) observed, an answer like:

Only Socrates is wise.

means something different as a reply to the following two questions:

Who is wise?

(9) Which Athenian is wise?

In reply to the first, it asserts that Socrates is the only wise person, while in reply to the second it only asserts that Socrates is the only wise Athenian. Also, if $A$ asks:

Which students join the trip?

then $B$ 's counter question:

Who want to join?

can be taken to mean which students want to join. And we can also identify a difference between the following assertions with 'embedded questions':

(12) Mary was surprised who came.

(13) Mary was surpised who did not come.

Finally, using a technique deriving from (Zeevat 1994),

Who gave what to whom?

John a book to Mary.

Jane a funny hat to some hippie.

Somebody else all her recordings of "Friends" to Denise.

And nobody anything to anybody else.

can be interpreted totally compositionally. While the underlying notion of a question is exhaustive, the various answers can be interpreted as partial answers, while the closing statement is eventually interpreted as telling us that the full exhaustive answer has by now been given. See (Dekker 2003) for details.

\section{The Pragmatics of Questions and Answers}

The two types of dynamics discussed in the previous section will be assumed in the explanation of the third type, in this section, but they are not sufficient to motivate it. The fact that certain questions are asked, and certain assertions are made, nor structural relations between the two, may help explain what is the intended or interpreted relevance of the two. So, while it is obvious 
that John comes to the banquet, and no other students do. can be relevant in response to a question Who will come to the banquet?, almost any other utterance (indicative or interrogative) can be relevant as well. This has already been noticed in (Groenendijk and Stokhof 1984), and (van Rooij 2003) gives a decision-theoretic explanation of the facts, in quantitative terms. In (Dekker 2004) I have argued that an intuitive, qualitative explanation along the lines of Grice can be furthered as well, as long as we do not give an imperative interpretation to these maxims, and formalize them sufficiently generally.

What is the point of posing questions and making assertions? There can be many such points, including that of keeping the conversation running, testing agreement, establishing face, making fun, etc. Focusing on inquisitive discourse, or games of information exchange, we may assume that the interlocutors come with their own questions (in relation to decision problems, or just out of interest) which they seek to be answered in a reliable and comfortable way. Bearing this in mind, we can say that a discourse is optimal iff the participants' questions are answered, to the best of the knowledge of all of the participants, and indeed in an efficient or otherwise convenient way.

Before I make this idea relatively precise, it is important to identify one difference with Grice's statement of the facts or principles. Grice's maxims are formulated as imperatives about how to behave in a rational and cooperative dialogue; I only want to state a notion of what would be an optimal dialogue, a notion against which actual dialogue facts can be evaluated. Even when we are engaged in an inquisitive discourse, facts of life have it that things need not be optimal: we can fail relevant information, we can fail the means to query the right type of information, and we can misjudge what is the most efficient or convenient way to achieve the intended result; besides, we may be right or wrong in assuming that our interlocutors are rational and cooperative. When engaged in a conversation, we may have to be well aware of all these possibilities. (See, however, work of Alexandru Baltag, Anton Benz, Robert Stalnaker and Ede Zimmermann for some of the philosophical and technical pitfalls in playing with notions of uncooperativity and irrationality.)

With the previous comments in mind, I have proposed the following notion of an 'optimal discourse' in (Dekker 2004), which is modeled after Grice's division into four maxims:

Definition 1 (Optimal Inquiry) Given a set of interlocutors $A$ with states $(\sigma)_{i \in A}$ a discourse $\Phi=\phi_{1}, \ldots, \phi_{n}$ is optimal iff:

$$
\begin{array}{lr}
\text { - } \forall i \in A: D([[\Phi]]) \cap D\left(\sigma_{i}\right) \models \sigma_{i} & \text { (relation) } \\
\bigcap_{i \in A} D\left(\sigma_{i}\right) \models D([[\Phi]]) & \text { (quality) } \\
\Phi \text { is minimal } & \text { (quantity) } \\
\Phi \text { is well-behaved } & \text { (manner) }
\end{array}
$$

The requirement of relation requires an optimal discourse to answer all questions of all interlocutors. The information provided by $\Phi$ is hoped to answer the questions in any state $\sigma_{i}$. That of quality requires these answers to be supported by the data which the interlocutors had to begin with. These two requirements are defined in full formal rigour in (Dekker 2004). The requirements of quantity and manner are deliberately left underspecified, but they ought to come with some intuitive understanding.

When agents engage in a cooperative conversation, it is reasonable that they make clear what questions they have, and that they provide information which they have support for. The above notion of an optimal inquiry accounts for this, but it also serves to guide agents in a dialogue in which the conditions are not guaranteed to be optimal. 
Let us first look at an optimal situation. Suppose $A$ wishes to know whether Sue comes to the banquet (?s), and $B$ wants to know whether Tim comes to the banquet (?t), and assume that $B$ knows that Sue will come, and that $A$ knows that Tim will not come if Sue comes. The following dialogue is optimal then:
A: Will Sue come?
B: Yes.
Will Tim come?
$A$ : No, not if Sue comes.

Both questions are answered, by information which was initially there distributed over the two original information states. The discourse is also quite minimal, and, depending on one's standards, well-behaved.

Example (15) can be used to show that some standard felicity requirements (like informativity, non-redundancy, consistency, and congruence of answers with questions) can be derived from the notion of an optimal discourse. More interestingly, it can also be used to explain why certain dialogues are perfectly reasonable also if certain contributions are not direct replies to questions posed just before, or if questions posed differ from questions faced. Information management may need more sophistication because understanding actual discourse requires reasoning about beliefs and intentions (epistemic logic and decision theory).

Even if we do not take into account any suspicions about irrationality or uncooperativity, the following situation must be telling. Suppose I am wondering whether or not to go to the banquet tonight. Being an academic, I don't say to myself: "Go there and have fun," but I count my blessings. I'd like to talk to professors $A$ and $C$, but there are some complications. If, besides professor $A$, professor $B$ is there as well she will absorb $A$, if $B$ doesn't absorb professor $C$, that is, if $C$ is not absorbed by professor $D$; furthermore, if neither $B$ and $C$ are present, $D$ will absorb $A$. This is not an abnormal academic situation. The following table lists the configurations under which it is appropriate for me to go (given that my assumptions about $A, B, C$ and $D$ are right, of course):

\begin{tabular}{|c|c|c|c|c|}
\hline & $C \& D$ & $C \& \neg D$ & $\neg C \& D$ & $\neg C \& \neg D$ \\
\hline$A \& \quad B$ & - & + & - & - \\
\hline$A \& \neg B$ & + & + & - & + \\
\hline$\neg A \& \quad B$ & - & - & - & - \\
\hline$\neg A \& \neg B$ & - & + & - & - \\
\hline
\end{tabular}

All I want to know is if I am living in a + or - world, which corresponds to a positive or negative decision about going to the party, and which basically is a polar (Yes/No-) question. I could ask:

Will I go to the party? (?Ci)

which, normally, is a stupid thing to ask, of course, in an academic environment. The question I face is a polar one so, in order to characterize my question I have to ask you whether I am in one of the + or - worlds. This is somewhat awkward. One of the most minimal 'linguistic' means to distinguish the + from the - worlds that I could find is rendered by the following formula:

$$
(A \text { AND }[(\neg B \text { AND }(D \rightarrow C)) \text { OR }(B \text { AND } C \text { AND } \neg D)]) \text { OR }(C A N D \neg B \text { AND } \neg D) ?
$$


Nobody will be happy answering (or even interpreting) a natural language analogue of this. Instead, I could ask:

Who come? $(? x C x)$

Formally, and semantically speaking, this asks for more than I need to know: not just whether I am in a + or - configuration; rather, it asks in which of the 16 possible situations I am in the configuration displayed above. Even so, any answer to this question entails an answer to the question I face (the publicly posed question formally entailing the first one I really face), so the question makes sense, and, as we can see, question (18) is much more convenient than question (17).

The upshot of this discussion is that we can ask for more information than we actually need, formally speaking. This observation can be strengthened by means of the sequence that possibly follows an utterance of (18). A partial answer to (18) may be:

Arms will not come, but Baker does... .

In the situation sketched this would already be sufficient to resolve my decision problem. All possibilities in which Arms does not come but in which Baker does, are ones in which it does not make sense, I think, to go to the banquet. (Inspect the third row of the table, which contains only -'s.) So, even though you are not aware of my predicament, and do not know how to sort out to fulfill the purpose of giving a full exhaustive answer to my question (18), I can stop you by saying: "I know enough, thanks, I will not go myself; but let this not stop you from going there yourself." (Kind, and irrelevant, as I am.)

The upshot of this discussion is twofold. Again, as in section 2, we face a question actually posed which does not exactly match a question actually faced. This time, however, a pragmatically partial answer to a question posed may serve to definitely settle a question actually faced. What is more, such a resolving partial answer may be anticipated, and this fact brings to bear on a quite theoretical issue, that of the exhaustive versus mention-some understanding of questions and answers in general. If a partial answer to a question, semantically understood exhaustively, can be reasonably interpreted as being settling, pragmatically, then both the semantic ('exhaustive') interpretation can be saved, as well as its pragmatic ('mention some') interpretation.

\section{An Application: "Mention Some"}

In the academic debate there is extensive discussion about the issue whether or not an 'exhaustive' or a 'mention some' meaning of interrogatives should be taken as basic, even though this issue is not represented by polemics in the standard journals. The issue is 'academic' in that, in general, both approaches are intertranslatable to a certain firm degree. Exhaustive interpretations of questions entail mention-some ones, and exhaustive sets of mention-some replies to questions equal their exhaustive answers. In this paper I have taken an exhaustive semantic interpretation as basic, and allowed for a natural pragmatic interpretation of partial, or 'mention some' answers, basically, like Groenendijk and Stokhof (1984) did. Before we evaluate this proposal, it makes sense to inspect some examples that have been put forward to argue for the opposite approach.

The following examples typically have a 'mention some' interpretation: 
Who's got a lighter?

How can I open a .gzip file?

How do I get to the station?

Where do they serve Thai food?

Intuitively, one instantiation of the queried variable (Wh-term, How- or Where-phrase) may serve to answer these question satisfactorily. They don't seem to be used, in general, to query all of their possible values. One light is enough to light a cigarette; nobody seems to be interested in all possible ways to open .gzip files; certainly nobody needs an explanation of the infinite number of ways in which one can reach the station; and one good Thai restaurant nearby will serve my purpose, not necessarily knowing all of the ones around.

Do these examples speak against an exhaustive semantics of questions? I don't think so. Two observations are in place first. All of the above questions can be used to ask for exhaustive specifications in the first place, and one really needs little imagination to see so. If there has been a big fire, and lighter owners are suspect, then the inspector asking (20) is most probably interested in the whole set of lighter owners, not just an occasional one who can light Kojak's cigar. Similarly for the other examples. In the second place, any exhaustive answer to these questions entails one or more of the possibly required mention some replies. This is simply so by definition.

The only question seems to be, then, why to raise an issue ("Who's got a lighter?") while a semantically more simple issue ("Has anybody got a lighter?") is at stake? Any smoker with some linguistic interest, and any linguist with some interest in her smoking colleagues, can figure out the answer.

I do not believe there are hard and fast arguments against or in favor of exhaustive readings of questions and their supposed answers. I do have qualms, however, like Grice, against positing ambiguities though. One line of explaining the facts is advocated here: a speaker can expect the hearer to realize that her decision problem is more difficult to formulate than the question actually posed and that the latter entails the first. This part of the show can be adequately formalized, as has been done before. I have doubts about the other way around, but, of course, my doubts by themselves don't constitute an argument.

To round up this paper, I would like to discuss in some detail a typical 'mention some' example. Consider again example (23):

Where do they serve Thai food?

Just to be sure, this example can naturally be used on an exhaustive interpretation, and any exhaustive reply will satisfy any 'mention some' demands of the questioner. Even so, it seems, people tend to think it is typically used with a 'mention some' interpretation.

But now wonder what will be the predicament of someone who comes up with such a question with such an interpretation. Simplifying matters, we can imagine you on a junction where you can go North, East, South and West; your intention is to have good Thai food. Your decision problem resides in choosing one of the four directions, but the chosen one must be taken to lead to a nice Thai restaurant. The question you face, and which does not make much sense to pose, is "Where do I go?" If we translate this question into a relevant one about the facts of the matter, it could be something like the conjunction of the following four: 
(24) Will I go North and find a nice Thai restaurant?

Will I go East and find a nice Thai restaurant?

Will I go South and find a nice Thai restaurant?

Will I go West and find a nice Thai restaurant?

The four questions are mutually exclusive, as is required on a partition approach. All four of them are also based on the assumption that you do find a nice Thai restaurant, a presupposition which can be cancelled of course. (Like we saw before in our discussion of example (18), it may be acutely relevant to dismiss such presuppositions if they are not obviously satisfied.)

Let us assume that there is indeed a nice Thai restaurant around, even in all of the four possible directions. Still the conjunction in (24) is quite laborious and even oppresive. Instead, you might ask (23) and you and I will be sensible enough to figure out that question (24) is what you aim to find out.

A pragmatic explanation of 'mention some' interpretations of questions which are assumed to be exhaustive semantically, of course does not suffice to explain 'mention some' interpretations of embedded questions (Beck and Rullmann 1999). On a first score, this is as we want it to be. Consider:

Mildred knows who come to the banquet.

We don't want to render this qualification of Mildred true if she knows of only one person that he or she will come to the banquet. Asserting (25) implies that Mildred has exhaustive knowledge about who come, among the relevant persons, of course. The following example might cast some doubt on this conclusion:

George knows where they serve Thai food.

Asserting (26) seems to be well motivated if George knows one place where they serve Thai food and where to find it. I am not sure whether this can be taken as an argument against an exhaustive interpretation of questions. My own intuitions do not decide on the evaluation of (26) in case various good places serve Thai food; besides, arguments from attitudinal contexts like those presented by 'know,' 'believe,' and the like, are suspect anyway. My interpretation of Kripke's puzzle about belief is that there is a bigger problem about belief ascriptions in general than about the rigid semantics of proper names, and I get similar conclusions from Stalnaker's work. Indeed all of this may imply that an autonomous semantic enterprise is eventually doomed to failure, and maybe this is even Martin Stokhof's conclusion in (Stokhof 2002). Nevertheless, as long as we do not bring semantics to the grave, and do not prematurely cremate formal pragmatics, there is hope for a very well established line of exhaustive research.

\section{Conclusions}

In this paper I aimed to focus on a Gricean type of dynamic interpretation which, I claim, is different from two other types of dynamics extensively studied in the literature. I have suggested that this type of dynamics stands in need of both motivation and formalization. A motivation has been given in terms of a notion of an optimal discourse, which is based upon principles of rationality and cooperativity, but which does not presuppose them. The formalization has been partial, because some of it is crucially social, cultural, or otherwise underdetermined. 
I have focused on the use of declaratives and interrogatives in what are called inquisitive dialogues. The semantics of these types of sentences has been assumed to be classical: satisfaction conditions, and, in case of interrogatives, (exhaustive) answerhood conditions. Not for the purposes of this paper, but for a general semantic program in the long run, I have assumed a more structured approach along the lines of Krifka, as has also been suggested by Groenendijk and Stokhof themselves.

One of the main observations is that questions posed and questions faced, although logically related, may diverge. Thinking of it, this is not a very surprising observation. I could ask you whether Sue comes to the banquet, not because I want to know, but because I know that if she comes, Tim comes as well, and because I do not want you to know that I am interested in the question whether Tim is coming. Theoretically, the observation has some impact. It allows us to explain that we may ask for more information than we actually need, and, properly understood, our respondents may act accordingly. A 'mention some' interpretation of questions and answers, even on an 'exhaustive' semantic evaluation, can thus be rapidly explained.

As appears from the lack of definitions in this paper, it is by and large programmatic. The real work has to be done by means of some epistemic logic and decision theoretic reasoning. I hope to have shown, however, that this can be neatly based on a classical semantic understanding of declarative and interrogative sentences.

\section{References}

Aloni, M., Beaver, D. and Clark, B.: 1999, Focus and topic sensitive operators, in P. Dekker (ed.), Proceedings of the 12-th Amsterdam Colloquium, ILLC/Department of Philosophy, Amsterdam, pp. 55-60.

Beck, S. and Rullmann, H.: 1999, A flexible approach to exhaustivity in questions, Natural Language Semantics 7, 249-298.

Dekker, P.: 2003, Topical restriction and answerhood, in M. Weisgerber (ed.), Proceedings of the Seventh Annual Meeting Sinn und Bedeutung, Universität Konstanz, Konstanz, pp. 110-119.

Dekker, P.: 2004, Satisfying questions, in C. Meier and M. Weisgerber (eds), Proceedings of the Eighth Annual Meeting Sinn und Bedeutung, Universität Konstanz, Konstanz, pp. 83-94.

Ginzburg, J.: 1996, Interrogatives: questions, facts, and dialogue, in S. Lappin (ed.), The Handbook of Contemporary Semantic Theory, Blackwell, Oxford.

Groenendijk, J.: 1999, The logic of interrogation, in T. Matthews and D. Strolovitch (eds), Proceedings of SALT IX, CLC Publications.

Groenendijk, J. and Stokhof, M.: 1984, Studies on the Semantics of Questions and the Pragmatics of Answers, $\mathrm{PhD}$ thesis, University of Amsterdam, Amsterdam.

Hulstijn, J.: 2000, Dialogue Models for Inquiry and Transaction, PhD thesis, University of Twente.

Jäger, G.: 1996, Only updates. On the dynamics of the focus particle only, in M. Stokhof and P. Dekker (eds), Proceedings of the Tenth Amsterdam Colloquium, ILLC, University of Amsterdam, Amsterdam, pp. 387-405. 
Krifka, M.: 1991, A compositional semantics for multiple focus constructions, in S. Moore and A. Wyner (eds), Proceedings from SALT I, Cornell, pp. 127-158.

Roberts, C.: 1996, Information structure in discourse, in J. H. Yoon and A. Kathol (eds), Working Papers in Linguistics 49, Ohio State University, pp. 91-136.

Stalnaker, R.: 1978, Assertion, in P. Cole (ed.), Syntax and Semantics 9 - Pragmatics, Academic Press, New York, pp. 315-332.

Stalnaker, R.: 1998, On the representation of context, Journal of Logic, Language and Information 7, 3-19.

Stokhof, M.: 2002, Meaning, interpretation and sermantics, in D. Barker-Plummer, D. Beaver, J. van Benthem and P. S. di Luzio (eds), Words, Proofs, and Diagrams, CSLI Publications, Stanford.

van Rooij, R.: 2003, Questioning to resolve decision problems, Linguistics and Philosophy 26, 727-763.

von Stechow, A.: 1991, Focusing and backgrounding operators, in W. Abraham (ed.), Discourse Particles: descriptive and theoretical investigations on the logical, syntactic and pragmatic properties of discourse particles in German, John Benjamins, Amsterdam.

Zeevat, H.: 1994, Questions and exhaustivity in update semantics, in H. Bunt, R. Muskens and G. Rentier (eds), Proceedings of the International Workshop on Computational Semantics, ITK, University of Tilburg, pp. 211-221. 


\title{
COPUlar SENTENCES IN RUSSIAN VS. SPANISH AT THE SYNTAX-SEMANTICS INTERFACE
}

\author{
Ljudmila Geist \\ Universität Stuttgart
}

\begin{abstract}
Russian and Spanish each have two variants of the predicational copular sentence. In Russian, the variation concerns the case of the predicate phrase, which can be nominative or instrumental, while in Spanish, the variation involves the choice of the copular verb, either ser or estar. It is shown that the choice of the particular variant of copular sentence in both languages depends on the speaker's perspective, i.e., on whether or not the predication is linked to a specific topic situation.
\end{abstract}

\section{Introduction}

In predicational sentences in Russian, the predicate noun phrase can have nominative or instrumental case, provided that the copula is non-zero, i.e., that it occurs in the past tense or future tense form (cf. (1a/b) with the copula byt' 'be' in the past). In the present tense, where the copula is zero, the predicate NP always bears nominative case. ${ }^{1}$
a. Katja byla pevicej.
Katja was singer ${ }_{\text {INS }}$
'Katja was a singer.'
b. Katja byla pevica.
Katja was singer ${ }_{\mathrm{NOM}}$
'Katja was a singer.'

The difference in meaning between sentences with the nominative NP and sentences in which the NP has instrumental case is so subtle that even native speakers cannot always pinpoint what it is. In the literature on Russian, a number of semantic oppositions are proposed to describe the difference between the two variants.

Traditionally it has been assumed that the choice of the predicate's case reflects the distinction between a temporal and a permanent property (cf. Jakobson 1971). Wierzbicka (1980) uses the notions accidental vs. essential to describe the same dichotomy. According to this view, example (1a), with the instrumental NP, could imply that Katja changed her profession at a later point in time. In this case, Katja's being a singer is regarded as temporal and accidental, whereas in (1b), the state of being a singer is interpreted as a permanent and essential property.

Potebnja (1958:504) indicates another interpretation of the variants in (1a/b). According to him, the instrumental case in (1a) implies that the individual has further professions or occupations at the same time. In (1a) the property of being a singer is presented as one of many properties that can be attributed to Katja. Put differently, the property of being a singer in (1a) describes only one facet, one part of the person. The right paraphrase for this reading would be: "Katja was, among other things, a singer." In contrast to this, the (b) sentence, with

\footnotetext{
$1 \quad$ Katja pevica / *pevicej.

Katja singer $_{\mathrm{NOM}} / \mathrm{Katja}_{\mathrm{INS}}$

'Katja is a singer.'

In this paper only sentences with an overt copula verb will be considered.
} 
the nominative NP, presents the property of being a singer as an exhaustive and identificational property of the person. The property characterizes a person as a whole. Let us call the interpretational opposition observed by Potebnja the part vs. whole opposition. A different interpretation of the instrumental case is triggered in the context given in (2).

Byla by Katja pevicej, ona by davala koncerty v raznych stranach mira.

was Conj. Katja singer ${ }_{\text {INS }}$ she Conj. gave concerts in different countries world ${ }_{\text {GEN }}$

'If Katja were a singer, she would give concerts all around the world.'

The sentential context triggers the contrast between the real situation, in which Katja is not a singer, and the situation in which she is a singer. Since the sentence in (2) with the predicate NP in instrumental case does not refer to a real situation but expresses an imagined state, I will call such an interpretation triggered by the instrumental case subjective. In contrast to the instrumental case, the nominative normally occurs in descriptions of real situations, that is, it triggers an objective interpretation. The interpretations of the case alternations are summarized in (3):

(3)

\begin{tabular}{|l|l|l|}
\hline & Instrumental & Nominative \\
\hline Interpretation 1 & temporal & permanent \\
\hline Interpretation 2 & part & whole \\
\hline Interpretation 3 & subjective & objective \\
\hline
\end{tabular}

Recent analyses of this case alternation as in Bailyn (2001), Bailyn \& Citko (1999), Matushansky (2000) and Pereltsvaig (2001) concentrate on the morpho-syntactic difference between the (a) and (b) variants, but don't provide an explanation of all the interpretational differences mentioned in (3).

From a typological perspective, Russian is not the only language that exhibits two variants of the copular sentence. Spanish, for instance, displays a similar contrast. However, in the case of Spanish, the distinction is not realized as a morphological case alternation on the predicate but lies in the (lexical) choice of the copula verb. In Spanish, there are two counterparts for the English copula 'be': ser and estar. In combination with predicate adjectives, the two copulas can be used interchangeably. ${ }^{2}$ Interestingly, the interpretational oppositions put forward for Russian copular sentences pattern with interpretations suggested for copular sentences in Spanish.

a. La carretera está ancha.

'The road is ESTAR wide.' b. La carretera es ancha. (Maienborn 2005:171) 'The road is $\mathrm{SER}$ wide.'

It has often been assumed that the opposition ser vs. estar reflects the semantic opposition Individual Level Predicate (i.e., permanent property) vs. Stage Level Predicate (i.e., temporal property); cf. for example Diesing (1992) and Kratzer (1994). However, in addition to the opposition temporary vs. permanent, the grammars on Spanish propose another semantic opposition to describe the difference in interpretation between the two variants of copular sentence: the contrast subjective vs. objective (cf. the overview given in de Bruyne 1993). The subjective reading of (4a) is discussed in Maienborn (2005) under the term "discovery interpretation." This reading can be triggered by the following context: It was announced that the road would be narrowed, however, the road remained wide. Under this context, the current

\footnotetext{
${ }^{2}$ Besides adjectives that can occur with either copula, there is a small group of adjectives that only combine with estar, e.g., vacío 'empty', lleno 'full', ausente 'away'.
} 
situation "the road is wide" contrasts with a situation "the road is not wide" expected by the speaker. The speaker uses estar in such a context to express the difference between the expected situation and the real situation.

Maienborn (2005) offers a third possible interpretation of (4) available in certain contexts. In her discussion she mentions that the property of being wide can be interpreted as being restricted to a local part of the subject referent road. The paraphrase for this reading would be: "The part of the road I am speaking of is wide." This reading corresponds to the part-whole interpretation mentioned above for the Russian example (1a). The table in (5) summarizes the interpretations discussed for the examples $(4 \mathrm{a} / \mathrm{b})$.

(5)

\begin{tabular}{|l|l|l|}
\hline & estar & ser \\
\hline Interpretation 1 & temporal & permanent \\
\hline Interpretation 2 & part & whole \\
\hline Interpretation 3 & subjective & objective \\
\hline
\end{tabular}

It is obvious that the contrast Russian makes via two different morphological cases on the predicate noun phrase is the same one that Spanish expresses through the selection of the copula verb in predicational sentences with adjective phrases. ${ }^{3}$ The question now arises of how this similarity can be accounted for in formal semantics. Could the number of interpretational oppositions of the two variants of copular sentence be reduced to one common denominator? Intuitively, estar predications in Spanish and predications with instrumental case in Russian imply some contrast and the predication is bounded in some respect. I will present a formal analysis based on this intuition in sections 2 and 3.

The paper argues that the difference which Russian and Spanish encode with two distinct variants of predicational sentence is the same. This difference is discourse-pragmatic in nature. The copula estar in Spanish and instrumental case in Russian indicate the restriction of the predication to a specific topic situation, while ser in Spanish and nominative case in Russian are neutral in this respect.

The paper is organized as follows: Sections 2 and 3 introduce the analyses of copular sentences in Spanish and Russian. Section 4 concludes the paper.

\section{A discourse-pragmatic account of ser vs. estar in Spanish}

As we have seen in the introduction, the interpretation of copular sentences with estar in Spanish and copular sentences with the instrumental case in Russian depends on the context. The question now arises of how to account for the different readings of one particular copular construction. I do not want to ascribe every reading to the copula in Spanish or to the suffix for instrumental case in Russian, thereby creating polysemy. What I want is to trace back all

3 In Russian, predicate adjectives in copular constructions may come in two "flavors," the so-called long form and the so-called short form. The short form is inflected for gender and number, whereas the long form is inflected for gender, number and case. Like predicate nouns, the long form of adjectives can occur in nominative and instrumental case.
(i) Doroga byla širokaja.
way was wide LF.NOM
(ii) Doroga byla širokoj.
way was wide LF.INS
(iii) Doroga byla široka.
way was wide $_{\mathrm{SF}}$

Since the interpretational difference between long form adjectives in nominative and long form adjectives in instrumental is less obvious than with predicate nouns and the division of labor between the short form and the long form deserves a separate study, I restrict my analysis of Russian copular sentences to sentences with predicate nouns. 
the readings to one invariant semantics. The analysis by Maienborn $(2003 / 05)^{4}$ for ser vs. estar heads in this direction. Maienborn assumes that the semantic representation of the copula estar contains a free contextual parameter, which can be specified on the level of the context. In what follows I present the analysis of ser and estar proposed by Claudia Maienborn (2003/05) with some minor changes. In section 3, it will be shown how this analysis can be adopted in order to account for the Russian data.

Consider the examples in $(6 \mathrm{a} / \mathrm{b})$, taken from Luján (1981). Speakers would use estar to express that they expect a change in Jacinta's marital status, while the variant with ser would be used when no such expectation on the part of the speakers is expressed. Thus, the property of having the marital status of being single will be interpreted as temporary if used with estar.

$$
\begin{array}{ll}
\text { a. Jacinta está soltera. } & \text { b. Jacinta es soltera. } \\
\text { 'Jacinta is } & \text { 'Jacinta is } \text { SER }_{\text {ESTAR }} \text { single.' }
\end{array}
$$

The situation in the real world described by (6a) and (6b) is the same: at the utterance time Jacinta is single (unmarried). It is obvious that in (6), the decision to use either of the verbs in question depends on the speaker's estimation of the situation and is thus largely independent of the real situation. (6a) with estar is an utterance about a specific topic situation which contrasts with some other possible topic situation, whereas in (6b) no such contrast is involved.

The term "topic situation" was introduced by Maienborn and is similar to the term "topic time" introduced by Klein (1994) in his theory of tense. According to Maienborn, "the topic situation of a sentence is the relevant discourse situation to which a speaker restricts his or her claim, the speaker being able to relate this claim to specific as well as non-specific/arbitrary topic situations" (Maienborn 2005).

To account for the serlestar distinction, Maienborn (2005) assumes the following hypothesis:

\section{(7) Ser/estar hypothesis (Maienborn 2005:169)}

By using estar speakers restrict their claims to a particular topic situation they have in mind; by using ser speakers remain neutral as to the specificity of the topic situation.

The restriction to a specific topic situation only makes sense if there are alternatives to this topic situation. She states that "... the use of estar is pragmatically legitimated only if the context supports some topic situation contrast" (Maienborn 2005:171). There are several dimensions along which a topic situation contrast can be established. The choice of the particular dimension depends on the context. Maienborn mentions the following dimensions to which the contrast can apply: temporal, spatial and epistemic dimensions.

\section{Temporal dimension}

"The current topic situation contrasts with previous or later topic situations in which the predicate does not apply to the subject referent" (Maienborn 2005:172).

[This contrast gives rise to the interpretation that the predicate holds on the subject referent only temporarily. In our example (4), the temporal contrast can lead to the interpretation that the road was used to be narrow before.]

\section{Spatial dimension}

"The current topic situation contrasts with differently located topic situations in which the predicate does not apply to the subject referent" (Maienborn 2005:172).

\footnotetext{
${ }^{4}$ Another analysis recently proposed by González-Vilbazo \& Remberger (in print) is on the whole similar to that of Maienborn, but it focuses on the syntax of ser/estar-sentences, and does not leave the semantics transparent enough. Since the focus of this paper is put on semantics, I prefer the analysis by Maienborn.
} 
[This contrast leads to a spatial restriction. In example (4), the speaker can restrict his claim to stating that the relevant part of the road is wide, acknowledging that there might be other parts where this road is not wide.]

\section{Epistemic dimension}

"The current topic situation contrasts with topic situations which were expected instead" (Maienborn 2005:172).

[This contrast leads to the subjective vs. objective interpretation. In example (4), the current situation described by the sentence contrasts with a situation expected by the speaker.]

To conclude, the different interpretations provided by the selection of ser and estar, like i.e., temporary vs. permanent, part vs. whole, and subjective vs. objective, thus receive a common basis: the linking (or the lack of such linking) to a specific topic situation. The next step is the integration of these findings in the semantic representation of the copulas in Spanish.

Maienborn assumes that these copulas have basically the same meaning as their English counterpart be and its counterparts in many languages, but unlike the representation of ser, the representation of estar contains a free parameter, which can be specified by the context. I follow Maienborn in this assumption, but my implementation of this idea is based on the lexical representation of verbs suggested by Bierwisch (1988). I assume for ser (9) the lexical entry that Bierwisch (1988) proposes for the copula sein in German (8). The relation INST in this representation links the situation argument of the copula $\mathrm{z}$ to the proposition $\mathrm{P}(\mathrm{x})$. $\mathrm{z}$ INST $[\mathrm{P}(\mathrm{x})]$ is construed as " $\mathrm{z}$ instantiates $\mathrm{P}(\mathrm{x})$." The variable $\mathrm{z}$ is an anchor for adverbial modifications as well as a take-up point for the temporal and aspectual characterization of the proposition.

sein: $\quad \lambda \mathrm{P} \lambda \mathrm{x} \lambda \mathrm{z}[\mathrm{z}$ INST [P(x)]] (Bierwisch 1988:46)

$$
\text { ser: } \quad \lambda P \lambda x \lambda z[z \operatorname{INST}[\mathrm{P}(\mathrm{x})]]
$$

The lexical entry of estar in (10) differs from that of ser. The difference between them is a pragmatic one: "Estar ... carries an additional presupposition linking the predication to a specific discourse situation" (Maienborn 2005:167).

$$
\text { estar: } \left.\lambda \mathrm{P} \lambda \mathrm{x} \lambda \mathrm{z}[\mathrm{z} \operatorname{INST}[\mathrm{P}(\mathrm{x})] \underbrace{\left[\mathrm{R}\left(\mathrm{z}, \mathrm{s}_{\mathrm{i}}\right)\right]}_{\text {specificity presupposition (cf. Maienborn 2005:168) }}]\right]
$$

According to the presupposition of estar the situation $\operatorname{argument} \mathrm{z}$ is linked to a specific topic situation $s_{i}$ via the $R$ relation. $R$ is a free parameter, and $s_{i}$ is a free variable for specific topic situations. The free variable $\mathrm{s}_{\mathrm{i}}$ and the relation $\mathrm{R}$ can be resolved in the course of the semantic composition, as will be shown below.

To make the derivation of the meaning of copular sentences with ser and estar more precise, some background assumptions about the syntax and semantics of copular sentences from Maienborn (2003/05) need to be introduced.

- The copulas ser and estar are base-generated in the head of VP and take a predicate $\mathrm{AP}$ as their complement.

- As Spanish belongs to the aspect languages, a functional Aspect phrase can be assumed in which aspect is specified. Following Maienborn, I further assume that the functional category Aspect introduces a contextually determined topic situation s* (cf. also Klein 1994). 
- The semantic contribution of the functional head Asp in (12) is the establishing of a relation between the VP referent (here: e) and the topic situation $\mathrm{s}^{*}$. Imperfective aspect indicates that the topic time $\tau\left(\mathrm{s}^{*}\right)$ is fully contained in the situation time $\tau(\mathrm{e})$, while perfective aspect indicates that the situation time $\tau(\mathrm{e})$ is fully contained in the topic time $\tau\left(\mathrm{s}^{*}\right)$ (where $\tau$ maps situations onto their temporal extensions). The semantic representations for both aspectual features, imperfective and perfective, are given in (11) from Maienborn (2005).

imperfective aspect: $\lambda \mathrm{Q} \lambda \mathrm{s}^{*} \exists \mathrm{e}\left[\left[\tau\left(\mathrm{s}^{*}\right) \subset \tau(\mathrm{e})\right] \& \mathrm{Q}(\mathrm{e})\right]$

perfective aspect: $\quad \lambda \mathrm{Q} \lambda \mathrm{s}^{*} \exists \mathrm{e}\left[\left[\tau(\mathrm{e}) \subset \tau\left(\mathrm{s}^{*}\right)\right] \& \mathrm{Q}(\mathrm{e})\right]$

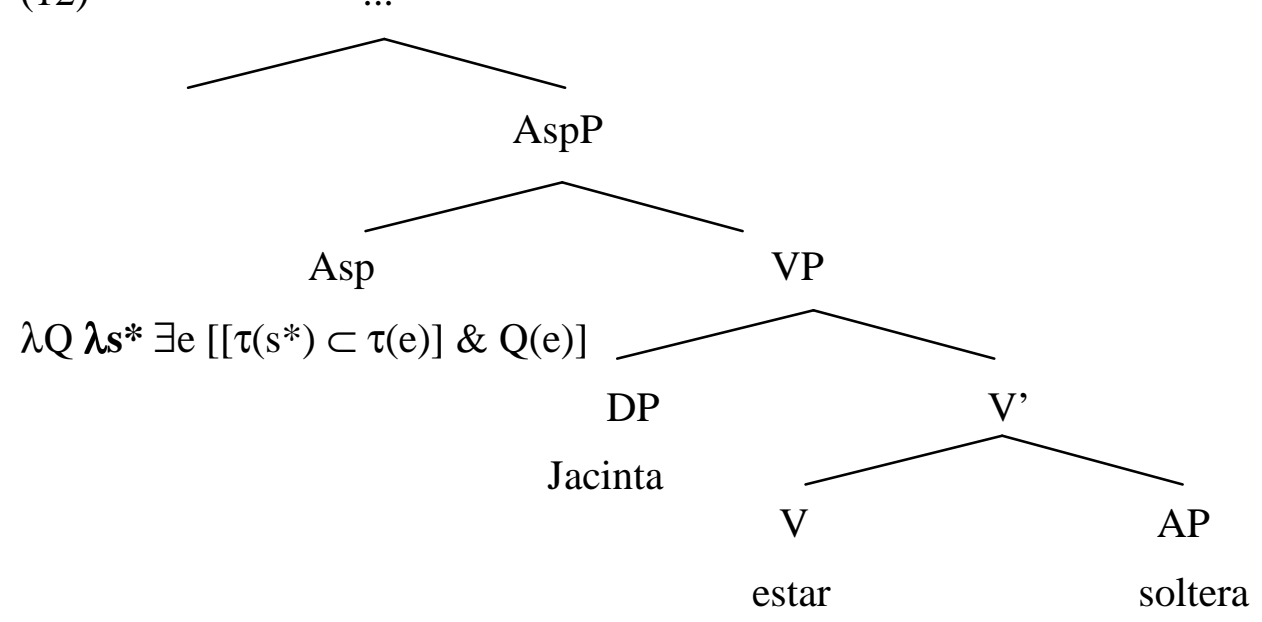

$\lambda \mathrm{P} \lambda \mathrm{x} \lambda \mathrm{z}\left[\mathrm{z} \operatorname{INST}[\mathrm{P}(\mathrm{x})] /\left[\mathrm{R}\left(\mathrm{z}, \mathrm{s}_{\mathrm{i}}\right)\right]\right]$

For the sake of simplicity, I will not consider the semantic discussion of tense, which, according to Klein (1994), establishes a relation between topic time and speech time.

We are now in a position to derive the sentences with ser and estar compositionally in the way suggested by Maienborn (2003/05). First, I will show how the semantic derivation works in a sentence with estar. For the sake of simplicity I will only consider the semantics of the sentence on the level of the AspP, as illustrated in (13).

(13) Jacinta está soltera. ('Jacinta is ESTAR $_{\text {single.') }}$

(estar, imperfective)

a. Jacinta: Jacinta

b. soltera: $\lambda y$ [SINGLE(y)]

c. estar: $\lambda \mathrm{P} \lambda \mathrm{x} \lambda \mathrm{z}\left[\mathrm{z} \operatorname{INST}[\mathrm{P}(\mathrm{x})] /\left[\mathrm{R}\left(\mathrm{z}, \mathrm{s}_{\mathrm{i}}\right)\right]\right]$

d. imperfective aspect: $\lambda \mathrm{Q} \lambda \mathrm{s}^{*} \exists \mathrm{e}[[\tau(\mathrm{s} *) \subset \tau(\mathrm{e})] \& \mathrm{Q}(\mathrm{e})]$

e. [v, estar soltera]: $\lambda \mathrm{P} \lambda \mathrm{x} \lambda \mathrm{z}\left[\mathrm{z} \operatorname{INST}[\mathrm{P}(\mathrm{x})] /\left[\mathrm{R}\left(\mathrm{z}, \mathrm{s}_{\mathrm{i}}\right)\right]\right](\lambda \mathrm{y}[\operatorname{SINGLE}(\mathrm{y})])$

$\equiv \lambda x \lambda z\left[z\right.$ INST $\left.[\operatorname{SINGLE}(\mathrm{x})] /\left[\mathrm{R}\left(\mathrm{z}, \mathrm{s}_{\mathrm{i}}\right)\right]\right]$

f. [vP Jacinta está soltera]: $\lambda x \operatorname{xz}\left[\mathrm{z} \operatorname{INST}[\operatorname{SINGLE}(\mathrm{x})] /\left[\mathrm{R}\left(\mathrm{z}, \mathrm{s}_{\mathrm{i}}\right)\right]\right]$ (Jacinta)

$\equiv \lambda z\left[z\right.$ INST $[\operatorname{SINGLE}($ Jacinta $\left.)] /\left[\mathrm{R}\left(\mathrm{z}, \mathrm{s}_{\mathrm{i}}\right)\right]\right]$

g. [AspP Jacinta está soltera]: $\lambda \mathrm{Q} \lambda \mathrm{s}^{*} \exists \mathrm{e}\left[\left[\tau\left(\mathrm{s}^{*}\right) \subset \tau(\mathrm{e})\right] \& \mathrm{Q}(\mathrm{e})\right]$

$\left(\lambda \mathrm{z}\left[\mathrm{z}\right.\right.$ INST $\left.\left.[\operatorname{SINGLE}(\mathrm{Jacinta})] /\left[\mathrm{R}\left(\mathrm{z}, \mathrm{s}_{\mathrm{i}}\right)\right]\right]\right)$

$\equiv \lambda \mathrm{s}^{*} \exists \mathrm{e}\left[\left[\tau\left(\mathrm{s}^{*}\right) \subset \tau(\mathrm{e})\right] \&\left[\mathrm{e} \operatorname{INST}[\operatorname{SINGLE}(\mathrm{Jacinta})] /\left[\mathrm{R}\left(\mathrm{z}, \mathrm{s}_{\mathrm{i}}\right)\right]\right]\right]$ 
In the representation in $(13 \mathrm{~g})$, two topic situations are available: the topic situation $\mathrm{s}^{*}$ is introduced by the functional head Asp, while the second topic situation $\mathrm{s}_{\mathrm{i}}$ is part of the lexical entry of estar. Since a sentence is a claim about a single topic situation, $\mathrm{s}^{*}$ and $\mathrm{s}_{\mathrm{i}}$ must be identified $\left(\mathrm{s}^{*}=\mathrm{s}_{\mathrm{i}}\right)$. According to van der Sandt (1992), presuppositions can be treated as anaphors. They can be specified by the identification with its antecedent. The identification of the two topic situations permits the resolution of the specificity presupposition. The semantics of the resulting sentence after the existential binding of the topic situation is represented in (14):

(14) Jacinta está soltera:

$$
\exists \mathrm{s}^{*} \exists \mathrm{e}\left[\left[\tau\left(\mathrm{s}^{*}\right) \subset \tau(\mathrm{e})\right] \&[\mathrm{e} \operatorname{INST}[\operatorname{SINGLE}(\text { Jacinta })]] \&\left[\mathrm{~s}^{*}=\mathrm{s}_{\mathrm{i}}\right]\right]
$$

The precondition for the identification of $\mathrm{s}^{*}$ with $\mathrm{s}_{\mathrm{i}}$ is that $\mathrm{s}^{*}$, like $\mathrm{s}_{\mathrm{i}}$, is specific. According to Maienborn's analysis, only a specific $\mathrm{s}^{*}$ can serve as a suitable antecedent for estar's specificity presupposition.

The sentence in (14) is true if there is a situation characterized by Jacinta's being single whose temporal extension includes a contextually specific topic time.

The derivation of a ser sentence is represented in (15).
Jacinta es soltera. ('Jacinta is SER $_{\text {single.') }}$
(ser, imperfective)
a. Jacinta: Jacinta
b. soltera: $\lambda \mathrm{y}[\operatorname{SINGLE}(\mathrm{y})]$
c. ser: $\lambda \mathrm{P} \lambda \mathrm{x} \lambda \mathrm{z}[\mathrm{z} \operatorname{INST}[\mathrm{P}(\mathrm{x})]]$
d. imperfective aspect: $\lambda \mathrm{Q} \lambda \mathrm{s}^{*} \exists \mathrm{e}\left[\left[\tau\left(\mathrm{s}^{*}\right) \subset \tau(\mathrm{e})\right] \& \mathrm{Q}(\mathrm{e})\right]$
e. [v'ser soltera]: $\lambda \mathrm{P} \lambda \mathrm{x} \lambda \mathrm{z}[\mathrm{z} \operatorname{INST}[\mathrm{P}(\mathrm{x})]](\lambda \mathrm{y}[\operatorname{SINGLE}(\mathrm{y})])$
$\equiv \lambda \mathrm{x} \lambda \mathrm{z}[\mathrm{z}$ INST $[\operatorname{SINGLE}(\mathrm{x})]]$
f. [vp Jacinta es soltera]: $\lambda x \lambda z$ [z INST [SINGLE(x)]] (Jacinta) $\equiv \lambda z[\mathrm{z}$ INST [SINGLE (Jacinta)]]
g. [AspP Jacinta es soltera]: $\lambda \mathrm{Q} \lambda \mathrm{s}^{*} \exists \mathrm{e}[[\tau(\mathrm{s} *) \subset \tau(\mathrm{e})] \& \mathrm{Q}(\mathrm{e})]$
$(\lambda z$ [z INST [SINGLE(Jacinta)]])
$\equiv \lambda \mathrm{s}^{*} \exists \mathrm{e}[[\tau(\mathrm{s} *) \subset \tau(\mathrm{e})] \&[\mathrm{e} \operatorname{INST}[\operatorname{SINGLE}(\operatorname{Jacinta})]]]$

The sentence Jacinta es soltera is true if there is a situation of Jacinta being single whose temporal extension includes the topic time. Again, I will not touch on the interpretation of tense.

I will leave the discussion of Spanish here. In the next section, I will develop a formal analysis of the copular sentences in Russian. The analysis of copular sentences in Spanish by Maienborn introduced in this section will serve as the basis for my analysis of copular sentences in Russian.

\section{An analysis of Russian copular sentences}

Our examination of the Russian and Spanish data in section 1 showed that the interpretative effects brought about by the choice of the respective copular sentence variant are in fact parallel. The instrumental case on the predicate noun in Russian triggers the same interpretative effects as estar in Spanish. The nominative case in Russian yields the same interpretations as Spanish ser. In order to account for the similarity between the two languages I assume the following hypothesis: 
(16) Nominative/Instrumental hypothesis

By using the predicate noun phrase with the instrumental case, speakers restrict their claims to a particular discourse situation they have in mind; by using the nominative speakers remain neutral as to the specificity of the discourse situation.

For the semantic analysis of copular sentences in Russian I assume that the instrumental suffix located on the predicate noun in Russian contains a specificity presupposition in its lexical entry, like Spanish estar. The following schema illustrates the main difference between Russian and Spanish:

Spanish
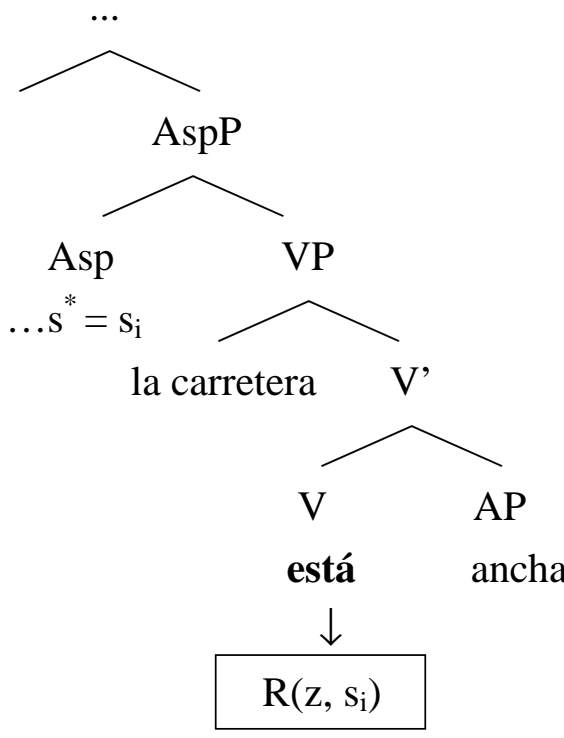
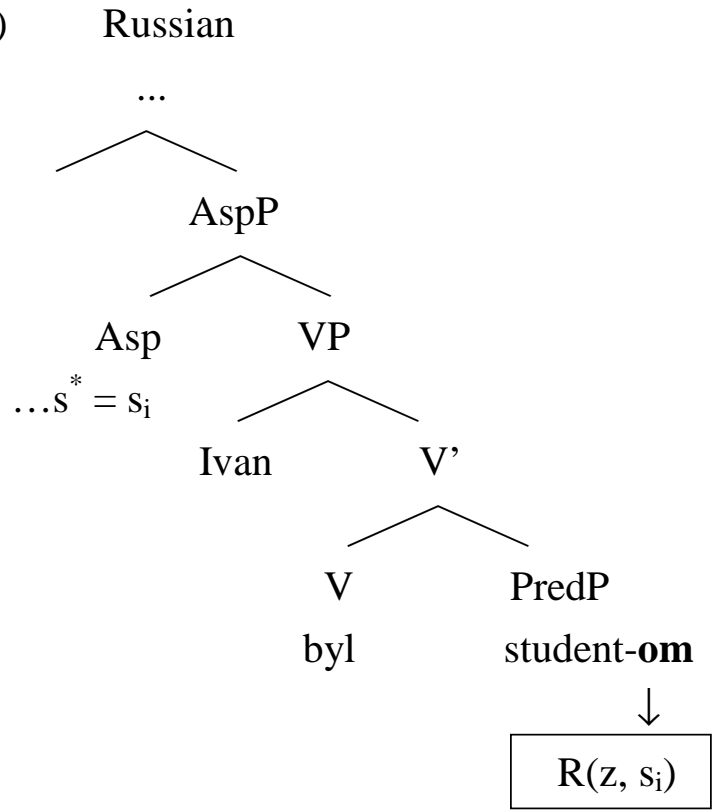

In order to develop a formal reconstruction of the difference between predicate nouns in nominative case and predicate nouns in instrumental case, I propose that there are two types of predicate phrases. The predicate phrase in the nominative case receives its case via agreement with the subject of the copular sentence, which bears nominative case. The predicate phrase in the instrumental case is more complex, syntactically and semantically. This NP is embedded in a functional projection PredP, ${ }^{5}$ whose head checks instrumental case.

\section{Two types of predicate phrases}

a. agreement-predicate

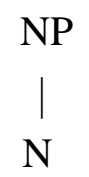

b. instrumental-predicate

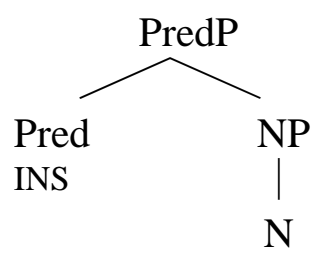

With Bailyn \& Citko (1999) I assume that the Pred head has an instrumental case feature which must be checked when merged onto a noun phrase. This instrumental feature has the following lexical content:

\footnotetext{
${ }^{5}$ This Predicate Phrase (PredP) roughly corresponds to the PredP for secondary predications in Bowers (2000), but does not contain a specifier.
} 
(20) INS: $\quad \lambda \mathrm{P} \lambda \mathrm{x}\left[\mathrm{P}(\mathrm{x}) /\left[\mathrm{R}\left(\mathrm{z}, \mathrm{s}_{\mathrm{i}}\right)\right]\right]^{6}$

The instrumental feature contains the specificity presupposition. Thus, the semantic contribution of the Pred head consists of providing the link to a specific topic situation. The pragmatic-semantic difference between the NP pevica 'singer ${ }_{\mathrm{NOM}}$ ' and the PredP pevicej 'singer ${ }_{\text {INS' }}$ ' is illustrated in (21).

(21) a. [NP pevica NOM $\left._{1}\right]: \lambda \mathrm{u}[\operatorname{SINGER}(\mathrm{u})]$

b. [PredP pevicej $\left.j_{\text {INS }}\right]: \lambda u\left[[\operatorname{SINGER}(\mathrm{u})] /\left[\mathrm{R}\left(\mathrm{z}, \mathrm{s}_{\mathrm{i}}\right)\right]\right]$

(21b) means that the property of being a singer applies to the individual $\mathrm{u}$ in a specific topic situation $\mathrm{s}_{\mathrm{i}}$. To derive the semantics of the whole copular sentence in Russian the semantics of the copula has to be specified. Russian differs from Spanish in that it has only one copula, as do English and German. I therefore assume the same lexical entry for Russian byt' as for be and sein.

byt'/ be / sein : $\lambda \mathrm{P} \lambda \mathrm{x} \lambda \mathrm{z}[\mathrm{z} \operatorname{INST}[\mathrm{P}(\mathrm{x})]]$

Now we are in a position to derive the semantics of a copular sentence with the instrumental; cf. (23). The corresponding sentence with nominative is derived in (25).

(23) Katja byla pevicej. ('Katja was a singer ${ }_{\text {INS') }}$

(byt', imperfective)

a. Katja: Katja

b. [PredP pevicej $\left.j_{\text {INS }}\right]: \lambda u\left[[\operatorname{SINGER}(\mathrm{u})] /\left[\mathrm{R}\left(\mathrm{z}, \mathrm{s}_{\mathrm{i}}\right)\right]\right]$

c. byt' ('be'): $\lambda \mathrm{P} \lambda \mathrm{x} \lambda \mathrm{z}[\mathrm{z} \operatorname{INST}[\mathrm{P}(\mathrm{x})]]$

d. imperfective Aspect: $\lambda \mathrm{Q} \lambda \mathrm{s}^{*} \exists \mathrm{e}\left[\left[\tau\left(\mathrm{s}^{*}\right) \subset \tau(\mathrm{e})\right] \& \mathrm{Q}(\mathrm{e})\right]$

e. [v' byla pevicej]: $\lambda \mathrm{P} \lambda \mathrm{x} \lambda \mathrm{z}[\mathrm{z} \operatorname{INST}[\mathrm{P}(\mathrm{x})]]\left(\lambda \mathrm{u}\left[[\operatorname{SINGER}(\mathrm{u})] /\left[\mathrm{R}\left(\mathrm{z}, \mathrm{s}_{\mathrm{i}}\right)\right]\right]\right)$

$\equiv \lambda \mathrm{x} \lambda \mathrm{z}\left[\mathrm{z} \operatorname{INST}[\operatorname{SINGER}(\mathrm{x})] /\left[\mathrm{R}\left(\mathrm{z}, \mathrm{s}_{\mathrm{i}}\right)\right]\right]$

f. [vp Katja byla pevicej]: $\lambda x \lambda z$ [z INST [SINGER (x)] / [R(z, si $)]$ (Katja)

$\equiv \lambda z\left[z\right.$ INST $\left.[\operatorname{SINGER}(\operatorname{Katja})] /\left[\mathrm{R}\left(\mathrm{z}, \mathrm{s}_{\mathrm{i}}\right)\right]\right]$

g. [AspP Katja byla pevicej]: $\lambda \mathrm{Q} \lambda \mathrm{s}^{*} \exists \mathrm{e}\left[\left[\tau\left(\mathrm{s}^{*}\right) \subset \tau(\mathrm{e})\right] \& \mathrm{Q}(\mathrm{e})\right]$

$\left(\lambda \mathrm{z}\left[\mathrm{z} \operatorname{INST}[\operatorname{SINGER}(\operatorname{Katja})] /\left[\mathrm{R}\left(\mathrm{z}, \mathrm{s}_{\mathrm{i}}\right)\right]\right]\right)$

$\equiv \lambda \mathrm{s}^{*} \exists \mathrm{e}\left[[\tau(\mathrm{s} *) \subset \tau(\mathrm{e})] \&\left[\mathrm{e} \operatorname{INST}[\operatorname{SINGER}(\operatorname{Katja})] /\left[\mathrm{R}\left(\mathrm{z}, \mathrm{s}_{\mathrm{i}}\right)\right]\right]\right]$

At the level of AspP, the specificity presupposition of the instrumental suffix can be resolved by identifying $\mathrm{s}_{\mathrm{i}}$ with the topic situation $\mathrm{s}^{*}$ introduced by Aspect. This presupposition resolution and the existential binding of the topic situation yield (24).

$$
\exists \mathrm{s}^{*} \exists \mathrm{e}\left[[\tau(\mathrm{s} *) \subset \tau(\mathrm{e})] \&[\mathrm{e} \operatorname{INST}[\operatorname{SINGER}(\operatorname{Katja})]] \&\left[\mathrm{~s}^{*}=\mathrm{s}_{\mathrm{i}}\right]\right]
$$

The sentence is true if there is a situation characterized by Katja being a singer whose temporal extension includes a contextually specific topic time.

A sentence with nominative case has a similar composition but it is more straightforward since no specificity presupposition is introduced. The representation for a sentence with nominative case is given in (25):

\footnotetext{
${ }^{6}$ A more elaborated representation which accounts for other functions of the instrumental case in Russian is proposed in Geist (in print); compare also a different account in Demjjanow \& Strigin (2003).
} 
[AspP Katja byla pevica]:

$$
\lambda \mathrm{s}^{*} \exists \mathrm{e}\left[\tau\left(\mathrm{s}^{*}\right) \subset \tau(\mathrm{e})\right] \&[\mathrm{e} \operatorname{INST}[\operatorname{SINGER}(\operatorname{Katja})]]
$$

The sentence is true if there is a situation characterized by Katja being a singer whose temporal extension includes the topic time.

Now, compare the composition results for the estar sentence in (14) and the sentence with instrumental case in (24) on the one hand, and the sentence with ser in (15g) and with nominative case in (25). Except for their idiosyncratic meaning components, the structural meaning components are identical in the compared sentence pairs. This is a desirable result.

Now, the result of the analysis of copular sentences in Russian on the basis of the analysis of Spanish copular sentences by Maienborn (2003/05) can be summarized as follows: With the choice of instrumental case in Russian and the choice of the copula estar in Spanish, the speaker expresses in an explicit manner that the proposition relates to a specific topic situation. This relation to a specific topic situation is embedded in the lexical entry of the case suffix in Russian and in the lexical entry of the copular verb in Spanish. The predicate noun in the nominative in Russian and the copula ser in Spanish are neutral with respect to the specificity of the topic situation. That is, Spanish and Russian choose different structural options to indicate the linking of a predication to a specific topic situation that the speaker has in mind.

The assumption that the instrumental case suffix in Russian serves as a link to a specific discourse situation is crucial for our comparative analysis, and one would like to have further evidence for such an assumption. An independent motivation for such an assumption comes from another use of instrumental case with predicate nouns, ${ }^{7}$ namely the use in sentence initial adjuncts; cf. (26a/b). Like predicates in copular sentences, such adjuncts can also occur in nominative and in instrumental case.

a. Soldatom Boris ne imel zhalosti.

Soldier INS Boris not had compassion

'When Boris was a soldier he was not compassionate.' b. Soldat, Boris ne imel zhalosti. Soldier $_{\mathrm{NOM}}$ Boris not had compassion 'Being a soldier, he was not compassionate.'

As the English translation in (26a) suggests, the instrumental case triggers a contrast to alternative situations in which Boris was not a soldier (cf. similar observations in Demjjanow \& Strigin 2003). No such contrast is implied in (26b) with nominative case. This is what our analysis of the instrumental suffix as a link to a specific discourse situation predicts.

\section{Concluding remarks}

In this paper, I have explored the mapping between the syntax and semantics of copular sentences in Russian in comparison to Spanish. Such a comparison makes it clear that the distinction Russian makes via two different morphological cases on the predicate noun phrase is the same as the one Spanish expresses through the selection of the copula verb in combination with predicate adjectives. The assignment of the instrumental case to the predicate noun in Russian and the selection of the copular verb estar in Spanish reflect the speaker's perspective on a predication in a particular discourse. By using instrumental case in Russian and the copula estar in Spanish the speaker restricts the predication in copular

\footnotetext{
${ }^{7}$ I consider only the combination of the instrumental suffix with predicate NPs, i.e., non-referential NPs which denote properties of an individual. The external argument of such NPs is assigned to the referential argument of some other NP in the clause. The instrumental case can also be used with non-predicate NPs. The correlation between "predicate instrumental" and other uses of the instrumental in Russian is discussed in Geist (in print).
} 
sentences to a specific topic situation he/she has in mind. By using nominative case in Russian and ser in Spanish the speaker remains neutral as to the specificity of the topic situation.

This analysis leaves some questions for further research. I will mention one of them. How can we explain that the alternation serlestar in Spanish is restricted to sentences with predicate adjectives while only ser can occur with predicate nouns? In Russian, in contrast, the situation is different. The case alternation nominative vs. instrumental applies to predicate nouns as well as to adjectives, although the instrumental occurs less frequently with adjectives than with nouns (Timberlake 1983:862).

\section{References}

Bailyn, J. F.: 2001, The syntax of Slavic predicate case, ZAS Papers in Linguistics 21, ZAS, $1-23$.

Bailyn, J. F. and Citko, B.: 1999, Case and agreement in Slavic predicates, in K. Dziwirek et al. (eds), Annual Workshop on Formal Approaches to Slavic Linguistics. The Seattle Meeting, Michigan Slavic Publications, pp. 17-37.

Bierwisch, M.: 1988, On the grammar of local prepositions, in: M. Bierwisch, W. Motsch, and I. Zimmermann, (eds.), Syntax, Semantik und Lexikon (=studia grammatica XXIX). Berlin, Akademie-Verlag, pp. 1-65.

Bowers, J.: 2000, Predication, in M. Baltin and C. Collins (eds), The Handbook of Contemporary Syntactic Theory, Blackwell, pp. 299-333.

Bruyne, J. de: 1993, Spanische Grammatik. Translated by Dirko-J. Gütschow. Tübingen: Max Niemeyer. Demjjanow, A. and Strigin, A.: 2003, Real adjuncts in instrumental in Russian, in E. Lang, C. Maienborn and C. Fabricius-Hansen (eds), Modifying Adjuncts, Mouton de Gruyter, pp. 591-625.

Demjjanow, A. \& Strigin, A.: 2003, Real adjuncts in instrumental in Russian, in: E. Lang, C. Maienborn \& C. Fabricius-Hansen (eds.), Modifying Adjuncts. Berlin: Mouton de Gruyter, pp. 591-625.

Diesing, M.: 1992, Indefinites (Linguistic Inquiry Monograph 20). Cambridge, MA/London, England: The MIT Press.

Geist, L.: (in print), Die Kopula und ihre Komplemente. Zur Kompositionalität in Kopulasätzen. Tübingen: Niemeyer.

González-Vilbazo, K.-E. and Remberger, E.-M.: in print, Ser and estar: The syntax of stage level and individual level predicates in Spanish, in A. Wöllstein-Leisten and C. Maienborn (eds), Event Arguments in Syntax, Semantics, and Discourse, Niemeyer.

Jakobson, R.: 1971, Beitrag zur allgemeinen Kasuslehre: Gesamtbedeutungen der russischen Kasus, in: Roman Jakobson, Selected Writings II. Word and Language, Mouton, pp. 2371.

Klein, W.: 1994, Time in Language. London: Routledge.

Kratzer, A.: 1994, The Event Argument and the Semantics of Voice, Ms., U Mass Amherst. 
Luján, M.: 1981, The Spanish copulas as aspectual indicators, Lingua 54, 165-210.

Maienborn, C.: 2003, Die logische Form von Kopula-Sätzen. Berlin: Akademie-Verlag.

Maienborn, C.: 2005, A discourse-based account of Spanish ser/estar, Linguistics 43/1, 155180.

Matushansky, O.: 2000, The instrument of inversion: Instrumental case and verb raising in the Russian copula, in R. Billerey and B. D. Lillehaugen (eds), Proceedings of WCCFL 19, Cascadilla Press, pp. 288-301.

Pereltsvaig, A.: 2001, On the Nature of Intra-Clausal Relations: A Study of Copular Sentences in Russian and Italian. Ph.D. Diss., McGill University, Montréal.

Potebnja, A. A.: 1958, Iz zapisok po russkoj grammatike. Vol. I-II. Moskva: Min. prosv. RSFSR.

Sandt, R. van der: 1992, Presupposition projection as anaphora resolution, Journal of Semantics 9, 333-377.

Timberlake, A.: 1986, The Semantics of Case in Russian Predicate Complements. Russian Linguistics 10/2, 137-165.

Wierzbicka, A.: 1980, The Case for Surface Case. Ann Arbor, Michigan: Karoma. 


\title{
MANNer Modification OF States
}

\author{
Wilhelm Geuder, \\ Universität Konstanz / SFB 471 \\ wilhelm.geuder@uni-konstanz.de
}

\begin{abstract}
In a recent contribution to a long-standing discussion in semantics as to whether the neoDavidsonian analysis should be extended to stative predicates or not, Maienborn $(2004,2005)$ proposes to distinguish two types of statives; one of them is said to have a referential argument of the Davidsonian type, the other not. As one of her arguments for making such a distinction, Maienborn observes that manner modification seems to be supported only by certain statives but to be excluded by others (thus linking the issue to the use of manner modification as one major argument in favour of event semantics, cf. Parsons 1990). In this paper, it is argued that the absence of manner modification with Maienborn's second group of statives is actually due to a failure of conceptual construal: modification of a predicate is ruled out whenever its internal conceptual structure is too poor to provide a construal for the modifier; hence, the effects observed by Maienborn reduce to the fact that eventive predicates have a more complex conceptual substructure than stative ones. Hence, the issue of manner modification with statives is shown to be orthogonal to questions of logical form and event semantics. The explanatory power of the conceptual approach is demonstrated with a case study on predicates of light emission, adapting the representation format of Barsalou's (1992) frame model.
\end{abstract}

\section{Introduction}

\subsection{General Background: Neo-Davidsonian Semantics}

This paper is about the interpretation of manner modifiers and its implications for the neoDavidsonian framework of semantics (cf. e.g. Parsons 1990). The neo-Davidsonian theory rests on two major pillars, one semantic and one ontological. Semantically, it is a theory of the logical form of sentences which is based on the idea that logical form involves predication and quantification over event variables. In particular, manner adverbs (A) modifying a verb (V) are analysed via joint predication of the event variable, hence manner modification is represented via a conjunction of the form: $V(e) \& A(e)$. This is, of course, the standard pattern of intersective modification that is also posited for nouns and adjectives when they predicate of concrete individuals.

The ontological aspect of the theory is that events are seen as particulars in the world; they are not abstract objects in the way facts or properties are. Some consequences which ensue from this view are pointed out by Maienborn (2004, 2005):

a. Eventualities are perceptible.

b. Eventualities can be located in space and time.

c. Eventualities can vary in the way that they are realized.

The third point might require some explanation. For one thing, it reflects the fact that events, being particulars, occur as instantiations of a type, i.e. the event property denoted by some verb. Another aspect implicit in (1c) is that predicates of events allow manner modification; 
in this way, instantiations of an event type give rise to subtypes. When this happens, "the way in which events are realized" can be characterised via some sort of conceptual content, i.e. the "manner" of an event.

Before a neo-Davidsonian semantics can be put to work, of course, it is necessary to know precisely which types of predicates have a neo-Davidsonian argument and which ones do not.

\subsection{Events and States}

Parsons (1990), and many semanticists after him, distinguish two sorts of "eventualities" (i.e. events in a broad sense), namely events proper and states. However, other authors have denied that states should be treated as Davidsonian individuals, beginning with Davidson (1967) himself. On this second view, stative verbs and adjectives would not have referential e-arguments (a view that has also been elaborated and defended by Katz (2000, 2003), and others).

In this connection, Maienborn (2004) has recently proposed that there are actually two types of "states": certain stative predicates refer to a neo-Davidsonian entity (called "D-states" by Maienborn), others refer to an abstract entity (which she calls "K-states", i.e. "Kimian states" after Kim (1976), who proposed to explain events as basically a propositional type of entity). From the background of the characterisation of events in (1), Maienborn (2004) adduces a number of empirical effects as supporting her distinction:

a. "Eventuality expressions can serve as infinitival complements of perception verbs".

Ich sah Bardo schlafen.

(I saw B. sleep(ing))

* Ich hörte das Radio laut sein. ～(I heard the radio be(ing) loud)

b. "Eventuality expressions combine with locative and temporal modifiers."

Die Perlen glänzen in ihrem Haar. (The pearls are gleaming in her hair)

* Das Kleid ist auf der Wäscheleine nass. (The dress is on the clothes-line wet)

c. "Eventuality expressions combine with manner adverbials, instrumentals, comitatives, etc."

Bardo schläft friedlich/mit seinem Teddy/ohne Schnuller.

(Bardo is sleeping \{peacefully / with his teddy / without dummy\})

* Bardo war friedlich/mit seinem Teddy / ohne Schnuller müde.

(Bardo was tired \{peacefully / with his teddy / without dummy\})

The examples in (2c) show an asymmetry with respect to manner modification, supposedly establishing two subtypes of stative predicates, and this is the phenomenon that the present paper is centred on. I want to argue in this paper that the peculiar behaviour of (certain) statives with respect to manner modification is actually not related to a distinction in terms of different sorts of external arguments, and that it cannot (directly) be used to determine the range of application of the neo-Davidsonian analysis.

Rather, I want to show that the crucial factor which governs the applicability of manner modifiers is the conceptual complexity of the property expressed by a verb or an adjective. To this end, verb meanings will be decomposed into a richer conceptual structure, consisting of property values and sorted in conceptual dimensions; manner modifiers then typically have the effect of restricting the admissible property values of one dimension. 


\section{Manner Modification: Beyond Event Predication}

The striking thing about the examples seen in (2) above is that verbs and adjectives may behave differently with respect to the licencing of modifiers, in spite of being fairly similar in meaning. It should be made clear, however, that the distinction at issue here is not tantamount to the categorial distinction between verbs and adjectives (even though the selection of examples given in (2) might suggest this). For one thing, there are verbs in Maienborn's data that pattern with the "K-states" (e.g. wissen / know or wiegen / weigh(intransitive)). For another, it seems that there are a few predicative adjective constructions in German which denote events and pattern with eventive verbs in the perception verb construction (e.g. German behilflich sein, which as far as I can tell means exactly the same thing as the verb helfen and English help, and behaves in the same way according to the tests - all this in spite of the adjectival derivational affix -lich).

Therefore, a truly semantic explanation is needed for the differences with respect to modification. Any such explanation will have to posit that similarities of meaning, as between sleep and tired, are actually misleading and that there are subtle semantic factors which make a decisive difference. As already outlined, Maienborn (2004) offers the explanation that the distinction is related to the fact that adjectives like müde / tired do not refer to events (e), but to abstract "property exemplifications" (of a sort k, i.e., "Kimian states"). Apparently, then, the modifiers in the problematic cases would not be able to accomplish exactly this kind of predication:

$$
\begin{array}{ll}
\text { sleep }(\mathrm{e}) \& \operatorname{peaceful}(\mathrm{e}) & \text { (to sleep peacefully) } \\
\operatorname{tired}(\mathrm{k}) \& * \text { peaceful(k) } & \text { (to be tired peacefully) }
\end{array}
$$

However, there are some immediate objections that can be raised against this sort of approach. For one thing, it seems that the effect is not strong enough for the predicted sortal mismatch. Consider the following attempts at predicating the adjective "peaceful" of different sorts of entities:

$$
\begin{array}{lll}
\text { Event: } & \text { peaceful(e) } & \text { John is sleeping peacefully } \\
\text { "K-state": } & \text { peaceful(k) } & \text { ? John is peacefully tired } \\
\text { Fact: } & \text { peaceful(f) } & * \text { The fact that John is tired is peaceful } \\
\text { Proposition: } & \text { peaceful(p) } & * \text { It is true, and it is peaceful, that John is tired }
\end{array}
$$

Truly abstract entities are found to produce a deviance that is markedly more profound. To save the idea of a sortal mismatch, one would have to posit that abstractness is a matter of degrees and that this makes K-states produce relatively weaker deviations.

However, a second objection is that the clear contrast in perception verb constructions, another diagnostic for the K-/D-distinction with states, does not align with the patterning of modifiers. In (5), it can be seen that we get clear differences between verbal and adjectival expressions for various kinds of "being open" in German:

a. offen sein $\approx$ offenstehen

?? Ich sah die Türe offen sein ${ }^{\text {ok }}$ Ich sah die Türe offen stehen
(I saw the door be open)

(I saw the door stand(ing) open)

b. offen sein $\approx$ klaffen

$$
\begin{array}{ll}
\text { ? Ich sah da eine Lücke offen sein } & \text { (I saw a gap be open) } \\
{ }^{\text {ok }} \text { Ich sah da eine Lücke klaffen } & (\sim \text { I saw a gap yawn(ing) })
\end{array}
$$


c. offen haben $\approx$ aufsperren

? Ich sah ihn den Mund offen haben (I saw him have his mouth open)

${ }^{\text {ok }}$ Ich sah ihn den Mund aufsperren ( I saw him have his mouth (wide) open)

In spite of these clear contrasts, modifiers are applicable in the very same way. For instance the asymmetry shown in $(5 \mathrm{c})$ above cannot be replicated with modification data:

a. weit "wide":

Er hatte den Mund weit offen / Er sperrte den Mund weit auf

b. locker "slack, relaxed"

Er hatte den Mund locker offen / \# Er sperrte den Mund locker auf

While in (6a) the adverb wide is able to modify both predicates, there is a deviation in (6b) with the supposed K-state - however, it is of an interesting kind: the sentence Er sperrte den Mund locker auf is felt to be contradictory. This, however, shows that the modifier locker is semantically applicable, because otherwise the contradictoriness of its contribution could not be ascertained. This is to say, the word meaning of the verb aufsperren contains a component that is the opposite of locker: it is a manner of keeping one's mouth open with the application of some force.

This is a simple example for why conceptual explanations may be needed to rule out deviant modification structures, and it provides an initial motivation to investigate how far such conceptual explanations can be carried, and how they can be formulated, to begin with.

\section{Conceptual Structure}

\subsection{A Simple Example: Colours and Colour Terms}

\subsubsection{Feature Dimensions}

As a first approach to an analysis of conceptual structure, let us have a brief look at a fairly narrow and well-understood conceptual domain, namely colours, taking up a recent proposal of conceptual modelling by Gärdenfors (2000). Colours involve three perceptual parameters: hue, brightness, and saturation. Each of these can be represented as an array of values, depicted below as arrays of points; in reality, however, the degrees of brightness, saturation, and the hue values must be continuous scales. Following Gärdenfors (2000), I will call each of these scales a property (in a narrow sense); it is made up of property values.

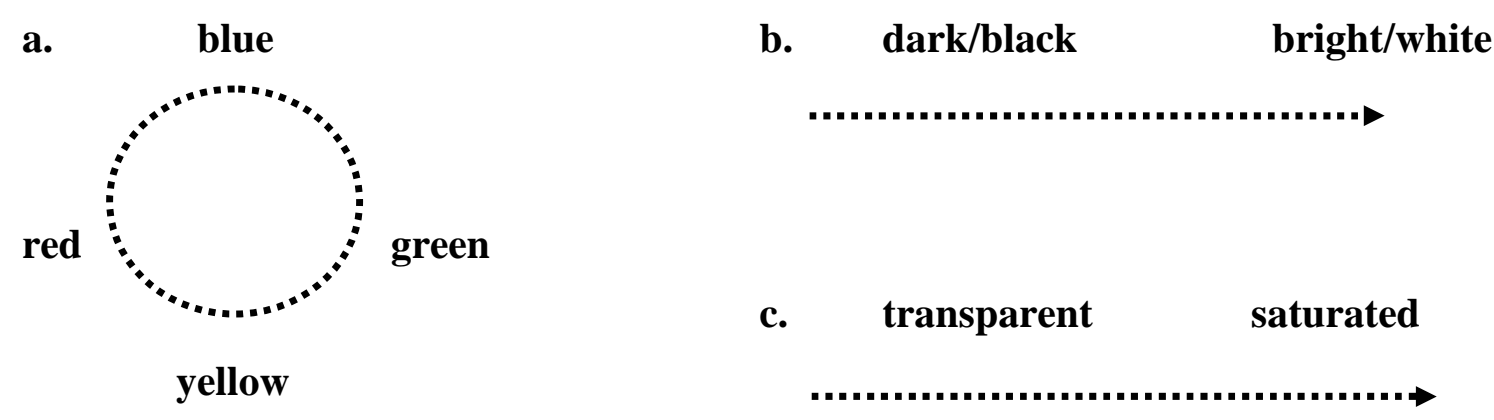

Gärdenfors (2000) proposes to represent the internal structure of the conceptual domain "colour" as a unified quality space, with hue, brightness, and saturation as its three 
dimensions. A particular colour concept, e.g. "green", would then correspond to a coherent region in such a 3D-space. It would involve the hues around the "prototypical green" in (7a); a medium range of brightness values from $(7 \mathrm{~b})$, coupled with a range of saturation values from (7c) that at least excludes the transparent end of the scale.

However, as argued in detail by Geuder \&Weisgerber (2005), a literally geometrical representation in terms of a unified metrical space is not a generally viable technique for the representation of concepts of all kinds, even though it does seem to work for colours and other simple properties. Therefore, let me use a more abstract representation that takes up the idea of having separate tiers ("feature dimensions") which are made up from property values.

Let us say that the conceptual substructure of a predicate $\mathrm{P}$ provides sets $\mathrm{Q} 1, \mathrm{Q} 2, \ldots$, Qn, called the conceptual dimensions of $\mathrm{P}$, such that each $\mathrm{Q}$ is made up of a number of mutually incompatible property values:

$$
\begin{aligned}
\mathrm{P}: & <\mathrm{Q} 1=\{\mathrm{q} 1 \mathrm{a}, \mathrm{q} 1 \mathrm{~b}, \mathrm{q} 1 \mathrm{c}, \ldots\}, \\
& \mathrm{Q} 2=\{\mathrm{q} 2 \mathrm{a}, \mathrm{q} 2 \mathrm{~b}, \mathrm{q} 2 \mathrm{c}, \ldots\}, \\
& \mathrm{Q} 3=\{\mathrm{q} 3 \mathrm{a}, \mathrm{q} 3 \mathrm{~b}, \mathrm{q} 3 \mathrm{c}, \ldots\}, \ldots>
\end{aligned}
$$

For the colour "green" as an example, we would have the substructure Q1 x Q2 x Q3, which can be characterised as follows:

green:

$<$ QHUE $=\{\ldots, \mathrm{q} 1 \mathrm{a}, \mathrm{q} 1 \mathrm{~b}, \mathrm{q} 1 \mathrm{c}, \ldots\}$ (a set which includes the various "green" hues), QBRIGHTNESS $=\{\ldots, \mathrm{q} 2 \mathrm{~b}, \mathrm{q} 2 \mathrm{c}, \ldots\}$ (brightness values, excluding at least the extrema "black" and "white"),

QSATURATION $=\{\ldots \mathrm{q} 3 \mathrm{~b}, \mathrm{q} 3 \mathrm{c}, \ldots\}$ (excluding at least the extreme values in the region "fully transparent") >

While in this particular case, an ordering can be imposed on the values, this need not be the case in general.

\subsubsection{Modifiers}

Let us now see how this simple model can be used to account for modification. The idea in Gärdenfors (2000) is to see modification as an operation that restricts the allowed range of property values of a concept in (at least) one dimension. Indeed, it appears that the modifiers which can appear with colour terms can be sorted into the dimensions outlined above:

$$
\begin{array}{lll}
\text { blaugrün } & \text { hellgrün } & \text { blassgrün } \\
\text { blueish green } & \text { bright green } & \text { pale green }
\end{array}
$$

Here is a sketch of how the modification operation works. Let us consider the example hellgrün ("bright / light green"). The modifier hell is indexed for the quality dimension "brightness" and hence targets only the brightness dimension of the modified concept "green", leaving its other dimensions unchanged.

(11) a. hell QBRIGHTNESS $=\{\ldots, \mathrm{hw}, \mathrm{hx}, \mathrm{hy}, \mathrm{hz}\}$

b. grün $<\mathrm{QHUE}=\{\ldots, \mathrm{ga}, \mathrm{gb}, \mathrm{gc}, \ldots\}$,

$$
\begin{aligned}
& \text { QBRIGHTNESS }=\{\ldots, \mathrm{q} 2 \mathrm{~b}, \mathrm{q} 2 \mathrm{c}, \ldots\}, \\
& \text { QSATURATION }=\{\ldots \mathrm{q} 3 \mathrm{~b}, \mathrm{q} 3 \mathrm{c}, \ldots\}>
\end{aligned}
$$

c. hell (grün)

$<$ QHUE - unchanged, 


\section{QBRIGHTNESS = QBRIGHTNESS(hell) ^QBRIGHTNESS(grün),} QSATURATION - unchanged >

While this account of modification targets property values, it is equivalent to the familiar view of modification as intersection of extensions. This is so because the feature values on each dimension are mutually exclusive, so every object in the extension of a predicate must have exactly one value in each dimension. Consequently, all n-tuples of values from $Q 1 \times Q 2$ $x \ldots x Q n$ are mapped onto disjoint sets of objects, and every operation that restricts the set of admissible feature values has the same effect on the extension of the predicate.

\subsubsection{Manners vs. Degrees}

Given that the modification operation just described involved scales of ordered feature values, there is some similarity with degree modification, and some remarks are in order as to the distinction between subsective modification and degree modification. It is not immediately clear whether the instances discussed above should be called "manner modification", but manner modifiers can in any event be grouped with other typical intersective modifiers and contrasted with degree modifiers.

Obviously, degree scales are based on a decomposition of properties into feature values, too. In modifying the property scales that form the dimensions of colour concepts, however, we used modifiers which themselves had a conceptual content in terms of a property scale. This, then, is a first difference to degree modification: Degree modifiers carry an abstract specification for regions on arbitrary property scales, e.g. very denotes the upper end of any degree scale. Therefore, degree modification involves an additional step of mapping from a set of feature values onto an abstract scale of degrees, and degree modifiers operate on the latter.

Moreover, it could be seen that we were dealing with modifiers that applied to "multidimensional" conceptual structures, and these are exactly the ones that are hard to combine with degree modifiers. This difference is expected because modifiers that are indexed for some particular conceptual domain will be able to retrieve their designated domain when applied to a larger conceptual structure in the process of modification. For degree modifiers to work, however, we need a predicate that denotes one single scale, i.e. a property (in the narrow sense). It is possible to force the application of degree adverbs to complex concepts, for instance, in German we find clear cases of degree modification with verbs (cf. Stamm 2005). Either we have to formulate specific conditions as to the accessibility of particular gradable meaning dimensions inside a complex concept, a particular type of prominence that makes a conceptual dimension accessible for simple degree modifiers; or we have to formulate a mechanism that is able to map the whole concept onto a scale (say, a scale of intensity), and apply the degree modifier to this derived scale. In any case, the distinction between degree and intersective / manner modification remains intact.

As a last aspect of this distinction, we cannot reasonably suppose that all property dimensions of arbitrary concepts will always involve a scale of ordered values, although this was the case with the three dimensions of colour. The mechanism of restricting sets of feature values sketched in 3.1.2 above is also available for property dimensions without scalar ordering, while degree modification cannot apply in such a case. This is the case with the more complex concepts that I am now turning to.

\subsection{Predicates of Light Emission}

In this section, the conceptual approach will be applied (with modifications and extensions) to a set of examples that are more crucial for Maienborn's (2004) argument that certain statives do not show effects of an event argument. Consider her example (12a) along with the 
contrasting examples $(12 b-c)$ :

a. Die Perlen glänzten matt / rötlich / feucht

(The pearls were gleaming + modifiers: dull / reddish / moist)

b. Das Licht war ?? feucht hell / ?? rötlich hell

(The light was moistly / reddishly bright)

c. Die Lampe leuchtete hell / rötlich / ?? feucht

(The lamp was shining brightly / reddishly / moistly)

Example (12b) (not provided by Maienborn) contrasts with (12a) in the same fashion as the group of examples introduced earlier in (2c): glänzen (gleam, glow) allows a whole range of modifiers while the adjective hell (bright) does not admit any of them. In spite of the neat contrast between (12a) and (12b) it can already be seen that there is no clear-cut division between just two types of predicates: the verb leuchten (shine (intr.)) allows some of the modifiers that may appear with glänzen, but not others. This calls for an examination of the conceptual interpretations in more detail.

\subsubsection{Re: (12b) Das Licht war ?? feucht hell / ?? rötlich hell}

Example (12b) can already be understood on the basis of what has been said in the section on colour concepts above. Modification fails because the conceptual substructure of hell (bright) is a simple scale and does not provide isolable property dimensions that manner modifiers could target inside it. There is a slight complication here in that the construction rötlich hell is not immediately judged as deviant by many German speakers, but this is arguably due to interference with a compound rötlich-hell which does not have rötlich (reddish) as a modifier but rather means "reddish and bright", thus not modifying the brightness value itself. This interpretation is irrelevant to the point at hand, however.

\subsubsection{Re: (12c) Die Lampe leuchtete hell / rötlich (The lamp was shining brightly / reddish)}

With the analysis of the concept leuchten / shine we get to cases that do not yield easily to a description in terms of orthogonal feature dimensions, which is one of the things that speak against Gärdenfors' (2000) geometrical interpretation of the conceptual decomposition (in addition to the points raised in Geuder \& Weisgerber 2005).

Many concepts require an analysis with a richer structure in which the conceptual dimensions are linked via additional relations and constraints. Such structures have been described e.g. in the frame theory of Barsalou (1992). A first inspection of the model in Barsalou (1992) shows that some of the "relational links" which his model provides correspond to aspects of the model already given in section 3.1 above. In particular, Barsalou's "TYPE" relation mirrors the relation between conceptual dimensions and their property values, i.e., the "TYPE" relation serves to split a concept into mutually exclusive values that implement it. A further relation which Barsalou calls "ASPECT-OF" is what serves to couple a set of (what we have called) "dimensions" to form a concept. This structuring is thought to be recursive, however: a concept may be decomposed into sub-concepts which themselves exhibit a decomposition into quality dimensions.

A comprehensive review of frame theory is clearly beyond the scope of this paper, and for the present purpose, it will suffice to adapt its major ingredients into a simplified representation. However, a weakness of the system in Barsalou (1992) which must be pointed out is that the "ASPECT-OF" link serves as a cover term for a whole number of different relations without reflecting any further differences. In particular, it treats conceptual dimensions of verb 
meanings on a par with participant roles. In my representation of the verb leuchten / shine, I will therefore annotate the structure with functor-argument relationships. Hence, the meaning of leuchten will be decomposed basically as "(for a source) to emit light", with the appropriate "ARGUMENT" links between these two aspects of the concept, plus a some sub-aspects of each of the main constituents that can be easily identified. The component "light" makes recourse to the concept "colour" which has already been analysed.

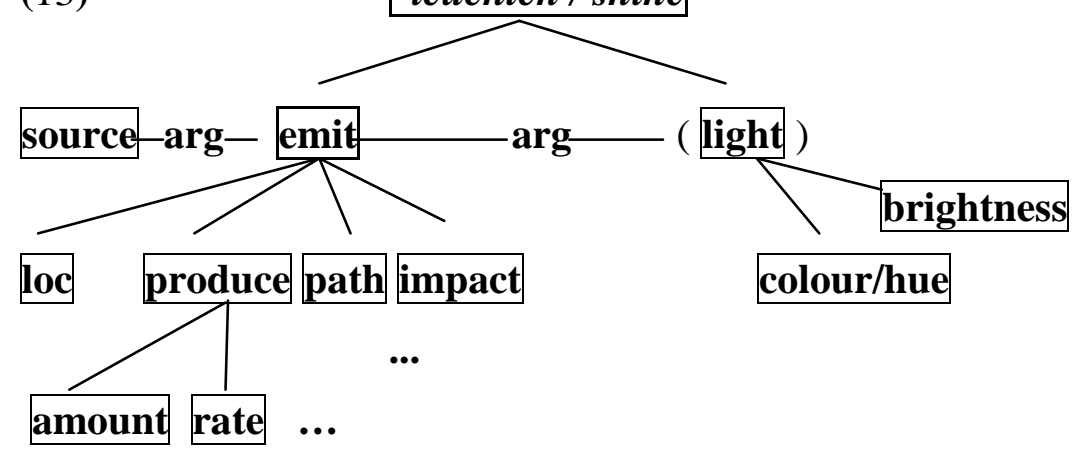

The conceptual constituent related to "emission" will minimally have to involve the characterisation of a process of light production, a path of the light emitted and a characterisation of what happens at the endpoint ("impact", e.g. visibility). Obviously, the argument relation that connects "emit" with "light" has to be inherited by the subconcepts of "emit". The component "light" functions as an argument, it is true, but does not surface in the argument structure of the verb; therefore it is simultaneously classified as a conceptual dimension (more on this topic below).

Without going too far into the details of conceptual knowledge that are implicit in this decomposition, let me point out that many modifiers can be easily identified as pertaining to specific sorts of sub-concepts or property values:

\section{hell leuchten (shine brightly) : BRIGHTNESS}

rot leuchten (shine red) : COLOUR/HUE

konstant leuchten (shine constantly) : PRODUCE: RATE

schwach leuchten (shine weakly) : PRODUCE: AMOUNT \& IMPACT

In this way it becomes clear why the verb leuchten / shine supports more modifiers than hell / bright: the reason is its greater conceptual complexity. Since leuchten includes the conceptual dimension of hell, modifiers of the latter carry over to the former.

\subsubsection{Re: (12a) Die Perlen glänzten matt / rötlich / feucht (The pearls were gleaming + modifiers: dull / reddish / moist)}

As a next step, let us consider the conceptual structure of glänzen /gleam, which involves an additional degree of complexity. First of all, we can observe that nearly all the modifiers that were found to combine with the verb leuchten / shine are found here again: we get hell glänzen, rot glänzen, schwach glänzen, in parallel to the data in (14). This indicates that glänzen / gleam should incorporate much of the conceptual structure of light emission concepts.

An intriguing case, however, is the use of the adjective feucht (moist, wet) as a modifier. Note the contrast between glänzen and leuchten in this respect:

\section{(15) Die Perlen glänzten feucht}

?? Die Kugel leuchtete feucht (the pearls gleamed wet)

(the sphere shone wet) 
This contrast can be explained as being due to a meaning component of glänzen that makes reference to properties of a surface and which is absent from leuchten / shine. To see this, note that feucht as a modifier can only be construed with respect to a surface in this example, although other construals would be allowed by the lexical meaning of the adjective. A log of wood, for instance, can be said to be feucht when it is soaked through with moisture. However, in (16) this construal is excluded:

Das Holz glänzte feucht

(the (piece of) wood gleamed wet)

Here, we must be dealing with a situation in which there is water on the surface (it is easier to imagine a piece of wood with a varnished surface, which is wet), not with a piece of wood which is damp and rotten and at the same time has a varnished surface which is gleaming in the sun. How do we know that feucht may only refer to a property of a surface when it modifies glänzen? The reason must be that the verb does not provide for any other way of linking the modifier to the situation frame. This demonstrates that the notion of a surface is accessible from the verb meaning. And the reason for this is the specific way in which glänzen / gleam specidies a concept of light emission: it is light emission by reflexion at a surface. Here is a sketch of the relevant parts of the situation frame:

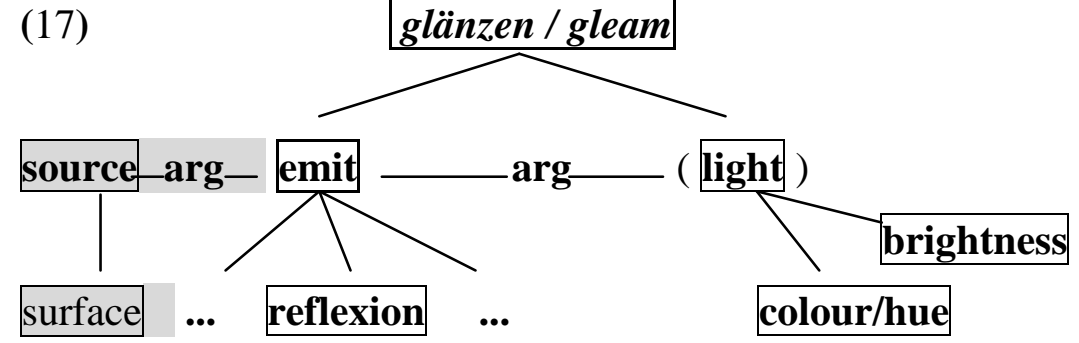

If we say that there is a "surface" feature which licences the application of the modifier feucht, however, we are running into new problems, because not any adjective that is applicable to surfaces can become a manner adverb; for instance we don't get zerkratzt or schmutzig glänzen (gleam + modifiers "scratched /dirty"). And more generally, one might raise the question of how the content of such conceptual representations is to be kept within bounds, and how endless chainings of world knowledge can be avoided: do all kinds of conceptual knowledge that are related to surfaces have to be included in (17) as well?

I propose that, indeed, we need a fixed, and selective, representation of that part of conceptual information that may interact with the semantics. Let us make the general stipulation that event concepts do not automatically inherit the conceptual dimensions of the possible referents of their argument roles - only if a predicate specifies implicit argument roles does their sortal information count as part of the predicate's meaning. This stipulation is also needed to secure the conclusion from the discussion surrounding (16) above: the alternative interpretation which was found unavailable for (16) (a log of wood soaked through with moisture and gleaming for some other reason) would actually correspond to a simple predication of feucht / moist on the subject of the sentence. Therefore, we generally have to exclude a construal of modifiers as simply predicating of the subject argument. Arguably, this predicational relationship is only possible in a different grammatical construction, namely a depictive construction. (See Geuder 2004 for details about the semantic delimitation between depictives and adverbial modifiers, and Geuder (2000, ch. 3) for further substantiation of the claim that manner modifiers exclude predication of a syntactic argument but can be licenced by implicit argument roles).

These considerations lead to the conclusion that the shadowed part in (17) is not a possible target for a manner modifier. If this is true, the mechanism of modification in the example feucht glänzen must be of a different kind than the one in (13-14). We are led to the conclusion that one of the core conceptual dimensions must undergo modification, not just the 
"source / surface" part.

The solution to this problem is that, this time, the modifier applies in an indirect fashion technically, by invoking what is called a CONSTRAINT in Barsalou (1992), i.e. a correlation between values which is part of the knowledge base. The very concept of "reflexion of light at a surface", which is at the heart of the meaning of glänzen / gleam, involves knowledge about a correlation between properties of a surface and corresponding qualities of the light emitted by it. To begin with, the surface has to have a certain smooth texture for reflexion to be possible at all, and moreover particular materials, such as water, are associated with their own characteristic pattern of light reflexion. This piece of knowledge must enter into the calculation of the conceptual interpretation of the modifier.

Let us invoke an additional attribute "radiance" in the representation below to capture more differences in the qualities of the light emitted:

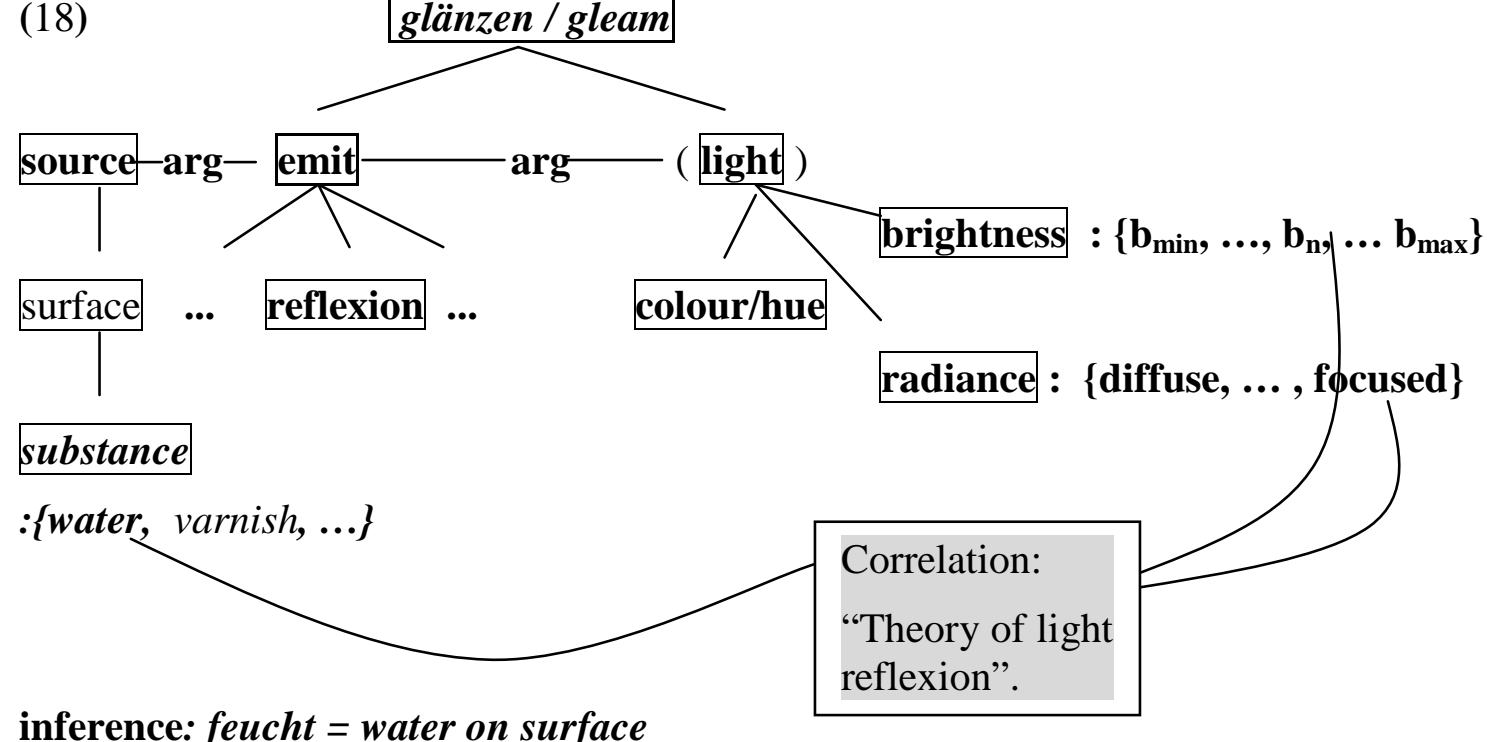

As I have said, manner modification must involve one of the core conceptual dimensions of glänzen. This is indeed possible due to the correlation of "radiance" and probably "brightness" with properties of surfaces - provided that an inference is added that the predication by the modifier feucht concerns a surface. Via the said correlation, this modifier then effects a restriction of property values in the "radiance" and "brightness" dimensions, and thus indirectly targets the conceptual core of glänzen, even though it does not bear a lexical specification that targets these conceptual dimensions.

Let us sum up the findings concerning the indirect restriction of an event property, in which properties associated with entities external to the event concept plus a constraint on correlations of property values yields a restriction on event-internal property values. The shifted interpretation of an adjective A, for application as a modifier to an event concept $\mathrm{C}$ then derives as follows:

(19) $\operatorname{MANNER}_{(\mathbf{C})}(\mathrm{A})$ is a set $\mathrm{S}$ of property values q such that for some $\mathrm{a} \in \mathrm{A}$ :

$\exists \mathrm{Q}$ in $\mathrm{C}$ with $\mathrm{q} \in \mathrm{Q}$, and GEN $[\mathrm{a}(\mathrm{x}) \Rightarrow \mathrm{q}(\mathrm{e})]$ (for some $\mathrm{x}$ )

Interpretation:

$\operatorname{MANNER}_{(\mathbf{C})}(\mathrm{A})(\mathrm{C})$, with $\mathrm{Q}_{\mathbf{1}}, \ldots, \mathrm{Q}_{\mathbf{n}}$ as the conceptual dimensions (attributes) of C: $=$ the structure $C$ with $S \cap Q_{i}$ replacing $Q_{i}$, unchanged elsewhere. 


\subsection{D-States}

We have now arrived at a fairly elaborate view on how manner modification may be governed by the conceptual complexity of verb meanings. Naturally, all that could be done here is to lend this claim some credibility; there is no proof in the strict sense, because the argumentation would be complete only after in-depth analyses have been conducted of each single verb type and its modifiers.

In order to provide some further substantiation for the conceptual approach to manner modification, let me now sketch an account for the intriguing contrasts uncovered by Maienborn (2004, 2005) which concern "minimal pairs" such as the following (partly taken from Maienborn, with contrasting examples added to (20b-c):
a. Bardo schläft friedlich.
(B. is sleeping peacefully)
* Bardo war friedlich müde
(B. was peacefully tired)
b. Carolin saß reglos am Tisch.
(C. sat motionless at the table)
?... war reglos aufrecht
(? C. was motionless upright)
c. $\quad *$ Carolin war geduldig durstig
(* C. was patiently thirsty)

Carolin schmachtete geduldig in der Hitze

(roughly: C. was patiently suffering / parched in the heat)

These examples show manner modification with "D-states", i.e. Maienborn's "eventive" subtype of states. I think it is important to observe that all these modifiers form a coherent semantic class — they speak about "things not happening":

$$
\begin{array}{lll}
\text { friedlich } & \text { peaceful } & =\text { "without disturbance" } \\
\text { reglos } & \text { motionless } & =\text { "without moving" } \\
\text { geduldig } & \text { patient } & =\text { "without losing calmness / without change of attitude" }
\end{array}
$$

Accounting for these cases requires a new property dimension, which I would like to identify as "the continuation / termination conditions for a state". Hence, we are dealing here with a feature that is to some extent a dynamic, hence eventive, feature. While this feature is not dynamic in the sense of asserting change, it speaks about potentials of change. A device for representing this is already in place in the framework of Barsalou (1992), namely a link of the type "STATE". This relation serves to specify property values (of object concepts) which cooccur in an event because they appear in a sequence. The particular pattern of sequencing itself is stated separately as a conceptual dimension of its own. Consider the following sketch of the concept schlafen / sleep:
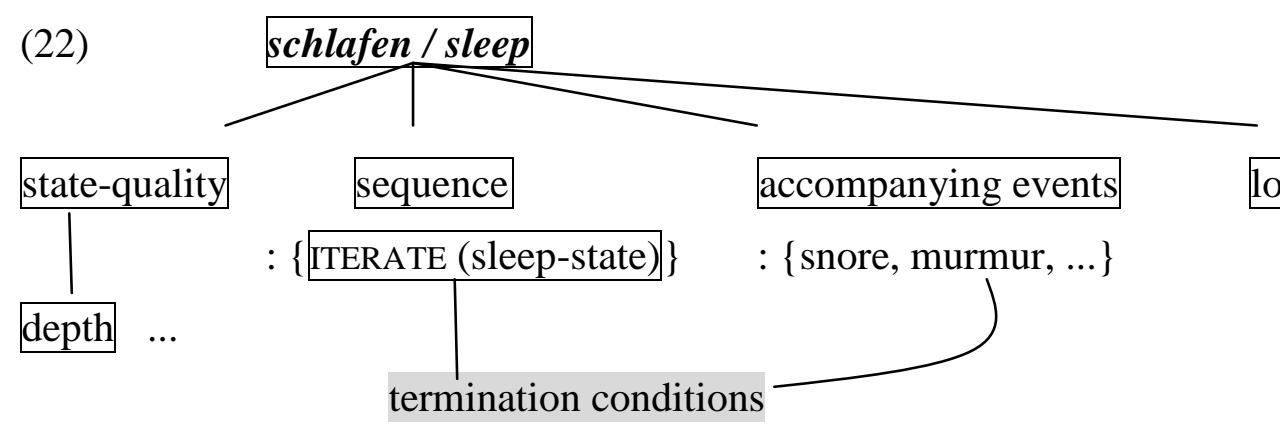

In this representation, Barsalou's "STATE" link has been rewritten as an iteration instruction, since we are dealing with a succession of states of the same type. The basic idea is then that event and state concepts may specify termination conditions: it is certainly part of our conceptual knowledge about sleeping that it is terminated by waking up. We can now begin to 
understand the meaning of the modifier friedlich / peaceful via a correlation between termination conditions and accompanying events of sleeping: the modifier indicates "absence of disturbance", i.e. there are no accompanying events of a kind that could trigger, or come close to triggering, termination of the situation.

The introduction of a conceptual dimension of iteration / termination conditions should suffice to indicate the direction of an analysis; however, for reasons of space, this cannot be elaborated in more detail in this paper. In sum, however, it seems to me that this type of attribute is at the core of Maienborn's $(2004,2005)$ distinction between "event-like" and "property-like" statives. It should have become clear that this distinction can be modelled without making recourse to different types of referential arguments.

At the same time, however, it would not seem to be incompatible with Maienborn's analysis: predicates referring to abstract objects may well turn out to have a poorer conceptual structure than concrete, eventive predicates. The sortal distinction would then be in parallel to the differences in conceptual structures. In the first place, therefore, the conclusion to be drawn is that the the analysis of manner modification is independent of the issue of neo-Davidsonian arguments with statives. The argument that predicates lack an event argument because they do not support (certain) manner modifiers is not valid.

\section{Conclusions and Outlook}

In the preceding sections, the restrictions on how various verbs and adjectives select their modifiers have been derived from the conceptual content of the predicates in question. I have defended the thesis that it is the factor of conceptual complexity which determines the range of modification options. If a group of predicates is observed to allow fewer modifiers than others, this can therefore be seen as pointing to a smaller conceptual complexity.

We are then led to the expectation that what Maienborn $(2004,2005)$ identifies as K-states on the basis of manner modification data, is actually to be characterised as a group of concepts with relatively poor conceptual substructure. It has already been pointed out that restrictions on manner modification cannot be used as an argument against a neo-Davidsonian analysis of states, because these two issues are orthogonal. We are now left with the question of whether the results of the conceptual model of modification are at least compatible with the claim of sortal differences.

One thing that casts doubt on having a sortal distinction between two types of statives is that it predicts a clear-cut dichotomy. The analysis of modifiers (e.g. with bright / shine / gleam) does not support such a dichotomy. The considerations in section 3.3 rather suggest that between "static" and "dynamic" concepts there is a grey area of concepts variously involving "dynamic potentials". It is not clear that all such concepts can uniformly be analysed as eventdenoting and as being in contrast to nondynamic concepts. Deciding this point has to be left for future work, though.

Moreover, we are still not in a position to provide a clean definition of what is a manner adverb and what is not, although, of course, the claim that (certain) statives do not allow manner modification would require such a definition. This problem similarly applies to the work of Katz (2003), who likewise maintains that statives do not have Davidsonian arguments, and who proposes that all modifiers of statives might be explained away as predicate operators, instead of being neo-Davidsonian predicates. From my perspective, this distinction is not so clear-cut. In a way, I have sketched a view in which all kinds of manner modification are reduced to operations on predicates; but this only concerned the level of conceptual analysis, not semantic composition in the clause. My account could be implemented in Logical Form either as composition via predicate operators or via Davidsonian predication. In an extensional, neo-Davidsonian representation, a manner adverb 
would appear as a context-sensitive property of events. This is to say, adverbial modifiers, defined via a set of property values as in (19) above can always be mapped onto a set of events, i.e. a neo-Davidsonian predicate of events. The template $\operatorname{MANNER}_{(\mathbf{C})}(\mathrm{A})$ (for a modifier $\mathrm{A}$ in the context of an event predicate $\mathrm{C}$ ) would then represent a lexical operation that shifts an adjective A, initially a predicate of some other sort of entities, to a predicate of events, in a way which is sensitive to the meaning of $\mathrm{C}$. Then, the neo-Davidsonian representations of the modifiers would not reflect their underlying lexical-conceptual format; rather, the neo-Davidsonian semantics for manner modification would have to be seen as a purely compositional device. (This position has already been expressed in Geuder 2000).

In spite of the continuing uncertainty as to the precise delimitation of manner modification, one of the positive results of the present work is that a conceptual definition of "manner modification" is at least within reach. Still, we have various options as to how we can define a class of "manner adverbs" from the background of conceptual structures:

- Variant 1: Manner $=$ "Modifiers that restrict some conceptual dimension of a multidimensional concept (a predicate of category V?)"

This is the most liberal way of defining manner. It would create a minimal contrast between hell rot "brightly red" (more than one dimension, hence "manner") and angenehm hell "pleasantly bright" (scalar adjective, hence no "manner"). Usually, however, all subsective modifiers of nouns would also be excluded from the class of "manner modifiers", in spite of well-known semantic parallels between many noun and verb meanings; and I have never seen the term "manner" applied to adjectives. It also remains unclear whether all subsective modifiers of verbs should be included.

- Variant 2: Manner = "Modifiers that restrict some conceptual dimension of an eventdenoting predicate"

The distinction sounds intuitively appealing, but, evidently, it begs the question as to which predicates denote events! The definition probably creates minimal pairs like: hell leuchten "shine brightly" (manner) vs. hell rot "brightly red", but it would not contribute to an understanding of the difference.

- Variant 3: Manner = "Modifiers that restrict an eventive type of conceptual dimension"

In this way, not all subsective modifiers of verbs, but only those addressing change-ofstate concepts or continuation conditions (etc.) inside a verbal concept would qualify as manner modifiers. This begins to appear overly strict, as it would characterise friedlich schlafen "sleep peacefully" as manner modification, but exclude the type hell leuchten "shine brightly".

Probably, "manner modification", while not devoid of content, is going to remain a notion without sharp boundaries. All in all, then, I conclude that the facts about manner modification point to a continuum between eventive and stative concepts, and that manner modification cannot be reduced to matters of Logical Form and predication of Davidsonian arguments.

\section{References}

Barsalou, L.: 1992, Frames, Concepts, and Conceptual Fields, in A. Lehrer \& E. Kittay (eds), Frames, Fields, and Contrasts. Hillsdale NJ: Erlbaum, pp. 21-74

Davidson, D.: 1967, The logical form of action sentences, in N. Rescher (ed), The Logic of Decision and Action, Pittsburgh: The University of Pittsburgh Press, pp. 81-95 
Geuder, W.: 2000, Oriented Adverbs. Issues in the Lexical Semantics of Event Modifiers, doctoral dissertation, Universität Tübingen. (Universität Tübingen online publication service: http://w210.ub.uni-tuebingen.de/dbt/volltexte/2002/546/ )

Geuder, W.: 2004, Depictives and Transparent Adverbs, in J. Austin, S. Engelberg \& G. Rauh (eds), Adverbials. The Interplay between Meaning, Context and Syntactic Structure. Amsterdam: Benjamins, pp. 131-166.

Geuder, W. \& Weisgerber, M.: 2005, On the Geometrical Representation of Concepts. Ms. Universität Konstanz.

Katz, G.: 2000, Anti neo-Davidsonianism: against a Davidsonian semantics for state sentences, in C. Tenny \& J. Pustejovsky (eds), Events as Grammatical Objects, CSLI Publications, 393-414

Katz, G.: 2003, Event arguments, adverb selection, and the Stative Adverb Gap, in E. Lang, C. Maienborn \& C. Fabricius-Hansen (eds): Modifying Adjuncts, Berlin: Mouton de Gruyter, pp. 455-474

Kim, J.: 1976, Events as Property Exemplifications, in M. Brand \& D. Walton (eds), Action Theory. Proceedings of the Winnipeg Conference on Human Action, Dordrecht: Reidel, pp. 159-177.

Maienborn, C.: 2004 (Ms., forthcoming), On Davidsonian and Kimian states, To appear in I. Comorowski \& K. v. Heusinger (eds), Existence: Semantics and Syntax. Berlin: Springer.

Maienborn, C.: 2005, On the Limits of the Davidsonian Approach: The Case of Copula Sentences (Target Article), Theoretical Linguistics 31-3, 275-316

Parsons, T.: 1990, Events in the Semantics of English, Cambridge MA: MIT Press.

Stamm, H.: 2005, On the Semantics of Gradation of Verbs. Talk presented at "Sinn \& Bedeutung X", Berlin, Humboldt University, October 15, 2005 


\title{
ManNer ANd Causation in Movement VerbS
}

\author{
Wilhelm Geuder \& Matthias Weisgerber, \\ Universität Konstanz / SFB 471
}

\{wilhelm.geuder | matthias.weisgerber\}@uni-konstanz.de

\begin{abstract}
This paper investigates the semantic underpinnings of the distinction between two syntactic types of "manner of movement" verbs in Levin (1993), namely the RUN and ROLL classes. According to Levin's (1993) and Levin \& Rappaport's (1995) work on unaccusativity, a semantic factor of "internal causation" should be the trigger for the classification of a movement verb as intransitive (=not-unaccusative), and hence for its belonging to the RUN class. We point out empirical problems for this characterisation, mainly coming from the different readings of the German verb fliegen (fly). From a comparison with other semantically similar verbs, we conclude that the semantic description which underlies the class distinction should be refined: instead of "internal causation", the crucial semantic factor is described here as "inherent specification for a momentum of movement". This result indicates that forces, and relations between forces, have to be part of the semantic description of the manner component in movement verbs.
\end{abstract}

\section{Introduction: Manner-of-Movement Verbs}

\subsection{A Syntactic Distinction}

A topic in verb semantics that has continued to attract attention is the distinction between two types of movement verbs, viz. "directed motion" vs. "manner of motion" verbs. In view of the large amount of literature devoted to this distinction, astonishingly few authors have addressed the issue of explicating the notion of "manner of movement", which lies at the bottom of this whole strand of research. One work which offers at least a subclassification of manner of movement verbs is Levin (1993). Levin notes a major contrast between two classes of manner of motion verbs, which she dubs the ROLL class and the RUN class. Here are some examples:

\begin{tabular}{|l|l|}
\hline run-class & roll-class \\
\hline $\begin{array}{l}\text { amble, climb, fly, jump, } \\
\text { tiptoe, ... }\end{array}$ & $\begin{array}{l}\text { drift, drop, float, revolve, } \\
\ldots\end{array}$ \\
\hline
\end{tabular}

This grouping first and foremost reflects a syntactic distinction and is therefore connected to verb semantics only in an indirect fashion. As amply discussed in Levin \& Rappaport (1995), the ROLL class consists of verbs whose single argument behaves as an underlying object, i.e. they are unaccusative verbs (even when occurring in isolation), while the RUN class, in contrast, consists of verbs which are intransitive in a strict sense $^{1}$, i.e., verbs with an underlying subject argument (even if these verbs may enter into unaccusative constructions when combined with directional PPs).

\footnotetext{
${ }^{1}$ We want to avoid the awkward terminological opposition "unaccusative" / "unergative", so the term "(strictly) intransitive" will be reserved here for verbs with an underlying subject, as opposed to unaccusative verbs; the cover term which we use for the larger class of verbs with one argument is "one-place verbs".
} 
An important test for this distinction in English are constructions with a resultative adjective. As a rule, an adjective that adds a resultant state to a process verb can only be predicated of a syntactic object, cf. (2a-b) below. True intransitive verbs may still appear in this construction, but then a dummy reflexive object has to be inserted, as in $(2 \mathrm{~b})$.

(2) a. John kicked the door open

b. The children ran themselves tired. / * The children ran tired.

c. The door ${ }_{i}$ rolled $\left[t_{i}\right]$ open

Example (2c) then shows how resultative constructions can be used as an unaccusative diagnostic: unaccusative verbs are a class of seemingly exceptional one-place verbs which may appear in this construction with just their sole argument and without dummy reflexive object. The reason is that the sole argument of an unaccusative verb counts as an object for the purpose of the predication rule. ${ }^{2}$

\subsection{Semantic Correlates}

Levin \& Rappaport (1995) have investigated the question as to the semantic triggers of unaccusativity in great detail. They propose a set of linking rules, whose interaction derives the difference between verbs with underlying objects and underlying subjects. Given that verbs of manner of movement do not intrinsically denote a change of state - which is the single most important factor that triggers unaccusativity - what is most important for us are their "immediate cause linking rule" and the "default linking rule".

Consider first the formulation of the "immediate cause" linking rule:

\section{Immediate Cause Linking Rule}

"The argument of a verb that denotes the immediate cause of the eventuality described by that verb is its external argument."

(Levin \& Rappaport (1995), p.135)

One-place verbs which assign such an immediate causer role to their only argument are therefore intransitive. It is important to sort out some fine points in the interpretation of this rule, however. As the authors stress, an immediate cause(r) is not the same as an agent or a participant that exerts control over a situation. For example, verbs like hiccup may describe involuntary actions, but the immediate cause of the situation still lies with the subject. The same is true for verbs of emission, like shine or stink, and for verbs which denote the maintenance of a position or configuration, like kneel. With respect to examples of this kind, the authors explain their concept of causation as follows:

\section{(Internal) Causation:}

“...The concept of internal causation subsumes agency. However, an internally caused verb need not be agentive ... For example, the verbs blush and tremble ... can ... be considered to describe internally caused eventualities, because these eventualities arise from internal properties of the arguments."

(Levin \& Rappaport (1995, p. 91))

The notion of "internal causation", which figures here is a subcase of the general concept of causation. If we are to apply the immediate causer rule to movement verbs, then internal causation is what is relevant for manner of movement verbs. In general, the notion of "internal causation" serves to separate verbs like the ones just discussed from "external causation" in which the causer is not involved in the manner of the event but merely sets

\footnotetext{
${ }^{2}$ For our purposes, it is not necessary to resolve the question of whether the unaccusativity tests really establish a difference in the syntactic position of the argument, or whether they are sensitive to a semantic classification of verbs. For ease of exposition, we adopt the syntactic parlance.
} 
things into motion. This latter class of verbs allows the causer to be dropped, giving rise to the causative-inchoative alternation, which occurs e.g. with roll:
a. They rolled the cheese to the train station
b. The cheese rolled to the train station

External causers can only appear with transitive verbs, because otherwise the remaining core of the situation (minus the causer) would not have a participant. One-place verbs therefore can only appear with internal causers, or be unaccusative, i.e. without causer at all. This leads us to an additional criterion that supports the classification of movement verbs: If there is a transitive variant with a meaning of direct causation - like (5a) above - the corresponding one-place variant was unaccusative, and hence belongs to the ROLL class.

When we are dealing with a member of the RUN class, there may sometimes be transitivecausative variants, too, but they invariably have a meaning of indirect causation. Since the lexical meaning already specifiies an internal causer, the addition of another causer subject in the transitive construction leads to a chaining of causes, i.e. a role of indirect causer for the highest argument, and a role of immediate causer for the other one. For example, in (6) below, the subject is an indirect causer because it is understood that it is still the rat itself that does the running:

(6) The psychologists ran the rat through the maze

Levin \& Rappaport (1995) point out that in such examples the directional PP is needed for the example to be grammatical. This seems to be related to the finding that addition of a directional PP creates a change in syntactic categorisation, turning any agentive movement verb into an unaccusative construction. In other words, there is a linking rule according to which a feature of directionality of movement triggers unaccusativity, and this rule overrides the causer rule (Levin \& Rappaport 1995, p. 158). Apparently, then, what happens is that a syntactically unaccusative structure is needed as a basis for causativisation to apply. The conceptual content of the verb's meaning is not lost, however, even if the directional PP creates a change in syntactic categorisation. Hence, the interpretation is that of indirect causation.

In sum, we can use causativisation patterns to diagnose a lexical verb as unaccusative, provided we make sure that the interpretation involves direct causation and that the derivation also works in the absence of a directional PP. Verbs of the RUN-class, in contrast, show a different causativisation pattern: causatives are confined to structures with directional PPs.

\subsection{Unaccusativity as Default}

There is one further component of Levin \& Rappaport's model that we need to take into account here:

\section{Default Linking Rule}

"An argument of a verb that does not fall under the scope of any of the other linking rules is its direct internal argument."

(Levin \& Rappaport (1995, p.154))

We need not be concerned with the question of which other linking rules there are - none of them would be relevant to the group of manner of movement verbs. But what is important is the default status of unaccusativity that follows for one-place verbs: if no particular semantic property is present that triggers linking of a verb's sole argument to the subject position (or object position), the single argument will be treated like an object. As a consequence, it would only be the RUN-class which carries a positive semantic specification for a feature "internal 
causation". In contrast, the unaccusative ROLL-class is an "elsewhere" case with no unified semantic definition.

In sum, then, the ROLL class emerges as a class of verbs which appears to be underspecified in two respects: these verbs do not provide a causer of the situation they describe, and they do not exhibit a positive specification that defines them as a unified semantic class. In contrast, RUN verbs are a type of manner of movement verbs which have a positive semantic specification (internal causer) that defines them as a unified class in terms of syntactic and semantic classification.

\section{The Problem of Double Classification}

We now want to discuss an apparent drawback of the classification of manner of movement verbs shown in (1) above, namely the fact that a large number of verbs is listed by Levin (1993) in both groups simultaneously. In other words, there appears to be a large amount of lexical variability with respect to the semantic factor that determines unaccusativity, and one might ask whether this blurring of the categories is a reason to doubt the lexical-semantic relevance of the grouping.

\begin{tabular}{|l|l|}
\hline RUN-class & ROLL-class \\
\hline amble, climb, fly, jump, & drift, drop, revolve, rotate, \\
float, glide, slide, roll (!), ... & float, glide, slide, roll, ... \\
\hline
\end{tabular}

The doubling of the entries in the second line of each cell points to the fact that certain verbs can be construed as internally caused movement or, alternatively, as movement brought about by an implicit external force. The resultative test confirms that these really belong to two separate classes:

a. The curtain rolled [ $(*$ itself $)$ open].

b. The children rolled [the grass flat].

(Levin \& Rappaport 1995: 209-10)

Example (9b) is understood as describing a volitional action by the children. The resultative construction displays the structure of intransitive verbs in that it allows an additional object that is not selected by the verb roll but case-marked by it. The appearance of a non-selected object is a phenomenon which is akin to the insertion of a dummy reflexive; unaccusative verbs are unable to support either type of object.

The reason for the fact that only some of the verbs but not all of them allow the alternation in (9) should obviously be sought in their lexical semantics. Levin \& Rappaport (1995: 211) state: "The variable behavior of certain verbs of manner of motion is simply the result of the existence of a lexical semantic constant that, by virtue of its nature, is basically compatible with more than one lexical semantic template." In other words, the manner component in the meaning of the verb roll is neutral with respect to the feature [ \pm internal causation], and so a feature of internal causation may be freely added. We take the quotation to mean that this difference in interpretation can be represented as the augmentation of a semantic template:

$$
\mathrm{x} \text { PROCESS }_{<\text {ROLL }>} \rightarrow \quad \mathrm{x} \text { PROCESS }<\text { ROLL }><\text { INTERNALLY CAUSED }>
$$

It may be noted that the variability of ROLL verbs only concerns causation while the manner of movement remains unchanged. Hence, this is not a case of lexical ambiguity, i.e. involving different lexical entries, but an instance of productive polysemy. The augmentation is only possible if the specification of a causer feature is absent from the semantic core of the verb, 
and this in turn is exactly a trigger of unaccusativity. Therefore, we conclude that the existence of these two variants is actually not an irregularity that threatens the semantic relevance of the classification, but rather on the contrary, it shows a hallmark of the ROLLclass, which is to be predicted from lexical semantics. We have to view the alternating verbs as ROLL verbs in their underlying form, with the proviso that they may acquire an additional semantic feature and switch to a grammatical realisation as an intransitive.

In this way, the phenomenon of double classification is a direct result of the semantically underspecified character of ROLL verbs noted in section 1.3 above. Note, incidentally that the class of unaccusatives again proves to be heterogeneous, because not all ROLL verbs are able to undergo the shift in (10). Hence, it is possible for a verb to belong to the ROLL class, and be unaccusative, not because it is unspecified with respect to causation, but because it is negatively specified wrt. the possibility of internal causation and so blocks the application of (10).

\section{The Problem of the Verb fliegen / fly}

\subsection{Variants: Conceptual Modulation}

In this section, we get to a problem that turns out to be the mirror image of the case discussed in section 2, namely a verb that should be expected to switch between classes but which doesn't. The German verb fliegen, and its English counterpart to fly display a range of uses that seems to replicate the distinction between internally caused and externally caused variants:

(11) a. Ein Vogel flog durch das Fenster

A bird flew through the window

b. Das Flugzeug flog durch die Wolken

The plane flew through the clouds

c. $\quad$ Ein Stein / Eine Gewehrkugel $\}$ flog durch das Fenster

\{A stone / A bullet\} flew through the window

In (11a) it is clear that the bird is an internal causer, since birds fly by moving their wings. For examples like (11b) it is hard to judge to which extent causation is internal (do we have to acknowledge the pilot of the plane as an external causer?), but it is clear that the plane is still generating the movement. (11c) behaves differently from (11a-b) since the bullet is known to have been fired from a gun - the bullet itself is not something that brought about the situation because of its intrinsic properties. In light of the preceding discussion, such examples are expected to class with the ROLL verbs. An example that clearly demonstrates that fly may describe situations with external causes is (12), where the context explicitly refers to one:

(12) He was shielding his head with his arms, and was hit by a large force of some kind. Nick flew through the window, shattering the glass, and ... ${ }^{3}$

In spite of all this, we are going to show that there are no indications that fliegen / fly may ever display unaccusative behaviour (in isolation). ${ }^{4}$ It can also be noted that fly is listed only

\footnotetext{
${ }^{3}$ quizilla.com/users/Sorrow1991/quizzes/Forever

${ }^{4}$ Remember that any kind of movement verb gives rise to an unaccusative construction when combined with directional PPs. Therefore, constructions with a directional PP have to be left out of consideration in our search for the correct lexical classification of the verb fliegen / fly.
} 
with the RUN class in Levin (1993), but in the detailed study of Levin \& Rappaport (1995) and in the other literature that we are aware of, there is no discussion on whether this classification is correct, and whether it is in need of explanation. So establishing and explaining the intransitive status of (11c) will be our central concern for the rest of this paper.

The unaccusative pattern of the resultative construction does appear with fly, it is true, but not in the sense of a movement verb:

(13) a. The machine flew to pieces

b. The door flew open

c. Old Nathan flew hot frequently, and the anger puffed away like flame from thistledown. But he was capable of cold rages also. ${ }^{5}$

Example (13a) could simply be about an explosion, it does not mean that pieces came off the machine as a result of flying in the air. Likewise, in (13b) there is no door flying through the air which becomes open as a result of that movement, and (13c) is a metaphorical extension that bears very little resemblance to the movement sense.

Whenever there is a sense of movement through the air, we rather get the intransitive pattern. Compare the unaccusative (13a) above with the intransitive pattern of the resultative in (14), which describes literal flying:

(14) The future looks grim My friends, if Nasa don't [...] start working on a new shuttle, one that doesn't fly itself to pieces. ${ }^{6}$

Also, we were unable to find German examples with the unaccusative pattern of the resultative construction. Most combinations of fliegen with a resultative adjective sound very marginal. One of the few clear examples ${ }^{7}$ is shown in (15) below: imagine an inflated balloon which is flying around as it is emitting the air inside. If, in the end, the balloon is empty, this would have to be expressed as in (15b), not as in (15a):
a. \# Der Luftballon ist leer geflogen ${ }^{8}$
The balloon has flown empty
b. Der Luftballon hat sich leer geflogen
The balloon has flown itself empty

Note, however, that this does probably still not count as a case of external causation, even though an agent is lacking. So we are still without a clear test to check the type (11c) above for unaccusativity.

\footnotetext{
${ }^{5}$ www.webscription.net/10.1125/ Baen/0671720848/0671720848___ 1.htm

${ }^{6} \mathrm{http}: / /$ blogorants.blogspot.com/

${ }^{7}$ Here is our second best attempt at a counterexample: In German you can have an unaccusative resultative construction with a polysemic variant of laufen / run:

(i) Der Pilot bemerkte, dass der Motor heiß lief.

The pilot noticed that the machine was running hot

Let us consider its somewhat magical counterpart in a fairy-tale world:

(ii) [Die Hexe, die den neuen Besen zum ersten mal flog, bemerkte, dass etwas nicht in Ordnung war: ] ? Der Besen flog heiß

[The witch, who was riding the new broom for the first time, noticed that something was wrong:] the broom flew hot

To the best of our judgement, example (ii) is syntactically not acceptable, but it is indeed hard to judge.

${ }^{8}$ A surface string like (15a) is syntactically acceptable but only on the irrelevant reading as an adjectival passive, not as a verbal construction with a perfect auxiliary. (15a) as an adjectival passive is the regular outcome of derivation from the verbal construction $(15 b)$.
} 
There is a second criterion that can be applied, namely causativisation. If fliegen / fly had an unaccusative variant (lacking internal causation), one might expect direct causatives. In the case of $f l y$, a direct causative would have to be similar to the meaning of "throw":

(16) * Er flog einen Stein durch mein Fenster

He flew a stone through my window

What we have to note with respect to this example is a divergence between German and English. The German sentence is clearly impossible with the intended interpretation. For the English version, we do have attestations, although they seem to be rare. Since the point is important, and tricky, we should consult our results from a web search:

(17) hi everyone, need to get a 3rd gen headlight have a hole in ours where a lorry flew a stone up and hit us (www.yotasurf-online.co.uk/ public/forums/showthread.php?p=90648)

(18) Will you fly a stone through my window like you used to do? (http://www.poetryvault.com/Display_Print.asp?ID=4729)

(19) Japan and the US began joint research into a next-generation missile defence system shortly after North Korea flew a missile over Japan in 1998. (http://news.bbc.co.uk/2/hi/asia-pacific/4104301.stm)

(20) Here's an accurate analogy of an [Toyota] MR2 being driven fast: It's like trying to fly an arrow backwards.

(http://www.hondaswap.com/forums/lofiversion/index.php/t46259.html)

(21) 'Cos You fly an arrow Straight to my heart Blow it apart...

(www.lyricshost.com/lyrics.php/

95274/Badly_Drawn_Boy_lyrics/Chaos_Theory_lyric)

When going through these examples, it seems hard to judge intuitively whether the semantics is one of direct causation of not. With respect to the example (19) involving a missile, indirect causation is most plausible, as the missile is moving by itself. More importantly, all examples involve a directional complement. This in fact aligns the examples with the derived causatives from agentive intransitive verbs that we introduced in section 1.2. There are very few exceptions with fly:

(22) It keeps hundreds, if not thousands, of people who can barely fly a paper dart rushing to your LHS to buy brightly coloured boxes covered in shrinkwrap and ... (www.wattflyer.com/forums/showthread.php?t=4400)

(23) Throw a piece of cardboard straight out like you were flying a paper plane. It will almost immediately fly at an upward angle (www.yale.edu/ynhti/curriculum/ units/1988/6/88.06.02.x.html)

It is possible, however, that single agentive verbs or even single collocations acquire a lexicalised causative variant; the same happens with walk the dog and run the dog, which do not generalise so as to yield ??The general walked the soldiers etc. Our impression is that the same is the case with the collocation fly a paper dart. A collocation fly an arrow, which would be closely analogous, could not be found in an internet search: from roughly 800 attestations of the string "fly an arrow" all relevant ones had as their larger context the construction "let fly an arrow" (with object extraposition). One may speculate that the use of "let" here even points to a conceptualisation of the situation as some kind of self-propelled movement (even though the flying of an arrow is clearly an instance of externally caused movement in terms of physics). 
So in sum, the behaviour of the verb fly exhibits close parallels to run: we have directionals in the productive causativisations, and the exception fly a paper dart is an idiosyncratic case which does not generalise.

Another observation can be made which points in the same direction: the causative uses of fly attested in (17) through (23) do not have counterparts in German. This seems remarkable in view of the fact that German fliegen otherwise exhibits almost exactly the same range of readings as fly. It reminds us of the fact, however, that German systematically disallows causative derivations of agentive movement verbs. The following sentences exemplify a pervasive pattern (the a.-sentences translate the German b.-sentences):

(24) a. The cheese rolled to the train station / They rolled the cheese to the train station

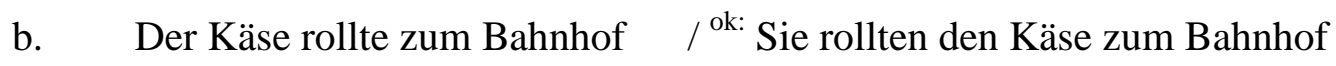

(25) a. The soldiers marched to the tent / The general marched the soldiers to the tent.

b. Die Soldaten marschierten zum Zelt

/ * Der General marschierte die Soldaten zum Zelt

In order to drive home this point, note that there are also some unaccusative verbs which block causative derivations, probably for reasons of their individual lexical semantics. For example, the verb rotate has a causative only in the sense of "turn something around an axis" (rotate the picture), but the use which involves movement along a trajectory (a planet rotates around a star) does not have a causative (with a hypothetical meaning like "insert into orbit"). This very subtle patterning of causative readings is exactly replicated by German rotieren and other German verbs of similar meaning. This parallelism is to be expected if the reason lies in some lexical semantic factor. Hence, the lack of a causativised variant of the movement verb fliegen in German is a highly significant indicator for its status as a RUN verb: it must be the pattern in (25) that we are dealing with.

We conclude that there are good reasons to believe that all uses of fliegen / fly as a movement verb pattern with the RUN-class, in spite of the fact that objects like arrows, bullets or stones are unable to act as internal causers of the movement.

\subsection{Polysemous Variants: Vehicle and Transport Readings}

There are more variants of the verb fliegen which may give some further indications as to its status as a movement verb. In this paper, we will not consider variants which we think belong to differenc conceptual domains, like a use which makes German fliegen near-synonymous to fall (Er flog in den Matsch "He fell into the mud"). What is of interest to us here is rather that there are more variants which denote a movement through the air: the German example (26) shows fliegen as a vehicle verb, and (27) as a transport verb (the range of usage in English is mostly parallel, though not entirely: many intransitive uses of fliegen in the vehicle reading would be translated as to pilot a plane). These two types are the only transitive-causative uses that German allows for fliegen:

(26) Er flog den Airbus nach Hamburg

He flew the Airbus to Hamburg

(27) Er flog die Eulen nach Athen

He flew the owls to Athens

The relevant interpretation of (26) is one in which the subject argument refers to the person who was piloting the airplane. In (27), we normally get the interpretation that the owls were carried as the load of a plane. Since the surface structure of the two sentences is the same, we 
get a number of additional interpretational possibilities that can be discarded only on the basis of reasoning from world knowledge, like the transport interpretation for (26) (but a jet will not normally be airfreighted in another one); or a kind of vehicle interpretation for (27) (but live birds would not normally do service as a mount; exceptions belong to the realm of fiction). Note also that no purely causative reading is available for (26) and (27), whether direct or indirect. Example (26), though, comes fairly close to being a causative, because piloting an airplane can be seen as indirect causation of a flying situation. Furthermore, the manner components in this use of the verb are exactly the same as in the intransitive movement variant The airbus was flying to Hamburg (compare also (11b)). Therefore, the vehicle variant can actually be said to involve the derivation of an indirect causative from the movement verb $f l y$ (even though there are other semantic differences along with this).

In sum, the absence of direct causatives in German that are based on flying as movement through the air, and the fact that some extensions of the underlying concept of movement through air display indirect causativity, is further support for the classification of the manner of movement verb fly as a RUN verb. This, however, is severely at odds with the impression that it has uses with external causation.

\section{Analysing the Meaning of fliegen /fly}

\subsection{Decomposing Causation}

As argued in section 2, the switch of some ROLL verbs to an interpretation with internal causer does not constitute an instance of deep lexical variation but is due to an underspecified slot in the lexical semantics of the verb. Notably, the manner of the movement, e.g. "rolling", does not change in this alternation. It could be argued that this is different with the variants of fliegen / fly shown in 3.1. At the very least, flying with the active use of one's wings, as birds do, seems to involve a different manner of movement than flying as of bullets. Therefore, it might be that we are dealing with real lexical polysemy in the case of fly. If the differences in manner point to lexical polysemy, the explanation of the different uses of fly would have to proceed in a way that is entirely different from the simple augmentation model that we sketched for ROLL. The variants of $f l y$ also give the intuitive impression that agentive flying is not to be described as an augmented variant of a pure manner of movement involving passive projectiles; since these are felt to be the more marginal variants, the connection should rather work the opposite way: the uses with inactive projectiles would somehow seem to constitute degenerated variants of the prototypical agentive case.

While this is all true, consideration of the manner differences does not really open up a way of analysing fly. One would need a full-blown model for a classification of manner of movement, which we can't accomplish in this paper (although we firmly believe that a calculus for explicating manner is a desideratum in current verb semantics). And to be sure, polysemy would multiply the problem of explaining the behaviour of the verb fly / fliegen, rather than solve it.

In the following, we rather want to show that the puzzle might be resolved by elaborating on the notion of "internal / external causation"; more precisely: by reinterpreting the relevant condition in terms of forces rather than causation. The various manners associated with the variants might then even be taken as belonging to a unified category.

Let us start our analysis with the observation that we must be dealing with more than a bivalent opposition [ \pm internal cause] in our examples, in view of the fact there are many intermediate cases to consider - like for instance: 
The problem is that in the middle range of this continuum, it is unclear to which extent causation should count as "internal". As a first step to clarify this, we propose to decompose the cause of the situation into two components, which may be dubbed Control and Force. The second refers to the source of the "energy" in the movement; the first is what guides the direction. The notion of control may be further split up into "intention of movement" (in a wide sense) or, alternatively, non-intentional factors that direct the movement. In our prototypical example (11a), all causal factors coincide in the subject argument, the bird. However, the other examples differ in the exact allocation of causal factors.

First, the examples differ in whether the source of energy lies with the subject of fly or not: animals and all kinds of aircraft with engines generate the movement's FORCE, and with respect to this they appear to be prototypical internal causers. Flying stones and the like do not localise the source of energy in the event of flying; here, it is known that this source must be external to this event, namely it must lie in some other prior event (cf. 12 above).

Similarly, the degree of CONTROL that can be attributed to the subject is decreasing over the items (28a) to (28d). This may mean that either, control devolves on some entity outside the scope of the event description (different types of "remote control" in (28b) and (28c)), or that it is an uncontrolled event. This is what must be posited for (28d). The pecularity of (28d) is that it is an event which must have an external origin of FORCE, but which nevertheless disallows external CONTROL. More precisely: while the generation of force (by the thrower) may be under control, the event of flying is not. Let us elaborate on this point via a comparison of fliegen with some related movement verbs.

\subsection{Verbs of Movement Through a Medium}

In this section we will elucidate the meaning of fly via a comparison with other verbs that denote movement of freely suspended objects: German schweben (float, hover), schwimmen (float [in water], swim), and fallen / fall.

German, as can be seen from these examples, does not make a distinction that seems systematically encoded in English: schwimmen refers to situations of active movement in water (swim) or passive movement or suspension in water (float). Likewise, schweben encompasses passive suspension in air (or water) (float) as well as situations in which an agent invests force to remain in a suspended position (hover). ${ }^{9}$ The relevant distinction is one in terms of the forces at play. In the illustrations below, we represent forces that are produced by the participant of the situation as curled arrows, and environmental forces as straight arrows. In a first approximation, this reflects a distinction between internal and external causation:

\footnotetext{
${ }^{9}$ Another piece of evidence for this lexical regularity (but of a different semantic type) is the pair bounce / jump, indiscriminately rendered as springen in German.
} 


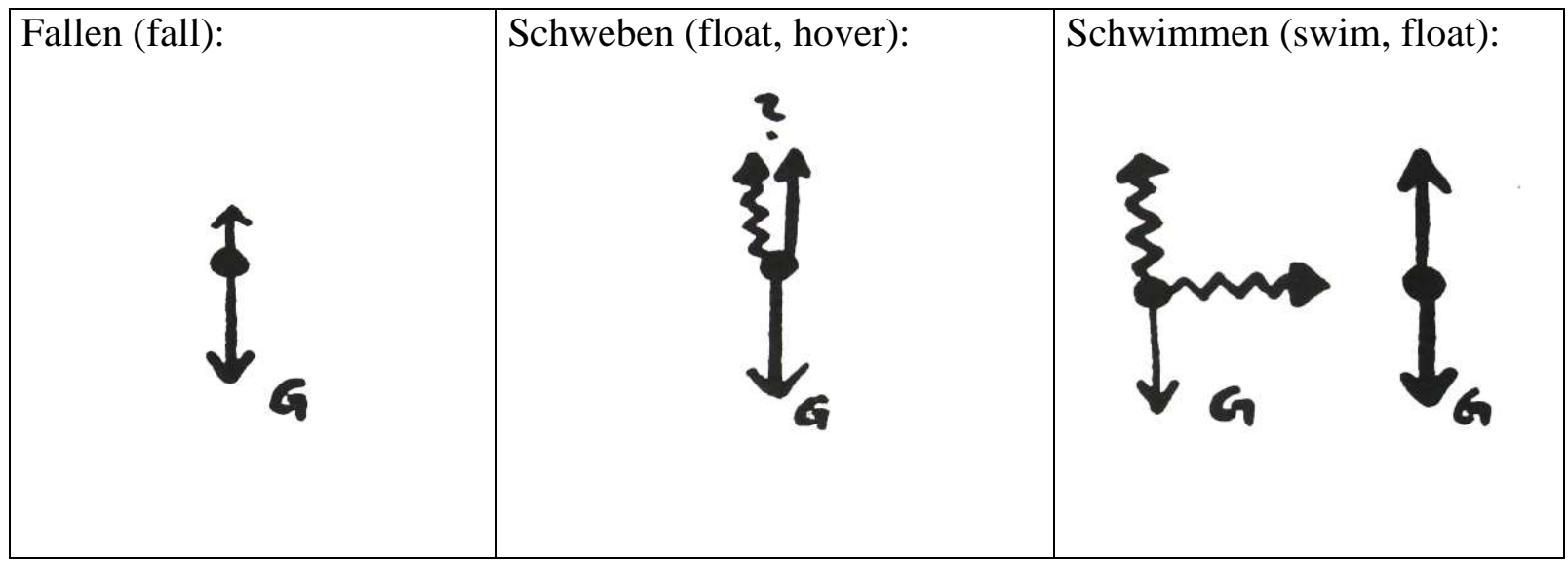

The external forces at play can be identified as gravitational and buoyant forces. In a situation of falling, a movement is created by gravitation, which at least outweighs bouancy. Schweben, is depicted in (30) with two upward arrows which are to be understood as alternative, i.e. as underspecified wrt their quality; choosing the curly force arrow would represent hover, the straight arrow float, because the latter relies on the environmental force of buoyancy. Schwimmen, on one reading, is represented via two force components, which secure staying at the surface and locomotion, respectively; the constellation to the right is an alternative interpretation for the German word, which would then correspond to float.

It might be expected that fliegen / fly should exhibit the same variability between selfpropelled motion and motion caused by environmental forces. If so, however, there would be an irregularity in that English does not make the lexical distinction which it makes in the cases swim/float and hover/float. A second peculiarity is that float is unspecified as to whether there is movement or not, while in contrast, fliegen has no interpretation with the object being at rest.
a. $\quad$ Eine Feder flog durchs Fenster
A feather flew through the window
b. Eine Feder schwebte in der Luft
A feather floated in the air
c. \# Eine Feder flog in der Luft
A feather flew in the air

Example (32c) needs careful analysis: it is acceptable on the interpretation that a feather is flying past, with unspecified direction. However, it does not allow a stationary reading (with, say, the feather being supported in a more or less stationary position by small turbulences in the air; this would not yield a movement path).

We believe that there is good reason why fliegen / fly does not alternate with a stationary interpretation in the same way as other verbs do, like schwimmen, schweben. There is no stable position with fliegen for a reason that is rooted in the very physics of flying: in this special case, the support is created by the motion itself. In other words, fliegen / flying is a situation in which an object carries a momentum of movement that prevents it from going straight downwards. 
Thus we claim that the relevant distinction between fliegen and schweben (float) is to be represented as a lexical specification for a movement with an intrinsic momentum. ${ }^{10}$ Schweben / float, in contrast, is a verb that describes an equilibrium of buoyancy and gravitational forces; movement is extrinsic to this description and can be freely added. The difference can be illustrated as follows - note that the curly arrows now have to be reinterpreted as referring to inherent as opposed to environmental forces. The momentum, depicted in (33) by a diagonal arrow, can be decomposed into two components, upward and forward, in keeping with the observation mentioned above that flying is a situation in which it is the movement which creates a support vector.



\subsection{Conclusion}

If our analysis is correct that fliegen requires its participant to carry a momentum of movement, this aligns it with the RUN-class in some sense: it is a factor intrinsic to the participant and to the situation. On the other hand, however, this factor is not the causation of the movement, which must be acknowledged as external in the case of flying stones etc. Therefore, we believe that the crucial semantic factor that distinguishes the RUN-class is not agentivity (even though this class is usually listed under "agentive verbs of manner of motion" even in Levin \& Rappaport 1995), nor is it situation-internal cause of the movement. Rather, it has to be inherent specification of a momentum of movement.

An observation which supports this conclusion is that the RUN verbs listed in Levin \& Rappaport (1995) in general disallow readings in terms of stationary support or passive movement by environmental forces, as far as we can determine. This is even true for the case of hover (which a reviewer mentioned as a potential counterexample). The verb hover specifies the exertion of a force in vertical direction which balances gravitation, and so this is another type of intrinsic force specification. It is true that hover behaves like float with respect to sideward movements, i.e. it is neutral as to whether they occur or not and leaves this to environmental forces; but this parallelism is only due to the fact that hover specifies a momentum of force only in one spatial dimension. The verb float also describes an equilibrium between two vertical forces (gravitation and buoyancy), but this is an equilibrium of external, environmental forces. A stone or arrow inherits a momentum of movement from

\footnotetext{
${ }^{10}$ The use of German fliegen in a sense similar to fall mentioned at the beginning of section 3.2 still reflects this, as the interpretation seems to be a falling with a forceful component. However, we continue to assume that it is a separate lexical variant that is connected via a similarity link to the sense of movement through air
} 
the external force which launched it, and then carries it as its own intrinsic property; as soon as the projectile is flying, it is no longer under external control with respect to this property.

Many situations that may be described by words like roll, spin, etc. are situations in which an object likewise has inherited a momentum of movement. This, however, is merely a fact about the situation, it is not part of the property expressed by the verb. The property denoted by these verbs rather lies in the domain of shape or directionality properties of the movement. By virtue of their not carrying any intrinsic specification concerning momentum of movement, they are classed as unaccusative.

\section{Acknowledgement}

This work was written with support from the SFB 471 "Variation and Evolution in the Lexicon", funded by the Deutsche Forschungsgemeinschaft.

\section{References}

Levin, B.: 1993, English Verb Classes and Alternations. Chicago: Univ. of Chicago Press.

Levin, B. \& Rappaport Hovav, M.: 1995, Unaccusativity. Cambridge MA: MIT Press. 


\title{
EFFECTS OF TOPIC AND FOCUS ON SALIENCE*
}

\author{
Elsi Kaiser, \\ University of Southern California \\ elsi.kaiser@usc.edu
}

\begin{abstract}
This paper investigates what factors make a particular referent a good antecedent for subsequent pronominal reference. In particular, it explores two seemingly conflicting claims in the literature regarding the effects of topicality and focusing on referent salience. In light of new experimental results combined with a review of existing work, I conclude that neither topicality nor focusing alone can explain referent salience as indicated by patterns of pronoun reference. Rather, the data provide support for a multiple-factor model of salience (e.g. Arnold 1999). More specifically, the results show that grammatical role has a striking effect: being a subject makes a referent more salient than either pronominalization/givenness or focusing alone. Furthermore, the results of the experiment suggest that the likelihood of subsequent pronominal reference is also influenced by structural focusing and pronominalization, but not as strongly as by subjecthood. I argue that these data are best captured by a multiple-factor model in which factors differ in how influential they are relative to one another, i.e. how heavily weighted they are. A single-factor system does not seem adequate for these data.
\end{abstract}

\section{Introduction}

The notion of 'salience' plays a crucial role in theories of reference resolution, as it is widely assumed that the most reduced (and least semantically informative) referring expressions refer to the most salient referents - i.e., the referents which are most prominent, most accessible at that point in the discourse. This, of course, raises the crucial question of what makes a referent salient. A number of factors have been proposed in the literature, and this paper focuses on two apparently contradictory claims, namely that both topicality and focusing which are often thought of as opposites - increase referent salience. In light of new experimental results combined with a review of existing work, I conclude that neither topicality nor focusing alone can explain referent salience as indicated by patterns of pronoun reference. Rather, the data provides support for a multiple-factor model of salience, suggesting that a referent's salience depends on a number of competing factors which differ in the strength of their influence (see Arnold 1998, 1999).

The structure of this paper is as follows. Section 2 provides an overview of the notion of salience, including claims that have been made in the literature regarding the connections between salience and referential form, and discusses four factors that have been argued to influence the salience of entities, namely subjecthood, givenness, pronominalization and focus. In Section 3 we turn to existing research on the question of whether topical or focused entities are more salient, and Section 4 outlines the open questions that this paper aims to tackle. Section 5 presents the results of the sentence completion experiment, and conclusions and wider implications are discussed in Section 6.

\footnotetext{
* Many thanks to Rebekka Puderbaugh, Sasha Eloi and Joyce McDonough for assistance with the experiment described in this paper. I would also like to thank Christine Gunlogson, Jeffrey Runner, Michael Tanenhaus and the audience at Sinn und Bedeutung for useful feedback and comments.
} 


\section{Salience}

Many researchers have claimed that there are correlations between different kinds of referential expressions (full NPs, pronouns, demonstratives etc) and the level of salience/accessibility of their antecedents (e.g. Gundel, Hedberg and Zacharski 1993, Givón 1983 and Ariel 1990). The general consensus appears to be that the more reduced an anaphoric expression is, the more salient / accessible its antecedent has to be. In this research, the term 'salient' is generally used to mean entities that are currently at the center of attention, i.e. those that are most prominent at that point in the discourse. The view that most researchers assume is summed up in this quote from Arnold (1998): "Loosely speaking, all researchers have observed that pronouns are used most often when the referent is represented in a prominent way in the minds of the discourse participants, but more fully specified forms are needed when the representation of the referent is less prominent" (Arnold 1998:4).

However, in order for the claim that salient referents are referred to with reduced anaphoric forms to be meaningful, the notion of salience needs to be defined. More specifically, if we accept the claim that the most salient entities are referred to with the most reduced forms, then we can use pronouns as a tool to investigate the notion of salience in more detail. In other words, we can probe what factors make an entity likely to be referred back to with a pronoun, and assume that these factors are what influence salience. ${ }^{1}$ A number of factors have been put forth in the literature as increasing the likelihood of subsequent pronominalization (see Arnold 1998 for an overview), many of which could be regarded as increasing the topicality of a referent. These include occupying the grammatical position of subject, being given information and being realized as a pronoun.

However, before we go any further, it is worth pointing out that the term 'topic' is used differently by different researchers. Strawson (1964) defines the topic of an utterance as "what is of current interest or concern" (Strawson 1964:104). Reinhart (1982) defines the topic of a sentence as "the expression whose referent the sentence is about" (Reinhart 1982:5). Gundel (1985) characterizes topics in terms of 'shared knowledge': "the topic of a speech act will normally be some entity that is already familiar to both speaker and addressee" (Gundel 1982: 92). In more recent work, Prince (2003) and Beaver (2004) use the term 'topic' to refer to the backward-looking center in Centering Theory (Grosz, Joshi \& Weinstein 1995); a use which links topicality with pronominalization and givenness. As will become clearer later, in this paper my aim is not to provide an exhaustive definition of topicality; rather, I would simply like to point out that many of the factors that have been claimed to influence referent salience (and which I try to 'pull apart' in order to see what their individual contributions are) have also been linked to the general notion of topicality.

\footnotetext{
1 The assumption that degree of salience and degree of 'reduction' of the referential form are related is not entirely unproblematic (see Kaiser 2003, Kaiser \& Trueswell in press). In particular, it seems that not all referential forms (e.g. pronouns vs. demonstratives in languages like Finnish that allow both to have human antecedents) are sensitive to the same supposedly salience-influencing factors, which argues for a more complex mapping between referential forms and degree of salience of the antecedent that is normally assumed (for details, see Kaiser 2003, Kaiser \& Trueswell in press). However, in this paper we are focusing only on one referential form, namely personal pronouns in English, and thus the conclusions should be interpreted as restricted to this form. For the purposes of this paper, we assume that English personal pronouns can be used as a tool to probe referent salience. Even if one wants to argue that this assumption is problematic (e.g. due to the nature of the mapping between salience and referential forms, or due to differences in bottom-up and top-down processing), the results are still relevant: Even if one wants to argue that they do not shed light on the factors that influence salience per se, they still shed light on the factors that influence pronoun interpretation (e.g. whether pronoun interpretation is sensitive to only one factor or several differently-weighted factors) as well as the processes that underlie reference resolution.
} 
In contrast to the claims that topicality-related factors make a particular referent especially salient and hence a good antecedent for a pronoun, some researchers have claimed that focusing is what makes a referent salient. In this section, we briefly review these two claims, which seem to conflict, at least at first glance. We will first consider claims regarding subjecthood, givenness and pronominalization, which could be regarded as being related to topicality, and then move onto a discussion of the claims regarding the effects of focusing.

\subsection{Subjecthood}

A number of researchers have claimed that grammatical role is correlated with salience; more specifically, that entities realized in subject position are more salient than those in non-subject positions (Brennan, Friedman \& Pollard 1987, Matthews \& Chodorow 1988, Crawley \& Stevenson 1990, Stevenson et al. 1994, and McDonald \& MacWhinney 1995, inter alia). Both corpus evidence and psycholinguistic research support this claim. For example, in a sentence completion study, Crawley \& Stevenson (1990) found that when given sentence fragments such as "Shaun led Ben along the path and he....", participants tended to continue the sentence such that the pronoun referred back to the preceding subject more often than to the object. These findings are corroborated by self-paced reading studies, such as Gordon, Grosz and Gilliom (1993) and Stevenson \& Urbanowicz (1995), which also found that the grammatical role of an antecedent influences reading times for subsequent pronouns.

\subsection{Givenness}

Another factor that has been claimed to increase the salience of a referent is givenness, i.e. being 'old' information. For example, Strube \& Hahn (1996) argue that the salience of referents is determined by "the functional information structure (IS) of the utterance" (Strube \& Hahn 1996:272); more specifically, that "any context-bound expression...is given the highest preference as a potential antecedent of an anaphoric or elliptical expression" (Strube \& Hahn 1996:272). In other words, when a sentence with a discourse-old referent and a discourse-new referent is followed by an anaphoric expression, the anaphor refers to the discourse-old referent. In related work, Ballantyne (2004) conducted a corpus study of Yapese (Oceanic language in Micronesia) and found that givenness is a better way of ranking referents (in Centering-theoretic terms, leads to more coherent transitions between utterances) than grammatical role or linear order.

\subsection{Pronominalization}

A number of researchers have found that the referential form with which an entity is realized can affect that entity's salience. Kameyama (1999) claims that a pronominalized referent in non-subject position gains in salience by virtue of being pronominalized, and becomes so salient that it 'competes' in salience with a non-pronominalized entity in subject position. Similarly, Beaver (2004) suggests an Optimality-theoretic approach to anaphora resolution that includes a constraint called SALIENT FORM, which states that "If in the previous sentence discourse entity $\alpha$ was realized by a more minimal form than discourse entity $\beta$, then $\alpha$ is more salient than $\beta$ " (Beaver 2004:31). It is important to note that the constraint SALIENT FORM is different from the idea that the most salient referents are referred to with the most reduced forms, since, as Beaver point out, SALIENT FORM "implies that being pronominalized makes a referent salient in the future" (Beaver 2004:31 fn 30, italics added, see also Kehler 2001:169).

As mentioned above, factors such as subjecthood, givenness and pronominalization could all be regarded as increasing the topicality of a referent. Thus, one might be tempted to conclude 
that a salient referent is a topical referent. However, as we will see in the next section, not all researchers agree that salience is necessarily linked to topicality. In addition, not all researchers agree that a conglomeration of factors is what determines salience. Some researchers seem to either assume or claim that salience is determined by only one factor (e.g. see Strube \& Hahn 1999), whereas others argue in favor of a multiple-factor view (e.g. Ariel 1990, Arnold 1998, see also Givón 1983). We return to this question in Section 4.

\subsection{Focus}

This section reviews claims that focused referents are more salient than non-focused referents. Like the term 'topic', the term 'focus' would also benefit from some clarification. Focus is often divided into contrastive focus (or identificational focus, to use Kiss's (1998) term) and presentational focus (information focus, according to Kiss). The existing psycholinguistic work investigating focusing has tended to look at the effects of contrastive focus, since it has used structures such as it-clefts ('It was Mary who called Lisa'), which are usually regarded as expressing contrastive (identificational) focus. ${ }^{2}$ The experiment, described in Section 5, uses both clefts and in-situ focus constructions, but due to the context in which they occur, both involve contrastive focus. (Green and Jaggar (2003) claim that in-situ focus can also be interpreted contrastively.) Thus, the claims made in this paper regarding focus only apply to contrastive focus. The effects of presentational focus are an important direction for future work (see also Hajičová, Kubon \& Kubon 1992).

Now, let us turn to the research that supports the claim that (contrastively) focused entities are more salient than non-focused ones. In a cognitive psychology experiment, Hornby (1974) presented participants with pictures and sentences, and asked people to say whether the sentence matches the picture. When participants were presented cleft sentences (e.g. 'It is the girl who is riding the bicycle'), Hornby found that the participants were better at detecting mismatches when the mismatching information was focused than when it was presupposed. This suggests that participants attend more to the non-presupposed, focused part of the sentence (but see Delin 1990). In related work, Singer (1976) probed people's memory of focused and non-focused referents using sentences such as 'It was the king who led the troops' and 'It was the troops that the king led.' He found that focused referents are remembered better than non-focused referents. Thus, it seems that focused information is noticed and remembered better than non-focused information, which could be regarded as result of its being perceived or represented differently from non-focused information due to its being more salient.

Extending this work to reference resolution, Almor (1999) conducted a reading time study which found that reference to focused referents is read faster (i.e., presumably processed with greater ease) than reference to non-focused referents. Almor tested sentence pairs such as those in (1) (with focused subjects) and (2) (with focused objects), and found that (1a) is read faster than (1b), and (2b) is read faster than (2a), suggesting that an anaphoric expression (e.g. the bird, the fruit) is interpreted faster when it refers to an antecedent that is in focus than when it refers to an antecedent that is not focused (in this case, presupposed).

(1) a. It was the robin focus $_{\text {that }}$ ate the apple.

The bird seemed very satisfied.

\footnotetext{
2 It is important to note that corpus studies have shown that regarding all clefts as structures where the clefted constituent is contrastively focused and the rest of the sentence is presupposed is a gross oversimplification (see e.g. Delin 1990). However, the it-clefts used in the experiment described in Section 5 were all very simple in that the focused constituent was new information and the rest of the sentence was given (see example (8)).
} 
b. It was the robin ${ }_{\text {focus }}$ that ate the apple. The fruit was already half rotten.

(2) a. What the robin ate was the apple focus $_{\text {. }}$ The bird seemed very satisfied.

b. What the robin ate was the apple focus. The fruit was already half rotten.

If we assume that a referring expression referring to a highly salient referent is read faster (processed with greater ease) than one referring to a low-salience referent, these results indicate that the focus of a cleft is more salient than the non-focus. These findings also appear to be compatible with the claim that clefts involve low topic continuity (Givón 1983), which can be roughly paraphrased as stating that a cleft is used when the discourse is shifting to a new center of attention, namely the entity that is focused in the cleft.

In a different tradition, Hajičová, Kubon \& Kubon (1992) claim, on the basis of computationally-oriented corpus work on Czech, that entities in the focal part of an utterance are the most salient, and entities in the topical part are less salient. In contrast to the other research on focus, however, Hajičová et al. use the term 'focus' to refer not to the focus of clefts, but to the 'contextually non-bound' parts of an utterance, i.e. those parts which are, roughly, new information. Moreover, it is worth noting that according to Hajičová et al., certain pronominal forms tend to refer to focused entities and others prefer topical entities i.e. even though they explicitly claim that focused referents are more salient than topical referents, they do not claim that the most reduced referring expressions refer to the most salient (i.e. focused) referents.

Thus, there exists an intriguing division in the literature. On the one hand, a number of factors have been claimed to render a particular referent highly salient and thus a good antecedent for a subsequent anaphor, and many of these factors could also be argued to be related to the general notion of topicality. On the other hand, it has also been argued that (contrastively) focused referents are especially salient and prominent in people's mental models of the discourse. In the next section, we turn to some existing experimental work that aims to shed light on this seeming contradiction.

\section{Topic vs. focus: Which is more salient?}

In light of the contrasting claims presented in the preceding sections, let us now turn to existing experimental work (Arnold 1999, Cowles 2003) that aims to resolve the conflicting claims regarding the salience of topics and the salience of foci.

Arnold (1999) conducted a number of psycholinguistic experiments investigating the salience of topics and foci. She used pronouns as a tool for probing which referent in the preceding discourse is the most salient. To test whether topical and focused referents are more salient than other referents, she tested three-sentence 'mini-narratives' such as (3) and (4) in a rating study. She manipulated whether the second sentence was clefted ${ }^{3}$ or not, whether the subject of the third sentence referred to the first- or second-mentioned character of the second sentence ((c) vs. (c')), and whether the subject of the third sentence was a pronoun or a name. The subscripts on the examples illustrate which constituents Arnold assumes to be topics and

\footnotetext{
3 Arnold used clefts with 'the one' rather than it-clefts or wh-clefts, but she notes that the 'one'-construction has been called a cleft with a lexical head by Prince (1978). In Arnold's cleft sentences, strictly speaking, the subject and object of the matrix copular sentence (e.g. 'the one [+ relative clause] was Emily') both refer to the same entity, namely the focus. The topic in these one-clefts is the subject of the relative clause modifying 'one' (e.g. 'the one [he decided on at last] was Kysha'). This is in contrast to the it-clefts used in the experiment described in this paper, where the topic is either the matrix subject or the matrix object.
} 
foci. It is important to note that she constructed these sentences such that the non-clefted ones contained a topic (she follows existing research in assuming that the subject functions as a topic) but no syntactically marked focus, and the clefted ones contained a clear focus but no strong topic. This was done because the aim of this experiment was to investigate topics and foci independently of each other.

(3) a. The guests were nervously standing around in the living room, trying to decide which person to talk to.

b. Ann $_{\text {topic }}$ decided to say hi to Emily ${ }^{4}$ first. (NON-CLEFT)

c. Emily/She looked like the friendliest person in the group.

c'. Ann/She hated to be in a room full of people where no-one was talking.

(4) a. The guests were nervously standing around in the living room, trying to decide which person to talk to.

b. The one $A n^{5}$ decided to say hi to first was Emily focus. (CLEFT)

c. Emily/She looked like the friendliest person in the group.

c'. Ann/She hated to be in a room full of people where no-one was talking.

The results of the rating study indicate that, in general, topics and foci are more salient than other referents. More specifically, with nonclefted sentences (3), participants prefer pronouns in the third sentence to refer to the subject of the second sentence (the topic), as in (3c'), and with clefted sentences (4), participants prefer pronouns to refer to the object of the second sentence (the focus), as in (4c). Furthermore, for referring to entities other than the topic in non-clefts and the focus in clefts, full names are preferred.

To investigate what happens when topics and foci are directly pitted against each other, Arnold conducted a production study, where participants were given sequences of sentences such as those in (5), ending in either a clefted or an non-clefted sentence ((5a) vs. (5b)). In this experiment, Arnold established a particular referent as the discourse topic by introducing it in the subject position of the first sentences, and referring back to it with a pronoun in the next two sentences. The participants' task was to provide a continuation for the story.

(5) Ron was looking through his address book, trying to make up his mind.

He had an extra ticket to the opera, but he didn't know which friend to invite.



b. At last he $\mathrm{t}_{\text {topic }}$ decided on $\mathrm{Kysha}_{\text {focus }} /$ Fred $_{\text {focus. }}$ (NON-CLEFTED)

An analysis of the pronouns occurring in participants' continuations reveals a strong preference to use pronouns to refer to the subject of the preceding sentence (the topic), regardless of whether the sentence was clefted (97\%) or not clefted (98\%). This suggests that topics are more salient than foci, regardless of the syntactic form of the sentence.

In a third experiment, Arnold investigated the difference between a well-established discourse topic (as in (5), a referent that has already been mentioned in preceding discourse by the time it is realized, as a pronoun, as the topic of a cleft) and a sentence topic (as in (4), a referent that is realized, as a full NP, in the topic position of a cleft but had not been mentioned in the preceding discourse). The results of a rating study indicate that when a clear discourse topic exists, participants prefer the focus of the cleft to be referred to with a name, but when no discourse topic is present, there is no such preference. Arnold concludes that this is because the absence of a clear discourse topic makes it possible for the focus to be relatively more salient than it could be in the presence of an overwhelmingly salient discourse topic; in other

\footnotetext{
${ }^{4}$ As Arnold notes, this referent is realized as an oblique object, and not syntactically marked for focus.

5 Note that this referent is realized as an embedded subject, which Arnold notes is not highly topical. It is also new information.
} 
words, she regards salience as a competitive phenomenon, where "where the representations of different referents in a particular discourse compete for activation" (Arnold 1999:28).

Using a different methodology, Cowles (2003) reaches a somewhat different conclusion. She uses cross-modal priming to investigate the impact of discourse-topicality, sentence-topicality and contrastive focus on referent salience. She uses clefts to mark focus, and uses the term 'discourse topic' for referents that have been realized twice in subject position, and the term 'sentence topic' for referents that have been realized once in subject position. The results indicate that "[a]ll three information statuses [discourse topic, sentence topic and contrastive focus, EK] appear to make their referent more likely to be interpreted as the antecedent of a subsequent pronoun" (Cowles 2003:93). In fact, in contrast to Arnold who found that established discourse topics are more salient than foci, Cowles concludes that "two information structure types that are considered distinct .... appear to have the same psychological effect" (2003:94). However, it appears that Cowles tested referents that were subjects whereas Arnold tested subject topics and object foci. It seems that their studies differ not only in methodology but also in the nature of the materials, which may be partly responsible for the different findings.

In sum, although existing experimental work suggests that topics and contrastive foci are more salient than other referents (see also Navarretta 2002), the results conflict when it comes to the question of which is more salient, a topic or a focus.

\section{Effects of different factors}

As we saw in Section 2, subjecthood is very often regarded as being correlated with salience/topicality, but based on the research discussed in Section 3, it appears that (to the best of my knowledge) existing experiments on pronoun resolution have not fully investigated possible consequences of grammatical role on the effects of topicality and focusing. In light of the claim that grammatical role influences salience, I would like to suggest that in order to improve our understanding of how topicality and focusing influence salience, we should investigate both subject and non-subject topics and foci. For example, how do topics in object position compare to foci that are objects?

Let us briefly consider the nature of the relation between subjects and topicality. As already noted, many researchers have observed that entities realized in subject position tend to be interpreted as topical. However, it seems that this does not always have to be the case. Consider the example below:

(6) After serving little more than a year in jail, Cruz-Mendoza was deported for a third time in January, records and interviews show. U.S. Border Patrol agents arrested him in Arizona a month later. At that point, he could have been charged with a felony....

(Los Angeles Times, October 30, 2005)

Most approaches would agree that the topic of the second sentence is the referent of the object pronoun 'him' and not the subject of the sentence 'U.S. Border Patrol agents' (see e.g. Prince 2003 on Centering Theory, Beaver 2004 and others) ${ }^{6}$. Thus, it is not the case that topics are restricted to occurring in subject position. In the case of foci, it is also clear that they are not restricted to occurring in object position, as illustrated by examples such as (7) below. Here we see a subject it-cleft, where the subject 'Lisa' is in focus:

\footnotetext{
6 Of course, this statement would not be compatible with a theory where the notion of topic is inherently linked to subjecthood. However, the burden would then be on such a theory to show that 'U.S. Border Patrol agents' is more topical than the referent of 'him.'
} 
(7) Mesmerized, I called them up and asked for an interview to discuss how they cast applicants for reality TV. First, I talked to Debbie, who said she'd get back to me. Instead, it was Lisa who returned my call.

(www.themorningnews.org/archives/manufacturing_reality/mirror_mirror.php)

If we combine the observation that topics do not have to be subjects and foci do not have to be objects with the well-known claim that subjecthood influences referent salience, it becomes clear that investigating subject topics and object foci, for example, may result in overestimation of the effects of topicality as a result of associating it with subjecthood. However, looking only at subject foci and subject topics may also be insufficient, since if subjects turn out to be highly salient simply due to their subject status, then this could potentially 'wash out' effects of the topic/focus distinction. One of the main aims of the experiment described in this paper is to investigate subject-topics, subject-foci, object-topics and object-foci (in both clefted and nunclefted sentences) in order to see which factors are the most influential in determining which referents are good antecedents for subsequent pronouns.

More generally, these issues are related to the larger question of how different factors interact during reference resolution. In particular, as mentioned earlier, is it the case that a single factor determines which entities can be referred to with pronouns in subsequent discourse, or might it be the case that a number of factors, perhaps with different degrees of influence (different weights) all play a role? In other words, if we accept the claim that the most salient entities are referred to with the most reduced referential forms, then we can use pronouns as a tool to ask: Does one unique factor determine salience, or can multiple factors interact? If multiple factors interact, are they all weighted equally, or are some more influential than others? These are the questions that the experiment in the next section explores.

\section{Experiment}

In order to shed light on the issues sketched out above, this experiment investigates how subjecthood, pronominalization, semantic focusing and syntactic focusing influence subsequent pronoun use. The specific aim of the experiment is to pull apart the subject-topic / object-focus correlation that is common in previous experimental work. On a more general level, in disassociating these factors the experiment will also help us to better understand the issues sketched out above regarding the interaction and degree of influence of different kinds of information during reference resolution.

We manipulated syntactic form (cleft vs. SVO) and the grammatical role of the topical/focused constituent, as illustrated in example (8). Thus, there are four conditions, which will be referred to with the following shorthand labels: [SVO.Object=focus], [SVO.Subject=focus], [Cleft.Object=focus] and [Cleft.Subject=focus]. The referent marked as 'focus' in (8) is always semantically focused thanks to the context, and in the clefted conditions it is also structurally focused as a result of being in the focus position of the cleft. The referent subscripted as 'topic' in the example in (8) is discourse-old and pronominalized, and follows Prince's (2003) and Beaver's (2004) use the term 'topic' to refer to the Centering Theory notion of backward-looking center. (However, my use of the subscript 'topic' in (8) is not intended to convey the claim that the referent of the pronoun is more salient than the focused expression. See Section 5.1.)

The participants' task was to provide a natural-sounding continuation sentence using the pronoun prompt that followed each critical sentence. They were told to imagine that someone has just made the claim in part $\mathrm{A}$, and that they were now responding to this other person by saying part B and providing a continuation. Participants were recorded using a Tascam digital tape recorder and a Shure unidirectional headmounted microphone. 
All verbs were agent-patient verbs, as defined by Stevenson et al (1994). This was done in order to control for any potential verb focusing effects. Both human referents mentioned in the sentences were of the same gender; either both (stereotypically) male or both (stereotypically) female. There were 16 target items and 16 fillers.
A: The maid scolded the bride.
a. B: No, that's wrong! She topic $_{\text {scolded the secretary }}$ focus. She....
b. B: No, that's wrong! The secretary focus $_{\text {scolded }}$ her $_{\text {topic. }}$ She...
c. B: No, that's wrong! It was the secretaryfocus that she topic $_{\text {f }}$ scolded. She...
d. B: No, that's wrong! It was the secretary focus $_{\text {who scolded }}$ her $_{\text {topic. }}$ She...

Participants' $(n=24)$ continuations were digitized and transcribed, and the referent of the prompt pronoun in each of the continuations was double-coded by two coders working independently. Disagreements were resolved by discussion. If it was not clear who the pronoun refers to, the item was coded as 'unclear.' Table 1 provides some examples.

\begin{tabular}{|l|}
\hline (i) A: The waiter criticized the sailor. \\
\hline B: No, that's wrong! He criticized the businessman. He gave him too small a tip. \\
\hline Coded as: he = businessman, i.e. object \\
(ii) A: The waiter criticized the sailor. \\
B: No, that's wrong! He criticized the businessman. He didn't get a very good tip. \\
\hline Coded as: he = waiter, i.e. subject \\
\hline (iii) A: The maid scolded the bride. \\
\hline B: No, that's wrong! She scolded the secretary. She told me about it after it happened. \\
\hline Coded as: she = unclear
\end{tabular}

Table 1. Coding samples

\subsection{Predictions}

As mentioned earlier, there are different hypotheses regarding the nature of the relation between factors such as subjecthood and focusing. In particular, some researchers seem to espouse a single-factor view, which assumes that one factor plays a decisive role in determining which referents can be subsequently referred to with pronouns, whereas others appear more supportive of a multiple-factor view.

Let us start by considering the predictions that a single-factor view would make for the factors investigated in this experiment, namely subjecthood, pronominalization, semantic focusing and syntactic focusing. ${ }^{7}$ If subjecthood is the one factor that determines referent salience, the prediction is that prompt pronouns will refer to preceding subjects, regardless of NP form or topic/focus status. In contrast, if pronominalization (and givenness) determines referent salience, we predict that prompt pronouns will refer to whatever is pronominalized in the preceding sentence, regardless of whether it is the subject or the object, clefted or unclefted. However, if semantic focusing is the one factor that determines referent salience, prompt

7 These factors are not fully crossed in this design - partly due to the nature of the phenomena being investigated. For example, syntactically focused entities are also necessarily semantically focused, but not vice versa. Furthermore, in this design pronominalization and focusing are in complementary distribution in the sense that a particular referent is either pronominalized or focused, but never neither and never both. 
pronouns are predicted to refer to the focused referent, regardless of syntactic role or sentence structure (cleft vs SVO). If structural focusing (clefting) alone is what determines referent salience, the prediction is that prompt pronouns will refer to the focus of the cleft in clefted sentences, but it is not clear what the prediction would be for unclefted sentences.

Let us now turn to the multiple-factor view, according to which two or more factors could be influencing referent salience, and hence the likelihood of subsequent pronominal reference. Let us assume, for expository ease, that all four factors are relevant and weighted equally. The rightmost column of Table 2 summarizes which referent in each condition is predicted to be most likely to be referred to with a subsequent pronoun.

In the [SVO.Object=focus] condition (line A of Table 2), two factors (subjecthood and pronominalization) contribute to the salience of the subject. Semantic focusing contributes to the salience of the object. This could also be cast in terms of activation in the participant's mental model of the discourse: both subjecthood and pronominalization increase the level of activation of the subject, and semantic focusing increases the activation level of the object. Thus, if all factors are weighted equally, the subject 'wins' over the object; it is more activated. In the [SVO.Subject=focus] condition (line B), pronominalization points towards the object, but subjecthood and semantic focusing both point towards the subject. Thus, if all factors are weighted equally, we again predict that the subject wins out over the object. Note that in this condition the subject is focused, whereas in the preceding condition it was the discourse-old, pronominalized referent.

Now, turning to the first of the two cleft conditions, in the [Cleft.Object=focus] condition (line C) we see that both subjecthood and pronominalization increase the salience of the subject, but structural and semantic focusing both point towards the object. Thus, in contrast to the [SVO.Object=focus] condition, now the object is focused both structurally and semantically. Assuming that this would have a stronger effect than semantic focusing alone (see also Navarreta 2002 on the effect of information-structural devices being used to mark focus) leads us to the prediction that in the [Cleft.Object=focus] condition, the subject and object are tied. Put differently, they have equal levels of activation. Finally, in the [Cleft.Subject=focus] condition (line D), everything except pronominalization is pointing towards the subject: subjecthood status, structural focusing and semantic focusing. This leads to the prediction that the subject has a higher level of activation than the object.

It is important to note that I have been assuming that all factors are weighted equally; i.e. that they make equal contributions to the salience levels of the subject or the object. Of course, this might very well not turn out to be the case. In fact, in constraint-based models of language processing (e.g. MacDonald et al., 1994, Tanenhaus \& Trueswell, 1995, Trueswell et al., 1994, see also Bates and MacWhinney, 1989) which claim that language processing is guided by weighted constraints, the constraints differ in their weights and hence can differ in magnitude of the impact they have on language processing, depending also on the number of competing alternatives (see also Arnold 1998).

\begin{tabular}{|l|l|l|l|l|l|l|}
\hline \multicolumn{2}{|l|}{} & Subject & Pronom & Sem foc & Str foc & Overall \\
\hline A & She scolded the SECRETARY. & S & S & O & $\ldots$ & S (top) \\
\hline B & The SECRETARY scolded her. & S & O & S & $\ldots$ & S (foc) \\
\hline C & It was the SECRETARY that she scolded. & S & S & O & O & $?$ \\
\hline D & It was the SECRETARY who scolded her. & S & O & S & S & S (foc) \\
\hline
\end{tabular}

Table 2. Multiple-factor view (if each factor is weighed equally) 


\subsection{Results and discussion}

Overall, participants' continuations reveal an overall preference to interpret prompt pronouns as referring to subjects, regardless of whether the subject was a topic or a focus. This is illustrated in Figure 1, which shows the average subject advantage scores for the four conditions. These scores were calculated by taking the proportion of subject continuations in each condition and subtracting from that the proportion of object continuations. Thus, a positive subject advantage score indicates more subject continuations than object continuations, and a negative subject advantage score indicates more object continuations than subject continuations. As Figure 1 clearly shows, the subject advantage score is positive in all four conditions, indicating that there were more subject continuations than object continuations. Participants were more likely to interpret the subsequent pronoun as referring to the subject than to the object.

The overall subject preference indicates that subjecthood matters more than pronominalization, more than semantic or structural focusing. It seems that subjecthood makes both topics and foci good antecedents for a subsequent pronoun.

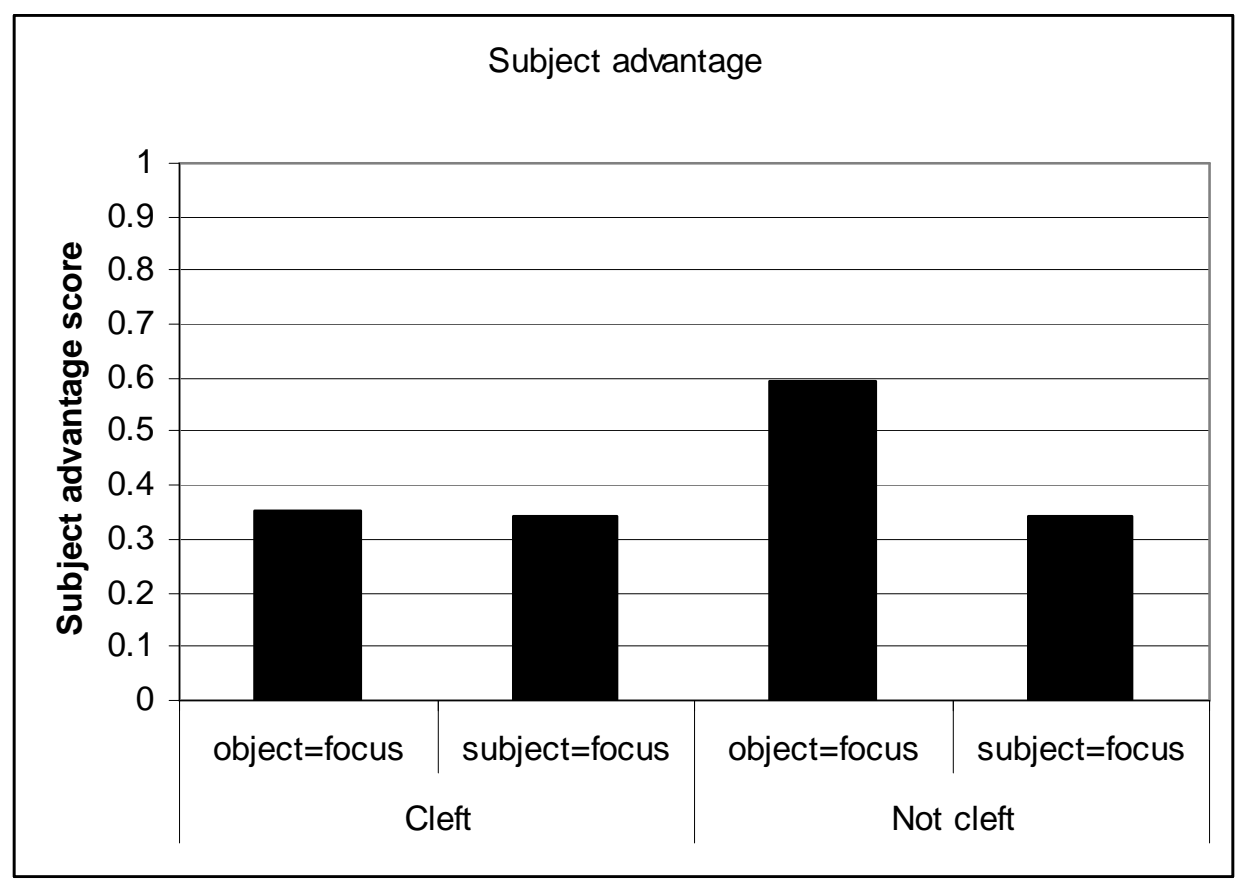

Figure 1. Subject advantage scores (proportion of subject continuations minus proportion of object continuations)

However, let us now look more closely at the different conditions. Let us first compare conditions with clefted and non-clefted focused objects. As Figure 1 shows, in the conditions with focused objects, there is a greater subject advantage in the non-clefted condition [SVO.Object=focus] than in the clefted condition [Cleft.Object=focus]. Why is this? A possible reason for the weaker subject preference in the [Cleft.Object=focus] condition is that in this particular condition, both semantic and structural focusing point towards the object. In other words, the only difference between the [SVO.Object=focus] and the [Cleft.Object=focus] conditions is structural; the latter is clefted (see also Navarreta 2002 for related corpus work on clefts in Danish). Thus, the difference between these conditions can be straightforwardly captured if one assumes, as Arnold (1999) suggests, that salience is a competitive phenomenon. More specifically, I hypothesize that the combination of syntactic and semantic focusing increases the salience of the object sufficiently so that it can compete 
with the subject and weaken the subject advantage in the clefted version. Thus, the results indicate that clefting a focused object increases its chances of being referred to by a subsequent pronoun, compared to a non-clefted focused object. ${ }^{8}$

However, if this is the reason for the difference that emerges between the [SVO.Object=focus] and [Cleft.Object=focus] conditions, then why do the [SVO.Subject=focus] and [Cleft.Subject=focus] conditions not show as strong a subject preference as the [SVO.Object=focus] condition does? Why do they both show a subject preference comparable to that in the [Cleft.Object=focus] condition, as Figure 1 clearly illustrates? In the two Subject=focus conditions, there is no structurally focused object to pull participants away from the subject, so that cannot be the reason for the weakened subject preference. However, it is important to note that in the Subject=focus conditions, subjecthood and pronominalization are pitted against each other. As we saw in Section 2, in previous work both of these factors have been found to influence referent salience. Again, if we assume that salience is a competitive phenomenon, then it follows that the conflict between subjecthood and pronominalization is responsible for the weaker subject preference we see in the Subject=focus conditions, since pronominalization increases the salience (or activation) of the object, which leads to it being better able to compete with the subject.

It is worth noting that in these particular conditions, the SVO vs. cleft distinction does not appear to have any effect on the strength of the subject advantage; it is not the case that the [Cleft.Subject=focus] condition has a stronger subject preference than the [SVO.Subject=focus] condition. However, in light of the claim that subjecthood is more heavily weighted than structural focusing, this is not entirely surprising, as it could be explained simply by the much greater influence of subjecthood masking or 'swamping' the effects of structural focusing. In other words, structural focusing seems to have a stronger effect on the salience of objects than on (already 'inherently' salient) subjects.

Taken as a whole, the results support the multiple-factor model. However, it is clearly not the case that all factors are weighted equally. The results suggest that subjecthood is more influential (weighted more heavily) than either pronominalization or structural or semantic focusing. However, the effects of subjecthood are modulated by structural focusing and pronominalization. As we saw, the contrast between the [SVO.Object=focus] and the [Cleft.Object=focus] conditions suggests that structural focusing can increase the salience of a referent. Furthermore, the finding that the subject advantage is stronger in the [SVO.Object=focus] condition than in the [SVO.Subject=focus] and [Cleft.Subject=focus] conditions suggests that if pronominalization and subjecthood are pitted against each other, the effects of subjecthood are weakened. In sum, even though the pattern of results is fairly complex and will of course need to be investigated more in future work, it seems clear that we are dealing with a competition-based system sensitive to multiple factors which are weighted differently.

\section{Conclusions}

Let us now return to the conflict sketched out at the beginning of this paper, namely the seemingly contradictory claims that topics are the most salient or that foci are the most

\footnotetext{
8 One might also wonder whether parallelism is at work here. According the Smyth's (1994) parallelism account, pronouns prefer antecedents that are in the same syntactic position as the pronoun itself. However, this preference only holds, according to Smyth, when the relevant sentences both have the same global constituent structure and the thematic roles of the verbs in the two sentences match. Consider, for example, a sentence like 'Peter hit John. Alex pinched him.' However, an examination of participants' continuations suggests that the required degree of matching across sentences does not seem to be consistently present. This casts doubt on the idea that parallelism is at work here.
} 
salient. The results of the sentence completion experiment suggest that both claims are partly right, but that the picture is actually more complex and involves multiple interacting factors mediating between referents competing for salience. Crucially, the results show that subjecthood makes both topics (pronominalized, discourse old referents) and foci good antecedents for a subsequent pronoun. The observation that being a subject makes a referent more salient than pronominalization / givenness or focusing alone suggests that looking only at subject topics and object foci may result in an inadvertent overestimation of the effects of topicality, and that looking only at subject topics and subject foci may not be very fruitful due to the overwhelming effects of subjecthood.

However, subjecthood is not the only thing that matters; there are also effects of structural focusing and pronominalization. As mentioned in Section 5, the subject advantage difference between sentences with clefted and unclefted focused objects suggests that structurally clefting a focused object influences its salience - but to a lesser degree than subjecthood. Furthermore, we also saw in Section 5 that the finding that the [SVO.Subject=focus] and [Cleft.Subject=focus] conditions do not show as strong a subject preference as the [SVO.Object=focus] can be straightforwardly explained if we assume that pronominalization increases the salience of a referent. Like structural focusing, pronominizalition has an effect on the salience of a referent, but is not as 'powerful' a factor as subjecthood.

Of course, many questions still remain open, and further research is needed to investigate the validity of the hypotheses presented here, both in English and other languages. For example, given data suggesting that different factors are weighed differently, I would like to know more about the reasons or causes of these weight differences, as well as the extent of crosslinguistic variation in this domain. In future work, I would also like to investigate the intonational patterns used in these kinds of contexts, in particular in the in-situ focus sentences as compared to the clefts, in order to see how prosodic information is contributing to the reference resolution process. The distinction between stressed and unstressed pronouns is also a crucial question for future work. Another issue that would benefit from further research is the relation between agentivity and subjecthood. This experiment only investigated agentive subjects, and thus confounds agentivity and subjecthood. Comparing agentive and non-agentive subjects (e.g. experiencers) would shed light on the question of whether it is the structural notion of subjecthood or the semantics of agentivity that is behind the subjecthood effect observed in the sentence completion experiment.

In sum, the results of the experiment presented here suggest that in order to begin to untangle the seemingly conflicting claims regarding the impact of topicality and focusing on salience, subjecthood must be taken into account. Furthermore, the results indicate that the strong effect of subjecthood on referent salience is modulated by effects of pronominalization and structural focusing. Thus, as a whole, the data presented here are best captured by a multiplefactor model in which factors differ in how influential they are relative to one another, i.e. how heavily weighted they are, and referents compete for activation (see Arnold 1998, 1999, inter alia). ${ }^{9}$ A single-factor system does not seem adequate for this kind of data, and thus it seems reasonable to conclude that salience (at least insofar as we are measuring salience by looking at likelihood of subsequent pronominal reference) is not a monolithic concept.

\footnotetext{
${ }^{9}$ It would also be very interesting to see whether the findings reported here could be captured in an Optimality-theoretic system, perhaps similar to the one in Beaver (2004).
} 


\section{References}

Almor, A. (1999) Noun-phrase anaphora and focus: The informational load hypothesis. Psychological Review, 106(4), 748-765.

Ariel, M. 1990. Accessing NP antecedents. London: Routledge, Croom Helm.

Arnold, J. 1998. Reference form and discourse patterns. Ph.D. dissertation, Stanford University.

Arnold, J. 1999. Marking Salience: The similarity of topic and focus. Manuscript, Univ. of Pennsylvania.

Ballantyne, H.G. 2004. Givenness as a Ranking Criterion in Centering Theory: Evidence from Yapese. Oceanic Linguistics, Volume 43(1): 49-72.

Bates, E. \& MacWhinney, B. (1989). Functionalism and the competition model. In E. Bates, \& B. MacWhinney (Eds.), The crosslinguistic study of sentence processing. Cambridge: Cambridge University Press.

Beaver, D. 2004. The optimization of discourse anaphora. Linguistics and Philosophy 27(1):3-56.

Brennan, Susan E., Friedman, Marilyn A. \& Pollard, Charles J. 1987. A Centering approach to pronouns. Proceedings of the $25^{\text {th }}$ Annual Meeting of the Association for Computational Linguistics, Stanford, Calif., 155-162.

Cowles, H.W. 2003. Processing Information Structure: Evidence from Comprehension and Production. Ph.D. dissertation, UCSD.

Crawley, R.J. and Stevenson, R.J. 1990. Reference in single sentences and in texts. Journal of Psycholinguistic Research 19(3):191-210.

Delin, J. 1990. A psychological investigation of the processing of cleft constructions. Blue Book note no. 2.

Givón, T. 1983. Topic continuity in discourse: A quantitative cross-language study. Amsterdam: John Benjamins.

Gordon, P.C., Grosz, B.J., \& Gilliom, L.A. 1993. Pronouns, names, and the Centering of attention in discourse. Cognitive Science 17:311-347

Green, M. and Jaggar, P. 2003. Ex-situ and In-situ Focus in Hausa: syntax, semantics and discourse. In Lecarme, J (Ed.) 2003. Research in Afroasiatic Grammar II. [CILT 241]. Amsterdam: John Benjamins: 187-213.

Grosz, B., Joshi, A. \& Weinstein, S. 1995. Centering: A Framework for Modelling the Local Coherence of Discourse. Computational Linguistics, 2(21).

Gundel, Jeanette K., Hedberg, Nancy \& Zacharski, Ron. 1993. Cognitive status and the form of referring Expressions in Discourse. Language 69, 274-307. 
Gundel, Jeanette. 1974. The role of topic and comment in linguistic theory. University of Texas Ph.D. dissertation.

Hajicova, E., Kubon, V., \& Kubon, P. 1992. Stock of shared knowledge - a tool for solving pronominal anaphora. Proc. of COLING-92, Vol. 1, 127-133.

Hornby, P.A. 1974. Surface structure and presupposition. Journal of Verbal Learning and Verbal Behavior 13:530-538.

Kaiser, E. 2003. The quest for a referent: A crosslinguistic look at reference resolution. Ph.D. dissertation, University of Pennsylvania.

Kaiser, E. \& J.C. Trueswell (In press) Investigating the interpretation of pronouns and demonstratives in Finnish: Going beyond salience. To appear in E. Gibson \& N. Pearlmutter (eds), The processing and acquisition of reference. Cambridge, Mass.: MIT Press.

Kameyama, M. 1999. Stressed and unstressed pronouns: Complementary preferences. In Focus: Linguistic, Cognitive, and Computational Perspectives, ed. P. Bosch \& R. van der Sandt, 306-321. Cambridge University Press.

Kehler, A. 2001. Coherence, Reference and the Theory of Grammar. Stanford: CSLI

Kiss, K. 1998. Identificational focus vs. Information Focus. Language 74(2):245-273.

MacDonald, M.C., N.J. Pearlmutter \& M.S. Seidenberg. 1994. The lexical nature of syntactic ambiguity resolution. Psychological Review 101: 676-703.

Matthews, A. \& Chodorow, M. 1988. Pronoun resolution in two-clause sentences: Effects of ambiguity, antecedent location, and depth of embedding. Journal of Memory and Language 27:245-260.

McDonald, J.L. \& MacWhinney, B. 1995. The time course of anaphor resolution: Effects of implicit verb causality and gender. Journal of Memory and Language 34:543-566.

Navarretta, C. 2002. Combining Information Structure and Centering-based models of salience for resolving intersential pronominal anaphora. In A. Branco, T. McEnery and R. Mitkov (eds), Proceedings of the 4th Discourse Anaphora and Anaphor Resolution Colloquium, pp.135-140. Lisbon: Edições Colibri

Prince, E.F. 1978. A Comparison of Wh-Clefts and It-Clefts in Discourse. Language 544:883906.

Prince, E.F. 2003. The Yiddish impersonal pronoun men 'one' in discourse. Presented at the Annual Meeting of the Linguistic Society of America, Atlanta, January 2003. (available online at www.ling.upenn.edu/ ellen)

Reinhart, Tanya. 1982. Pragmatics and linguistics: an analysis of sentence topics. University of Indiana Linguistics Club. (also Philosopica 1981, 27.53-94).

Singer, M. 1976. Thematic structure and the integration of linguistic information. Journal of Verbal Learning and Verbal Behavior 15:549-558. 
Smyth, R. 1994. Grammatical determinants of ambiguous pronoun resolution. Journal of Psycholinguistic Research, 23:197-229.

Stevenson, R. and Urbanowicz, A. 1995. Structural focusing, thematic role focusing and the comprehension of pronouns. In Proceedings of the $17^{\text {th }}$ Annual Conference of the Cognitive Science Society, 328-332. Pittsburg, PA.

Stevenson, Rosemary J., Crawley, Rosalind J. and Kleiman, D. 1994. Thematic roles, focus and the representation of events. Language and Cognitive Processes, 9, 519-548.

Strawson, P.F. 1964. Identifying reference and truth-values. Theoria 30:96-118. Reprinted in Semantics: An Interdisciplinary Reader in Linguistics, Philosophy and Psychology, ed. by Danny D. Steinberg and Leon A. Jakobovits. 1971. Cambridge: Cambridge University Press.

Strube, M. \& Hahn, U. 1996. Functional Centering. In Proceedings of ACL '96, 270-277.

Strube, M. \& Hahn, U. 1999. Functional Centering: Grounding Referential Coherence in Information Structure. Computational Linguistics 25(3).

Tanenhaus, M. K., \& Trueswell, J. C. 1995. Sentence comprehension. In J. L. Miller \& P. D. Eimas (Eds.), Handbook of Perception and Cognition: Volume 11, 217-262. Academic Press, San Diego.

Trueswell, J.C., Tanenhaus, M.K., \& Garnsey, S. 1994. Semantic influences on parsing: Use of thematic role information in syntactic ambiguity resolution. Journal of Memory and Language 33:285-318. 


\title{
WHAT INFLUENCES THE REFERENTIAL PROPERTIES OF REFLEXIVES AND PRONOUNS IN FINNISH?*
}

\author{
Elsi Kaiser, \\ University of Southern California \\ elsi.kaiser@usc.edu \\ Jeffrey T. Runner, Rachel S. Sussman and Michael K. Tanenhaus, \\ University of Rochester
}

\begin{abstract}
According to standard Binding Theory, pronouns and reflexives are in (nearly) complementary distribution. However, representational NPs (e.g. 'picture of her/herself') allow both. It has been suggested that in English, reflexives in representational NPs (RNPs) have a preference for 'sources of information' and that pronouns prefer 'perceivers of information.' We conducted two experiments investigating the effects of structural and non-structural (source/perceiver) factors on the interpretation of two kinds of RNP structures in a typologically different language, namely Finnish. Our results reveal source/perceiver effects for postnominal but not for prenominal RNPs in Finnish, with a difference in the degree of sensitivity that pronouns and reflexives exhibit to the source/perceiver manipulation, and our results also suggest that morphological differences in Finnish reflexives correspond to interpretation differences. As a whole, these results support a multiple-factor model of reference resolution, which assumes that multiple factors can play a role in reference resolution and that the relative contributions of these factors can be different for different anaphoric forms (Kaiser 2003b, Kaiser \& Trueswell in press).
\end{abstract}

\section{Introduction}

According to standard binding theory, pronouns and reflexives are in (nearly) complementary distribution. This complementarity breaks down in representational NPs (e.g. picture of $\{$ her/herself\}), and it has been suggested that in English, non-Binding Theory compatible reflexives in representational NPs are acceptable if they refer to "sources-of-information" (e.g. Kuno 1987) and pronouns with local antecedents are acceptable if they refer to "perceivers-of-information" (Tenny 2004). Psycholinguistic experiments support these claims for English (Kaiser, Runner, Sussman \& Tanenhaus 2005, in press). In this paper, we present two experiments investigating whether these claims hold for a typologically different language, Finnish, whether they arise in more than one structural domain, and whether morphological differences in Finnish reflexives correspond to interpretational differences.

The structure of this paper is as follows. In Section 1.1, we discuss the basics of Binding Theory, and in Section 1.2 we turn to some of the structures where traditional Binding Theory runs into trouble, including so-called representational noun phrases. Section 1.3 considers some of the non-structural factors that have been argued to influence anaphor resolution in cases where Binding Theory is not sufficient. Section 2 summarizes the psycholinguistic work we have conducted on English, investigating the role of nonstructural factors in anaphor resolution, and Sections 3 and 4 present the experiments we conducted on Finnish. Section 5 is the conclusion.

\footnotetext{
${ }^{*}$ We gratefully acknowledge support from NSF grant BCS-0110676 and NIH grant HD-27206.
} 


\subsection{Basics of Binding Theory}

It is well known that pronominal and reflexive noun phrases in English have a nearly complementary distribution, as illustrated in (1).

(1) a. Julius saw $_{\text {him }} *_{\mathrm{i} / \mathrm{j}}$.

b. Julius saw himself $_{\mathrm{i} / *_{\mathrm{j}} \text {. }}$.

c. Julius $s_{i}$ saw a picture of him $*_{i} / j$.

d. Julius $\mathrm{i}_{\mathrm{i}}$ saw a picture of himself $\mathrm{i}_{\mathrm{i} / \mathrm{j}}$.

Principles A and B of Chomskyan Binding Theory (BT) offer a structural account of this complementarity (e.g. Chomsky 1981, 1986). Principle A states that an anaphor (a reflexive pronoun) must be bound (by a c-commanding antecedent) in a local domain, whereas Principle B states that a pronoun must be free in a local domain. For the purposes of this paper, we can simply regard the clause as the relevant local domain. For the most part, we will use the term 'reflexive' rather than 'anaphor', but the two terms can be regarded as synonymous.

\subsection{Where traditional Binding Theory runs into trouble}

Although Binding Theory captures many of the configurations in which reflexives and pronouns can and cannot appear, it has been known for a long time that there are certain structures where the predicted complementarity between pronouns and reflexives does not arise. Some naturally-occurring examples of non-Binding Theory compatible reflexives (reflexives without local antecedents) are given in (2), and examples of non-Binding Theory compatible pronouns (pronouns with local antecedents) are in (3).

(2) a. Bismarck's impulsiveness has, as so often, rebounded against himself. (quoted in Zribi-Hertz 1989)

b. Warren says it's a good time to be an astrophysicist. Fifteen years ago, "we were starved for observations," he says. Now it's the opposite: Theorists like himself are drowning in data from modern telescopes. (from The New Mexican newspaper in Santa Fe, NM, 6/28/04)

(3) a. Poor John. Now he's got an ambitious little snake next to him.

(www.freerepublic.com/ regulator/in-forum)

b. Except he could not throw the ball because he was getting tackled. He was about to hit the ground. He had to do something else. He saw someone behind him. He flipped the ball in desperation. (www.wildbillschiefs.com/news/data/604.txt)

The existence of such examples raises the question of what guides the choice of one form over the other in these contexts. This question has been investigated by a number of researchers, focusing primarily on English (e.g. Cantrall 1974, Kuno 1987, Zribi-Hertz 1989, Pollard \& Sag 1992, Reinhart \& Reuland 1993, Tenny 1996, 2003, 2004), who have suggested that choice of referential form in these contexts is influenced by semantic and/or discourse factors.

In this paper we will focus on a subclass of structures known to be problematic for standard Binding Theory, so-called representational NPs (RNPs), e.g. 'a picture of her/herself', 'a story about him/himself', which are well-known for showing clear discourse/semantic effects ${ }^{1}$ for

\footnotetext{
${ }^{1}$ We often use the hybrid label 'discourse/semantic factors' when discussing the effects of non-structural factors on pronouns and reflexives. One could argue that the source/perceiver manipulation to be discussed below is a semantic, thematic role manipulation. However, it could also be argued that source/perceiver is related to
} 
both pronouns and reflexives (e.g. Kuno 1987, Pollard \& Sag 1992, Reinhart \& Reuland 1993, Keller \& Asudeh 2001, Tenny 2003).

Let us first consider reflexives in RNPs. Strikingly, example (4a) is acceptable, although the antecedent of 'himself' is not in the same sentence as the reflexive, and thus cannot bind 'himself'. The contrast between (4a) and (4b) (both from Pollard \& Sag 1992) shows that pragmatic factors such as 'point of view' can have a strong influence on the acceptability of such reflexives. Example (4a) is judged to sound better than (4b), and Pollard \& Sag suggest that this is because (4a) - but not $(4 b)$ - is from John's point of view. In other words, it appears that reflexives referring to 'point of view'-antecedents are acceptable, even if the antecedent does not bind the reflexive as required by Binding Theory.

(4) a. $J \mathrm{ohn}_{\mathrm{i}}$ was going to get even with Mary. [That picture of himimimself $\mathrm{f}_{\mathrm{i}}$ ] in the paper would really annoy her, as would the other stunts he had planned.

b. Mary was quite taken aback by the publicity $\mathrm{John}_{\mathrm{i}}$ was receiving. [That picture of $\operatorname{him}_{\mathrm{i}} /{ }^{*}$ himself $\left._{\mathrm{i}}\right]$ in the paper would really annoy her, as would the other stunts he had planned.

More generally, Kuno (1987) argues that factors like point of view, awareness and semantic roles influence whether a given entity can act as the antecedent for a non-BT compatible reflexive (see also Pollard \& Sag 1992, Reinhart \& Reuland 1993). We focus on the hypothesis in (6), based on Kuno's claims (see his example (5)) and drawing on Sells (1987)'s definition of source as the one who is the intentional agent of the communication

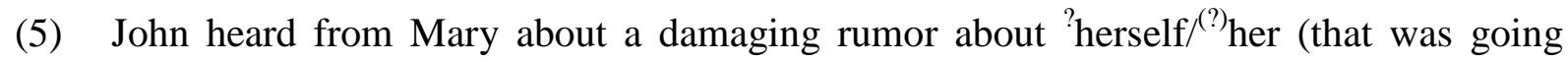
around). (Kuno 1987:175)

(6) Hypothesis for reflexives: BT-incompatible reflexives in RNPs are acceptable if they refer to sources-of-information.

Let us now turn to the question of what kinds of pragmatic factors have been claimed to influence pronouns in RNPs. According to standard Binding Theory, none of the examples in (7) (based on Reinhart \& Reuland 1993) should be grammatical, since in each case the pronoun is c-commanded by a local antecedent.

(7) a. Lucie $_{i}$ saw the picture of her.

c. Max $_{i}$ heard the story about himi . b. ${ }^{*}$ Lucie $_{\mathrm{i}}$ took the picture of her $\mathrm{i}_{\mathrm{i}}$

d. $*$ Max $_{\mathrm{i}}$ told the story about himi .

However, (7a) and (7c) tend to be judged as more acceptable than (7b) and (7d). Tenny (2003) calls these kinds of pronouns short-distance pronouns (SDPs) and notes that "verbs that provide a sentient, perceiving antecedent are especially conducive to SDPs" (Tenny 2003:42). She continues that "....SDPs in representational contexts [.....] are especially felicitous with perceiving subjects" (Tenny 2003:42). In light of this claim, it is not surprising that (7a) and (7c) are judged to sound better, since in both cases the antecedent is a perceiver. Thus, for pronouns we investigate the hypothesis in (8):

(8) Hypothesis for pronouns: BT-incompatible pronouns in RNPs are acceptable if they refer to perceivers-of-information.

Although Kuno and Tenny do not comment on this, the hypotheses in (6) and (8) can be regarded, in some sense, as 'two sides of the same coin' - given that verbs like tell/hear involve both a source-of-information and a perceiver-of-information. Thus, it might turn out to be the case that BT-incompatible pronouns and reflexives have a (non-structurally driven) complementary distribution. 


\subsection{What kinds of information contribute to anaphor resolution?}

The more general theme underlying our investigation of pronouns and reflexives in RNPs concerns the question of what kind of information contributes to reference resolution - in particular, how structural and non-structural information interact in the course of reference resolution. RNPs provide an ideal tool to further test the 'multiple-factor model' of reference resolution argued for by Kaiser (2003b) and Kaiser \& Trueswell (in press). According to this approach, different referential forms are sensitive to different kinds of information (e.g. syntactic, semantic, discourse) to different degrees. For example, certain referential forms are primarily sensitive to syntactic factors, whereas others are influenced mainly by discourselevel factors such as referent salience. In other words, the claim is that the relative contributions of different factors for each referential form can vary. Kaiser (2003b) (see also Kaiser \& Trueswell, in press; Brown-Schmidt, Byron \& Tanenhaus, 2005) argues in favor of the multiple-factor model on the basis of reference resolution across clauses in Finnish, Dutch and Estonian, and RNPs provide an ideal tool for testing whether the same model can be applied to reference resolution within clauses, which is a domain that has traditionally been regarded as more constrained by syntactic factors than across-clause reference resolution.

In this paper, we compare the predictions of a multiple-factor approach (which we will refer to as an interactive/modulation view in this paper) to those of two 'single-factor' approaches, which we will refer to as the pure structural view and the pure discourse/semantic view. We focus on the interpretation of pronouns and reflexives in sentences such as those in (9):

(9) a. Peter told Andrew about the picture of $\{$ him/himself $\}$ on the wall.

b. Peter heard from Andrew about the picture of $\{$ him/himself $\}$ on the wall.

According to the pure structural view, only syntactic factors are relevant for determining the antecedents of pronouns and reflexives, and differences only on the level of verb semantics do not lead to differences in binding patterns. The prediction is that reflexives always refer to local c-commanding antecedents (here, subjects) and pronouns to non-commanding antecedents (here, objects; see also footnote 2). In contrast, the other extreme of the scale is the pure discourse/semantic view, according to which the antecedents of pronouns and demonstratives in RNPs are determined on basis of discourse/semantic role only. According to this approach, reflexives are predicted to refer to sources of information (e.g. the subject of 'tell' and the object of 'hear') and pronouns to perceivers of information (e.g. the subject of 'hear' and the object of 'tell') - regardless of grammatical role. Finally, according to the interactive/modulation view (which assumes that multiple factors can be relevant), both structure and discourse/semantics play a role. The predictions are, therefore, that reflexives will have more non-BT compatible object-antecedents with 'hear' than with 'tell' (since the object is the source with 'hear'), and pronouns will have more non-BT compatible subject with 'hear' than 'tell' perceivers than sources (since the subject is the perceiver with 'hear').

\section{Representational NPs in English: Previous work}

In earlier experimental work (Kaiser, Runner, Sussman \& Tanenhaus 2005, in press), we explored the three hypotheses sketched out in section 1.3 for pronouns in picture NP constructions in English (ex.(9)). We opted to investigate these issues experimentally because judgments concerning these kinds of constructions are notoriously variable. With an experimental approach, we can manipulate the structural and pragmatic/semantic variables that we are interested in test, and we can collect a set of data from a large group of participants that can then be statistically analyzed to see whether there are any reliable patterns. In addition, using eye-tracking methodology (see Kaiser et al. in press), we can obtain incremental, real-time information about interpretation. Thus, we obtain information about participants' final referential choices and also about the possible referents they consider 
before they make a choice. These kinds of data can shed further light on the nature of the relation between syntactic and discourse/semantic factors in anaphora resolution.

Our results show that the interpretation of pronouns and reflexives in RNPs in English is influenced by the source/perceiver manipulation. More specifically, pronouns exhibit a strong preference for perceivers, and reflexives show a weaker preference for sources. Thus, as a whole the results support the modulation view, which posits that both structural and discourse/semantic information play a role in the processing and interpretation of pronouns and reflexives in RNPs. Furthermore, as the asymmetrical nature of the results reveals, the effects are not equally strong for reflexives and pronouns. Pronouns display a much greater sensitivity to non-structural factors. This supports Kaiser (2003b)'s multiple-factor model, which claims that not only are multiple factors relevant, but the relative contributions of different factors for each referential form can vary. In other words, the Kaiser et al. (in press) results show that in English, the relative strength of discourse/semantic factors, when compared to structural factors, is greater for pronouns than for reflexives.

In this paper we focus on three questions left unanswered by our work on English. As will become clear later, Finnish is very well-suited for shedding light on these issues.

(i) Are the source/perceiver effects and the pronoun/reflexive asymmetry English-specific or do they extend to a typologically distinct language as well?

(ii) Is the source/perceiver preference for reflexives and pronouns respectively limited to one particular syntactic structure (RNPs where the pronoun/reflexive is embedded in a PP), or does it also show up in other syntactic configurations? This question will shed light on the question of whether different syntactic structures differ in how impervious they are to the effect of non-structural factors.

(iii) Given that many other languages exhibit greater morphological complexity in their pronominal and reflexive systems than English does, is it the case that morphological differences correspond to interpretational differences? For example, if a language has two reflexive forms, do they differ in their sensitivity to non-structural information? The multiple-factor model's claim that the relative contributions of different factors for each referential form can vary suggests that this could indeed be the case.

To investigate these questions, we conducted two experiments on Finnish. The first one investigates different referential forms in prenominal RNPs and the second one turns to postnominal RNPs.

\section{Experiment 1: Finnish prenominal RNPs}

\subsection{Finnish possessives}

In Finnish, possession is represented by a system of possessive pronouns and possessive suffixes (Px's). In this paper we will focus on the third person possessive suffix, which surfaces as [-nsA] or [-An] (the capital letter indicates that the vowel undergoes vowel harmony and can surface as [a] or [ä]). In third person possessive constructions with pronominal possessors (e.g. 'his car'), the possessive suffix is present on the possessed noun. However, the possessive pronoun itself is null in certain contexts: According to the judgments reported in the literature, when an overt possessive pronoun is not present, then - 'reflexivestyle' - the referent of the subject of the sentence is the possessor (Vilkuna 1996:228-230, Nelson 1998:13)

(10) a. Mari näki hänen autonsa.

Mari-NOM saw s/he-GEN car-ACC-3Px

'Mari $i_{i}$ saw her ${ }_{j}$ (someone else's) car.' 
b. Mari näki autonsa.

Mari-NOM saw $\varnothing$ car-ACC-3Px

'Mari saw her $_{\mathrm{i}}$ (own) car.'

Various analyses have been proposed concerning the Finnish possessive suffix and its relation to the possessive pronoun, and we briefly consider three of them here. One approach analyzes the possessive suffix as an anaphor (e.g. Vainikka (1989), Nelson (1998)). According to this view, third person possessive suffixes are anaphors which must be bound by the subject of the sentence or by a third person possessive pronoun (e.g. Nelson 1998:187-188; see Trosterud 1993 for a somewhat different account of the role of the third person possessive pronoun).

A different analysis is proposed by van Steenbergen (1991), who claims that possessive constructions without an overt possessive pronoun contain an empty element (pro). According to van Steenbergen's analysis, pro is an empty anaphor which can only be bound by the subject and occurs whenever 'it corefers with a c-commanding NP' (van Steenbergen 1991:234). She claims that the possessive suffix marks nominal inflection (van Steenbergen 1991:232). (It is worth noting that in this paper, we will often refer to constructions with no overt possessive pronoun as containing a null possessive pronoun. However, the question of whether such constructions contain a null possessive that acts as a reflexive or whether it is the suffix that acts as the reflexive is not central to our aims in this paper, and our choice of terminology should not be regarded as endorsing one theory over the others.)

A third approach is presented by Toivonen (2000) within Lexical Functional Grammar (LFG). She argues that the third person possessive suffix [-nsA] is 'a single phonological form [that] corresponds to two distinct sets of lexical features' (Toivonen 2000:34). She claims that when the third person possessive suffix occurs without an overt possessive pronoun in a context where the subject is the possessor, the possessive suffix is a subject-bound reflexive pronoun. In contrast, when the suffix occurs in the presence of an overt possessive pronoun and with a subject disjoint in reference, she argues that the possessive suffix is an agreement marker (Toivonen 2000:30).

Despite the important differences between these accounts, it appears that they resemble one another in terms of the predictions they are expected to make regarding the factors that influence the referential properties of reflexives and pronouns. In other words, all three accounts would presumably predict that sentences with no overt possessive pronouns should be influenced by whatever factors influence the referential properties of anaphors (reflexives), and that in sentences with overt possessive pronouns, the referential properties of the possessed NP should be influenced by whatever factors influence the referential properties of pronouns.

Before moving on to the details of the experiment, let us consider another form, besides the overt possessive pronoun, that Finnish offers for indicating reference to a non-subject: the demonstrative pronoun tämän 'this-GENITIVE'. In Finnish, tämä can be used to refer to human referents, and this form has been claimed to be used for human antecedents that are not highly salient (e.g. Varteva 1998, Kaiser \& Trueswell in press). Note that use of genitive tämä does not permit a possessive suffix on the possessed noun.

$$
\begin{aligned}
& \text { c. Mari näki tämän auton. } \\
& \text { Mari-NOM saw this-GEN car-ACC. } \\
& \text { 'Mari }{ }_{i} \text { saw her }{ }_{j} \text { (someone else's) car.' }
\end{aligned}
$$

The fact that both overt pronouns and the demonstrative can be used when the possessor is not the subject raises the question of how they differ. As far as we know, this question has not been investigated in the literature in any depth, although both forms are wide-spread in Finnish language use. Thus, in addition to the aims sketched out above, we also hoped that 
Experiment 1 might be able to shed light on potential differences between the overt pronoun and the demonstrative.

\subsection{Experimental design}

In this experiment, we manipulated verb type (kertoa 'to tell' vs. kuulla 'to hear') and anaphoric form. Participants $(n=32)$ read sentences and chose whose picture was mentioned in the sentence. They were able to choose among four options: subject / object / both are possible / someone else. Sample stimuli and their glosses and translations are shown below.

a. Null/Reflexive with 'told'

Mari kertoi Liisalle muotokuvastaan.

Mari-NOM told Liisa-ALL $\varnothing$ portrait-ELA-3Px

'Mari ${ }_{\mathrm{j}}$ told Liisa ${ }_{\mathrm{k}}$ about her ${ }_{\mathrm{j}}$ portrait.'

a.' Null/Reflexive with 'heard'

Mari kuuli Liisallta muotokuvastaan.

Mari-NOM heard-from Liisa-ABL $\varnothing$ portrait-ELA-3Px

'Mari ${ }_{\mathrm{j}}$ heard from Liisa ${ }_{\mathrm{k}}$ about her $_{\mathrm{j}}$ portrait.'

b. Pronoun

Mari kertoi Liisalle (kuuli Liisalta) hänen muotokuvastaan.

Mari-NOM told Liisa-ALL (heard-from L-ABL) s/he-GEN portrait-ELA-3Px

'Mari told Liisa $_{\mathrm{k}}$ (heard from Liisa ${ }_{\mathrm{k}}$ ) about her ${ }_{\mathrm{k}, \mathrm{i}}$ portrait.'

c. Demonstrative:

Mari kertoi Liisalle (kuuli Liisalta) tämän muotokuvasta.

Mari-NOM told Liisa-ALL (heard-from Liisa-ABL) this-GEN portrait-ELA



In Finnish, with both kertoa 'to tell' and kuulla 'to hear', the noun 'portrait' is in elative case (ELA). With kertoa 'to tell', the perceiver of information is marked with allative (ALL) case. With kuulla 'to hear from', the source of information is marked with ablative (ABL) case. According to Nikanne (1993), both ALL and ABL are semantic cases, which he distinguishes from the grammatical cases NOM, ACC, PART and GEN. Nikanne argues for the same structural analysis for both ALL and ABL. ${ }^{2}$

\subsection{Predictions}

Let us now consider the predictions that we can make based on the three different approaches mentioned above, namely the pure structural view, the pure discourse/semantic view and the interactive/modulation view (see also Table 1 below). According to the pure structural view, only structural information is relevant and thus the verb manipulation is predicted to have no effect on antecedent choice. More specifically, null possessive pronouns are predicted to refer to the subject, and overt pronouns and demonstratives to the object, regardless of verb. In contrast, the pure discourse semantic view claims that structural information is irrelevant and only source/perceiver preference matter. Thus, the prediction is that 'reflexive-style' null possessive pronouns will be interpreted as referring to the source of information (the subject

\footnotetext{
${ }^{2}$ Thus, Finnish allows us to sidestep the potential structural complication that at first glance seems to arise for English, namely that 'hear from someone' involves a preposition but 'tell someone' does not. Depending on what is assumed to be the syntactic position of the direct object, one could argue that in English the direct object of a verb like tell-unlike the object of a preposition, as with hear from-c-commands the RNP (see Contreras 1984, inter alia) and the direct object is therefore a possible antecedent for a reflexive pronoun and not a possible referent for a pronoun. However, as we show in Kaiser et al (in press), this alternative account for differences between tell and hear from does not receive support from the empirical data from our experiments on English.
} 
with 'tell' and the object with 'hear'), and that overt pronouns will refer to the perceiver of information (the object with 'tell' and the subject with 'hear'). It is not clear what this approach predicts for demonstratives, since they do not fall clearly into the reflexive class or the pronoun class.

\begin{tabular}{|c|c|c|c|}
\hline \multicolumn{4}{|l|}{ Tell } \\
\hline & Null & Pronoun & Demonstrative \\
\hline Syntax & Subject & Object & Object \\
\hline Discourse & Subject & Object & $? ?$ \\
\hline Interactive & Subject & Object & Object \\
\hline \multicolumn{4}{|l|}{ Hear } \\
\hline & Null & Pronoun & Demonstrative \\
\hline Syntax & Subject & Object & Object \\
\hline Discourse & Object & Subject & $? ?$ \\
\hline Interactive & $? ?$ & $? ?$ & Object \\
\hline
\end{tabular}

Table 1. Predictions for Experiment 1.

Finally, let us turn to the interactive/modulation view, which claims that both structural information and discourse/semantic information interact, and that both can influence the choice of antecedent. Let us assume, for reasons of expository ease, that both structural and discourse/semantic factors are weighted equally. As Table 1 shows, according to this view, a null possessive occurring with 'tell' has two kinds of information pushing it towards the subject of the sentence: the binding-theoretic preference towards the sentence subject and the discourse/semantic preference for the source of information. An overt pronoun occurring with 'tell', on the other hand, is pushed towards the object by both Binding Theory and the discourse/semantic perceiver preference. In the case of demonstratives, structurally speaking we expect an object preference, but it is not clear what, if any, effect there will be of the source/perceiver status of potential antecedents.

The picture is more complex with 'hear', however, since structural information and discourse/semantic information are pitted against each other in the case of both null and overt possessive pronouns, as shown in the bottom half of Table 1. Overall, then, we might predict more object choices with null pronouns occurring with 'hear' than null pronouns occurring with 'tell', as well as more subject choices for overt pronouns occurring with 'hear' than overt pronouns occurring with 'tell'. In other words, we predict that in the conditions with 'hear', the discourse/semantic factors will pull overt and null pronouns away from the structurallypredicted antecedents. In the case of demonstratives, as mentioned above, it is not clear what effects, if any, we expect the verb manipulation to have.

\subsection{Results and discussion}

Figure 1 illustrates the results for null possessive pronouns, overt possessive pronouns and demonstrative pronouns with the two verbs. Even a brief glance reveals a striking absence of any verb-driven effect. The pattern of responses is the same with both 'told' and 'heard' regardless of anaphoric form. Considering each anaphoric form in turn, we see that the null possessive pronoun clearly has a strong preference for the preceding subject and the demonstrative has a strong preference for the preceding object. The overt pronouns fall in between these two extremes. Although they are more likely to be interpreted as referring to the preceding object than the preceding subject, this preference is not as strong as in the case of the demonstratives. 


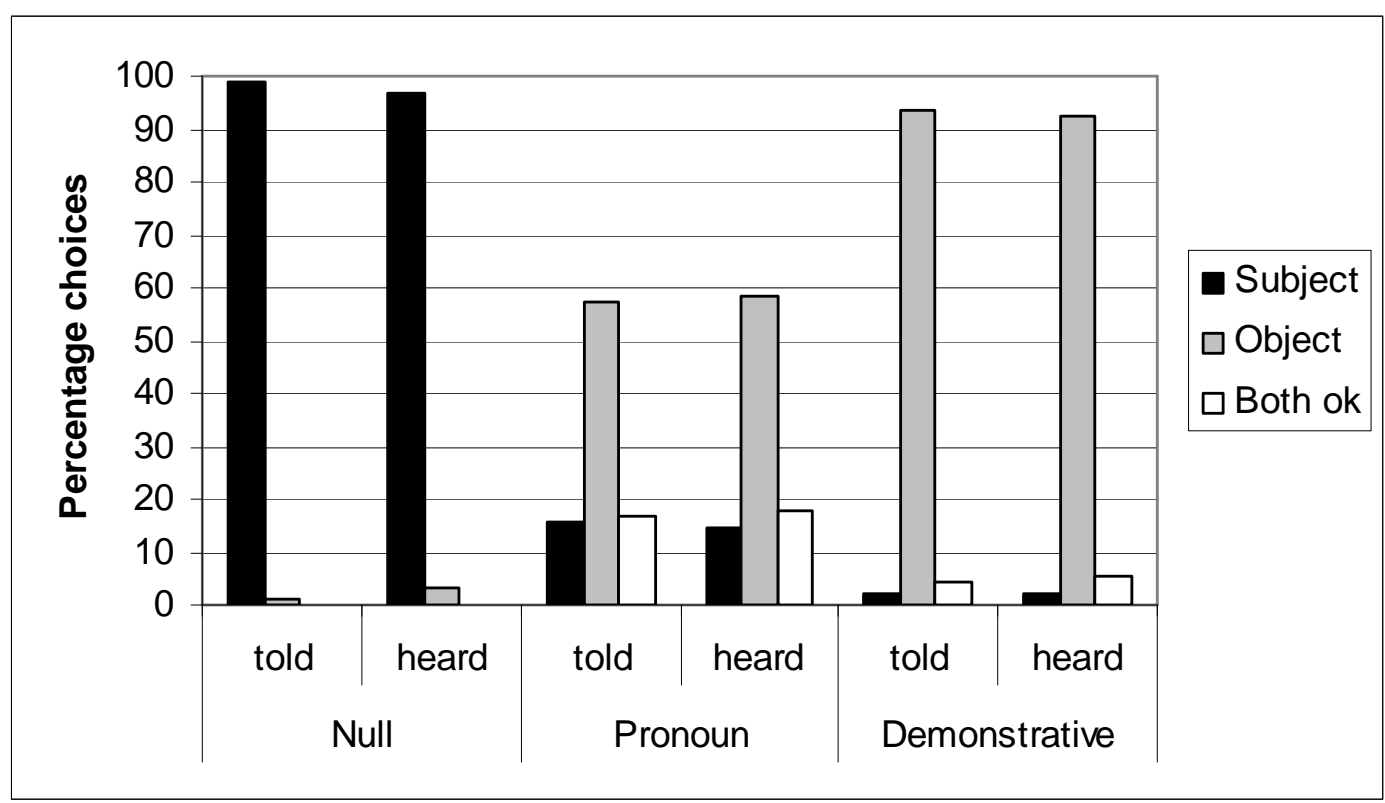

Figure 1. Percentage of antecedent choices for prenominal RNPs in Finnish

The fact that the object preference for possessive pronouns is not as strong as for demonstratives might seem rather surprising in light of the traditional claims that overt possessive pronouns cannot be interpreted as coreferential with the subject of the sentence. However, as Kaiser (2003a) notes, native speaker judgments on the referential properties of overt possessive pronouns seem to not be as clear as the literature might lead one to expect. This effect might be due to the influence of colloquial Finnish / Finnish dialects (see Paunonen 1995, see also Hakulinen et al. 2004:1240), given that in a number of Finnish dialects, it seems that an overt genitive pronoun can be interpreted as being coreferential with the subject as well as the object. (It is well-known that 'it' can be used in many Finnish dialects to refer to human as well as non-human referents without any derogatory connotations, in contrast to its use in Standard Finnish. Standard Finnish is the 'official' form of the language and used in formal writing and public/official speech (e.g. TV newscasts, speeches etc.), but virtually all Finns can speak both standard Finnish and a colloquial dialect of Finnish; they choose which register to use depending on the situation and the modality of language use.)
(12) Liisa
kerto Marille sen
muotokuvasta.
Liisa-NOM told Mari-ALL it-GEN portrait-ELA
'Liisa $a_{\mathrm{j}}$ told Mari about her $_{\mathrm{j}), \mathrm{k}, \mathrm{l}}$ portrait.' (colloquial southern urban Finnish)

As a whole, the results of Experiment 1 support the pure structural view, which posits that the referential properties of pronouns and reflexives are determined by only structural factors. In the prenominal domain in Finnish, in contrast to what was observed for RNPs in English, we see no sign of source/perceiver effects for pronouns or reflexives.

\section{Experiment 2: Postnominal RNPs in Finnish}

In the second experiment, we turn to a different structural configuration, namely postnominal RNPs. These are structurally more parallel to the English RNPs than the Finnish prenominal RNPs investigated in Experiment 1, and thus - if it the case that different syntactic configurations differ in how impervious they are to non-structural factors - we might expect postnominal RNPs in Finnish to be more likely to exhibit source/perceiver effects. 
The Finnish counterparts of 'a picture of herself/her' are shown in (13). Here the contrast is not between absence and presence of an overt genitive pronoun, but rather between the reflexive form itse+Px 'self+Px' (13a) and the pronoun hänestä 's/he-ELATIVE' (13b). (The same reflexive form, itse+Px, with the appropriate case marking, is also used in direct object position in sentence such as "Liisa saw herself.")

$$
\begin{aligned}
& \text { a. Liisa näki kuvan itsestään. } \\
& \text { Liisa-NOM saw picture-ACC self-ELA-3Px } \\
& \text { 'Liisa }{ }_{j} \text { saw a picture of herself } f_{j} \text {.' } \\
& \text { b. Liisa näki kuvan hänestä. } \\
& \text { Liisa-NOM saw picture-ACC s/he-ELA } \\
& \text { 'Liisa } \text { saw a picture of her/him }_{\mathrm{k}} \text {.' }
\end{aligned}
$$

In addition to these 'canonical' forms, we will also consider two other post-nominal reflexive forms, which have not received as much attention in the existing literature, namely a pronoun+reflexive compound form and an emphatic reflexive form. First, let us turn to the pronoun+reflexive compound hänestä itsestään (she/he-ELA self-ELA-3rd.Px) '(about) his/her+himself/herself'. This form appears to be ambiguous between (i) a pronominal with an 'emphatic' reflexive, akin to English structures like he himself, and (ii) a reflexive preceded by an 'emphatic' pronoun (see also Featherston 2002 on the ambiguity of German ihm selbst/ihn selbst). In Experiment 2, in addition to testing whether Finnish pronouns and reflexives in postnominal RNPs are sensitive to the source/perceiver manipulation, we will also test whether the pronoun+reflexive compound patterns more like pronouns or like reflexives in its sensitivity to source/perceiver and structural information, with the aim of shedding light on the question of whether this compound form should be regarded as pronominal or reflexive.

In Experiment 2 we also investigate the referential properties of the emphatic reflexive construction omasta itsestään (own-ELA self-ELA-3rd.Px) '(about) own+himself/herself.' This is presumably an unambiguous reflexive preceded by the emphatic marker 'own,' given that omasta cannot occur independently in post-nominal RNP constructions. Thus, the question arises whether it differs from the standard reflexive form (13a) in its sensitivity to the source status of the antecedent.

\subsection{Experimental design}

In this experiment we manipulated verb type and anaphoric form, as illustrated in (14). A different group of participants $(n=32)$ read sentences and indicated who the joke was about. As in Experiment 1, participants were given four choices: subject / object / both are possible / someone else.

a. Reflexive:

Mari kertoi Liisalle vitsin itsestään.

Mari-NOM told Liisa-ALL joke-ACC self-ELA-3Px

'Mari told Liisa a joke about herself.'

b. Pronoun:

Mari kertoi Liisalle vitsin hänestä.

Mari-NOM told Liisa-ALL joke-ACC she-ELA

'Mari told Liisa a joke about her.'

c. Compound:

...hänestä itsestään

...she-ELA herself-ELA-3rd.Px

...' $\{$ her/him $\}+\{$ herself/himself $\}$ ' 


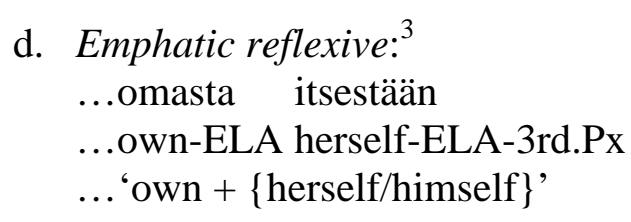

\subsection{Predictions}

In this section we consider the predictions made by the pure structural approach, the pure discourse/semantic approach and the interactive/modulation approach (Table 2). First, according to the pure structural view, we predict that pronouns will be interpreted as referring to the preceding object, regardless of the verb manipulation. Reflexives are predicted to be interpreted as referring to the subject of the sentence, again regardless of the verb, given that reflexives need to be bound by a local c-commanding antecedent. The predictions are less clear for the compound form and the emphatic reflexive. As mentioned above, the compound form seems to be ambiguous between a pronoun and a reflexive, and has not received much attention in existing work. As for the emphatic reflexive, we might expect it to show a subject preference, regardless of verb, since it is presumably a fundamentally reflexive element.

The predictions of the pure discourse/semantic view are different. According to this approach, source/perceiver preferences guide the reference resolution of referential forms in RNPs, and thus we predict that pronouns will opt for the object with tell (perceiver) and the subject with hear (perceiver), and that reflexives will be interpreted as referring to the subject with tell (source) and the object with hear (source). The emphatic reflexive might well pattern like 'regular' reflexives, and again the referential properties of the ambiguous compound form will presumably depend on whether it turns out to be pronominal or reflexive.

\begin{tabular}{|c|c|c|c|c|}
\hline \multicolumn{5}{|l|}{ Tell } \\
\hline & Pronoun & Reflexive & Compound & Emphatic refl \\
\hline Syntax & Object & Subject & $? ?$ & Subject? \\
\hline Discourse & Object & Subject & $? ?$ & Subject? \\
\hline Interactive & Object & Subject & $? ?$ & Subject? \\
\hline \multicolumn{5}{|l|}{ Hear } \\
\hline & Pronoun & Reflexive & Compound & Emphatic refl \\
\hline Syntax & Object & Subject & $? ?$ & Subject? \\
\hline Discourse & Subject & Object & $? ?$ & Object? \\
\hline Interactive & $? ?$ & $? ?$ & $? ?$ & $? ?$ \\
\hline
\end{tabular}

Table 2. Predictions for Experiment 2.

Now, let us turn to the interactive/modulation view. According to this approach, both structural information and discourse/semantic information influence the choice of antecedent. Let us assume, as we did above, that both structural and discourse/semantic factors are weighted equally. As in the first experiment, we find that with tell, both syntactic and discourse factors are pushing in the same direction, but with hear, they are pitted against each other. As a result, we predict that if discourse/semantic factors are playing a role, we should

\footnotetext{
${ }^{3}$ Corpus example:

(a) ....sitä samaa inhoa, jota omaa moraalikäsitystään vastaan rikkonut ihminen tuntee katsoessaan peiliin ja nähdessään kuvan omasta itsestään... (www.virhe.org, posted 12/16/2002)

'...the same hatred that is felt by someone who has acted against his own sense of morality, as he looks into the mirror and sees a picture of himself...'
} 
see more non-BT compatible responses with hear than with tell for both reflexives (perhaps also emphatic reflexives) and pronouns, since in the hear condition the discourse/semantic factors are pulling the referential choices towards the non-BT compatible antecedents (objects in the case of reflexives; subjects in the case of pronouns). The predictions are less clear for the compound form, since its predicted behavior depends on whether it should be analyzed as a pronoun or a reflexive.

\subsection{Results and discussion}

As Figure 2 illustrates, a perceiver preference arises with pronouns. Participants chose subjects as antecedents (i.e., go against Binding Theory) significantly more often with hear than tell. However, the pattern of responses indicates that structural factors also play a role. With tell, we see a clear difference between the rate of object choices and the rate of 'both are possible' choices, but with hear, the numbers are very close. As Table 2 shows, this is a pattern we would expect if both structural and discourse/semantic factors are relevant. In other words, it seems that with hear, the discourse/semantic factors were able to push participants away the object, but did not obliterate the effects of structural factors.

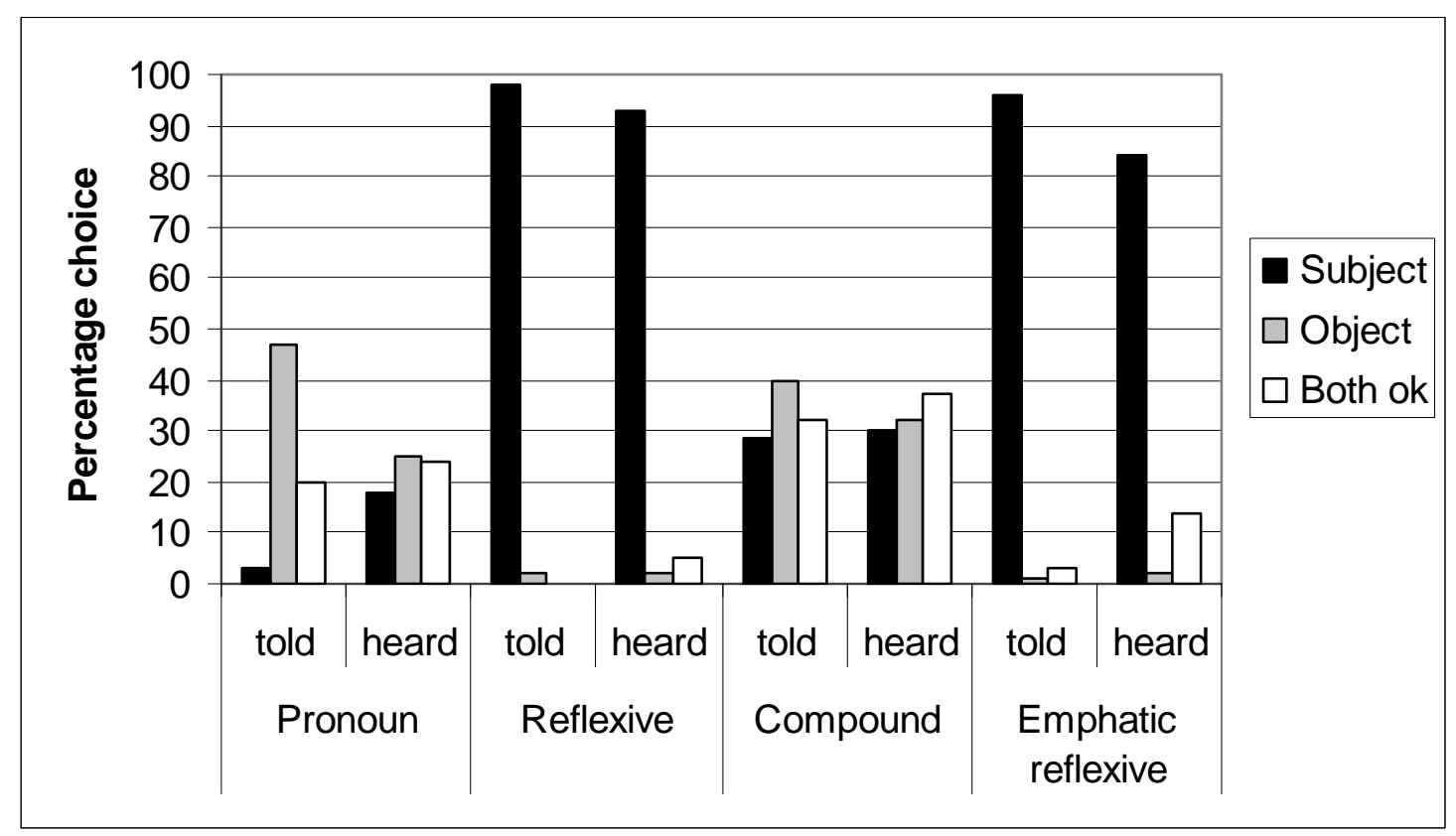

Figure 2. Percentage of antecedent choices for postnominal RNPs in Finnish

In contrast to pronouns, the reflexive and the compound pronoun+reflexive conditions show no clear verb effects. With reflexives, we see a very strong subject preference with both verbs (>90\%), and no effect of the source/perceiver manipulation. Thus, it appears that reflexives, even in postnominal RNPs in Finnish, are sensitive to structural factors only. The compound form, however, is split between subject and object choices with both verbs. This, unfortunately, does not shed as much light on the status of the compound form as one might have hoped. Its referential properties show that it does not pattern like regular reflexives since it does not exhibit an overwhelming subject preference, and thus one could argue that the compound form should not be regarded as fundamentally reflexive in nature. However, its referential properties do not closely match those of pronouns either, although numerically they are in the same direction (slightly more subject choices and 'both' choices with hear than with tell, slightly more object choices with tell than with hear). Thus, one could argue that the compound form appears to pattern somewhat more like a pronoun than a reflexive, but further research is clearly needed. 
Interestingly, the data show that the emphatic reflexive is sensitive to verb manipulation, as there are significantly more 'both' answers with hear than tell. In other words, participants are significantly more likely to consider both subject and object as possible antecedents with hear than with tell. That is, when the object is the source-of-information, it is more likely to be considered. However, given that the source preference shows up as an increase in the number of 'both' responses, rather than as an increase in the number of object responses, suggests that this effect is fairly weak. In contrast to the pronoun condition, where the number of subject choices increased significantly as a result of the verb manipulation, here it is the proportion of 'both' choices that increases. In other words, with the emphatic reflexive, participants are unwilling to abandon the BT-compatible subject choice, even though they are willing to consider an object choice as well if the object is the source.

The results indicate that the effect of the discourse/semantic factors is weaker with emphatic reflexives than with pronouns, which suggests that although the data support the modulation/interactive hypothesis, the structural and the discourse/semantic factors are not weighted equally for pronouns and emphatic reflexives. More specifically, it seems that discourse/semantic factors have a stronger effect on pronouns than on emphatic reflexives, even though structural factors are clearly also playing a role in both cases well. Thus, these data - like our findings for English - support Kaiser's (2003b) and Kaiser \& Trueswell's (in press) multiple-factor model which claims that different referential forms are sensitive to different kinds of information to different degrees.

\section{Conclusions}

In this paper we reported on two experiments that were designed to investigate what kinds of information contribute to the interpretation of pronouns and reflexives in Finnish RNPs. The results show that different syntactic configurations differ in their sensitivity to non-structural factors: Experiment 1, which investigated prenominal RNPs, showed no source/perceiver effects, but such effects arose in Experiment 2, which looked at postnominal RNPs. The findings of Experiment 2 indicate that the source preference for reflexives and the perceiver preference for pronouns (discussed by Kuno (1987) and Tenny (2003), and found experimentally by Kaiser et al. in press for English) also arise in a typologically different language, i.e. these effects do not appear to be a purely English-only phenomenon.

As the results of Experiment 2 show, morphological differences in Finnish reflexives seem to correlate with interpretational differences. The different reflexive forms differ in their sensitivity to the verb manipulation, which means that a fine-grained approach is necessary for capturing the referential properties of different anaphoric forms. Such a finding is fully compatible with the multiple-factor model, which assumes that multiple factors can play a role in reference resolution, and crucially also posits that the relative contributions of these factors can be different for different anaphoric forms (Kaiser 2003b, Kaiser \& Trueswell in press). This approach can also straightforwardly capture the finding that in Finnish, as in English, discourse/semantic factors contribute more to the interpretation of pronouns than to the interpretation of reflexive-type elements.

As a whole, our data from Finnish provide further support for a multiple-factor model of reference resolution. Hopefully future work can further investigate the validity of the multiple-factor model in other languages and other domains, and also shed light on whether representational NPs in languages other than Finnish and English show similar kinds of source/perceiver effects. 


\section{References}

Brown-Schmidt, S., Byron, D. \& Tanenhaus, M.K. (2005). Beyond salience: interpretation of personal and demonstrative pronouns. Journal of Memory and Language 53:292-313.

Cantrall, William R. (1974) Viewpoint, Reflexives, and the Nature of Noun Phrases. The Hague: Mouton.

Chomsky, N. (1981). Lectures on Government and Binding. Foris. Dordrecht.

Chomsky, N. (1986). Barriers. MIT Press. Cambridge, Mass.

Contreras, H. 1984. A Note on Parasitic Gaps. Linguistic Inquiry 15:698-701.

Featherston, S. 2002. Coreferential objects in German: Experimental evidence on reflexivity. Linguistische Berichte 192:457-484.

Hakulinen, A., Vilkuna, M., Korhonen, R., Koivisto, V., Heinonen T. R. \& Alho, I. 2004. Iso suomen kielioppi. SKS: Helsinki.

Kaiser, E. 2003a. Encoding (Non)Locality in anaphoric relations. In Nelson, D. \& Manninen, S. (eds.) Generative Approaches to Finnic and Saami Linguistics, 269-293. Stanford: CSLI Publications.

Kaiser, E. 2003b. The quest for a referent: A crosslinguistic look at referent resolution. Ph.D. dissertation, University of Pennsylvania.

Kaiser, E., Runner, J.T., Sussman, R.S. \& Tanenhaus, M.K. (in press). The Interpretation of Pronouns and Reflexives in Picture Noun Phrases: Effects of Non-structural Factors. To appear in A. Alcazar, R. Mayoral Hernandez \& M.T. Martinez (eds), Proceedings of the Western Conference on Linguistics 2004. Fresno: California State University at Fresno.

Kaiser, E., Runner, J.T., Sussman, R.S. \& Tanenhaus, M.K. 2005. Whose picture? Reference resolution in and out of picture NPs. Poster presented at the 18th Annual CUNY Conference on Human Sentence Processing. March 31-April 2, 2005. Tucson, AZ.

Kaiser, E. \& J.C. Trueswell (in press) Investigating the interpretation of pronouns and demonstratives in Finnish: Going beyond salience. To appear in E. Gibson \& N. Pearlmutter (eds), The processing and acquisition of reference. MIT Press.

Keller, F. \& Asudeh, A. 2001. Constraints on linguistic coreference: Structural vs. pragmatic factors. Proc 23rd Conf. of the Cog Sci Soc, 483-488.

Kuno, S. 1987. Functional Syntax: Anaphora, discourse \& empathy. Chicago: Chicago University Press.

Nelson, D. 1998. Grammatical Case Assignment in Finnish. New York: Garland

Nikanne, U. 1993. On assigning semantic cases in Finnish. In A. Holmberg \& U. Nikanne (eds.) Case and other functional categories in Finnish syntax, pp.75-88. Berlin/New York: Mouton de Gruyter.

Paunonen, H. 1995. Puhesuomen muuttuva omistusjärjestelmä. Virittäjä 99. 
Pollard, C. \& Sag, I. 1992. Anaphors in English and the scope of Binding Theory. Linguistic Inquiry 23:261-303.

Reinhart, T. \& Reuland, E. 1993. Reflexivity. Linguistic Inquiry 24:657-720.

Runner, J.T., Sussman, R.S. \& Tanenhaus, M.K. (to appear). The Influence of Binding Theory on the On-Line Reference Resolution of Pronouns, in Proceedings of North Eastern Linguistic Society 34.

Runner, J.T., Sussman, R. S. \& Tanenhaus, M.K. 2003. Assignment of reference to reflexives and pronouns in picture noun phrases: evidence from eye movements. Cognition 89(1):B1-B13.

Runner, J. T., Sussman, R. S. \& Tanenhaus, M. K. 2002. Logophors in Possessed Picture Noun Phrases. In L. Mikkelsen and C. Potts, eds., WCCFL 21 Proceedings, pp. 401414. Somerville, MA: Cascadilla Press.

Sells, P. 1987. Aspects of Logophoricity. Linguistic Inquiry 18 (3):445-479.

van Steenbergen, M. 1991. Long-distance binding in Finnish. Long-distance anaphora, ed. J. Koster and E. J. Reuland, 231-244. Cambridge: Cambridge University Press.

Tenny, C. 1996. Short distance pronouns and locational deixis. LinguistList on-line conference.

Tenny, C. 2003. Short distance pronouns, argument structure, and the grammar of sentience. Ms., 2003.

Tenny, C. 2004. Short Distance Pronouns in Representational NPs and a Grammar of Sentience. Ms.

Toivonen, I. 2000. The Morphosyntax of Finnish Possessives. Natural Language and Linguistic Theory 18(3):579-609.

Trosterud, T. 1993. Anaphors and Binding Domains in Finnish. In A. Holmberg \& U. Nikanne (eds), Case and Other Functional Categories in Finnish Syntax, pp.225-244. Berlin: Mouton de Gruyter.

Vainikka, A. 1989. Deriving Syntactic Representations in Finnish. Doctoral dissertation, University of Massachusetts.

Varteva, A. 1998. Pronominit hän ja tämä tekstissä. Virittäjä 2/1998, 202-223

Vilkuna, M. (1996). Suomen lauseopin perusteet. Helsinki: Edita

Zribi-Hertz, A. 1989. Anaphor Binding and Narrative Point of View English Reflexive Pronouns in Sentence and Discourse. Language 65(4): 695-727. 


\title{
A Unified Analysis of Passives and Anticausatives*
}

\author{
Dalina Kallulli \\ University of Vienna \\ dalina.kallulli@univie.ac.at
}

\begin{abstract}
Starting from the basic observation that, across languages, the anticausative variant of an alternating verb systematically involves morphological marking that is shared by passive verbs, the goal of this paper is to provide a uniform and formal account of these arguably two different construction types. The central claim that I put forward is that passives and anticausatives differ only with respect to the event-type features of the verb but both arise through the same operation, namely suppression by special morphology of a feature in $v$ that encodes the ontological event type of the verb. Crucially, I argue for two syntactic primitives, namely act and cause, whereto I trace the passive/anticausative distinction. Passive constructions across languages are made compatible by relegating the differences to simple combinatorial properties of verb and prepositional types and their interactions with other event functors, which are in turn encoded differently morphologically across languages. New arguments are brought forward for a causative analysis of anticausatives. Agentive adverbials are examined, and doubt is cast on the usefulness of by-phrases as a diagnostic for argumenthood.
\end{abstract}

\section{Introduction}

As is well-known, across languages, the anticausative alternant of an alternating pair systematically involves morphological marking that is shared by passive predicates. For instance, in Albanian, similar to Latin and Modern Greek (MG), both the sentence in (1a) containing an anticausative and the sentence in (1b) containing a passive are rendered homomorphously as in (2). ${ }^{1}$

a. The vase broke.

b. The vase was broken.

(2)
Vazoja
*(u) thye.
(Albanian)
vase $_{\mathrm{NOM}}$
NACT broke.AOR.3S
(i) 'The vase broke.'
(ii) 'The vase was broken.'

While both anticausatives and passives arguably lack an external argument (Marantz 1984), only the latter, but not the former, sanction by-phrases identifying the so-called logical subject, and can combine with purpose clauses and agent-oriented adverbs, as shown in (3) through (5).

\footnotetext{
* The research for this paper was funded by the Austrian Science Fund, grant T173-G03.

${ }^{1}$ The following abbreviations are used in the glosses in the examples: AOR (for aorist), CL (for clitic), DAT (for dative case), IMP (for imperfective), NACT (for non-active voice), NOM (for nominative case), s (for singular).
} 
(3) a. The window was broken by Pat / the earthquake.

b. *The window broke by Pat / the earthquake.

a. The boat was sunk to collect the insurance.

(Roeper 1987:268)

b. *The boat sank to collect the insurance.

a. The ship was sunk deliberately.

b. *The ship sank deliberately.

Depending on the theory, these facts have been taken to show that the external argument in the passive is still expressed in the syntax, albeit in an alternative manner (Baker, Johnson and Roberts 1989, Emonds 2000), or that the syntactically suppressed argument of a passive verb is present in argument structure (Roeper 1987, Grimshaw 1990), that is, that passives have an implicit argument. In contrast, the fact that anticausatives cannot combine with by-phrases, purpose clauses, or agent-oriented adverbs (Manzini 1983, Roeper 1987) is taken as evidence that the suppression of the external cause takes place in the mapping from the lexical semantic representation to argument structure (Levin and Rappaport Hovav 1995). In other words, in spite of differences of opinions concerning the proper treatment of passives, the consensual view has been that anticausatives are lexically reduced (see also Chierchia 1989, 2004 and Reinhart 1996).

In this paper, I examine certain properties of passives and anticausatives that to the best of my knowledge have hitherto not been systematically discussed in the literature, and the ensuing ramifications for a universal theory of these constructions. Specifically, I challenge the view that passives and anticausatives are formed in different modules of the grammar and offer a uniform analysis for both constructions. The paper is organized as follows. Section 2 investigates the distribution of by- and from-phrases across English, Albanian, Latin and MG and its significance for theories of passives and anticausatives. Based on a discussion of less well-known data, section 3 provides evidence for two primitives, namely act and cause, which I contend, underlie the passive/anticausative distinction. In section 4, I put forward a novel account for the distribution of purpose clauses and agent-oriented adverbs in passives.

\section{$2 B y$ - vs. from-phrases and the significance of the comparison}

\subsection{English}

While anticausatives in English do not sanction by-phrases, as Piñón (2001) notes, they can combine with from-phrases identifying the (external) cause of an event. This is shown in (6a) vs. (6b).

a. *The window cracked by the pressure.

b. The window cracked from the pressure.

However, though from-phrases identifying causes are generally fine with anticausatives, they are bad when the cause is not an event, as shown in (7). ${ }^{2}$

(7) *The window cracked from John / the book.

The contrast between (6b) and (7) is also replicated with non-alternating unaccusatives, as in (8a) vs. (8b), though there also are unaccusatives that do not combine with a from-phrase introducing a cause, as in (8c).

\footnotetext{
${ }^{2}$ It follows then that animate cause(r)s are exempted from anticausatives.
} 
(8) a. Eva died from cancer.

b. *Eva died from John / the book.

c. ${ }^{*}$ The refugees arrived from the invasion. ${ }^{3}$

Moreover, from-phrases are uniformly disallowed in passives, irrespectively of whether they introduce events, as in (9a), or non-eventive participants, as in (9b).
a. *Eva was killed from cancer.
b. *Eva was killed from John / the book.

To generalize over the data presented in this section, it seems that only what Levin and Rappaport Hovav (1995) refer to as external causation verbs can combine with a from-phrase identifying a cause.

\subsection{Albanian (and Latin and MG)}

Unlike in English, as we saw in (2), passives and anticausatives in Albanian, as in Latin and MG, can be formally indistinguishable. This is so for two reasons. First, these languages use two distinct conjugational paradigms, namely active versus non-active (Albanian and MG), or active versus passive (Latin), a distinction which often though not always corresponds to the transitive/unergative vs. unaccusative verb classes. ${ }^{4}$ Second, like Latin and MG, Albanian collapses (the distribution of) by-phrases and from-phrases. ${ }^{5}$ As this latter fact would lead us to expect, the santioning of by-phrases, which is taken to be one of the most salient properties of the passive in English and one that distinguishes passives from anticausatives, does not apply in Albanian (as in Latin and MG). To illustrate, the Albanian counterparts of the sentences in (6b) and (7) are given in (10a) and (10b), respectively. As expected then, the grammaticality contrast in the English examples in (6b) and (7) is not replicated in Albanian.
a.
Dritarja
u kris
nga
presioni.
window $_{\mathrm{NOM}}$
NACT crack.AOR.3s from/by
pressure
'The window cracked from the pressure.'

$\begin{array}{lllll}\text { b. Dritarja } & \text { u } & \text { kris } & \text { nga } & \text { Xhoni / libri. } \\ \text { window } & \text { NACT } & \text { crack.AOR.3S } & \text { from/by } & \text { John / book } \\ \text { 'The window was cracked by John / by the book.' } & \end{array}$

\footnotetext{
${ }^{3}$ The sentence in (8c) is of course fine if the prepositional phrase is interpreted as locative.

${ }^{4}$ The correspondence of the active vs. non-active distinction to the transitive/unergative vs. unaccusative verb classes is rough by virtue of the fact that while transitives/unergatives are always active morphologically, some unaccusative verbs appear in this voice (i.e., are morphologically unmarked) too. Crucially, however, in all three languages unergatives cannot be formally non-active/passive, just as passives and (lexical) reflexives cannot be formally active. For details, see Kallulli (1999a,b) on Albanian, Gianollo (2000, 2005) on Latin, and Alexiadou and Anagnostopoulou (2004) on Greek.
}

${ }^{5}$ Alternatively, the Albanian, Latin, MG counterparts of by-phrases are ambiguous between by- and fromphrases. While in Latin and MG the same word is used both for by and from in passives and anticausatives, Albanian has two distinct prepositions, namely $n g a$ and prej, each meaning both by- and from. (Due to space considerations, in this article I only use nga throughout.) Both $n g a$ and prej phrases are always interchangeable, or have identical distribution (i.e., they entail each other). Consequently, by- and from-phrases are indistinguishable in Albanian. 
Taken together, the arguments presented in this section, in particular the fact that the distribution of by- and from-phrases in English cannot be captured by appealing merely to the distinction between unaccusatives (whether anticausative or other) and passives, as well as the fact that there are languages that altogether collapse the distinction between by-and fromphrases, suggest that the significance granted to the fact that $b y$-phrases are sanctioned with passives but not with anticausatives is simply not justified. It is clear that once we draw into the picture languages that do not make the distinction between by-and from-phrases, the ability to license a by-phrase irrespective of the ability to license a from-phrase cannot be granted such a theoretical status as it has in studies that focus on the English verbal passive. In other words, if the ability of a passive verb to combine with a by-phrase is taken as evidence for the existence of the external argument in passives (irrespective of whether this argument is syntactically expressed or implicit, depending on the theory), so should the ability of an anticausative verb to combine with a from-phrase identifying the (external) cause of the event. Under this view, anticausatives cannot be lexically reduced, contrary to Chierchia (1989, 2004), Levin and Rappaport Hovav (1995) and Reinhart (1996). I suggest then that by-phrases and from-phrases are more closely related than has been assumed in discussions on the sanctioning of $b y$-phrases in passives in English.

Interestingly, as Clark and Carpenter (1989) note, children commonly use from-phrases instead of by-phrases in passives in English, too.

\section{Two primitives and one account of the distribution of by- and from-phrases}

The central claim of this paper is that the passive/anticausative distinction boils down to an event-based difference, namely the difference between an activity and a causative event, which I contend is syntactically relevant. In other words, while not attempting an exhaustive ontology of event types, I submit that act and cause are two syntactic primitives.

Let us first consider the evidence for the primitive status of act and cause.

Many languages share the construction in (11), in which a dative (or in some languages, a genitive) combines with a non-active (or reflexive) core yielding among other possible interpretations a reading that in previous work (Kallulli 2006) I have referred to as 'unintended causation'. 6

\begin{tabular}{|c|c|c|}
\hline Benit & $\mathrm{i}-\mathrm{u}$ & një vazo. \\
\hline Ben $_{\text {DAT }}$ & $\operatorname{him}_{\mathrm{CL}}-\mathrm{NACT}$ & break.AOR.3s a vase \\
\hline
\end{tabular}

On the other hand, many languages also share the construction in (12), where a dative combines with a non-active (or reflexive) core yielding among other interpretations what in previous work I have referred to as an involuntary state reading, rendered for lack of a better alternative through 'feel like' in the English translation. ${ }^{7}$

\footnotetext{
${ }^{6}$ The other possible readings are a possessor reading ('A vase of Ben's broke'), and an affected (in the sense: benefactive/malefactive) reading ('A vase broke on Ben'). I have shown in Kallulli (2006) that the unintended causation reading is not due to pragmatic factors but is really part of the semantics of the verb (root), that is, the sentences in (11) are not vague but truly ambiguous. Therefore I will not dwell on this issue here specifically, though one argument for this view is presented further down in this section.

${ }^{7}$ Indeed the construction has sometimes been referred to as the 'feel-like construction' (Dimitrova-Vulchanova 1999, Marušič and Žaucer 2004, to appear). Marušič and Žaucer (2004, to appear) also provide an extensive survey of previous analyses of this construction across several languages.
} 


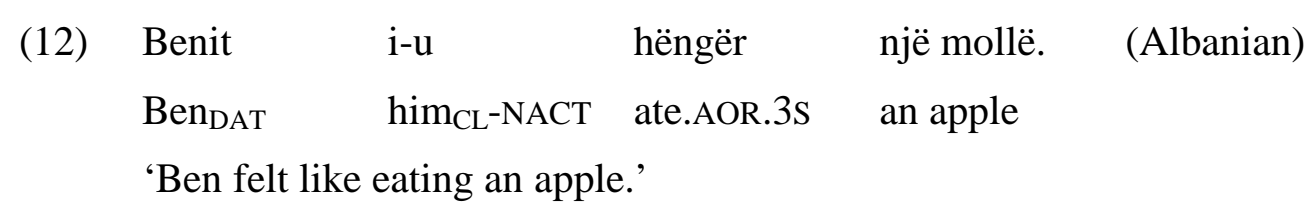

Formally, the sentences in (11) and (12) are identical. Yet, their interpretations vary greatly. Moreover, while the unintended causation reading is missing in (12), both the involuntary state reading and the unintended causation reading may obtain with one and the same verb, as illustrated through the Albanian examples in (13).
a. Benit
i-u
thye
një vazo.
Ben $_{\text {DAT }}$
$\operatorname{him}_{\mathrm{CL}}$-NACT break.AOR.3s a vase
(i) 'Ben unintentionally broke a vase'
(ii) *'Ben felt like breaking a vase'
b. Benit i thy-hej një vazo.
Ben $_{\text {DAT }} \quad \operatorname{him}_{\mathrm{CL}}$ break-NACT.P.IMP.3s a vase
(i) 'Ben felt like breaking a vase'
(ii) *'Ben unintentionally broke a vase'

Formally, the Albanian sentences in (13a) and (13b) constitute a minimal pair; they differ only with respect to their grammatical aspect. As is obvious from the glosses of these sentences, Albanian has two forms for the past tense, which differ in their aspectual value: Aorist, which is aspectually perfective, and Imperfective. ${ }^{8}$ Only the perfective sentence in (13a) but not the imperfective in (13b) can get an unintended causation reading. On the other hand, with imperfective aspect only the involuntary state reading but not the unintended causation reading obtains. That is, the semantic complementarity in (13a) vs. (13b) is effected solely by the choice of the aspectual morpheme. Note, however, that the verb in (13a) and (13b) is what Levin and Rappaport Hovav (1995) refer to as an external causation verb.

Consider now the Albanian examples in (14).
a. Benit
i-u
hëngër
një mollë.
Ben $_{\text {DAT }}$
$\operatorname{him}_{\mathrm{CL}}$-NACT ate.AOR.3S
an apple
(i) 'Ben felt like eating an apple'
(ii)*'Ben unintentionally ate an apple'

\footnotetext{
${ }^{8}$ In Albanian the non-active paradigm is built by employing three different linguistic means with a well-defined distribution. The definition of the distribution of non-active realization (adapted from Trommer 2005) is as in (i):

(i) If the clause contains perfective: express Non-active by choice of the auxiliary

Else: If the clause contains Tense (Present or Imperfect) but not Admirative: express Non-active by an inflectional affix

Else: express Non-active by a reflexive clitic
} 


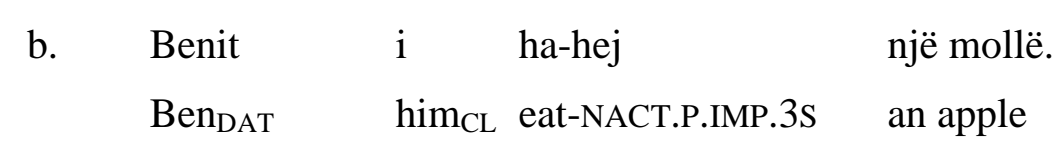

(i) 'Ben felt like eating an apple'

(ii)*'Ben unintentionally ate an apple'

Formally, (14a) and (14b) differ from each other in exactly the same way that (13a) and (13b) differ, that is, with respect to their grammatical aspect only: (14a), which is a repetition of (12), is aspectually perfective, whereas (14b), is aspectually imperfective. However, in spite of this difference, only the involuntary state reading but not the unintended causation reading obtains. That is, the semantic complementarity observed in (13a) vs. (13b) does not replicate in the examples in (14), despite the fact that morphologically (14a) is identical to (13a) and (14b) is identical to (13b). The question then arises as to why the semantic complementarity in (13a) vs. (13b) does not replicate in (14a) vs. (14b). The only possible explanation must be that non-active morphology interacts differently with different (feature) primitives. That is, the (lexical, and consequently, syntactic) feature composition make-up of eat must be different from that of break. In fact, one such difference is already argued for in Levin and Rappaport Hovav (1995), who distinguish between internal and external causation as a syntactically relevant meaning component. According to Levin and Rappaport Hovav (1995), break but not eat is an external causation verb. Capitalizing on this difference, I will assume that break-type verbs (or their roots) differ from eat-type verbs (or their roots) in that the former project a cause feature, whereas the latter an act feature in the syntax. In other words, the features [+cause] and [+act] represent two syntactic primitives that reflect an ontological event-type difference. ${ }^{9}$ Note, however, that though I assumed that the features [+cause] and [+act] in $v$ have the status of syntactic primitives, in principle, one could be derived from the other through morphological operations that take place before the projection of these features in the syntax. That is, under some version of the lexicalist hypothesis, one of these features could be the outcome of lexical (de)composition. A case in point here is that though the verb break is a cause verb and will ceteris paribus therefore project a [+cause] feature in $v$, due to a procedure such as event composition (Pustejovsky 1991) in the lexicon (i.e., prior to syntactic structure building), it could project a [+act] feature in the syntax instead. Specifically, if imperfective morphology is an event functor that invariably shifts the event type of a lexical item into an activity as I have argued in Kallulli (2006), then we could explain how break projects a [+act] and not [+cause] feature in syntax. So the idea is that reiteration of a causative event (e.g. breaking events) will yield an (e.g. breaking) activity. ${ }^{10}$ This point is crucial for the derivation of the involuntary state reading of (13b), which I will however not dwell into here. (The interested reader is referred to Kallulli (2006), where I have detailed the derivation of dyadic unaccusative constructions such as those in (13) and (14).)

Adopting the basic structure in Chomsky's (1995) shell theory, where the "internal" arguments of a verb occupy the positions of specifier and complement of $\mathrm{V}$, with the external argument occupying Spec of $v \mathrm{P}$, the difference between a causative predicate and an activity predicate can be depicted structurally as in (15) vs. (16). That is, unless event composition has applied previous to syntactic composition, break-type verbs project a [+cause] feature in $v$, as in (15), whereas eat-type verbs project a [+act] feature in $v$, as in (16). In other words, I contend that $v$ contains at least one (lexical-semantic) feature encoding the ontological event type of the verb, and further, that it is precisely the need of this feature to be saturated, or

\footnotetext{
${ }^{9}$ See also Wunderlich (1997:56) and Doron (2003).

${ }^{10}$ Interestingly, Davis (1997) and Demirdache (2005) argue that in St'át'imcets all activity predicates are morphologically derived from causative predicates.
} 
checked off, that makes Spec of $v \mathrm{P}$ an argumental position. Therefore, (non-oblique) argument realization proceeds because of the need to check off lexical-semantic features in a predicate structure (here: $v$ and/or other heads involved in predication). Consequently, when $v$ contains a [+cause] feature, the argument in Spec of $v \mathrm{P}$ will be interpreted as Cause(r), whereas when $v$ contains a [+act] feature in $v$, the argument in Spec of $v \mathrm{P}$ will be interpreted as an Actor.

(15) The basic structure of a causative verb

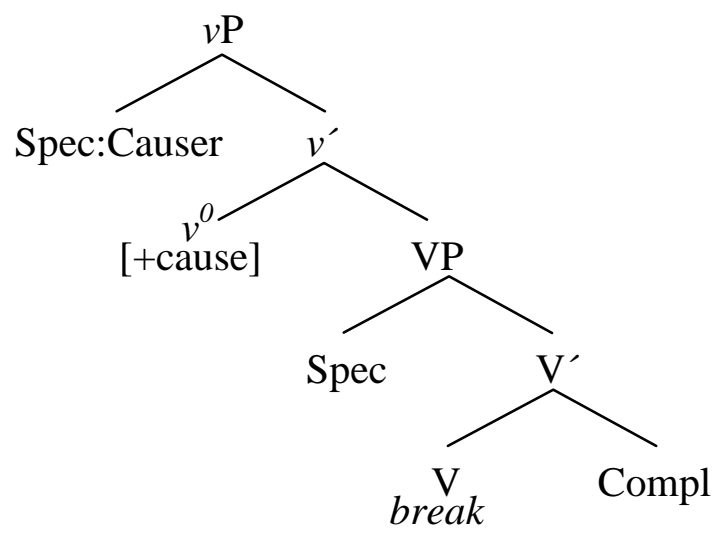

(16) The basic structure of an activity verb

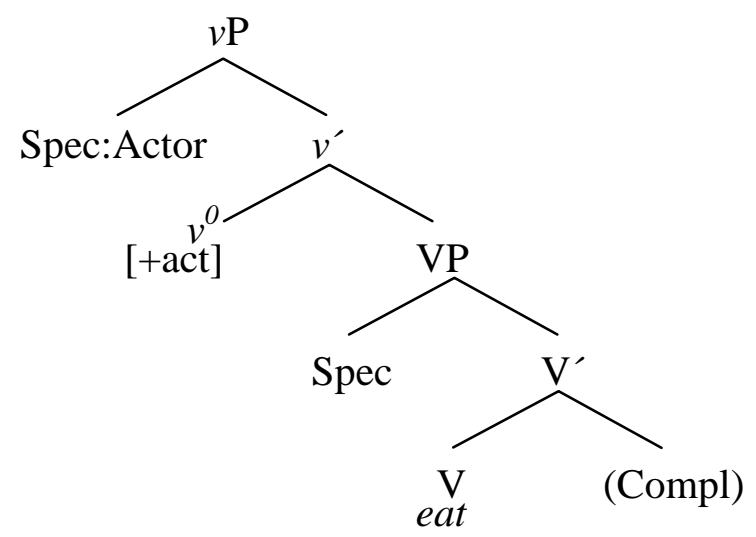

Abstracting away from further details, in Kallulli (2006), I define non-active (and/or reflexive) morphology as an operation that suppresses a feature in the syntactic structure of a predicate. Building on this proposal, I claim that while the passive is derived from an activity predicate through suppression by special (e.g., non-active or reflexive) morphology of a [+act] feature in $v$, the anticausative is derived from a causative predicate through suppression of a [+cause] feature in $v$. If non-active morphology suppresses the feature in $v$ that encodes the ontological event type of the verb, as I claim, when operating on the structures in (15) and (16), it will suppress the [+cause] or the [+act] feature, respectively. If, as I suggest, (nonoblique) arguments are realized in the specifier positions of verbal projections whose heads have at least one (lexical-semantic) feature that encodes the ontological event type of the verb, it follows that no arguments can be realized in Spec of $v \mathrm{P}$ once the feature [+cause] or [+act] in it is stricken out by non-active morphology. That is, the resulting structures will be strictly monadic (that is, containing only one internal argument), as in (17). 
(17)

a. Deriving the anticausative



b. Deriving the passive


eat

However, in spite of the effect of non-active morphology, namely the suppression of the feature [+cause] or [+act] in $v$ and the consequence that Spec of $v \mathrm{P}$ is in this way rendered inert, both the cause in anticausatives and the actor in passives can be realized obliquely, namely in a from-phrase and a by-phrase, respectively.

Assuming that accusative case is assigned in $v$ (that is, that accusative case is checked in Spec of $v \mathrm{P}$ only) and, that the complementarity of theta-checking (here: theta-feature-checking) and case-checking is a general property of the theory (Bennis 2004), then Burzio's Generalization follows trivially: the internal argument will need to have its case features checked by a higher head, namely $\mathrm{T}$, which assigns nominative.

The question however arises why languages vary with respect to whether they obfuscate the distinction between oblique actors and oblique causes, as is the case in Albanian, Latin, MG, English child language (Clark and Carpenter 1989) and Old English, or articulate this difference, as is the case in adult present-day English. One obvious difference between Albanian, Latin, MG on the one hand and adult present-day English on the other is precisely the fact that in English anticausatives and passives are always morphologically distinct, whereas, as already pointed out, in Albanian, Latin and MG passives and anticausatives are often identical morphologically. That is, there might exist some implicational relation between verbal morphology and the ability to distinguish between by-and from-phrases (i.e., oblique actors and oblique causes). Specifically, the generalization seems to be that languages that collapse the morphological distinction between passives and anticausatives also fail to differentiate between by- and from-phrases.

Consider now how the claim that the distinction passive vs. anticausative boils down to an event-based difference can accomodate the fact that break-type (i.e., causative) verbs can passivize, as in (18).

(18) The window was broken by Pat.

Emonds (2000) suggests that due to the fact that English lacks a verbally finite synthetic passive, both verbal and adjectival passives are in a sense "more adjectival" than in languages like Albanian, Latin and MG, which have a (partially) verbal finite synthetic passive. Indeed anticausatives are more eventive than passives in English, a point that cannot be made for Albanian, which as discussed above collapses the morphological distinction between passives and anticausatives. The idea then is that the passive in English in a sentence like (18) implies that the breaking event was more sustained, or involved an activity on Pat's part, as compared to the breaking event in an anticausative, which happens spontaneously, or all-at-once. That is, the English passive, whether or not due to its special (adjectival) morphology, induces an implicature of activity, or open-endedness, even for external causation verbs, which is obvious when comparing it to an anticausative like the one in (19). 
(19) The window broke.

Note that the feature [+act] entails an actor, that is, animacy. The question then arises how to account for sentences such as (20) where a natural force, namely the earthquake combines with the preposition by.

(20) The window was broken by the earthquake.

I suggest that these forces are conceptualized as animate, as opposed to inanimate forces that can cause breakage such as a construction fault, which is indeed ungrammatical in a byphrase. Interestingly, judgments on a sentence like (21) with a cause like pressure rising in a by-phrase seem to vary.

(21) (?)The window was broken by the pressure rising.

My interpretation of this fact is that a cause like the one in (21) could be seen as a very slow but nevertheless animate force, or else as a more stationary force. In the former case it would be acceptable in a by-phrase; in the latter it would not.

Turning to the distinction between passives/anticausatives on the one hand and middles on the other, I believe this is due to the presence of a dispositional aspectual operator in the latter. That is, the middle construction is derived when the verb in the structures in (17) is under the scope of a dispositional operator (Lekakou 2005), such as the imperfective.

\section{The distribution of purpose clauses and agent-oriented adverbs revisited}

Let us now turn to the facts illustrated in (4) and (5), repeated again here for ease of reference, namely that passives but not anticausatives can combine with purpose clauses and agentoriented adverbs.
a. The boat was sunk to collect the insurance.
(Roeper 1987:268, (3b))
b. *The boat sank to collect the insurance.
(Roeper 1987:268, (3a))
a. The ship was sunk deliberately.
b. *The ship sank deliberately.

Virtually all existing work on this distinction takes these facts to indicate: (i) the presence of an argument in the passive, which depending on the theory, is either syntactically expressed (Baker, Johnson and Roberts 1989, Emonds 2000) or implicit (Roeper 1987, Grimshaw 1990); and (ii) the lack of such an argument in unaccusatives (Levin and Rappaport Hovav 1995 and references therein).

However, all that purpose clauses and so-called agent-oriented adverbs do is identify an intention-bearing (i.e., animate) event participant as the source or initiation of the event named by the verb. Passives, but not anticausatives, control into purpose clauses and combine with agent-oriented adverbs because purpose clauses and agent-oriented adverbs simply make reference to participants capable of intentionality (i.e., actors). And as was stated earlier, unlike [+cause], the feature [+act] implies an actor, that is, a participant capable of wilful agency. However, this does not entail that the animate participant in passives is a non-oblique argument. One obvious alternative is that the animate participant here is not introduced by a non-oblique argument, but by a by-phrase, and this may in turn be either overt or implicit. If, as established in section 3.1, animate causers are disallowed with from-phrases in English and, anticausatives only license from-phrases but not by-phrases, then the inability of anticausatives to combine with purpose clauses and agent oriented adverbs follows straightforwardly without further stipulations. Further evidence for the view that it is the animate participant in an overt or implicit by-phrase that controls into the purpose clause involves the fact that whenever a purpose clause is licit, a by-phrase can be inserted overtly. 
Note in this context that agent-oriented adverbs are not incompatible with unaccusative syntax. The Italian examples in (22) show that the unaccusative verbs cadere 'fall' and rotolare 'roll' continue to exhibit the characteristic essere 'be' (vs. avere 'have') selection, even in the presence of an adverb like "on purpose".

(22) a. Gianni é caduto /*ha caduto apposta.

(Folli and Harley 2004: 47)

John is fallen / has fallen on purpose.

b. Gianni é rotolato / *ha rotolato giu apposta.

John is rolled / has rolled down on purpose.

The example in (23) shows that the same fact holds in German, as witnessed by the fact that the auxiliary sein 'be' and not haben 'have' is selected.

Peter ist / *hat absichtlich eingeschlafen.
Peter is / has deliberately fallen asleep
'Peter fell asleep on purpose'

To account for the facts in (22) and (23), I suggest that the so-called agent-oriented adverbs here do not necessarily tell anything about whether the event participants that they modify really act agentively (i.e., intentionally). These adverbs are rather interpreted at the pragmatic interface, that is, they merely provide information on the beliefs of the utterer of the sentences in which they occur.

\section{Conclusion}

In this article I have discussed a variety of - to my knowledge - new empirical arguments, which show that the picture depicted for the passive in English is quite idiosyncratic, and that the properties that have attained the status of identificational criteria of the passive are simply not revealing or even maintainable when looking at other languages. In particular, unlike generally assumed, neither by-phrases nor purpose clauses or agent-oriented adverbs witness the presence of a non-oblique argument (either implicit or syntactically encoded, depending on the theory). In contrast, the analysis that I have laid out here derives the properties of the passive and anticausative both in Albanian and English uniformly. The main conclusion here is that universally anticausatives and passives differ only with respect to the ontological event type feature in $v$ which can be affected by morphological operations in the syntax. The distinction between by- and from-phrases in English is a simple reflection of this feature: a byphrase introduces an oblique actor upon suppression of the act feature in $v$, whereas a fromphrase introduces an oblique causer upon suppression of the cause feature in $v$. I have shown that the English verbal passive can be made more compatible with its Albanian (or Latin and MG) cousin by relegating the differences to simple combinatorial properties of verbs and prepositional types and their interactions with other event functors, which are in turn encoded differently morphologically across these languages.

\section{References}

Alexiadou, A., Anagnostopoulou, E. and Everaert, M.: 2004, The Unaccusativity Puzzle. Oxford: Oxford University Press.

Alexiadou, A. and Anagnostopoulou, E.: 2004, Voice morphology in the causative-inchoative alternation: evidence for a non-unified structural analysis of unaccusatives, in A. Alexiadou et al. (eds.), 114-136. 
Baker, M., Johnson, K., and Roberts, I.: 1989, Passive arguments raised. Linguistic Inquiry 20: 219-252.

Bennis, H.: 2004, Unergative adjectives and psych verbs, in A. Alexiadou et al. (eds) 84-113.

Chierchia, G.: 1989. A semantics for unaccusatives and its syntactic consequences. Ms., Cornell University, Ithaca, N.Y.

Chierchia, G.: 2004, A semantics for unaccusatives and its syntactic consequences, in A. Alexiadou, E. Anagnostopoulou and M. Everaert (eds.) The Unaccusativity Puzzle 22-59. Oxford: Oxford University Press.

Chomsky, N.: 1995, The Minimalist Program. Cambridge, MA: MIT Press.

Clark, E.V. and Carpenter, K.L.: 1989, On children's uses of from, by, and with in oblique noun phrases. Journal of Child Language 16, 349-364.

Davis, H.: 1997, Deep unaccusativity and zero syntax in St'at'imcets, in A. Mendikoetxea and M. Uribe-Extebarria (eds.) Theoretical Issues on the Morphology Syntax Interface: Supplements of the International Journal of Basque Linguistics and Philology (ASJU) Vol XXVIII. Donostia, Spain.

Demirdache, H.: 2005, What do pieces of words "name"? Talk given at the workshop The Role of Morphology in Argument Expression and Interpretation, Vienna, 11-12 June.

Dimitrova-Vulchanova, M.: 1999, Semantics, Diathesis and Aspect. München/Newcastle: Lincom Europa.

Doron, E.: 2003, Agency and voice: the semantics of the semitic templates. Natural Language Semantics 11, 1: 1-67.

Emonds, J.: 2000, Lexicon and Grammar: The English Syntacticon. Berlin: Mouton de Gruyter.

Folli, R. and Harley, H.: 2004, Waltzing Matilda around and around: On the licensing of directed-motion resultatives. Manuscript, University of Cambridge and University of Arizona.

Gianollo, C.: 2005, Middle voice in Latin and the phenomenon of split intransitivity, in G. Calboli et al. (eds.) Proceedings of the XII Colloquium on Latin Linguistics 97-109. Roma: Herder.

Gianollo, C. 2000. Il medio in latino e il fenomeno dell'intransitività scissa. Master Thesis. University of Pisa.

Grimshaw, J.: 1990, Argument Structure. Cambridge, MA: MIT Press.

Kallulli, D.: 2006, Unaccusatives with dative causers and experincers: a unified account, in D. Hole, A. Meinunger and W. Abraham (eds.) Datives and Other Cases: Between argument structure and event structure 271-301. Amsterdam: John Benjamins

Lekakou, M.: 2005, In the Middle, Somewhat Elevated: The semantics of middles and ist crossliguistic realization. Doctoral dissertation. University College London. 
Levin, B. and Rappaport Hovav, M.: 1995, Unaccusativity. Cambridge, MA: MIT Press.

Marantz, A.: 1984, On the Nature of Grammatical Relations. Cambrigde, MA: MIT Press.

Marušič, F. and Žaucer, R.: 2004, A reanalysis of the FEEL-LIKE dative-reflexive construction in Slovenian, in O. Arnaudova, W. Browne, M.-L. Rivero, and D. Stojanović (eds.) Formal Approaches to Slavic Linguistics 12. The Ottawa Meeting 2003, 293-311. Ann Arbor: Michigan Slavic Publications.

Marušič, F. and Žaucer, R.: To appear, On the Intensional FEEL-LIKE Construction in Slovenian: A Case of a Phonologically Null Verb. Natural Language and Linguistic Theory.

Piñón, C.: 2001, A finer look at the causative-inchoative alternation. SALT Proceedings.

Pustejovsky, J.: 1991, The syntax of event structure. Cognition 41: 47-81.

Reinhart, T.: 1996, Syntactic effects of lexical operations: Reflexives and unaccusatives. OTS Working Papers in Linguistics.

Roeper, T.: 1987, Implicit arguments and the head-complement relation. Linguistic Inquiry $18: 267-310$.

Trommer, J.: 2005, Closest c-command in Albanian Non-active Constructions. Presentation at the workshop The Role of Morphology in Argument Expression and Interpretation. University of Vienna, 11-12 June.

Wunderlich, D.: 1997, Cause and the Structure of Verbs. Linguistic Inquiry 28, 1: 27-68. 


\title{
A UNified Semantic ANALYSIS OF FlOATED AND BinOMinal EACH
}

\author{
Mana Kobuchi-Philip \\ UiL-OTS, Utrecht University \\ mana.kobuchi@let.uu.nl
}

\begin{abstract}
This paper discusses a semantic analysis of three syntactic types of English each, namely, floated each, binominal each, and prenominal each. It is argued that floated each consists of two parts, a quantifier and an inaudible element which functions as its restrictor, which together form a tripartite quantificational structure when they compose with the predicate. Binominal each and an associated NP such as two topics (which is generally called the 'distributive share') are syntactically analyzed as forming a subject-predicate relation within a DP in which the NP undergoes so-called 'predicate inversion'. Semantically, binominal each is analyzed as having the same semantic value as floated each, while prenominal each is shown to have a different logical type from floated and binominal each. As can be seen from analogous constructions in some Romance languages, it does not lexically contain its restrictor.
\end{abstract}

\section{Three types of each}

English each can occur in several distinct syntactic contexts, three of which are exemplified in $(1):^{1}$
(1) a. Prenominal each
[Each student] picked two topics.
b. Floated each
The students have [each picked two topics].
c. Binominal each
The students picked [two topics each].

Each exemplified in (1a) occurs in a prenominal position and forms a syntactic constituent with the following NP, whose head noun must be singular. Each exemplified in (1b) occurs in a preverbal position on the surface. This is a so-called floated quantifier (FQ), like floated all and floated both. In the syntax literature (e.g. Sportiche 1988), an FQ construction such as (1b) has generally been taken to be related to the prenominal quantifier construction in (1a) via a transformation. Under such a hypothesis, the FQ is underlyingly a determiner, only it is dislocated in the surface form. ${ }^{2}$ On the other hand, in the semantics literature FQs have generally been analyzed as adverbial elements (e.g. Link 1983, Dowty and Brodie 1984, Roberts 1986, Junker 1990). Each exemplified in (1c) always occurs right-adjacent to an NP, which almost always contains a numeral. This each is generally referred to as binominal each (sometimes also as shifted each) (e.g. Safir and Stowell 1987, Choe 1987, Moltmann 1991, Zimmermann 2002a,b). In the syntax literature it has been shown that binominal each forms a syntactic constituent with the NP left adjacent to it.

\footnotetext{
1 In this paper we do not discuss other types of each such as that in reciprocal each other.

2 Under Sportiche's (1988) stranding account, the quantifier and its associating NP are generated as a DP in the VP-internal subject position (Spec VP), and in an FQ sentence the quantifier remains in this position when the NP moves to spec IP position so that EPP feature may be checked.
} 
On the surface, then, prenominal each looks like a determiner, floated each looks like an adverb, and binominal each looks something that is neither a determiner nor an adverb. Nonetheless, it is not the case that each may occur just anywhere. Rather, the positions in which each appears are quite limited. The simplest hypothesis is that each has a single semantic value and logical type. Thus, the goal of all analyses of each is to show how its distribution can be captured while maintaining this basic assumption. This is the objective of this paper as well, though we will not quite reach it.

In attempting to formulate a unified analysis of each, it can be useful to start with the native speaker intuitions of a linguist. Consider the following observation of Vendler (1966):

(2) "....the phrase each one of them is somewhat redundant. It looks as if each here already implies one and draws our attention to individual elements...." (p. 76)

Vendler's observation suggests that something similar to the meaning of one may lie hidden in the lexical content of each. That is, each might actually mean something like 'each one'. Such a hypothesis becomes quite plausible when we consider the semantics of the floated numeral quantification in a language that has such FQ, namely Japanese. A Japanese numeral e.g. san 'three' systematically co-occurs with a classifier e.g. nin 'CL' (unit for counting human individuals). According to Kobuchi-Philip (2003), the classifier functions as the restrictor for the numeral, denoting a set of just atoms. Thus, numeral quantifier san-nin '3CL' refers to 'three individuals (persons)'. This hypothesis can be extended to FQ each by analyzing it as consisting in the quantifier each plus a phonetically null, atom-denoting, restrictor. This is the hypothesis we will develop in this paper. Let us start by reviewing the background assumption of the hypothesis, that is, the analysis of Japanese numeral quantification proposed in Kobuchi-Philip (2003).

\section{Japanese floated numeral quantifiers}

As mentioned earlier, in the syntax literature it has frequently been suggested that the FQ is transformationally derived from a prenominal quantifier, i.e. that it is a dislocated determiner (e.g. Sportiche 1988, Kitahara 1992). However, in the case of the Japanese floated numeral quantifier (FNQ), there is strong evidence that, syntactically, the FQ must be an adverb. The reader is referred to Kobuchi-Philip (2003) for a review of the syntactic evidence supporting this claim. Here we give just one piece of particularly striking evidence, originally noted by Fukushima (1991). As shown in (3), the Japanese FNQ can be coordinated with an ordinary adverb:

(3) a. shoonin-ga

[[san-nin] katsu [tashikani]]

witness-NOM

$$
\text { 3-CL and certainly }
$$

sono jiko-o mokugekishita

the accident-ACC witnessed

(lit.) 'Witnesses [three and certainly] witnessed the accident.'

'Three witnesses certainly witnessed the accident.'

b. Mary-ga raamen-o

M-NOM soup noodle-ACC

[[san-bai] katsu [kireini]] tairageta

3-CL and completely ate up

(lit.) 'Mary ate up soup noodles [three and completely].'

'Mary ate up three bowls of soup noodles completely' 
In (3a), the FNQ san-nin 'three persons' is construed with the subject 'witness', but it is coordinated with the adverb tashikani 'certainly'. We might literally translate (3a) as "Witnesses three and certainly witnessed the accident." To capture its meaning with a grammatical English sentence, however, we must say something like "three witnesses certainly witnessed the accident." In (3b), the FNQ san-bai 'three bowls' is construed with the direct object 'soup noodles' and this FNQ is coordinated with an adverb kireini 'completely'. Again, literally, this sentence means "Mary ate up soup noodles three and completely." In sum, the fact that an FNQ can be coordinated with an adverb strongly suggests that the FNQ is itself an adverb.

Next, observe that the classifier in the Japanese FNQ is semantically significant in that it functions as the restrictor for the preceding numeral. Consider (4):
a. gakusei-ga,
go-nin kita.
$\rightarrow$ 5: the number of persons
student-NOM 5-CL came
'Five individual students came.'
b. gakusei-ga, go-kumi kita. student-NOM 5-CL came
'Five groups of students came.'
$\rightarrow \quad 5:$ the number of groups

The sentences in (4a) and (4b) form a minimal pair in which the only difference is the classifier. In (4a), the classifier is nin, a unit for counting people, and the sentence means that five individual students came. In contrast, in (4b), the classifier is kumi, a unit for counting groups, and the sentence means that five groups of students came. The NQ go-nin refers to five persons, and the NQ go-kumi refers to five groups. This shows that what the numeral counts is precisely what the classifier refers to. Our claim, then, is that the classifier actually denotes a set of objects, just like an ordinary noun, and functions as the restrictor for the numeral.

Next, we will show that the nuclear scope for the numeral in Japanese FNQ quantification is the predicate denotation. Consider the sentence in $(5 \mathrm{a})$ :

$$
\begin{aligned}
& \text { a. [narande hashitteita suu-dai-no torakku }]_{\mathrm{DP}} \text {-ga } \\
& \text { in a row running several-CL-NO truck-NOM } \\
& \text { (prenominal NQ) } \\
& \text { [san-dai gaadoreeru-ni butsukatta }]_{\mathrm{VP}} \text {. } \\
& \text { 3-CL guardrail-to hit } \\
& \text { (FNQ) }
\end{aligned}
$$

(Inoue, 1978)

'Three of the several trucks that were driving in tandem hit the guardrail.'

\section{b. Conservativity test}

Three dai-objects (i.e. machines) are dai-objects that hit the guardrail.

(5a) is an example of a special construction in which a prenominal NQ and an FNQ appear in the same clause. ${ }^{3}$ The classifier in both NQs is dai which is a unit for counting machines. San-dai 'three dai', refers to three machines. Now, consider what the numeral 3 of the FNQ is counting. This sentence can be translated into English as "three of the several trucks that were driving in tandem hit the guardrail." Thus, 'three' counts the number of machines that hit the

\footnotetext{
${ }^{3}$ Note that the co-occurrence of a prenominal NQ and an FNQ in a single clause cannot be accounted for under the stranding account of the FQ, since under this account the quantifier appears either in the stranded position or the prenominal position (in case it moves along with the associating NP), but never both at the same time.
} 
guardrail. That is, 'three' is the number of things that have the properties of being a machine and being a guardrail hitter. The classifier denotation and the predicate denotation intersect with each other, and the numeral of the FNQ indicates the number of elements in this intersection. Thus, the predicate denotation is the nuclear scope for FNQ quantification. This analysis is supported by the conservativity test in (5b). Note that the subject, 'several trucks that were driving in tandem', is not part of the meaning of 'three' at all. FNQ quantification has nothing to do with the material outside the verbal domain. To summarize, the Japanese FNQ is an adverb, and the three components of FNQ quantification are as shown in (6):

(6) Quantificational Analysis (Q=Quantifier, R=Restrictor, NS=Nuclear Scope)



The numeral, the classifier, and the predicate, function as the quantifier, the restrictor and the nuclear scope, respectively. Note that under this analysis the quantificational structure is directly mapped from the surface syntactic structure, strictly adhering to the principle of compositionality.

One point that calls for some elaboration is the observation that the classifier must denote a set of atoms. In other words, it must be a singular term. That the denotation of the restrictor is a set of atoms is a basic logical requirement for counting or enumeration in general (e.g. Kratzer 1989, Chierchia 1998, Landman 2000). Consider the verification of an English sentence such as (7a) with respect to a context containing boys a, b, c and d. ${ }^{4}$ Under the traditional analysis of numeral quantification, for (7a) to be true there must be (at least) three elements in the set of boys which are also elements in the set of individuals who jumped. Now, assuming that the denotation of boys is as shown in (7b), which includes atoms and sums, consider two hypothetical verifications of (7a), namely (7c) or (7d):

(7) a. Three boys jumped.

b. $\quad[[b o y s]]=\{a+b+c+d, a+b+c, a+b+d, a+c+d, b+c+d$, $a+b, a+c, a+d, b+c, b+d, c+d, a, b, c, d\}$

c. $\quad[[$ boys $]] \cap[[j u m p e d]]=\{a+b+c+d, c+d, d\}$

d. $\quad[[$ boys $]] \cap[[j u m p e d]]=\{\mathrm{c}+\mathrm{d}, \mathrm{c}, \mathrm{d}\}$

In both (7c) and (7d), there are three elements, thus numeral quantification yields truth. However, if we count the number of boys in these three elements, we find that in (7c) there actually are four of them, and in (7d) there are only two, rather than three. The discrepancy between the number of elements and the number of individuals are summarized in (8):

(8) $7 \mathrm{c} \rightarrow$ number of quantified elements number of boys

$$
\begin{aligned}
& =3 \quad \text { (namely a }+b+c+d, c+d \text { and } d) \\
& =4 \quad \text { (namely } \mathrm{a}, \mathrm{b}, \mathrm{c} \text { and } \mathrm{d})
\end{aligned}
$$

\footnotetext{
${ }^{4}$ Here we use a plus sign to represent the sum symbol. This corresponds to the plus sign within a circle in Link (1983), and the square union sign in Landman (2000).
} 


$$
\begin{aligned}
& 7 \mathrm{~d} \rightarrow \text { number of quantified elements } \quad=3 \quad \text { (namely } \mathrm{c}+\mathrm{d}, \mathrm{c} \text { and } \mathrm{d} \text { ) } \\
& \text { number of boys } \quad=2 \text { (namely } \mathrm{c} \text { and } \mathrm{d} \text { ) }
\end{aligned}
$$

The problem is that all sentences of the form [three boys $\mathrm{X}$-ed], where $\mathrm{X}$ is any predicate, are wrongly predicted to be true of any situation as long as the number of the elements is three, regardeless of the number of boys involved. In order for the noun phrase three boys to have its true meaning, the numeral three must count only individual boys, not any collection of boys. For this to happen, we must have a model in which $\mathrm{x}$-many elements entail $\mathrm{x}$-many individuals in them. In short, what is required is to exclude sums from the restrictor. Let us call this the 'atomicity condition' (on the restrictor of the numeral quantifier). In order to satisfy the atomicity condition, we must have an analysis of numeral quantification in which the restrictor includes only atoms, i.e. a denotation such as (9):

$$
\{\mathrm{a}, \mathrm{b}, \mathrm{c}, \mathrm{d}\}
$$

In conclusion, the Japanese FNQ quantification has the following semantic properties:

(10) The semantic properties of Japanee FNQ quantification

a. Japanese FNQs are adverbs of type $\langle\langle\mathrm{e}, \mathrm{t}\rangle,\langle\mathrm{e}, \mathrm{t}\rangle\rangle$.

b. FNQs contain a classifier, which functions as the restrictor, ans form a tripartite quantificational structure with the predicate.

c. The restrictor denotes a set of atoms.

d. FNQ quantification is computed within the verbal domain.

\section{Floated each}

Adopting the above account of Japanese numeral quantification, let us now consider English each. If we assume that the Japanese FNQ has the properties that it has because it is an ordinary sub case of FQs in general, as assumed in the literature, then we might expect the basic semantic properties of the Japanese FNQ to be found in all FQs. In other words, rather than treating the Japanese FNQ as an exception, let us consider the possibility that it is the norm. As with any norm, we expect to find marked exceptions in one language or another, but, generalizing from (10) above, we obtain the following hypotheses as to the general semantic properties of the FQ: ${ }^{5}$

(11) The hypothetical general semantic properties of FQ quantification
a. FQs are adverbs of type $\langle\langle e, t\rangle,\langle e, t\rangle>$.
b. FQs contain a nominal element that functions as the restrictor and forms a tripartite quantificational structure with the predicate.
c. The restrictor denotes a set of atoms.
d. FQ quantification is computed within the verbal domain.

The first claim of the hypotheses in (11a), which is taken for granted in much of the semantics literature, has abundant empirical motivation not only from Japanese but also from English and other Indo-European languages (e.g. Doetjes 1997). The second claim in (11b) calls for

\footnotetext{
5 For example, in a language such as Straits Salish an adverbial quantifier occurs as a morpheme attached to a verb (Jelinek 1995). The precise quantificational mechanism of such a language must be examined and considered in comparison to other languages. Here, however, we limit the scope of our examination to English floated each.
} 
some independent motivation, a matter we will address shortly. The third claim in (11c) is simply the atomicity condition discussed above. Finally, (11d) is a corollary of (11a-c). ${ }^{6}$

Let us now consider how English FQ each can be analyzed in accordance with (11b). Since there is no overt classifier adjacent to each in (12a) below, we must assume that element denoting the restrictor is phonetically null. Given this auxiliary assumption, (12a) is analyzed as (12c), on a par with the analysis of a Japanese FNQ, as schematically represented in (12b).

(12) a. The students each picked two topics.

b. Host NP [ Floated NQ Predicate ]

(Japanese)

Under this analysis, each is taken to be semantically a combination of a quantifier and its restrictor. ${ }^{7}$ The inaudible element is taken to mean something like one. Thus, literally, each literally means 'each one', in accordance with Vendler's intuition. This analysis receives some indirect support from the following Romance language data:

(13) a. Les enfants ont chacun acheté deux bonbons. (French) the children have each+one bought two candies 'The children each bought two candies.'

b. Los estudiantes escogiecon cada uno dos temas. the students picked each one two topics

(Spanish)

'The students each picked two topics.'

As shown here, in these languages the lexical element corresponding to English floated each is associated with an overt nominal element meaning 'one'. Assuming, then, that these two elements correspond to the first two components of quantification, it is reasonable to assume that they form a tripartite quantificational structure with the predicate, with the predicate functioning as the nuclear scope.

Pursuing this line of analysis, the constituent structure of an FQ sentence such as the students each picked two topics would form the semantic tree shown in (14a). For concreteness, we propose that the semantic value of each is as shown in the second line of (14b). The complete interpretation yields a distributive reading, as shown in (14c):

\footnotetext{
${ }^{6}$ We speculate that (11d) is the defining property of the FQ in general. That is, the FQ is distinct from the quantifier which composes syntactically with a nominal element (e.g. prenominal and/or determiner quantifier) in that it composes directly with the predicate.

7 Note that so-called adverbs of quantification such as always and sometimes can also be taken to consist of morphological combination of a quantifier and its restrictor:
(i)
all + ways
(ii)
some + times 
(14) a. the students each picked two topics

$\mathrm{t}$

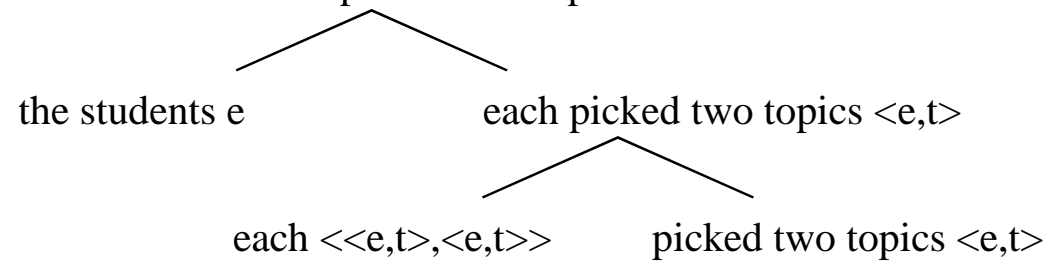

b. picked two topics: $\lambda \mathrm{x}_{\mathrm{e}}[\mathrm{p} 2 \mathrm{t}(\mathrm{x})]$

$\mid \begin{array}{ll}\text { each: } & \left.\lambda \mathrm{P}_{<\mathrm{e}, \mathrm{t}}\right\rangle \lambda \mathrm{x}_{\mathrm{e}} \exists \mathrm{K}[\mathrm{K} \subseteq(\mathrm{AT} \cap \mathrm{P}) \wedge+\mathrm{K}=\mathrm{x}] \\ \mid / & (\mathrm{AT}=\text { the set of atomic individuals) }\end{array}$

each picked two topics: $\lambda \times \exists \mathrm{K}[\mathrm{K} \subseteq(\mathrm{AT} \cap \mathrm{p} 2 \mathrm{t}) \wedge+\mathrm{K}=\mathrm{x}]$

$\mid$ the students: $\sigma(*$ student $) \quad(\sigma=$ 'supremum')

the students each picked two topics: $\exists \mathrm{K}[\mathrm{K} \subseteq(\mathrm{AT} \cap \mathrm{p} 2 \mathrm{t}) \wedge+\mathrm{K}=\sigma(*$ student $)]$

c. If $\mathrm{a}, \mathrm{b}$, and $\mathrm{c}$ are the students in the domain of discourse,

then $\sigma(*$ student $)=a+b+c$,

thus, $\exists \mathrm{K}[\mathrm{K} \subseteq(\mathrm{AT} \cap \mathrm{p} 2 \mathrm{t}) \wedge+\mathrm{K}=\sigma(*$ student $)]=\exists \mathrm{K}[\mathrm{K} \subseteq(\mathrm{AT} \cap \mathrm{p} 2 \mathrm{t}) \wedge+\mathrm{K}=\mathrm{a}+\mathrm{b}+\mathrm{c}]$,

i.e. $\quad \mathrm{a}=$ an individual two-topic picker

$\& b=$ an individual two-topic picker

$\& \mathrm{c}=$ an individual two-topic picker

In the proposed semantic value of each in (14b), P represents an $\langle e, t\rangle$ element which denotes a set containing both atoms and sums. Here P picks up the value of the predicate picked two topics, i.e. the set of two-topic pickers. This could include two-topic pickers who are not students, but it also includes both the individual two-topic pickers and all their sums. AT, which represents a set of atomic individuals, intersects with this set and this intersection is the set which contains only the atomic individuals which are two-topic pickers. Thus, if $a, b$, and c are the students in the domain of discourse, and if the sentence is true, then these three elements are in the intersection. The formula in (14c) states that there is a set $\mathrm{K}$ which is a subset of the intersection. Thus, if we designate $\mathrm{K}$ to contain precisely $\mathrm{a}, \mathrm{b}$, and $\mathrm{c}$, then the sum of the elements of this $\mathrm{K}$ turns out to be identical with the supremum denoted by the students. When the sentence is true, this is how its truth conditions are satisfied. Note here that AT is part of the lexical value of each, rather than being introduced by an additional operator. Under this analysis, the restrictor is part of the lexical content of the quantifier each. Its function is to form a singular term denotation out of a plural term denotation.

\section{Binominal each}

Next, let us consider binominal each, an example of which is shown in (15):

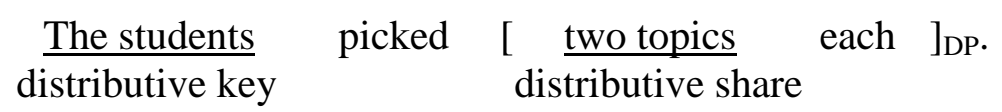

In such a sentence, the subject DP the students is generally called the 'distributive key' and the NP containing a numeral, namely two topics, is called the 'distributive share' (Choe 1987). In one of the few syntactic analyses of this construction, Safir and Stowell (1987) show that the NP containing the distributive share forms a syntactic constituent with each. Semanticists have handled binominal each in various ways (e.g. Choe 1987, Moltmann 1991, Zimmermann 2002a,b). Let us consider the most recent analysis, i.e., that of Zimmermann 
(2002a,b). Here the nominal constituent containing the distributive share and each is analyzed as a DP as shown in (16a). The proposed syntactic analysis is as shown in (16b):

(16) Zimmermann (2002a,b)

a. The students picked [two topics each $]_{\mathrm{DP}}$.

b.

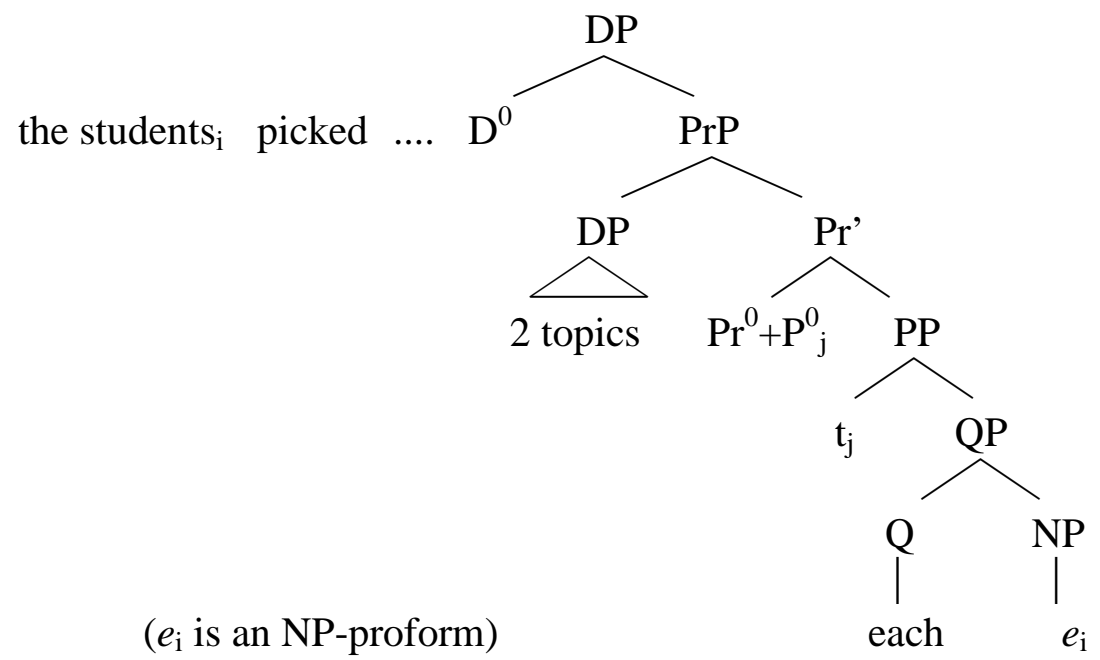

c. Each student picked two topics.

According to Zimmermann, there is a small clause inside the DP two topics each, represented as a Predicate Phrase, and its subject is two topics. The predicate, on the other hand, is taken to be each, which has the proform complement $e$. This proform is coindexed with the distributive key, i.e. the subject the students. In this way, each and the distributive key are semantically related. Thus, Zimmermann basically treats the binominal each sentence (16a) as semantically equivalent to the corresponding prenominal each sentence in (16c).

It seems reasonable to assume that the nominal constituent two topics each is a DP, given that a verb such as picked is a transitive verb. Furthermore, the small clause analysis is certainly plausible. In the syntax literature, there is a substantial amount of research devoted to socalled 'predicate inversion' within DP, which assumes the presence of a small clause within DP. This line of analysis has proved to be quite useful in accounting for data in languages such as English and Dutch (Kayne 1994, Den Dikken 1995, 1998, Bennis, et al 1998, Corver 1998, 2001). Thus, Zimmermann's approach is attractive in principle. Nevertheless, we propose a modification.

First, consider the subject-predicate relation inside the small clause. If the subject is two topics and the predicate is each, then what would a maximally simple representation of this subject-predicate relation be? Consider (17):

(17) The underlying proposition in [two topics each] (according to Zimmermann)

\begin{tabular}{|c|c|}
\hline Subject & two topics \\
\hline Predicate & each \\
\hline Proposition 1 & Two topics are each. \\
\hline Proposition 2 & Two topics are (for) each (of the students) \\
\hline
\end{tabular}

Proposition 1 is incomplete. Including the proform $e$ co-indexed with the distributive key, we arrive at Proposition 2. However, here we have to provide a significant meaning component, 
namely 'for' in order to make sense of Proposition 2. What we wish to claim here is that a much more natural and empirically sound analysis would be as follows:

(18) The underlying proposition in [two topics each] (according to our analysis)

\begin{tabular}{|c|c|}
\hline Subject & each (one) \\
\hline Predicate & two topics \\
\hline Proposition & Each one is (a set of) two topics. \\
\hline
\end{tabular}

The basic intuition in (18) is that each is not directly related to the distributive key the students. Rather, each is again analyzed as containing a hidden lexical component meaning one, so that the meaning of binominal each is analogous to 'each one'. The motivation again comes from the French and Spanish data, where the binominal each construction overtly contains the meaning component 'one':
Les enfants ont acheté deux bonbons
chacun.
(French)
the children have bought two candies each+one
'The children bought two candies each.'

b. Los estudiantes escogiecon dos temas cada uno.

the students picked two topics each one

(Spanish)

'The students picked two topics each.'

The idea we are pushing here is that each understood literally as 'each one' refers to the unit of the distributive share which is distributed over the distributive key. The predication relation between each and the NP containing a numeral, then, is a proposition about the quantity of objects in the distributive share. This is quite distinct from Zimmermann's underlying proposition in (17). In (17), the distributive share is taken to be the subject, and the predicate is are (for) each (of the students). This proposition is about the distribution itself and what the distributive share is distributed over.

Let us now consider more closely the claim that a binominal each sentence such as (19a) is semantically equivalent to a prenominal each sentence such as (19b):

(19) a. The boys bought three sausages each.

b. Each boy bought three sausages.

This equation results precisely from the syntactic analysis in which each is associated with the distributive key by coindexation. Putting aside the fact this coindexation seems rather ad hoc and inconsistent with a strict interpretation of the principle of compositionality, the hypothetical equivalence of (19a) and (19b) clashes with native speaker intuitions that there is some difference between these two sentences. ${ }^{8}$ Our analysis captures this intuition because we argue that, just as the surface forms suggest, prenominal each composes first with student while the binominal each composes first with two topics. Pursuing this line of reasoning, we are all the more motivated to formulate distinct semantic analyses for the two syntactic constructions.

In view of these considerations, we suggest that the syntactic structure of the binominal each construction is as shown in (20):

\footnotetext{
${ }^{8}$ One difference that can be identified is that the domain presupposition of each is already set by the boys in (19a) before interpreting each, whereas in (19b) quantification and presupposition accommodation must occur simultaneously (thanks to Bill Philip p.c. for pointing this out).
} 
(20) Predicate inversion analysis : e.g. Kayne 1994, Den Dikken 1995,

Corver 1998, Kobuchi-Philip 2004

a.

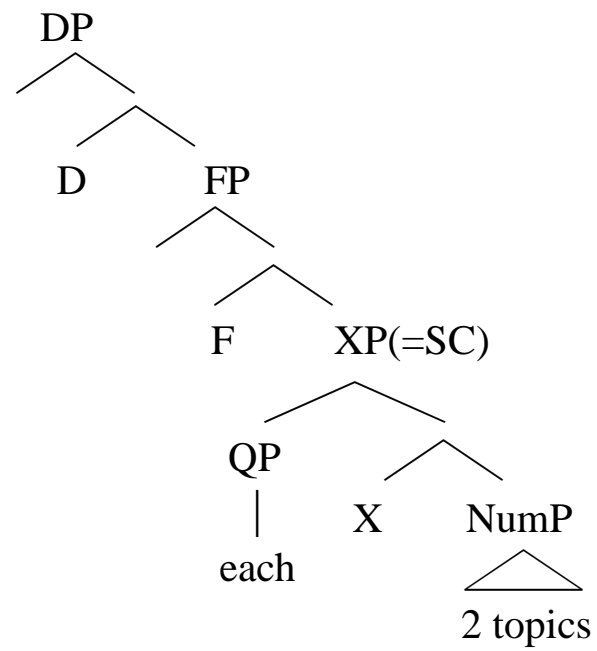

b.

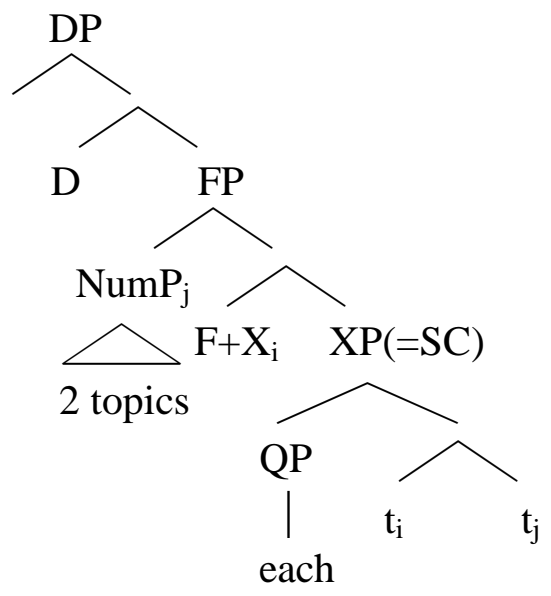

Here, each is the subject and 2 topics is the predicate in the small clause within DP, as shown in (20a). Subsequently, the predicate NumP is raised over the subject as an instance of predicate inversion, as shown in (20b).

When the syntactic structure in (20b) is semantically interpreted, the only structure visible to the interpretation mechanisms is the basic constituent structure shown in (21a). Here, we assume the presence of an inaudible determiner whose position corresponds to the head D position in (20b). Assuming the same denotation of each as floated each, we obtain the interpretation of the binominal each sentence as shown in (21b):

(21) a. the students picked two topics each t

the students e
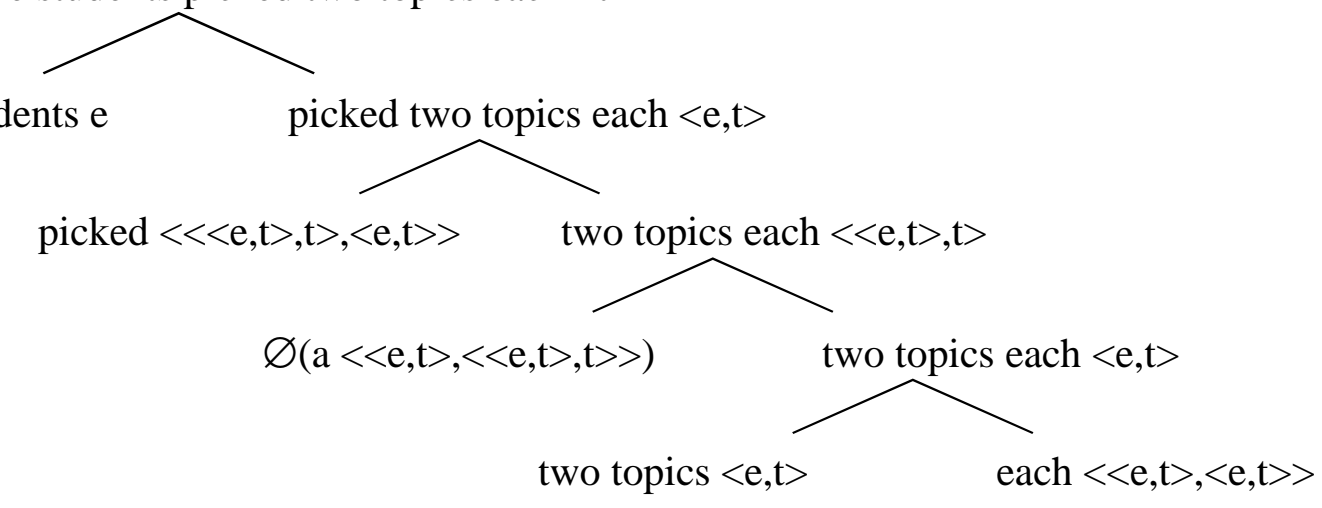

b. two topics: $\lambda \mathrm{x}_{\mathrm{e}}[2 \mathrm{t}(\mathrm{x})]$

$\left.\right|_{/} ^{\text {each: }} \lambda \mathrm{P}_{<\mathrm{e}, \mathrm{t}} \lambda \lambda \mathrm{y}_{\mathrm{e}} \exists \mathrm{K}[\mathrm{K} \subseteq(\mathrm{AT} \cap \mathrm{P}) \wedge+\mathrm{K}=\mathrm{y}]$

two topics each: $\lambda \mathrm{y} \exists \mathrm{K}[\mathrm{K} \subseteq(\mathrm{AT} \cap 2 \mathrm{t}) \wedge+\mathrm{K}=\mathrm{y}]$

| $a: \quad \lambda \mathrm{P}_{<\mathrm{e}, \mathrm{t}>} \lambda \mathrm{Q}_{<\mathrm{e}, \mathrm{t}\rangle} \exists \mathrm{x}_{\mathrm{e}}[\mathrm{P}(\mathrm{x}) \wedge \mathrm{Q}(\mathrm{x})]$

(a) two topics each: $\lambda \mathrm{Q} \exists \mathrm{x}[\exists \mathrm{K}[\mathrm{K} \subseteq(\mathrm{AT} \cap 2 \mathrm{t}) \wedge+\mathrm{K}=\mathrm{x}] \wedge \mathrm{Q}(\mathrm{x})]$

|, picked: $\lambda \mathrm{T}_{<<\mathrm{e}, \mathrm{t}>, \mathrm{t}\rangle} \lambda \mathrm{v}_{\mathrm{e}}\left[\mathrm{T}\left(\lambda \mathrm{s}_{\mathrm{e}}[(\operatorname{picked}(\mathrm{s}))(\mathrm{v})]\right)\right]$ 


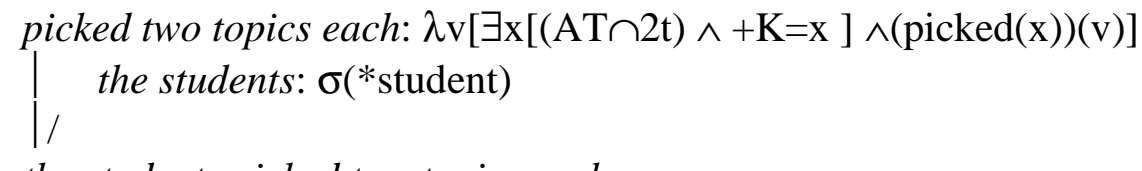

the students picked two topics each:

$$
\exists \mathrm{x}[\exists \mathrm{K}[\mathrm{K} \subseteq(\mathrm{AT} \cap 2 \mathrm{t}) \wedge+\mathrm{K}=\mathrm{x}] \wedge(\operatorname{picked}(\mathrm{x}))(\sigma(* \text { student })]
$$

c. If $\mathrm{a}, \mathrm{b}$, and $\mathrm{c}$ are the students in the domain of discourse,

and $\alpha$ is a set of two topics and $\beta$ is another set of two topics in the set $\mathrm{K}$,

then $\sigma(*$ student $)=a+b+c$, and $x=\alpha+\beta$,

thus, $\exists x[\exists K[K \subseteq(A T \cap 2 t) \wedge+K=\alpha+\beta] \wedge(\operatorname{picked}(x))(\sigma(*$ student $)]$

$$
=\exists \mathrm{K}[\mathrm{K} \subseteq(\mathrm{AT} \cap 2 \mathrm{t}) \wedge+\mathrm{K}=\alpha+\beta] \wedge(\operatorname{picked}(\alpha+\beta))(\mathrm{a}+\mathrm{b}+\mathrm{c})
$$

An example verification of the logical representation in the last line of (21b) is partially shown in (21c). The last line of (21c) can be described as follows: Suppose student a picked a set of two topics $\alpha$, student b picked a set of two topics $\alpha$, and student $\mathrm{c}$ picked a set of two topics $\beta$ (e.g. $\alpha$ represents the Civil War and the slavery, $\beta$ represents Vietnam War and the Hippie movement). Thus, $\mathrm{K}$ can be determined to contain $\alpha$ and $\beta$. Then, (picked $(\alpha+\beta)$ ) denotes a set containing every $\alpha$-picker and $\beta$-picker, and all their sums, which then include the sum $a+b+c$.

Note that, under this analysis, binominal each is of type $\langle<\mathrm{e}, \mathrm{t}\rangle,\langle\mathrm{e}, \mathrm{t}\rangle\rangle$, just like floated each In both cases, the quantifier is assumed to contain a hidden lexical component which denotes a set of atoms and which functions as the restrictor. However, while floated each syntactically composes with a verbal predicate, binominal each syntactically composes with an NP. This allows a unified analysis which is more strictly compositional since semantic interpretation is closely related to the surface form. In the next section we examine prenominal each, which turns out to be quite distinct from the two types of each we have discussed so far.

\section{Prenominal each}

Let us now consider prenominal each. Since we have shown how floated and binominal each can be taken to have identical semantic value, we might attempt to extend the analysis to cover prenominal each as well. However, prenominal each in fact looks quite distinct from floated and binominal each. Again, the clue comes from the Romance languages. Consider (22):

(22) Three types of each in French, Spanish and English

\begin{tabular}{|l|l|l|}
\hline & Floated/Binominal & Prenominal \\
\hline French & chacun & chaque $(\mathrm{N})$ \\
\hline Spanish & cada uno & cada $(\mathrm{N})$ \\
\hline English & each & each $(\mathrm{N})$ \\
\hline
\end{tabular}

As we observed earlier, in French and Spanish, the lexical elements which correspond to English floated and binominal each are chacun and cada uno, respectively, which include the overt meaning component 'one'. However, this component disappears in the prenominal use of the same lexical item. This suggests a sharp distinction between floated and binominal each, on one hand, and prenominal each, on the other. Specifically, it seems to be the case that prenominal each does not contain a hidden lexical component denoting a set of atoms that functions as the restrictor. Recall now that the original reason for positing a hidden classifier-like element for floated each follows from our hypothesis that FQ each needed this restrictor in order for the three components of FQ quantification to apply within the verbal 
domain. Thus, if prenominal each does not contain a restrictor, an immediate question is what functions as the restrictor and the nuclear scope.

In fact, prenominal each must be followed by a singular noun. This is also the case in French and Spanish and a singular noun denotes a set of atoms (Link 1983, Landman 2000). This suggests that, in accordance with the traditional analysis, the singular noun adjacent to it functions as the restrictor for prenominal each. Assuming that prenominal each and the singular noun adjacent to it are a quantifier and its restrictor, the predicate must be the nuclear scope, as shown in (23):

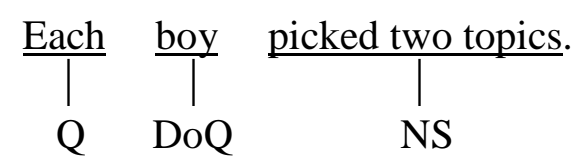

If this is the case, prenominal each does indeed seem to be a determiner. This explains why prenominal each cannot co-occur with a determiner, as illustrated in (24a), and this constraint applies to the analog of each in the Romance languages as well, as illustrated in $(24 \mathrm{~b}, \mathrm{c})$ :

(24) a. *the each $\mathrm{N}$

b. *le chaque $\mathrm{N}$

c. *de cada $\mathrm{N}$

To account for the determiner status of prenominal each, we hypothesize that here each the quantifier has incorporated into the definite determiner, as shown in (25):



In the syntax literature, a quantifier such as all has been argued to occupy the head position of $\mathrm{QP}$, which is generally assumed to be generated above DP as the top-most maximal projection within the nominal domain, as shown in (26a) below. Such a structure accounts for the word order of the phrase such as all the students:

(26) The internal structure of the nominal domain (Giusti 1991, Shlonsky 1991, etc.)

a.

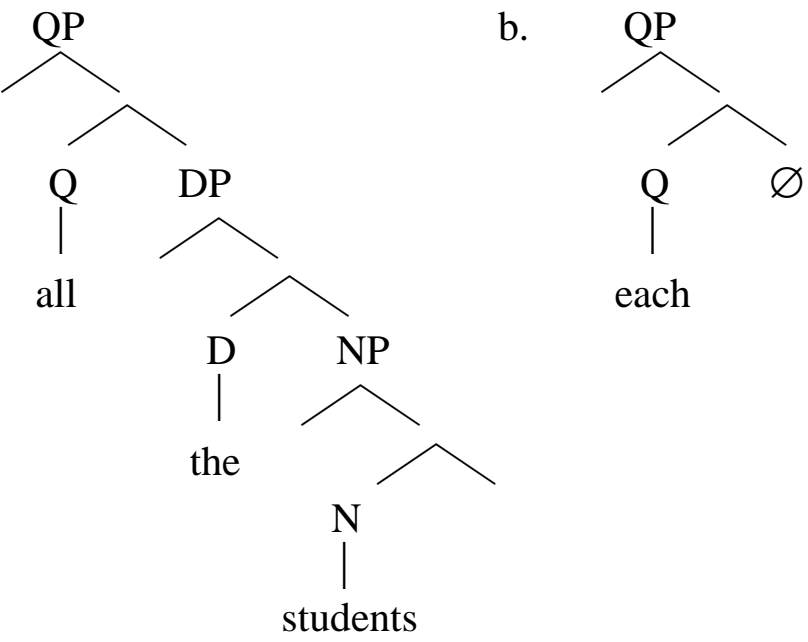

We could assume that floated and binominal each occupy the same Q-head position as shown in (26b) and that this QP is inserted in the appropriate positions in the sentence structure (a 
VP-adjoined adverbial position for FQ each, and subject position within DP for binominal each). However, since prenominal each combines with a noun and has lexically merged with the definite determiner, we suggest that prenominal each is not a Q-element but a D-element, as shown in (27):

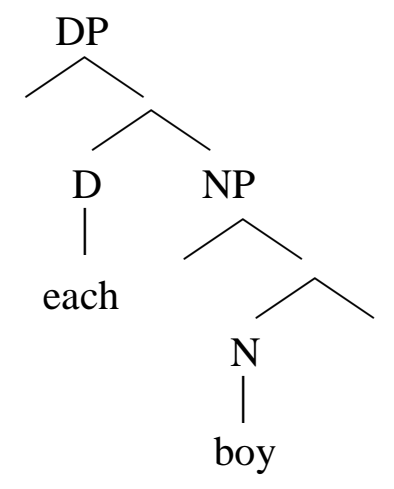

The semantic tree for a sentence with prenominal each would look like (28a) below. We suggest that the denotation of prenominal each is as shown in the first line of (28b). The outcome is as shown in $(28 \mathrm{c})$ :

(28) a.

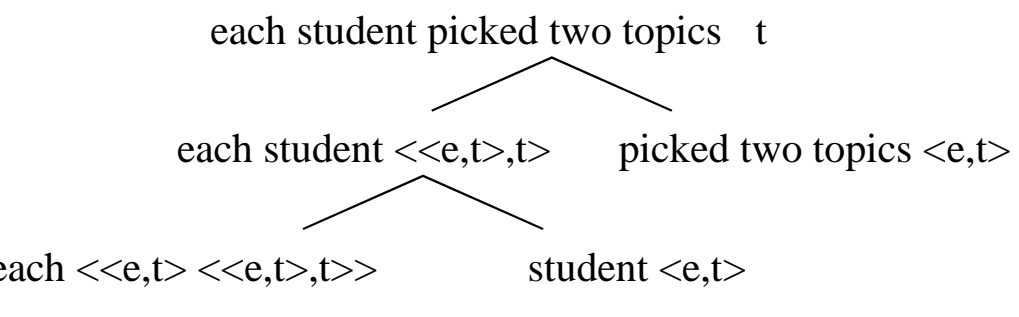

b. $\quad$ each: $\lambda \mathrm{P}_{\langle\mathrm{e}, \mathrm{t}\rangle} \lambda \mathrm{Q}_{<\mathrm{e}, \mathrm{t}\rangle}[\mathrm{P} \subseteq \mathrm{Q}]$

$\mid \begin{aligned} & \text { student }: \lambda \mathrm{x}_{\mathrm{e}}[\operatorname{student}(\mathrm{x})] \\ & \text { / }\end{aligned}$

each student: $\lambda \mathrm{Q}[\operatorname{student}(\mathrm{x}) \subseteq \mathrm{Q}]$

picked two topics: $\lambda \mathrm{x}_{\mathrm{e}}[\mathrm{p} 2 \mathrm{t}(\mathrm{x})]$

each student picked two topics: $\lambda \mathrm{x}[\operatorname{student}(\mathrm{x})] \subseteq \lambda \mathrm{x}[\mathrm{p} 2 \mathrm{t}(\mathrm{x})]$

c. student

$\lambda \mathrm{x}[\operatorname{student}(\mathrm{x})] \subseteq \lambda \mathrm{x}[\mathrm{p} 2 \mathrm{t}(\mathrm{x})] \quad: \quad \mathrm{a}=$ an individual two-topic picker

$\& \mathrm{~b}=$ an individual two-topic picker

$\& \mathrm{c}=$ an individual two-topic picker

Prenominal each first combines with a singular noun, in this case student. This denotes a set containing only atoms. If there are three students in the domain of discourse, then it denotes $\{a, b, c\}$. This singular noun functions as the restrictor and it intersects with the predicate denotation, though the intersection is itself the set denoted by the singular noun. That is, it is a subset of the predicate denotation. Thus, each member of the set dentoed by the singular noun, namely a, b, and c, is an atom and has the property of having picked two topics.

\section{Summary and further questions}

In this paper, we have examined three manifestations of the English lexical element each, namely, floated each, binominal each and prenominal each. On the basis of a general mechanism of FQ quantification induced from a recent semantic analysis of Japanese floated 
numeral quantifier, we have proposed that English floated each lexically contains an inaudible nominal element which denotes a set of atoms and which functions as the restrictor. As for binominal each, we modified the syntactic analysis suggested by Zimmermann $(2002 a, b)$ by means of a predicate inversion analysis. That allows for a simpler unified account of floated and binominal each that is more strictly compositional than previous accounts and that accords with native speaker intuitions. Prenominal each, however, turned out to be distinct from the other two types of each in the sense that, as suggested by Romance data, it does not contain the restrictor as a lexical component. Instead, prenominal each was analyzed as a determiner quantifier in the traditional sense except that, under our analysis it derives morphologically from FQ each. This derivation, which is probably historical rather than synchronic, is possible because the right-adjacent noun is singular and therefore can be a proper restrictor (satisfying atomicity condition).

The analysis given here is based on some novel assumptions. Obviously, these assumptions themselves require more thorough examination. Furthermore, under our analysis the denotations of floated and binominal each are very different from that of prenominal each. The syntax and the syntax-semantics interface issues of prenominal each must be investigated further. Specifically, future research questions posed by our analysis are: How can determiner each be analyzed as deriving from the internal components of floated each? What properties of UG makes this possible or obligatory? These are entirely new questions since in all prior research it was assumed, without question, that FQs derive from determiners.

\section{References}

Bennis, H., Corver, N., Den Dikken, M.: 1998, Predication in nominal phrases, The Journal of Comparative Germanic Linguistics 1, 85-117.

Chierchia, G.: 1998, Reference to kinds across languages, Natural Language Semantics 6, 339-405.

Choe, J.-W.: 1987, Anti-quantifiers and a theory of distributivity. Ph.D. Diss. University of Massachusetts, Amherst.

Corver, N.: 1998, Predicate movement in pseudopartitive constructions, in A. Alexiadou and C. Wilder (eds), Possessors, predicates, and movement in the determiner phrase. Amsterdam: John Benjamins, pp. 215-257.

Corver, N.: 2001, On predicate numerals, in T. van der Wouden and H. Broekhuis (eds), Linguistics in the Netherlands 2001. Amsterdam: John Benjamins, pp. 65-76.

Den Dikken, M.: 1995, Copulas, GLOW Newsletter 34, 20-21.

Den Dikken, M.: 1998, Predicate inversion in DP, in A. Alexiadou and C. Wilder (eds), Possessors, predicates, and movement in the determiner phrase, Amsterdam: John Benjamins, pp. 177-214.

Doetjes, J.: 1997, Quantifiers and selection: on the distribution of quantifying expressions in French, Dutch and English. Ph.D. Diss. Leiden University.

Dowty, D. and B. Brodie: 1984, The semantics of 'floated' quantifiers in a transformaionless grammar, in M. Cobler, S. Mackaye, and M. T. Wescoat (eds), WCCFL 3, 75-90.

Fukushima, K.: 1991, Generalized floating quantifiers. Ph.D. Diss. University of Arizona. 
Giusti, G.: 1991, The categorial status of quantified nominals, Linguistische Berichte 136, 438-454.

Inoue, K.: 1978, Nihongo-no bunpookisoku, Tokyo: Taishuukan.

Jelinek, E.: 1995, Quantification in Straits Salish, in E. Bach, E. Jelinek, A. Kratzer and B. Partee (eds), Quantification in natural languages, Dordrecht: Kluwer, pp. 487-540.

Junker, M-O.: 1990, Floating quantifiers and Georgian distributivity, in M. Ziolkowski, M. Noske, and K. Deaton (eds), CLS 26, 211-219.

Kayne, R.: 1994, The antisymmetry of syntax. Cambridge, MA: MIT Press.

Kobuchi-Philip, M.: 2003, Distributivity and the Japanese floating numeral quantifier. Ph.D. Diss. CUNY Graduate Center.

Kobuchi-Philip, M.: 2004, Syntactic and semantic licensing condition of the floating (numeral) quantifier, a talk at Linguistic Perspectives on Numerical Expressions Workshop, Utrecht.

Kratzer, A.: 1989, An investigation of the lumps of thought, Linguistics and Philosophy 12, 607-653.

Landman, F.: 2000, Events and plurality, Dordrecht: Kluwer.

Link, G.: 1983, The logical analysis of plural and mass terms: A lattice-theoretical approach, in R. Bäuerle, C. Schwarze, and A. von Stechow (eds.) Meaning, use, and interpretation of language, Berlin: de Gruyter, pp. 303-323.

Link, G.: 1987, Generalized quantifiers and plurals, in P. Gärdenfors (ed.) Generalized quantifiers. linguistic and logical approaches. Drdrecht: Reidel, pp. 151-180.

Moltmann, F.: 1991, On the syntax and semantics of binary distributive quantifiers, NELS 22, 279-292.

Roberts, C.: 1986, Modal subordination, anaphora and distributivity. Ph.D. Diss. University of Massachusetts at Amherst.

Safir, K. and T. Stowell: 1987, Binominal each, NELS 18, 426-450.

Shlonsky, U.: 1991, Quantifiers as functional heads: A study of quantifier float in Hebrew, Lingua. 84, 159-180.

Vendler, Z.: 1966, Linguistics in Philosophy. NY: Cornell University Press.

Zimmermann, M.: 2002a, A compositional analysis of anti-quantifiers as quantifiers, in B. Jackson (ed.) SALT 12, 322-338.

Zimmermann, M.: 2002b, Boys buying two sausages each. Ph.D. Diss. University of Amsterdam. 


\title{
YOU ONLY NEED A SCALAR $O N L Y$
}

\author{
Sveta Krasikova \& Ventsislav Zhechev, \\ Seminar für Sprachwissenschaft \\ Eberhard-Karls Universität Tübingen \\ svetlana.krasikova@ student.uni-tuebingen.de \\ vzhechev@sfs.uni-tuebingen.de
}

\begin{abstract}
We propose a compositional analysis for sentences of the kind "You only have to go to the North End to get good cheese", referred to as the Sufficiency Modal Construction in the recent literature. We argue that the SMC is ambiguous depending on the kind of ordering induced by only. So is the exceptive construction - its cross-linguistic counterpart. Only is treated as inducing either a 'comparative possibility' scale or an 'implication-based' partial order on propositions. The properties of the 'comparative possibility' scale explain the absence of the prejacent presupposition that is usually associated with only. By integrating the scalarity into the semantics of the SMC, we explain the polarity facts observed in both variants of the construction. The sufficiency meaning component is argued to be due to a pragmatic inference.
\end{abstract}

\section{Introduction}

Adverbial only has been recently argued to require special treatment when occurring in sentences expressing sufficient condition. The following sentence, first discussed in (von Fintel and Iatridou 2005), proved to be problematic for the existing analyses of only:

(1) To get good cheese you only have to go to the North End.

According to the observation in (Bech 1955/57), sentences like (1) are equivalent to:

(2) To get good cheese it suffices to go to the North End.

This suggests that only can 'reverse' the relation of necessity, expressed by the embedded have to, giving rise to the sufficiency reading.

Another striking fact about (1) and others of its kin is that they do not entail the truth of the prejacent, the propositional complement of only. In other words, in uttering (1), we do not convey that the embedded anankastic conditional in (3) is true.

(3) To get good cheese you have to go to the North End.

In other cases with only the prejacent is true, which is derived in one way or another from the meaning of the adverb. Interestingly, the absence of the prejacent presupposition in the sufficiency modal construction (SMC), as (von Fintel and Iatridou 2005) call (1), is limited to the positive cases, i.e. the negation of (1) does imply (3).

According to (von Fintel and Iatridou 2005)'s cross-linguistic survey of the morphosyntax of the SMC, a set of languages, like French, Modern Greek, etc., employs a negative adverb and an exceptive phrase instead of only:

(4) Si tu veux du bon fromage, tu n'as qu'à aller à North End.

if you want of good cheese you NEG have except go to North End

The goal of this paper is to develop a compositional analysis for "only have to" sentences and their "neg+except" counterparts. We claim that the data in question can involve scalar uses of only and except, which enables us to account for the the lack of the prejacent entailment/presupposition and derive the sufficiency meaning. In the literature on only the term 
'scalar' is used to describe the fact that only triggers an ordering on the alternative propositions it operates on. This can be either an ordering based on logical implication, or one based on a contextually salient scale. We reserve the term 'scalar' for the cases that are not implication-based. We argue that both kinds of orderings can occur in the SMC as it is the case in simple sentences with only. Except and the scalar version of only appear to be polarity sensitive, which receives a pragmatic explanation in our approach.

Further, we show that the choice of the modal in the SMC depends on the ordering in question and on the properties of the modal itself. Thus, embedding an existential modal in the SMC gives meaningful results only if we use the implication-based ordering. The can-variant in (5) does not seem to have a scalar reading:

(5) You can only take your wife to Italy to please her.

Finally, our analysis predicts that (2) is not equivalent to (1) and (4) but rather is a pragmatic inference from them.

The structure of the paper is the following: section 2 gives a brief overview of the existing analyses of the SMC and their problems; in section 3 we make a new proposal and give precise semantics and pragmatics for only and except; section 4 deals with the polarity issues and section 5 addresses the choice of modals in the SMC.

\section{Problems with Previous Analyses}

We will discuss two recent proposals for the analysis of the SMC - (von Fintel and Iatridou 2005) and (Huitink 2005) - and we will show what problems they run into while struggling to solve the "prejacent problem".

To solve the "prejacent problem" (von Fintel and Iatridou 2005) pursue a lexical decomposition alternative, assuming that only splits into the negation and except, drawing on the parallel to the "ne que" construction in French. Moreover, they allow the modal to intervene between the two operators:

(6) Splitting only hypothesis:

"only have to VP" = Neg > have to > other than VP

These assumptions would result in the LF in (7).

(7)

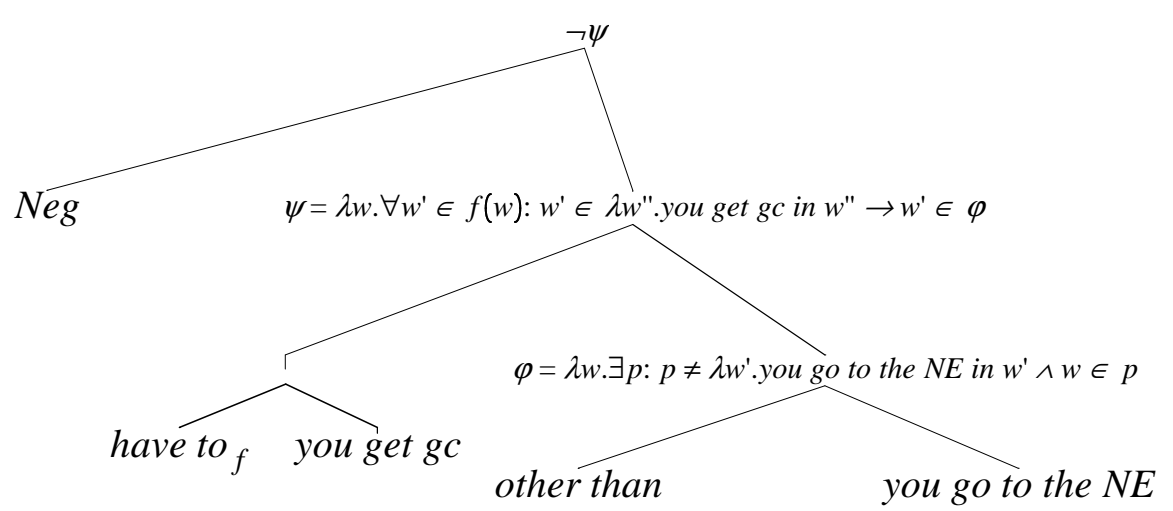

Thus, (von Fintel and Iatridou 2005) derive the following truth conditions for (1):

(8) In some of the good cheese worlds you don't do anything other than going to the North End.

This truth condition combined with the presupposition in (9) does not entail the prejacent. (9) is an existential presupposition triggered by only, as assumed in (Horn 1996).

(9) In all of the good cheese worlds you do something. 
The SMC is thus predicted to express the possibility to achieve the goal expressed by the subordinate clause if the condition in the matrix clause is fulfilled. However, this semantics appears too weak to account for those sentences that involve sufficiency in the logical sense:

(10) For the bomb to explode, you only have to press the button.

The condition in (8) would wrongly predict that (10) is true in a world in which pressing the button does not trigger an explosion. (von Fintel and Iatridou 2005) are aware of this fact, but claim that this is the desired result.

There are another two aspects in their theory that we find problematic. The first one concerns the observation that the negated SMC sentence does imply its prejacent.

(11) You don't only have to go to the North End to get good cheese.

$\rightarrow$ You have to go to the North End to get good cheese.

Adding a negation on top of the LF in (7) fails to explain (11).

Finally, by ignoring the scalarity of the construction, (von Fintel and Iatridou 2005) predict that (1) comes out true if you can get good cheese in the North End, regardless of the other possibilities for getting good cheese, i.e. even if there are easier ways.

Another proposal, due to (Huitink 2005), is to analyse only as a universal modal with reversed order of arguments and to use the notion of modal concord to dispense with the semantic contribution of have to. The truth condition she arrives at is:

(12) In all North End worlds you get good cheese.

which renders (1) equivalent to (2). This, similar to (von Fintel and Iatridou 2005)'s analysis, makes wrong predictions in case there are easier ways for obtaining good cheese than going to the North End. If you can as well get good cheese in the nearest shop, (1) is predicted true contrary to our intuitions. The general problem with the modal analysis is that it fails to capture the fact that the SMC does not only introduce a sufficient condition, but also ranks it as the easiest possible.

We can conclude that it is crucial to integrate the notion of 'scale' into the semantics of the $\mathrm{SMC}$, which we will turn to in the next section.

\section{Scalar Meaning of SMC}

We saw that it is important to take into account the scalarity of the construction. It seems natural to assume that the presence of a scale is due to the semantics of only. Two major inferences associated with (1) are that:

- none of the ways of achieving the goal ranked higher on an effort scale than the one that appears in the sentence ( $\llbracket n e \rrbracket)$ are necessary

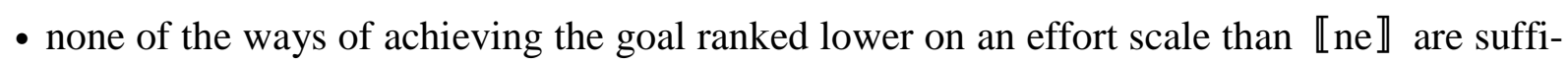
cient

Intuitively, the effort scale is constructed based on the comparative difficulty of actions described by different propositions. According to an observation of (von Fintel and Iatridou 2005), the scale consists not only of ways of achieving the goal, but may also include other propositions.

\subsection{The Scale}

The effort scale ranks propositions according to the degrees of difficulty they are assigned in the world of evaluation. To define the scale, we suggest that the degree of difficulty of a 
proposition corresponds to its possibility in the actual world. Thus, we take the comparative possibility relation from (Lewis 1973) and use it for ranking:

(13) $\forall p, q, w: p$ is at least as difficult as $q$ in $w$ iff

$$
q \preccurlyeq_{\mathrm{w}} p \text { (i.e. } p \text { is at most as possible as } q \text { in } w \text { ) }
$$

In the degree talk:

(14) $\forall p, q, w: p$ is at least as difficult as $q$ in $w$ iff $D(w)(p) \leq D(w)(q)$, where $D(w)$ is a function from propositions to their possibility degrees in $w$.

We can also define the relations of sufficiency and necessity between a degree and a proposition based on the corresponding relations holding between propositions:

$$
\begin{gathered}
\forall q \in \mathrm{D}_{\mathrm{st}}, d \in \mathrm{D}_{\mathrm{d}}, w \in \mathrm{D}_{\mathrm{s}}(d \text { is sufficient for } q \text { in } w) \Leftrightarrow \\
\left(\exists p \in \mathrm{D}_{\mathrm{st}}: p \text { is } d \text {-possible in } w \wedge \operatorname{sufficient}_{w}(p, q)\right)
\end{gathered}
$$

$$
\begin{gathered}
\forall q \in \mathrm{D}_{\mathrm{st}}, d \in \mathrm{D}_{\mathrm{d}}, w \in \mathrm{D}_{\mathrm{s}}(d \text { is necessary for } q \text { in } w) \Leftrightarrow \\
\left(\exists p \in \mathrm{D}_{\mathrm{st}}: p \text { is } d \text {-possible in } w \wedge \operatorname{necessary}_{w}(p, q)\right)
\end{gathered}
$$

Informally, for a degree $d$ to be sufficient for a proposition $q$ in a world $w$, there has to be another proposition $p$ corresponding to $d$, which is sufficient for $q$ in $w$. The same holds for necessity.

Further on, we assume that in the scalar context necessity and sufficiency are related in a certain intuitive way. We say that a degree $d$ is sufficient for some proposition $q$ in a world $w$ iff any smaller degree $d^{\prime}$ is not necessary for $q$ in $w$. This relation between sufficiency and necessity is formally defined in (17). It should be noted, that according to (14) greater degrees correspond to less effort on the scale, as can be seen on the diagram in (17). Here, the degree ' 1 ' corresponds to the propositions that are true in the world of evaluation, i.e. propositions that require zero effort to be fulfilled. The degree ' 0 ', on the other hand, corresponds to the propositions that are impossible in the world of evaluation, i.e. they cannot be fulfilled.

$$
\begin{aligned}
& \forall q \in \mathrm{D}_{\mathrm{st}}, d \in \mathrm{D}_{\mathrm{d}}, w \in \mathrm{D}_{\mathrm{s}}(d \text { is sufficient for } q \text { in } w) \Leftrightarrow \\
& \qquad \begin{array}{l}
\left(\forall d^{\prime}: d^{\prime}<d \rightarrow d^{\prime} \text { is not necessary for } q \text { in } w\right) \\
1
\end{array} \text { suff } \quad \neg \text { nec }_{0}^{\longrightarrow}
\end{aligned}
$$

Using (17) we can derive the monotonicity properties of sufficiency and necessity, formalised in (18) and (19). (18) states that if a degree $d$ is sufficient for a proposition $q$ in a world $w$, then all smaller degrees are also sufficient for $q$ in $w$, i.e. sufficiency is monotone decreasing in its degree argument. According to (19) if a degree $d$ is necessary for a proposition $q$ in a world $w$, then all greater degrees are also necessary for $q$ in $w$, i.e. necessity is monotone increasing in its degree argument.

$$
\begin{aligned}
& \forall q \in \mathrm{D}_{\mathrm{st}}, d \in \mathrm{D}_{\mathrm{d}}, w \in \mathrm{D}_{\mathrm{s}}(d \text { is sufficient for } q \text { in } w) \Rightarrow \\
& \left(\forall d^{\prime}: d^{\prime}<d \rightarrow d^{\prime} \text { is sufficient for } q \text { in } w\right)
\end{aligned}
$$


(19) $\forall q \in \mathrm{D}_{\mathrm{st}}, d \in \mathrm{D}_{\mathrm{d}}, w \in \mathrm{D}_{\mathrm{s}}(d$ is necessary for $q$ in $w) \Rightarrow$

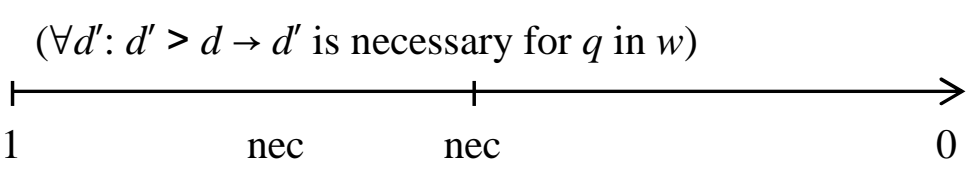

Having defined the scale and formalised the behaviour of 'sufficient' and 'necessary' with respect to it, we can now turn to the meaning of only in the SMC.

\subsection{The Meaning of Scalar Only in the SMC}

We assume that only can operate on a proposition and a modal operator. It can additionally take as an argument a function $D$ from worlds into functions from propositions to degrees, which is determined by the context and can change its range accordingly. In the case of the SMC, $D(w)$ will assign each proposition its probability degree in $w$ and will thus have the range from 0 to 1 . Only, applied to its arguments, asserts that the modal does not hold of any proposition for which $D(w)$ returns a smaller degree than the one it returns for the propositional argument. We follow (Horn 1996) in assuming a weak existential presupposition for only, i.e. that there is a proposition of which the modal holds. We, however, leave it open for now, whether the latter condition is strong enough to be empirically adequate.

Formally, the meaning we propose for only is the following:

$$
\begin{array}{r}
\llbracket \text { only } \rrbracket=\lambda w \cdot \lambda D \in \mathrm{D}_{\mathrm{s}((\mathrm{st}) \mathrm{d})} \cdot \lambda p \\
\forall q \in \mathrm{D}_{\mathrm{st}} \cdot \lambda M \in \mathrm{D}_{\mathrm{st}}\left[D \left(\mathrm{(st)t)}: \exists r \in \mathrm{D}_{\mathrm{st}}[M(q)<D(w)(p) \Rightarrow \neg M(w)(q)]\right.\right.
\end{array}
$$

The LF corresponding to (1) is the following:

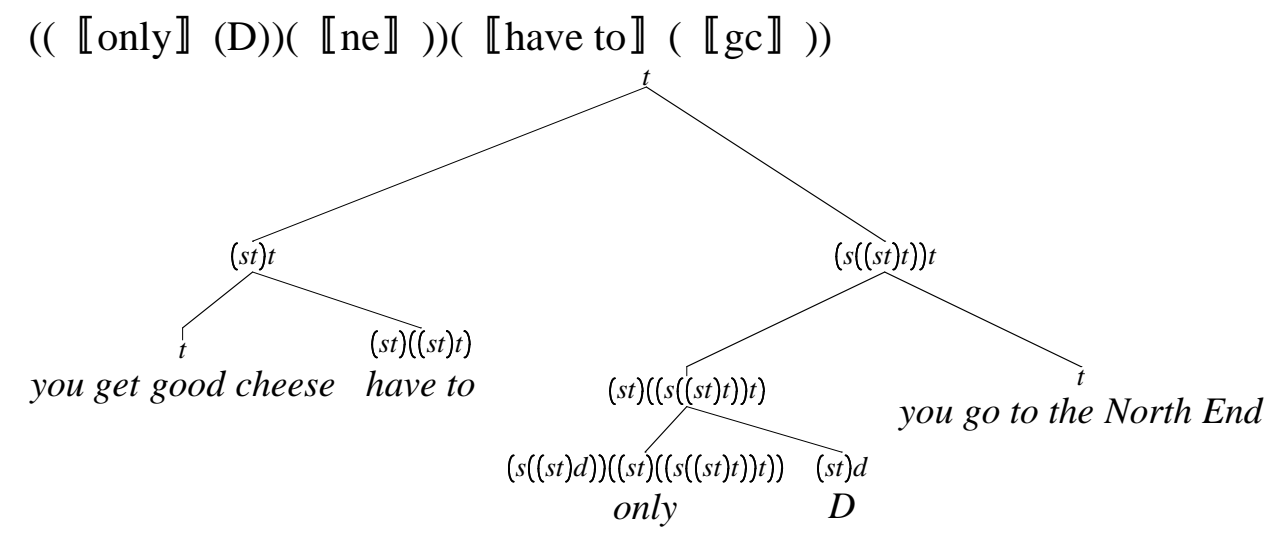

According to (20) we derive the following meaning:

(22) A: You don't have to do anything that is more difficult than going to the North End.

P: There is something that you have to do to get good cheese.

Formally, this is represented as follows:

(23) A: $\lambda w . \forall q \in \mathrm{D}_{\text {st }}[D(w)(q)<D(w)(\llbracket$ you go to the North End $\rrbracket) \Rightarrow$

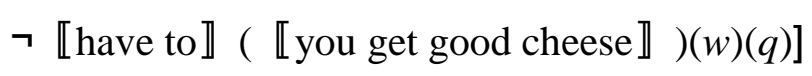

P: $\lambda w . \exists r \in \mathrm{D}_{\text {st }}[\llbracket$ have to $\rrbracket(\llbracket$ you get good cheese $\rrbracket)(w)(r)]$

By analogy, we analyse the French except as a scalar operator with the meaning in (24):

$$
\begin{aligned}
\llbracket \text { except } \rrbracket=\lambda w \cdot \lambda D \in \mathrm{D}_{\mathrm{s}((\mathrm{st}) \mathrm{d})} \cdot \lambda p & \in \mathrm{D}_{\mathrm{st}} \cdot \lambda M \in \mathrm{D}_{\mathrm{s}((\mathrm{st}) \mathrm{t})}: \exists r \in \mathrm{D}_{\mathrm{st}}[M(w)(r)] . \\
\exists q & \in \mathrm{D}_{\mathrm{st}}[D(w)(q)<D(w)(p) \wedge M(w)(q)]
\end{aligned}
$$


By putting except under negation, we will get the meaning for the French example in (4) that is equivalent to the meaning of its 'only have to' counterpart, cf. (22)/(23):

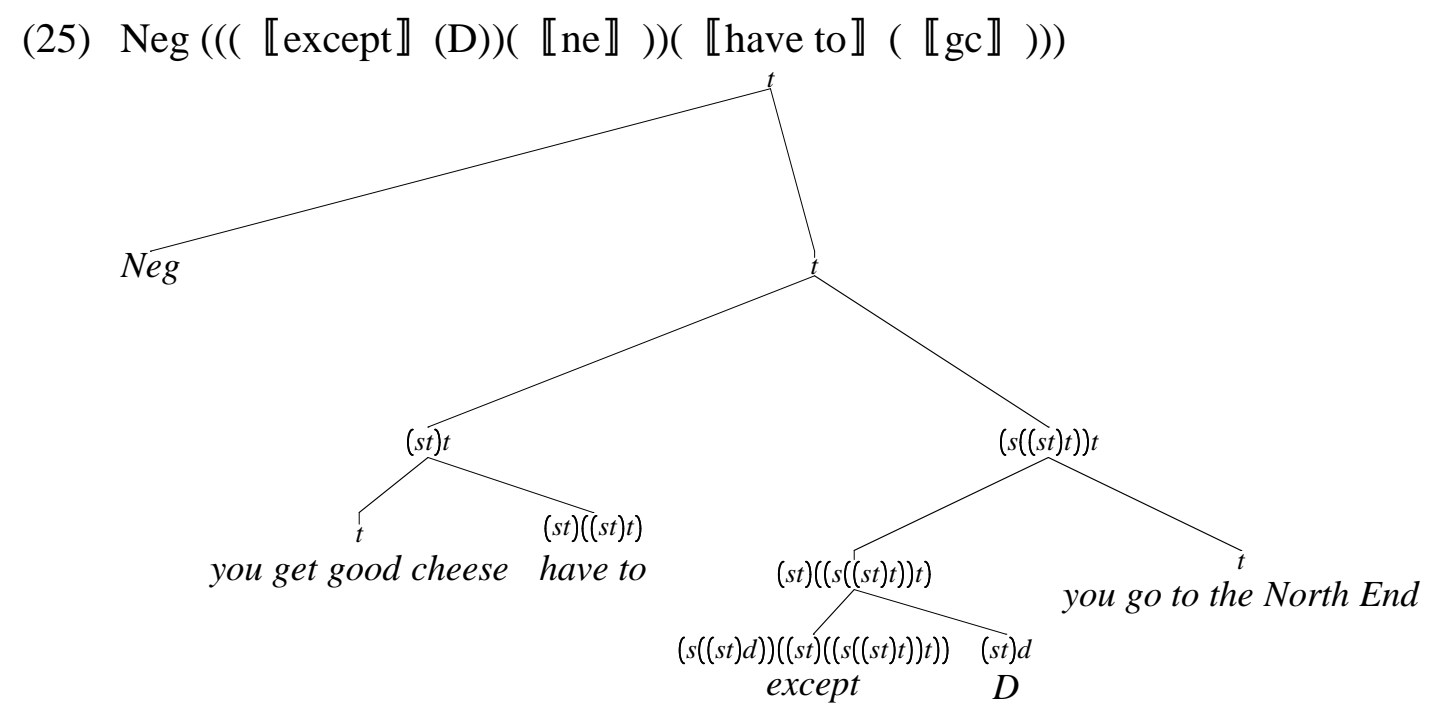

As to the question, why we cannot use except without negation, we will try to give an answer to it in section 4 .

\subsection{Strengthening by Implicature}

As we have observed in connection with the scalar inferences of the SMC, we have to make sure that sentences like (1) cannot be true or felicitous in scenarios in which there are easier alternatives for achieving the goal. To account for the non-sufficiency of easier alternatives, we need to strengthen the meaning by the requirement that any possibility degree greater than

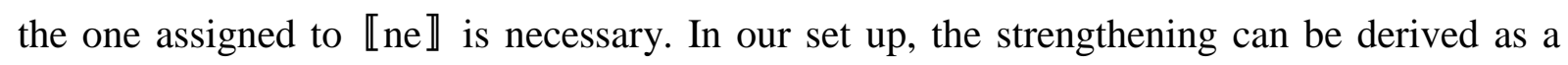
scalar implicature.

Suppose that we have the following scenario: going to the nearest shop (ns) is easier than going to the North End (ne), which in turn is easier than going to Italy (it). The presence of ordered alternatives in the context allows us to build alternative assertions of the type 'You only have to $x$ to get good cheese.' The alternative assertions are ordered according to their informational strength, as in (26). This ordering is the result of the monotonicity of only.

$$
\begin{aligned}
& \lambda w . \forall q \in \mathrm{D}_{\text {st }}[D(w)(q)<D(w)(\llbracket \mathrm{ns} \rrbracket) \Rightarrow \neg \llbracket \text { have to } \rrbracket(\llbracket \mathrm{gc} \rrbracket)(w)(q)] \subseteq \\
& \lambda w . \forall q \in \mathrm{D}_{\text {st }}[D(w)(q)<D(w)(\llbracket \text { ne } \rrbracket) \Rightarrow \neg \llbracket \text { have to } \rrbracket(\llbracket \mathrm{gc} \rrbracket)(w)(q)] \subseteq \\
& \lambda w . \forall q \in \mathrm{D}_{\mathrm{st}}[D(w)(q)<D(w)(\llbracket \text { it } \rrbracket) \Rightarrow \neg \llbracket \text { have to } \rrbracket(\llbracket \mathrm{gc} \rrbracket)(w)(q)]
\end{aligned}
$$

Following standard Gricean reasoning, we assume that all alternative assertions that are informationally stronger than the uttered one are believed to be false. Thus, we derive the following implicature:

$$
\begin{aligned}
\lambda w . \forall q \in \mathrm{D}_{\mathrm{st}}[D(w)(q)>D(w)(\llbracket \mathrm{ne} \rrbracket) \Rightarrow \\
\quad \exists r \in \mathrm{D}_{\mathrm{st}}[D(w)(r)<D(w)(q) \wedge \llbracket \text { have to } \rrbracket(\llbracket \mathrm{gc} \rrbracket)(w)(r)] \rrbracket
\end{aligned}
$$

This implicature states that there exists a proposition, whose possibility degree is less than or equal to the degree of $\llbracket n e \rrbracket$ and is necessary for getting good cheese. According to (19), this

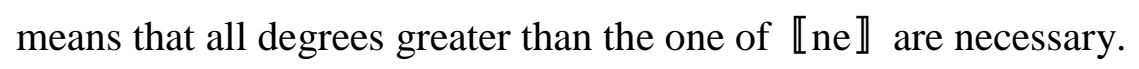


Finally, we combine this implicature with the meaning of (1) and we derive the expected results: that the degree of going to the North End is sufficient for getting good cheese and that it is the lowest degree which is necessary for getting good cheese.

However, we still haven't derived the fact, that going to the North End itself is sufficient for getting good cheese. We assume that the sufficiency inference is also a result of pragmatic strengthening: if the speaker had known that going to the North End is not sufficient, he would have chosen another alternative with the same degree of possibility to make a relevant statement. So the sufficiency can be considered a conversational implicature - according to the maxim:

\section{(28) Be relevant!}

\section{Polarity}

In this section we are going to discuss two issues related to the polarity sensitivity of only and except: the ambiguity of the 'only have to' sentences and the restriction of scalar only and except to positive and negative contexts respectively.

\subsection{Ambiguity}

If we look at different examples of 'only have to' sentences, we can find some that can be interpreted in different ways depending on what kind of alternatives they are associated with. Consider the following sentence:

(29) You only have to take four eggs in order to bake this cake.

On one of its readings (29) implies that you don't need more than four eggs to bake the cake. However, it can also mean - in a less natural scenario - that you can make the cake out of four eggs. In other words, in the first case the alternatives are of the form you take $\mathrm{x}$ eggs and therefore any two of them can be compared to each other. In the second case, we seem to build alternatives by taking various ingredients and combinations thereof: you take a cup of milk, you take four eggs and $500 \mathrm{~g}$ of flour, etc. Here a total ordering of the alternatives is impossible. Schematically, we can represent these two cases in the following way:

(30) Possible orderings of alternatives:
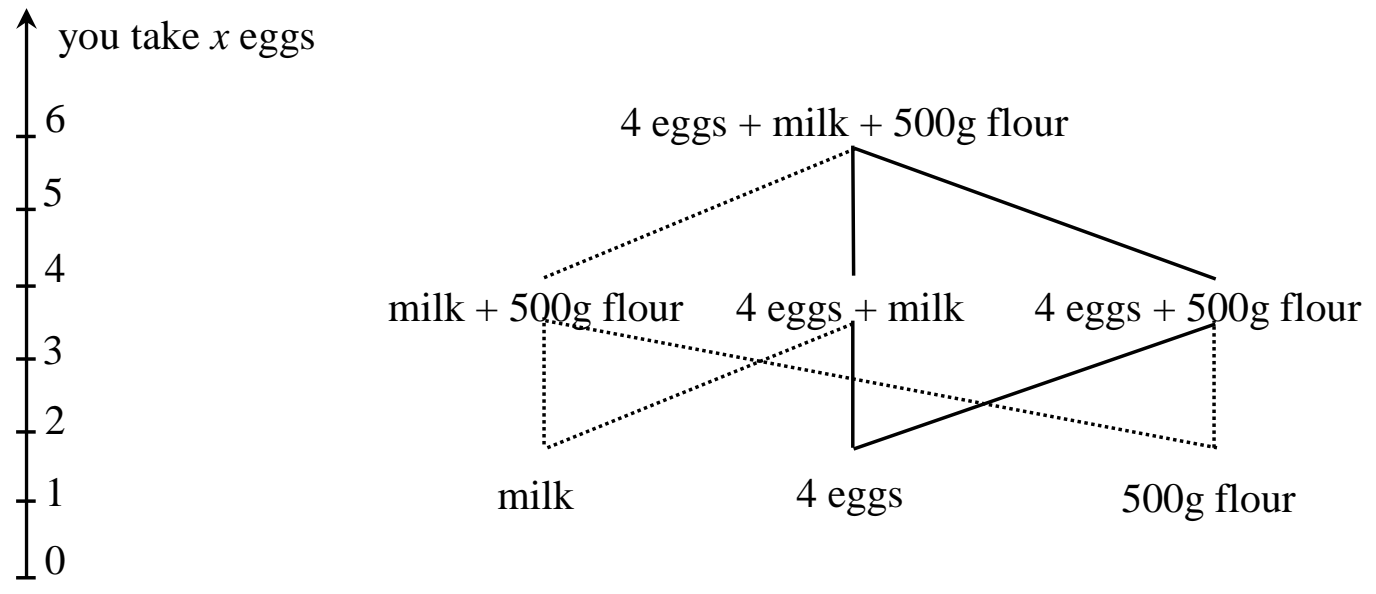

a) total order based on

b) partial order based on comparative possibility logical implication

In (30a) we have a situation, which can be dealt with using the semantics for only we presented above, i.e. it is more possible that you take three eggs than four eggs in a given state 
of affairs. On the contrary, in (30b) it is not immediately clear how to derive the comparative possibility order, required by the 'scalar' only analysis.

The implication-based case is usually difficult to come up with. For our initial sentence (1) for example, we would need a scenario with the following alternatives:

(31) you go to the North End and find the Italian shop;

you go to the North End and call your Italian friend;

you go to the North End, find the Italian shop and call your Italian friend

Another observation is that under negation we seem to always choose the implicature-based readings. Compare (32a) and (32b):

(32) You don't only have to take four eggs to bake this cake...

a) ...you need to take four eggs and a cup of milk.

b) \#...you need to take five eggs.

This suggests that the 'scalar' only is polarity sensitive, akin to its counterpart except, with the difference that it requires a positive licensing environment.

\subsection{Deriving Polarity}

To account for the absence of the scalar reading of only under negation and the restriction that except can only occur in the scope of negation, we treat only and except as a PPI and an NPI respectively, drawing on (Condoravdi 2002)'s analysis of until $P^{P}$ erst. We give a pragmatic explanation for their polarity sensitivity, in the spirit of (Krifka 1995)'s analysis of weak NPIs.

Let us consider the negated version of (1):

(33) You don't only have to go to the North End to get good cheese.

Applying our analysis to this sentence gives us the following truth conditions:

(34) A: $\lambda w . \exists q \in \mathrm{D}_{\text {st }}[D(w)(q)<D(w)(\llbracket$ you go to the North End $\rrbracket) \wedge$

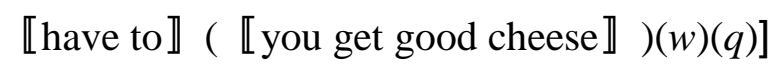

P: $\lambda w . \exists r \in \mathrm{D}_{\text {st }}[\llbracket$ have to $\rrbracket(\llbracket$ you get good cheese $\rrbracket)(w)(r)]$

This leads to a reversal of the informativeness order over alternative assertions:

$$
\begin{aligned}
& \lambda w . \exists q \in \mathrm{D}_{\text {st }}[D(w)(q)<D(w)(\llbracket \text { it } \rrbracket) \wedge \llbracket \text { have to } \rrbracket(\llbracket \mathrm{gc} \rrbracket)(w)(q)] \subseteq \\
& \lambda w . \exists q \in \mathrm{D}_{\text {st }}[D(w)(q)<D(w)(\llbracket \text { ne } \rrbracket) \wedge \llbracket \text { have to } \rrbracket(\llbracket \mathrm{gc} \rrbracket)(w)(q)] \subseteq \\
& \lambda w . \exists q \in \mathrm{D}_{\text {st }}[D(w)(q)<D(w)(\llbracket \mathrm{ns} \rrbracket) \wedge \llbracket \text { have to } \rrbracket(\llbracket \mathrm{gc} \rrbracket)(w)(q)]
\end{aligned}
$$

If we again follow the strategy of pragmatic strengthening, we will derive the following implicature:

$$
\begin{aligned}
\lambda w . \forall q \in \mathrm{D}_{\mathrm{st}}[D(w)(q)>D(w)(\llbracket \mathrm{ne} \rrbracket) \Rightarrow \\
\nexists g r \in \mathrm{D}_{\mathrm{st}}[D(w)(r)<D(w)(q) \wedge \llbracket \text { have to } \rrbracket(\llbracket \mathrm{gc} \rrbracket)(w)(r)] \rrbracket
\end{aligned}
$$

We can now prove that adding (36) to the assertion in (34) leads to a contradiction.

Assume that the truth conditions are satisfied in world $w$. Therefore, there is at least one proposition that is higher on the scale than $\llbracket n e \rrbracket$ and is necessary, say $r$ :




From the fact that we use a dense scale it follows that:

$$
\forall p \in \mathrm{D}_{\text {st }}\left[\exists q \in \mathrm{D}_{\text {st }}[D(w)(p)<D(w)(q)<D(w)(\llbracket \text { you go to the North End } \rrbracket)]\right.
$$

From (37) and (38) it follows that:

$$
\begin{aligned}
& \exists p \in \mathrm{D}_{\text {st }}[D(w)(p)<D(w)(\llbracket \text { you go to the North End } \rrbracket) \wedge \\
& \left.\exists q \in \mathrm{D}_{\text {st }}[D(w)(q)<D(w)(p) \wedge \llbracket \text { have to } \rrbracket(\llbracket \mathrm{gc} \rrbracket)(w)(q)]\right]
\end{aligned}
$$

This, however, contradicts the implicature in (36). Therefore, it is impossible to satisfy both the truth conditions and the implicature.

To sum up, the scalar interpretation of only is limited to positive contexts because of the conflict that arises during the process of pragmatic strengthening of the negated sentences. The same holds for the positive sentences with except, rendering it an NPI.

\section{Other Modals with Only}

Our analysis predicts that only can take different modals as its arguments. However, only very few modals can participate in the SMC. With respect to the universal modals in particular, the paradigm for English looks as follows:

(40) a) To get good cheese you only need to go to the North End.

b) \#To get good cheese you only must go to the North End.

c) \#To get good cheese you only should go to the North End.

(von Fintel and Iatridou 2005) offer a very neat generalisation for the pattern in (40): a universal modal can participate in SMC if it scopes under negation. Whatever is responsible for the behaviour of modals with respect to negation, if it is not based on purely structural considerations, then (von Fintel and Iatridou 2005)'s generalisation is compatible with our analysis of only, as the modal ends up in the scope of semantic negation.

As far as existential modals are concerned, an SMC with an embedded can is grammatical:

(41) You can only take your wife to Italy to make her happy.

It seems that a scalar interpretation is not available here. (41) merely states that taking your wife to Italy is the only way to make her happy. This interpretation can be derived if we use the implication-based version of only, but we will not pursue this here. We restrict ourselves to explaining why can cannot be selected by the 'scalar' only.

Let us see what would happen if we embedded can under the 'scalar' only. We would have the following LF:

(42) $((\llbracket$ only $\rrbracket(D))(\llbracket n e \rrbracket))(\llbracket c a n \rrbracket(\llbracket g c \rrbracket))$

If we adopt standard semantics for can, the LF in (42) will be interpreted as: "Any proposition $q$ that is less possible than going to the North End in a world $w$ is not compatible with getting good cheese in $w . "$ Formally:

(43) $\lambda w . \forall q \in \mathrm{D}_{\text {st }}[D(w)(q)<D(w)(\llbracket$ you go to the North End $\rrbracket) \Rightarrow$

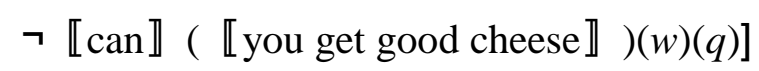

Here we can again construct alternative assertions and, due to the monotonicity of the universal quantifier, order them according to their informational strength: 
(44) $\lambda w . \forall q \in \mathrm{D}_{\mathrm{st}}[D(w)(q)<D(w)(\llbracket \mathrm{ns} \rrbracket) \Rightarrow \neg \llbracket \mathrm{can} \rrbracket(\llbracket \mathrm{gc} \rrbracket)(w)(q)] \subseteq$

$$
\begin{aligned}
& \lambda w . \forall q \in \mathrm{D}_{\mathrm{st}}[D(w)(q)<D(w)(\llbracket \mathrm{ne} \rrbracket) \Rightarrow \neg \llbracket \mathrm{can} \rrbracket(\llbracket \mathrm{gc} \rrbracket)(w)(q)] \subseteq \\
& \lambda w . \forall q \in \mathrm{D}_{\mathrm{st}}[D(w)(q)<D(w)(\llbracket \mathrm{it} \rrbracket) \Rightarrow \neg \llbracket \mathrm{can} \rrbracket(\llbracket \mathrm{gc} \rrbracket)(w)(q)]
\end{aligned}
$$

If we proceed with standard pragmatic strengthening by negating the informationally stronger alternative assertions, we derive the following implicature:

(45) $\lambda w . \forall q \in \mathrm{D}_{\mathrm{st}}[D(w)(q)>D(w)(\llbracket \mathrm{ne} \rrbracket) \Rightarrow$

$$
\left.\exists r \in \mathrm{D}_{\mathrm{st}}[D(w)(r)<D(w)(q) \wedge \llbracket \mathrm{can} \rrbracket(\llbracket \mathrm{gc} \rrbracket)(w)(r)]\right]
$$

This, together with the assertion in (43), implies that going to the North End is compatible with getting good cheese, as the reader can verify, i.e.

(46) $\lambda w . \llbracket \mathrm{can} \rrbracket(\llbracket \mathrm{gc} \rrbracket)(w)(\llbracket \mathrm{ne} \rrbracket)$

We will assume that logically stronger propositions correspond to lower possibility degrees, as stated in (47):

(47) $\forall p, q, w[(p(w) \Rightarrow q(w)) \Rightarrow(D(w)(p)<D(w)(q))]$

This assumption lets us derive (48) from (43):

(48) $\lambda w . \forall q \in \mathrm{D}_{\mathrm{st}}[(q(w) \Rightarrow \llbracket \mathrm{ne} \rrbracket(w)) \Rightarrow \neg \llbracket \mathrm{can} \rrbracket(\llbracket \mathrm{gc} \rrbracket)(w)(q)] \Leftrightarrow$ $\lambda w . \nexists q \in \mathrm{D}_{\mathrm{st}}[(q(w) \Rightarrow \llbracket \mathrm{ne} \rrbracket(w)) \wedge \llbracket \mathrm{can} \rrbracket(\llbracket \mathrm{gc} \rrbracket)(w)(q)]$

On the other hand, (46) is equivalent to:

(49) $\lambda w . \exists q \in \mathrm{D}_{\mathrm{st}}[(q(w) \Rightarrow \llbracket \mathrm{ne} \rrbracket(w)) \wedge(q(w) \Rightarrow \llbracket \mathrm{gc} \rrbracket(w))]$

(50) $\lambda w . \exists q \in \mathrm{D}_{\mathrm{st}}[(q(w) \Rightarrow \llbracket \mathrm{ne} \rrbracket(w)) \wedge \llbracket \mathrm{can} \rrbracket(\llbracket \mathrm{gc} \rrbracket)(w)(q)]$

From (49) we derive (50), which obviously contradicts (48). Thus, we have shown that embedding can under 'scalar' only leads to a contradiction after the computation of the scalar implicature.

\section{Conclusions}

Under the scalar analysis of only in SMC, the Prejacent Problem does not arise as a consequence of the use of a weak presupposition. At the same time, by utilising the scalar behaviour of necessity and sufficiency relations, we can derive the desired sufficiency inference in the form of sufficiency between a degree and a proposition, strengthened by a conversational implicature.

The oddity of "only have to" sentences in scenarios with easier ways for achieving the goal is explained as a scalar implicature violation.

Scalarity is also responsible for the negative/positive polarity of except and only, respectively.

It remains an open issue how to explain the restrictions on the modals that can be embedded under only. So far we have shown that the use of can leads to inconsistency. 


\section{Acknowledgments}

We are very grateful to our colleagues and teachers at the SfS, especially Arnim von Stechow, Doris Penka and Hedde Zeijlstra, for the instructive discussions and the support. Special thanks go to Magdalena Schwager for her critical and helpful comments. We also thank the participants of SuB 10 (Berlin, October 2005) and the 15th Amsterdam Colloquium (Amsterdam, December 2005) for the discussion.

\section{References}

Bech, G.: 1955/57, Studien über das deutsche verbum infinitum, Det Kongelige Danske Akademie av Videnskaberne, København.

Condoravdi, C.: 2002, Punctual 'Until' as a Scalar NPI, in S. Inkelas and K. Hanson (eds.), The Nature of the Word, MIT Press, Cambridge, Mass.

von Fintel, K. and Iatridou, S.: 2005, Anatomy of a Modal, MIT.

Horn, L.: 1996, Exclusive Company: Only and the Dynamics of Vertical Inference, Journal of Semantics, vol. 13(1): pp 1-40.

Huitink, J.: 2005, Analyzing Anankastic Conditionals and Sufficiency Modals, presented at SOLE 13.

Krifka, M.: 1995, The Semantics and Pragmatics of Polarity Items, Linguistic Analysis, vol. 25: pp 209-58.

Lewis, D.: 1973, Counterfactuals, Basil Blackwell, Oxford. 


\title{
FunCTIONS OF ENGLiSh Man*
}

\author{
Eric McCready \\ Osaka University/Aoyama Gakuin University \\ mccready@lang.osaka-u.ac.jp
}

\begin{abstract}
This paper discusses the semantics of the English particle man. It is shown that this particle does different things when used sentence-initially and sentence-finally. The sentenceinitial use is further shown to separate into two distinct intonational types with different semantic content. A formal semantics is proposed for these types.
\end{abstract}

Particles are usually taken to mark the pragmatic status of the information conveyed by a sentence; for instance, the German particle ja has been analyzed as marking hearer-old information, an idea which has been discussed in various frameworks (cf. Kratzer 1999, Zeevat 2003, Kaufmann 2004, Potts 2005). This paper shows that particles can have purely semantic effects as well, and in some cases even show locality effects in modification. The particular particle I consider here is English man. This particle can appear both sentence-initially and sentencefinally. In what follows I will call the sentence in which man appears the host sentence of the particle.

(1) Sentence-initial: Man, I know that.

(2) Sentence-final: I know that, man.

In this paper I will concentrate on sentence-initial man, mostly for reasons of space: since the particle shows quite different semantic and pragmatic effects in sentence-initial and sentencefinal position, it is difficult to give a full picture of both in a brief paper. I will, however, provide data that shows the two are distinct, in section 1. I will then move, in section 2, to providing data relating to the semantics of sentence-initial man that gives a picture of the semantics of the particle. A formalization of this picture, or at least steps toward such a formalization, will be provided in section 3. Section 4 summarizes and discusses how man compares with other particles in English, and with similar particles in other languages.

\section{Differences between the 'men'}

Here I will discuss some characteristcs of sentence-final man that serve to distinguish it from its sentence-initial counterpart. The end of the section will briefly discuss one way in which it can be formalized.

The first thing to note is that man, when used sentence-finally, produces a sense of insistence. In the imperative sentences in (3a), for instance, the speaker seems relatively neutral about how he guesses the hearer will react to his instruction, where in $(3 \mathrm{~b})$, he seems to anticipate that the hearer will resist carrying out the commanded action. Intuitively, man here makes the command stronger.

${ }^{*}$ I would like to thank Nicholas Asher, Rajesh Bhatt, Hans Kamp, Bernhard Schwarz, and audiences at SuB 10 and CSSP 2005 for helpful comments and discussion. 

(3) a. Go buy some beer.
b. Go buy some beer, man.

When testing this claim, it is important that the intonation of the two examples be kept as constant as possible 1$]$ There is a tendency to increase the range of pitch variations in $(3 \mathrm{~b})$, probably because man is associated with informal speech. This should be avoided because pitch variation of this sort usually marks emotion. Thus, when stress is increased or pitch peaks made higher, a sense of insistence appears anyway, so the point at issue is not resolved. Even when intonation is kept constant, however, the sense of insistence remains.

This situation is not limited to imperatives. In declaratives also, sentence-final man seems to try to force acceptance on the hearer, as shown by the following minimal pairs.

(4) a. You don't need that.

b. You don't need that, man.

(insistent/pushy)

(5) a. John came to the party.

b. John came to the party, man. (assumes doubt on part of hearer)

The situation can be clarified further by considering dialogues like the following. Here speaker A makes a statement which is contradicted by speaker B. Speaker A then repeats her first statement in hopes of getting speaker B to accept it. In this last utterance, it seems to me, use of man is much more natural than not. The same goal could also have been accomplished by use of emphatic focus in the second sentence; the second utterance by A seems odd with neither the particle nor any kind of special focus, as if A didn't care whether B accepted her statement, despite having taken the trouble to repeat it.

(6) a. A: John came to the party.

b. B: No he didn't.

c. A: John came to the party, man.

Another property of sentence-final man is perhaps its most puzzling in view of the previous discussion, which makes it look very much like it has a purely pragmatic function: It licenses modal subordination ${ }^{2}$ Modal subordination is a discourse phenomenon in which an anaphoric expression is dependent for its meaning on an antecedent which is in an ordinarily inaccessible position. As the name suggests, this position is canonically in the scope of a modal, as in the examples in (7), modelled after examples by Roberts (1989).

(7) a. A wolf might come in. \# It is big and hairy.

b. A wolf might come in. It would be big and hairy.

In English licensing of modal subordination by sentence-final man requires futurate will, probably for tense reasons; but will by itself clearly does not license modal subordination without the particle.

(8) a. A wolf might walk in. ? It will eat you first.

\footnotetext{
${ }^{1}$ Since the particle adds an extra syllable, intonation will of course change to some degree, however.

${ }^{2}$ See Siegel (2002) for formal semantic work on the English particle like that shows it also can have an impact on purely semantic content.
} 
b. A wolf might walk in. It will eat you first, man.

McCready (2005) gives an account of the above facts using SDRT (Asher and Lascarides 2003) and a dynamic modal semantics. The basic idea is that sentence-final man has an underspecified meaning, the realization of which depends on the discourse connection between the man-hosting sentence and its attachment point in previous discourse. In contexts like that in (8b), man receives a modal-like meaning, which does not arise elsewhere; in other contexts man serves to strengthen the assertion (or command), with the effect of forcing the hearer to accept its content.

Such an analysis, however, is not appropriate for sentence-initial man, which has a very different semantics. To see this, note first that while sentence-final man can license modal subordination, sentence-initial man cannot. As the following example shows, the tense of the sentence that hosts the particle does not make a difference here.

(9) A wolf might walk in. \# Man, it eats/ate/will eat you first.

Second, it is not clear that sentence-initial man is associated with any kind of insistence. While (10), which contains a sentence-final occurrence of the particle, expresses a kind of insistence, $(10 \mathrm{p})$ does not when intonation is kept constant. Again, one must take care here not to add new stresses and pitch contrasts.

(10) a. John didn't come to the party, man.

b. Man, John didn't come to the party.

I conclude that a story like that needed for sentence-final man is not right for the sentence-initial counterpart. But what is the right semantics for sentence-initial man? To answer this question, we must look at some more data; this will be the task of the next section.

\section{What does sentence-initial man mean?}

This section will show that sentence-initial man actually does multiple things, and that what exactly it does in a given sentence is dictated in large part by phonology, though in a different way than one might think given the above discussion. I will claim that sentence-initial man expresses both surprise and some emotion with respect to the proposition denoted by the sentence. Further, with the right intonation, it also strengthens the interpretation of some gradable predicate within the host sentence, in much the way that adverbials like very do. Thus, the meaning of the particle is complex; and, at least with one intonational pattern, is also clearly part of the extensional semantic content of the utterance.

First, the emotional content. Sentence-initial man expresses some emotion, positive or negative, about the content of the sentence that hosts it.

(11) Positive

a. Man, I got an A on my calculus test!!

(12) Negative

a. Man, I wrecked my car this morning. 
Exactly what emotion SI man expresses depends on the propositional content of the host sentence. Thus, where (11a) is interpreted as positive because the content is (ordinarily) understood pragmatically as being good-since it's ordinarily good to get good grades in calculus-the emotion expressed in (12a) is negative, since ordinarily wrecking one's car is bad for a variety of reasons. Of course, intonation must be kept constant here as well.

However, the conditioning of the emotion man expresses is not always just based on world knowledge. It can also depend on the speaker. In the following example, for instance, if the sentence is uttered by a rabid Republican supporter, it feels positive, while if it's uttered by someone who leans leftward politically, the hearer interprets man as expressing a negative emotion.

\section{(13) Man, George Bush won again.}

There are still other factors that can influence the interpretation of man. We have seen already that SI man is speaker- and content-dependent. As it turns out, it is also world-dependent:

(14) Man, I just won a million dollars in the lottery!

(15) a. Scenario A: lump sum payment, one-time tax of $40 \%$.

b. Scenario B: payment over 20 years, total tax payout of $120 \%$ after inflation.

On scenario A, the hearer will understand the expressed emotion as positive, and on scenario B, as negative, illustrating that the content also varies depending on the world of evaluation.

Of course, propositions are presumably understood as bad or good in the absence of particles too. One might think that the particle actually doesn't have much to do with this aspect of how the sentence is understood. But this is not quite right. What the particle does is make this emotion into a true part of the sentence meaning, by making it overt in the logical form. The emotional content is no longer implicit. Thus, sentence-initial use of man ensures that the hearer understands that the speaker has made the relevant judgement.

Now I would like to introduce intonation into the picture. I will continue, however, to avoid use of the kind of intonation that expresses emotion. Instead, I will focus on how the particle relates phonologically to the rest of the sentence. Sentence-initial man has, as it turns out, two possible intonations. It can be kept separate from the host sentence, forming a separate phonological or intonational phrase $]^{3}$ a use which I will call comma intonation. It can also be phonologically integrated into the rest of the sentence, which I will refer to hereafter as integrated intonation.

Interestingly, there are restrictions on which of these intonational patterns can be used with certain host sentences. Some host sentences, like (16a), are good with both comma and integrated intonation, though the meaning is different, as discussed in detail below. Some sentences, however, like (16b), are good with comma intonation only. There do not seem to be sentences which require integrated intonation, again for reasons that will become clear in the ensuing discussion.

(16) a. Man, this water is hot!

(comma or integrated)

b. Man, John came to the party last night.

(comma only)

To clarify the picture it is useful to look at some more data.

\footnotetext{
${ }^{3}$ I don't want to take a position here about the phrasal status of the particle in terms of phonology. The terms 'phonological phrase' and 'intonational phrase' here are purely descriptive.
} 
(17) OK with both intonational patterns:
a. Man, it's hot.
b. Man, that's a cool shirt.

(18) Bad with integrated intonation:

a. Man, over 70,000 people were killed by the tsunami in Asia.

b. Man, George Bush was reelected.

What do these examples have in common? The host sentences in (17) all express the speaker's judgement in the sense that they involve gradable predicates. In contrast, the host sentences in (18) do not include gradable predicates: they simply describe past events. Based on these and similar examples, the right generalization seems to be that man can be intonationally integrated only if the host sentence contains a gradable predicate. In this case, what is expressed by the particle is that the gradable predicate holds to a high degree: for instance, Man, it's hot with integrated intonation means something roughly similar to Man, it's really hot with comma intonation. From this we should conclude that man has two distinct semantic contents, one which appears when it is used with integrated intonation and one which appears when it is phonologically separate.

It is easy, however, to find examples that look problematic for the generalization just stated. For instance, the following examples describe past events and are not obviously gradable (when compared to predicates like long or red, at least); nonetheless, integrated intonation is fine with them.

(19) a. Man, we drank beer last night.

b. Man, George Bush won the election.

However, when one considers the interpretation of the sentences the generalization can be seen to hold. (19a) means that we drank a lot of beer last night; (19b) means that George Bush really won the election, for instance by a vast margin (meaning that it is literally false). However, these interpretations only arise when man is phonologically integrated with the host sentence. Thus we seem to get coercion of drink beer and win the election into something gradable when integrated intonation is used. Not so when we use comma intonation, however; in this case, the particle merely comments on the fact expressed by the host sentence. Examples like these therefore ultimately support the generalization that integrated man requires a gradable predicate.

Note though that the mere presence of a gradable predicate is not enough. The gradable predicate must retain its 'covert comparative' status, where it measures the degree of the property it denotes against some other salient degree (to anticipate the analysis).

(20) Man, that's the bluest shirt I've ever seen.

(comma only)

Here the use of a superlative precludes degree modification.

There is more to be said about intonation. Sentence-initial man can have at least two distinct tones in isolation, based on analysis using the Macquirer program $4_{4}^{4}$ Each tone can appear with both comma and integrated intonation. Descriptively they are the following.

- A low tone that rises $(\mathrm{R})$.

\footnotetext{
${ }^{4}$ There may be additional possibilities, but I will restrict myself to these two in the present paper.
} 
- A low tone that rises, then falls again (RF).

These two tones are associated with particular semantic content as follows.

- R: surprise

- RF: exasperation (= negative emotion)

These then are the basic lexical semantic phenomena our analysis must account for. I will now turn to giving a formal analysis. We will see later, however, that there are complications that will entail some revision of the first version I will give.

\section{Formal semantics}

Nearly everything we will do in this first attempt at a semantics will survive unchanged into the second. I will start out with defining the emotional expression part of man's meaning. I first define a function $E$ from (Kaplanian) contexts to propositions to emotional predicates.

- A context is a tuple $c=\left\langle c_{A}, c_{T}, c_{W}, c_{P}\right\rangle$, where

$c_{A}$ is the agent of $c$,

$c_{T}$ is the time of $c$,

$c_{W}$ is the world of $c$,

and $c_{P}$ is the place of $c$.

- $E: c \mapsto \wp(W) \mapsto A$, where $A \in\{$ bad, good $\}$.

Here bad, good are of type $\langle\langle s, t\rangle, t\rangle$ : functions from propositions into truth-values. Thus $E$ maps contexts to functions from propositions into emotion-describing predicates.

We can now take sentence-initial man to be defined as follows, as a first step. What this definition does is to apply an emotion-expressing predicate determined by context and the propositional content of the host sentence to that propositional content.

- $\llbracket m a n]]=\lambda p \cdot[p \wedge E(c)(p)(p)]$

This lexical entry is designed so that $P(\varphi), P$ an emotive particle, entails $\varphi$. The formula $A(\varphi)$ that the particle semantics outputs should be read 'the agent of the utterance context holds the attitude $A$ to $\varphi$ in $w$.'

The next step will be to add surprise to this picture. We can make use of a standard scale of likelihood, as do Guerzoni (2003) and McCready (2004).

- $\varphi>_{L_{c}} \psi$ iff $\Gamma \models \operatorname{Likelihood}(\varphi)>\operatorname{Likelihood}(\psi)$, where $\Gamma$ is a set of contextually relevant facts in $c$.

In words, $\varphi$ is more likely than $\psi$ in a context $c$ iff, given a contextually relevant set of facts, the likelihood of $\varphi$ is greater than that of $\psi$.

Recall that R(ising) intonation was associated with an expression of surprise. We can express this surprise in the following way, given the scale of likelihood defined immediately above. Here $C$ is a contextually determined set with respect to which the likelihood of $p$ is evaluated.

- $\llbracket R]]=\lambda p \cdot\left[\operatorname{MOST}_{q}(q \in C \wedge q \neq p)\left(q>_{L_{c}} p\right)\right]$ 
In words, the proposition $p$ is less likely than most other propositions in some contextually determined set: that is, of all possibilities that are comparable to $p, p$ was the least likely one to happen 5

This formula is of type $\langle\langle s, t\rangle, t\rangle$, similar to sentence-initial man. I therefore assume that it combines with the particle via functional composition, yielding

- $\left.\left.\llbracket \operatorname{man}_{R}\right]\right]=\lambda p \cdot\left[p \wedge E(c)(p)(p) \wedge \operatorname{MOST}_{q}(q \in C \wedge q \neq p)\left(q>_{L_{c}} p\right)\right]$

Given this, the semantics of (21) will be as in (21), which is as desired.

(21) a. Man, it's raining outside.

b. $\quad$ raining $(w, t) \wedge E(c)($ raining $(w, t))(\operatorname{raining}(w, t))$

$\wedge \operatorname{MOST}_{q}(q \in C \wedge q \neq \operatorname{raining}(w, t))\left(q>_{L_{c}} \operatorname{raining}(w, t)\right)$

That is, it is raining, the speaker holds some attitude, good or bad, toward that fact, and it was unlikely that it would rain (according to the speaker at least).

There is one more type of intonation to deal with: rising-falling intonation. Recall that this tone indicates a kind of exasperation. I will assume that this amounts to a simple indication that the speaker takes the propositional content of the host sentence to be negative.

- $[R F]]=\lambda p \cdot[\operatorname{bad}(p)]$

Combined with the semantic frame for the particles, this will yield the following:

- $\left.\left[\operatorname{man}_{R F}\right]\right]=\lambda p \cdot[p \wedge E(c)(p)(p) \wedge \mathbf{b a d}(p)]$

This semantics yields a prediction about what sorts of sentences are compatible with risingfalling intonation. Specifically, it predicts that if $E$ returns a positive emotion wrt a given sentence, it should be incompatible with RF intonation (on the natural assumption that it is incoherent for a speaker to simultaneously hold positive and negative attitudes toward a single proposition). This seems to be right. Since being rich can be assumed to (ordinarily) be a positive trait, $E$ will return good when applied to the sentence I' $m$ rich, yielding an incoherent result when rising-falling intonation is used. And, indeed, sentences like (22) are rather unnatural.

(22) \# Man, I'm rich!

$\mathrm{RF}$
a. $\quad[22 a)]]=$
$\operatorname{rich}(i) \wedge E(c)(\operatorname{rich}(i))(\operatorname{rich}(i)) \wedge \mathbf{b a d}(\operatorname{rich}(i))$
b. $\quad[22 a)]]=$
$\operatorname{rich}(i) \wedge \operatorname{good}(\operatorname{rich}(i)) \wedge \operatorname{bad}(\operatorname{rich}(i))$

The above picture seems right for man in its phonologically separate form. However, integrated intonation must be different, for it involves a notion of comparison. Further, this notion is not derivable (as far as I can see) from any of the above semantics. We thus must take the particle to be ambiguous. I turn my attention now to formulating the semantics of the integrated form.

\footnotetext{
${ }^{5}$ There are subtle issues here that relate to the evaluation time of likelihood. Certainly once something happens it is no longer unlikely that it happened; still, it perhaps was unlikely that it would happen before it did. I will ignore this complication in this paper.
} 
In order to talk formally about degrees to which properties hold, I want to introduce some notions from the semantics of gradable adjectives and comparatives. Here I'll assume a scalar theory of such adjectives (Kennedy 1999) on which they denote relations between individuals and degrees, which are a kind of measure of the extent to which a property is held. According to this theory, the logical form of a sentence with an adjectival predicate in the absolutive construction $\sqrt[6]{6}$ like that in (24), is as shown below in simplified form.

(24) This salsa is hot.

$$
\llbracket[24]]=\operatorname{hot}(\text { this_salsa })\left(d_{s}\right)
$$

In this formula, $d_{s}$ refers to a degree which comprises the 'standard' for the property in question, here hotness; $d_{s}$ thus denotes the degree of spiciness above which a taste can be truly stated to be spicy. In this particular instance, $d_{s}$ is contextually determined. The first argument of hot, this_salsa, here denotes an individual. degree. In the model theory, degrees are treated as points in a scale, modelled as a (dense) partial order. Each gradable predicate is associated with a scale. Whether a predicate applies truly to a particular individual depends on the position of the degree associated with that individual on the scale. Kennedy assumes a function $\delta$ that maps individuals to the degree associated with them; $\delta$ is relativized to predicates, so there are actually a family of $\delta$ functions, one for each predicate: $\delta_{\text {spicy }}, \delta_{\text {tall }}$, and so on..$^{7} \delta$ maps the individual argument to a point on the scale: in the present case, it maps the salsa to the degree of spiciness that the salsa has. If the degree associated with an individual $x, \delta_{P}(x)$, is greater than the standard $d_{s}$ (i.e. if $\delta(x) \geq d_{s}$ ), then $P(x)$ is true.

Given this background, we can think about the contribution of sentence-initial man with integrated intonation. In (26), the particle indicates that the salsa is spicy to a high degree.

(26) Man, this salsa is spicy.

We can understand this as meaning that the degree of its spiciness is greater than the degree of spiciness of most other spicy things; in this sense, it can be said to raise the standard of comparison (cf. (Klein 1980) on very).

$$
\operatorname{spicy}(\text { this_salsa })\left(d_{s}\right) \wedge \operatorname{most}_{y}\left(\operatorname{spicy}(y)\left(d_{s}\right)\right)\left(\delta_{\text {spicy }}(y) \ll \delta_{\text {spicy }}(\text { this_salsa })\right)
$$

Abstracting, we get the following: $x$ the individual denoted by the subject, $S$ the gradable property ('spicy'), $P$ a restrictor ('salsa').

$$
\lambda x \cdot\left[\lambda P .\left[\lambda S .\left[P(x) \wedge S(x)\left(d_{s}\right) \wedge \operatorname{most}_{y}\left(S(y)\left(d_{s}\right) \wedge x \neq y\right)\left(\delta_{S}(y) \ll \delta_{S}(x)\right)\right]\right]\right]
$$

Note that it is in no way straightforward to make this work out compositionally, since the particle is located at the left edge of the clause and has no access to the meaning constructors corresponding to the gradable property or the subject. Thus, if we want to adopt this semantics, we have to make assumptions about the combinatorics, such as raising the various elements or abstracting away from the tree as is done in, for instance, glue semantics (Dalrymple, Lamping, Pereira and Saraswat 1997).

We also must add the emotional content previously discussed to the reprsentation in (28). I will ignore the contribution of intonation for now, but note that in order to add it we also must assume that intonation is associated with a polymorphic type or that it is straightforwardly type-shifted, which seems anyway to be a natural move.

\footnotetext{
${ }^{6}$ Absolutive constructions are those in which a statement is made about the applicability of some gradable adjective to an individual. This construction should be set against e.g. comparatives, in which the applicability of the adjective is stated with reference to other individuals.

${ }^{7}$ For some predicates, these scales may be identical, however.
} 
(29) Integrated particles (minus tone):

a. $\quad\left[\left[\operatorname{man}_{i}\right]\right]=\lambda x \cdot\left[\lambda P .\left[\lambda S .\left[P(x) \wedge S(x)\left(d_{s}\right) \wedge \operatorname{most}_{y}\left(S(y)\left(d_{s}\right) \wedge x \neq y\right)\left(\delta_{S}(y) \ll \delta_{S}(x)\right) \wedge\right.\right.\right.$ $E(c)\left(S(x)\left(d_{s}\right) \wedge \operatorname{most}_{y}\left(S(y)\left(d_{s}\right) \wedge x \neq y\right)\left(\delta_{S}(y) \ll \delta_{S}(x)\right)\right)\left(S(x)\left(d_{s}\right) \wedge \operatorname{most}_{y}\left(S(y)\left(d_{s}\right) \wedge\right.\right.$ $\left.\left.\left.\left.x \neq y)\left(\delta_{S}(y) \ll \delta_{S}(x)\right)\right)\right]\right]\right]$

Very messy, but this seems to be what we need if we are going to go with this sort of account.

But, in fact, this account does not seem to be quite the right way to go (though the pieces are all more or less correct). We can see this by looking at some more data. The way the semantics is set up now, there are no restrictions put on what predicate the particle modifies. This is too permissive, as we will now see.

So far we have worked with VP predicates. Object-internal predicates are also possible (in predicative positions).

(30) Man, this is spicy salsa.

One then wonders whether gradable predicates in any position can serve as input to the particle. The answer is a definite no.

Sentence-initial man cannot modify gradable predicates within embedded sentences (thanks here to Bernhard Schwarz).

(31) a. Man, John thinks Bill ate some spicy salsa.

b. Man, Jimmy knows Fred has a beautiful girlfriend.

c. Man, it's too bad this data is so complicated.

Here, the particle can only modify the 'embedders'-think, know, be too bad. The gradable predicates in the complements of these verbs are not available at all.

These restrictions suggest that a semantics for the particles like the one proposed above, on which no (non-stipulative) restrictions are put on what the particle modifies, cannot be correct. I want now to explore an alternative that preserves the insights of the above while avoiding (I think) most of its problems..$^{8}$

The idea is that, rather than pulling out all the elements of the sentence and modifying them separately, the particle modifies rather a set of degrees. In order for this to work, it is necessary to modify the semantics given above, changing it to an object of type $\langle\langle d,\langle s, t\rangle\rangle,\langle s, t\rangle\rangle$, i.e. to a function that maps functions from sets of degrees to propositions, to propositions. Effectively we need the semantics of a modifier which however changes the type of its argument. This can be given as follows.

$$
\begin{aligned}
& \text { - } \lambda D_{\langle d,\langle s, t\rangle\rangle}^{\wedge} \exists d\left[D ( d ) \wedge \text { most } _ { d ^ { \prime } } ( D ( d ^ { \prime } ) \wedge d \neq d ^ { \prime } ) ( d ^ { \prime } \ll _ { S ( D ) } d ) \wedge E \left(D ( d ) \wedge \text { most } _ { d ^ { \prime } } \left(D\left(d^{\prime}\right) \wedge d \neq\right.\right.\right. \\
& \left.\left.\left.d^{\prime}\right)\left(d^{\prime} \ll_{S(D)} d\right)\right)\left(D(d) \wedge \text { most }_{d^{\prime}}\left(D\left(d^{\prime}\right) \wedge d \neq d^{\prime}\right)\left(d^{\prime} \ll_{S(D)} d\right)\right)\right]
\end{aligned}
$$

Note that this semantics in effect presupposes that a gradable predicate is contained in its argument, for if it is not, the expression will be undefined.

This semantics preserves the intuitions of what we had before, but is stated in a form that does not require the complicated combinatorics that the previous version did. Further, it allows us to derive the restriction on what gradable predicate the particle can modify, with a single stipulation. We must assume that an operation of existential closure of degree arguments takes

\footnotetext{
${ }^{8}$ I want to thank Hans Kamp (p.c.) for suggesting this line of attack.
} 
place at a node earlier than that at which modification by man happens. What exactly this node may be is open to question, because there is what looks at first glance like conflicting evidence about the exact syntactic position of man. Two likely candidates are Spec of CP and Spec of IP. Support for the first is provided by examples like these.

(32) a. Man, what did you buy?

b. Man, if you do that, what do you think is going to happen?

c. If you do that, man, then there's going to be some trouble.

Here man clearly precedes elements in C: the WH-element what and the conditionalizer if. Note however that all of these examples involve a comma intonation on the particle. Integrated intonation is not possible here. It is also possible to find what looks like evidence that man is in Spec of IP, as in the following example, in which the particle follows then, which is in C. This example, conversely, does not allow comma intonation; only integrated intonation is possible.

(33) If he comes tonight, then man there is going to be some trouble.

I conclude that there are two distinct positions for the particle. When it has comma intonation, it appears in Spec of CP; when it has integrated intonation, it appears in Spec of IP..$^{9}$

Now, given that integrated man performs its modification at IP and existential closure of degrees takes place at CP (if needed), it makes sense that gradable predicates in embedded clauses are not available for modification: the degree argument associated with them has been closed off, and is no longer visible to particles in the higher clause. The same holds for superlatives like (20); again, the degree argument is existentially closed, and cannot be modified. In fact we have a type mismatch. The two cases are as follows (with somewhat schematic syntax).

(34) Good case:



(35) Bad case:

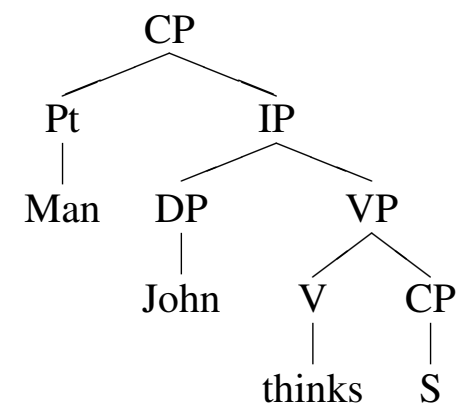

A further prediction of the analysis is that gradable predicates in relative clauses are not available for modification due to the presence of an intervening $\mathrm{CP}$ node. This prediction seems to be correct.

(36) a. Man, John ate a piece of cake that was big.

\footnotetext{
${ }^{9}$ There is a possible issue here in that this analysis seems to allow sentences like What man did you eat such a big piece of cake for?, on the reading where man modifies the predicate big, since man is in Spec of IP. I think there must be additional syntactic reasons for this. For now, I will put it aside.
} 
b. Man, John ate some salsa that was spicy.

Man in these sentences can only modify the main verb, not the embedded adjective.

Let me now mention some other restrictions, which I will not however deal with in this paper. Let's start with a consideration of DP-internal predicates. It appears that whether a particular predicate can be modified depends greatly on what the head of the DP is; in particular, it appears that predicates in the scope of indefinites can be modified, and those in the scope of definites cannot. (The examples that follow should all be understood as involving integrated intonation.)

(37) a. Man, John ate some spicy salsa.

b. * Man, John ate the spicy salsa.

In fact, the set of determiners that allow this kind of modification seems to be fairly small. I have manipulated the NP content in these examples to allow for determiners that prefer mass and count nouns.

(38) Possible:

a. Man, John ate a big piece of cake.

b. Man, John ate two big pieces of cake.

(39) Impossible:
a. * Man, John ate many big pieces of cake.
b. * Man, John ate few big pieces of cake.
c. * Man, John ate most big pieces of cake.
d. * Man, John ate all the big pieces of cake.
e. * Man, John ate $\{$ more than/less than $\}$ two big pieces of cake.
f. * Man, John ate every big piece of cake.

All the determiners in (38), as well as some, are indefinite, whereas all the determiners in (39) and also the are definite. Clearly there is a correlation to be found between indefiniteness and the possibility of NP-internal modification. However, it is not clear to me at present exactly how it should be characterized within the present theory, and so I will leave the problem for future work 10

Another interesting issue is that there is some freedom as to what predicate the particles modify. In examples in which there is more than one (potentially) gradable predicate, it seems that either can be modified.

(40) Man, George Bush won a hard election.

Here either the extent of the victory or the hardness of the election can be modified. One has the intuition that intonational prominence on a particular predicate influences which predicate is chosen. Therefore, it might be that focus should play a role in selecting $S$. I cannot resolve this question here, and leave this issue also for the future.

\footnotetext{
${ }^{10} \mathrm{~A}$ first idea is that the function of the predicate is different in the definite DPs than it is in the indefinite ones. Perhaps in definite DPs adjectives work more to pick out a referent than to say something about it, and therefore are not further modifiable. Formally we might say that there is existential quantification over the degree argument at, say DP level in definite but not indefinite DPs. The consequences of this proposal are not completely clear to me at present and so I will leave this as a speculation.
} 


\section{Conclusion}

In this paper I have given a semantic characterization of the behavior of sentence-initial man in English. We have seen that it involves degree modification on one use, and that intonation plays a large role in its meaning. I have left some issues unsettled, but I think the present framework is well suited to handle them 11

There are a number of particles in English and other languages that behave much like man. In English we find dude, boy (\%), girl (\%), G, bro, and many others. Interestingly, there are differences between these particles and man: dude can be used only with independent intonation, and boy only with integrated intonation. The reasons for these differences remain unclear.

(41) a. Man, this water is hot.

(independent or integrated)

b. Dude, this water is hot.

(independent only)

c. Boy, this water is hot.

(integrated only)

In other languages, it is quite common to find particles of this sort. In Japanese, for instance, there are the particles yo and zo (McCready In press), which are semantically similar to sentence-final man. There do not seem to be any particles corresponding to the sentenceinitial use: though there are several which are related to the comma use, none of these can be used with integrated intonation. The same seems to hold true for Spanish guey 'dummy/dude' and tio 'uncle' and French merde 'shit' and putain 'whore'. It may be that the reasons for this lie in independent intonational facts about these languages, but this must be explored further.

\section{References}

Asher, N. and Lascarides, A.: 2003, Logics of Conversation, Cambridge University Press.

Dalrymple, M., Lamping, J., Pereira, F. and Saraswat, V.: 1997, Quantifiers, anaphora and intensionality, Journal of Logic, Language and Information 6, 219-273.

Guerzoni, E.: 2003, Why Even Ask?, PhD thesis, MIT. Draft of July 2003.

Kaufmann, S.: 2004, A modal analysis of expressive meaning: German ja under quantifiers. Handout of talk presented at Kobe Shoin.

Kennedy, C.: 1999, Projecting the Adjective, Garland. 1997 UCSC dissertation.

Klein, E.: 1980, A semantics for positive and comparative adjectives, Linguistics and Philosophy 4, 1-45.

Kratzer, A.: 1999, Beyond ouch and oops: How descriptive and expressive meaning interact. Available from Semantics Archive.

McCready, E.: 2004, Two Japanese adverbials and expressive content, Proceedings of SALT $X I V$.

McCready, E.: 2005, The Dynamics of Particles, PhD thesis, UTexas-Austin.

McCready, E.: In press, Japanese yo: Its semantics and pragmatics, Sprache und Datenverarbeitung .

\footnotetext{
${ }^{11}$ It may turn out that a translation into alternative semantics will be needed to deal with the focus facts, though.
} 
Potts, C.: 2005, The Logic of Conventional Implicatures, Oxford University Press. Revised version of 2003 UCSC dissertation.

Roberts, C.: 1989, Modal subordination and pronominal anaphora in discourse, Linguistics and Philosophy 12, 683-721.

Siegel, M.: 2002, Like: the discourse particle and semantics, Journal of Semantics 19, 35-71.

Zeevat, H.: 2003, Particles: presupposition triggers, context markers, or speech act markers, in R. Blutner and H. Zeevat (eds), Optimality Theory and Pragmatics, Palgrave-MacMillan. 


\title{
ON TEMPORALLY BOUNDED QUANTIFICATION OVER EVENTUALITIES
}

\author{
Telmo Móia, \\ Faculdade de Letras da Universidade de Lisboa / ONSET-CEL \\ tmoia@netcabo.pt
}

\begin{abstract}
This paper focuses on different subtypes of constructions involving temporally bounded quantification, e.g. sequences like David visited Rome three times followed by temporal phrases as different as (i) last year, which defines a time interval; (ii) in less that two months, which defines an amount of time; and (iii) per month, which refers to a time unit. As for the first two types of temporal phrases, data will be presented which shows that they have specific linguistic properties in these quantifying contexts, and do not behave exactly as the locating or duration adverbials they are superficially identical with. The third type of phrases will receive special attention. Structures with frequency adverbials like $n$ times per month will be analysed compositionally, separating the quantified component $n$ times from the temporally binding phrase per month (whose role is comparable to that of adverbials (i) and (ii) in the relevant constructions). The data presented is mainly from Portuguese, although the issues at stake - the linguistic properties of temporally bounded quantification - are obviously relevant to parallel constructions in other languages.
\end{abstract}

\section{Introduction}

This paper concentrates on a subclass of temporal constructions with quantification over eventualities, namely those where the quantification is relative to a time parameter - either a time interval, an amount of time, or a time unit -, as in the following examples:

(1) O David visitou Roma três vezes \{o ano passado / em menos de dois meses / por ano\}. "the David visited Rome three times \{ the year past / in less of two months / per year" David visited Rome three times \{last year / in less than two months / per year\}.

The structure of the paper is as follows. In section 2, the analysis will focus only on constructions where the temporal frame for quantification is an interval of the time axis (like e.g. the one expressed by last year). Data from Portuguese will be used to distinguish linguistically these constructions from those where unquantified events are described, like:

(2) O David visitou Roma o ano passado.

"the David visited Rome the year past"

David visited Rome last year.

Still in section 2, a formal semantic characterisation of temporally bounded quantification structures is provided, which evinces the differences between these structures and those expressing simple (inclusive) temporal location, like (2). In section 3, a broader view of temporally bounded quantification is offered, extending it to the wider range of adverbials exemplified in (1). Temporal phrases associated with the expression of pure frequency - like the Portuguese counterparts of English per year - will be analysed in some detail; a compositional analysis of frequency phrases like [n-times per unit-of-time] will be defended, according to which the phrase [per unit-of-time] in those sequences is distinguished, and its role compared to the role of the other types of adverbials exemplified in (1) (as expressions that set time frames for quantification). 


\section{Temporal circumscription of quantification $v s$. temporal location}

\subsection{The distribution of Portuguese desde-adverbials}

In previous work (cf. Móia 2000, 2001), I showed that Portuguese desde-adverbials - as, for that matter, the Spanish, French and Italian counterparts of English since-adverbials - are dependent on the presence of event quantification in the clause to which they apply, namely when telic events are involved ${ }^{1}$. Observe the contrast in grammaticality between the following two sentences, which differ only in the absence or presence of an explicit quantifier over events:

*O David visitou a mãe desde Janeiro.

"the David visited the mother since January"

David has visited his mother since January.

${ }^{\mathrm{OK}} \mathrm{O}$ David visitou a mãe cinco vezes desde Janeiro.

"the David visited the mother five times since January"

David has visited his mother five times since January.

Furthermore, I showed in that work that the relevant licensing quantification (in the matrix clause) need not be explicit quantification over events, via a phrase like $n$ times, as in (4). It may as well be indirect quantification over events (cf. e.g. Krifka 1990, Schein 1993, Eberle 1998), associated with different types of quantification, as illustrated in (6) through (12), below.

(i) distributive quantification over discrete objects

(5) *Este urso morreu no zoo de Lisboa desde Janeiro. "this bear died in-the zoo of Lisbon since January"

This bear has died in the zoo of Lisbon since January.

${ }^{\mathrm{OK}}$ Cinco ursos morreram no zoo de Lisboa desde Janeiro.

"five bears died in-the zoo of Lisbon since January"

Five bears have died in the zoo of Lisbon since January.

${ }^{\mathrm{OK}} \mathrm{O}$ David restaurou o altar da igreja matriz de cinco cidades desde Janeiro ${ }^{2}$.

"the David restored the altar of-the church matrix of five towns since January"

David has restored the altar of the parish church of five towns since January.

(ii) measure quantification over discrete objects or massive entities

${ }^{\mathrm{OK}}$ Oitenta por cento deste edifício foi restaurado desde Janeiro.

"eighty per cent of-this building was restored since January"

Eighty per cent of this building has been restored since January.

\footnotetext{
${ }^{1}$ The combination of Romance counterparts of since-adverbials with descriptions of atelic eventualities is not subject to the same restrictions. When this combination occurs, sentences involve typically a durative - rather than an inclusive - location reading (i.e. the situation is said to hold throughout the whole location interval - cf. e.g. Vlach 1993, Móia 2000):

(i) O David mora em Lisboa desde 1974.

"the David lives in Lisbon since 1974"

David has been living in Lisbon since 1974.

The durative location reading is irrelevant for the issues addressed in this paper and will be ignored henceforth. However, provided the right context, a temporal quantification structure of the type under analysis in this paper is also possible with atelic predicates - cf. (13) below.

${ }^{2}$ Notice that the quantifying element can occur in very deeply embedded positions, as this example shows.
} 
(9) ${ }^{\mathrm{OK}}$ Esta máquina reciclou cinco toneladas de detritos desde Janeiro.

"this machine recycled five tons of wastes since January"

This machine has recycled five tons of waste since January.

(iii) temporal measure quantification over atelic eventualities:

(10) ${ }^{\mathrm{OK}} \mathrm{O}$ David trabalhou neste projecto durante cerca de duzentas horas desde Janeiro.

"the David worked on-this project for around of two-hundred hours since January"

David has worked on this project for about two hundred hours since January.

(iv) quantification via exclusive operators, like só, the Portuguese counterpart of only (whose omission in the following sentence would yield ungrammaticality)

${ }^{\mathrm{OK}} \mathrm{O}$ David só escreveu este artigo desde Janeiro.

"the David only wrote this paper since January"

David has only written this paper since January.

(v) conjunction associated with an implicature of exhaustive enumeration (of the relevant entities), as in the following sentence which is grammatical only under the interpretation where the set of all relevant towns visited during the mentioned period is being listed

${ }^{\mathrm{OK}} \mathrm{O}$ David visitou Londres, Paris e Berlim desde Janeiro.

"the David visited London, Paris and Berlin since January"

David has visited London, Paris and Berlin since January.

Other types of licensing quantification structures, besides these five, have been identified in Móia (2000, 2001), but they will be ignored here, for the sake of simplicity.

The examples above involve a combination of desde-phrases with descriptions of telic events. Similar structures, however, can be obtained with atelic eventualities, if (i) the same type of quantification structure occurs and (ii) the tense of the main verb expresses anteriority to the temporal perspective point (as is the case, for instance, with the "pretérito perfeito simples" or the "pretérito mais-que-perfeito"):

${ }^{\mathrm{OK}}$ O David morou em Lisboa três vezes desde 1974.

"the David lived PERFECTIVE SIMPLE PAST in Lisbon three times since 1974"

David has lived in Lisbon three times since 1974.

The difference between the grammatical and the ungrammatical structures above can be described as follows. Structures that refer to single episodic (telic) events - like (3) or (5) yield ungrammaticality when combined with desde-phrases. Conversely, all grammatical examples with desde-phrases refer to sets of events made up of possibly discontinuous subevents (happening within the time frame set by the adverbial). Furthermore, one may note that ungrammaticality arises whenever - in similar examples - the interpretation of possibly discontinuous events is blocked. This may result from the use of an explicit expression - like the counterpart of all at once, in (14) - or from an inference based on world knowledge - as in (15), with the counterpart of $a$ bomb, but not with the counterpart of a bulldozer.

(14) *Esta máquina reciclou cinco toneladas de detritos de uma só vez desde Janeiro.

"this machine recycled five tons of wastes of one only time since January"

This machine has recycled five tons of waste all at once since January.

(15) a. *Uma bomba destruiu trinta por cento deste edifício desde Janeiro.

"a bomb destroyed thirty per cent of-this building since January"

A bomb has destroyed thirty per cent of this building since January.

b. ${ }^{\mathrm{OK}}$ Um buldózer destruiu trinta por cento deste edifício desde Janeiro.

"a bulldozer destroyed thirty per cent of-this building since January"

A bulldozer has destroyed thirty per cent of this building since January. 
Likewise, it may be observed that group - contrary to distributive - NPs with cardinal quantifiers do not license the use of desde-adverbials, because they are associated with single events rather than with sets of (possibly) distinct events. Thus, the following sentence, with a single-event group reading, is ungrammatical:

$$
\begin{aligned}
& \text { *O David ofereceu este quadro a três amigos desde Janeiro. [group reading] } \\
& \text { "the David offered this painting to three friends since January" } \\
& \text { David has offered the painting to three friends since January. }
\end{aligned}
$$

\subsection{Distinguishing temporal circumscription of quantification from temporal location}

In order to explain the distributional facts observed in section 2.1, I have argued that structures where temporal adverbials are associated with (explicit) quantification over eventualities - like (4), (6)-(12) or (13) above - are of a semantically distinct type from those where temporal adverbials merely provide a frame for locating (non-quantified) eventualities. In sum, two distinct constructions have to be taken into account:

- Temporal circumscription of quantification, or temporally bounded quantification

(full-scanning construction, in Móia 2000)

\section{- Temporal location}

The peculiarity of Portuguese desde-adverbials - or, more generally, of the Romance counterparts of since-adverbials - is that they are particularly sensitive to this distinction: the may define temporal boundaries for quantification, but they may not simply provide a frame for inclusive location ${ }^{3}$. Many other adverbials, however, readily occur in both types of constructions - cf. e.g. em Janeiro ('in January'):
(17)a. ${ }^{\mathrm{OK}} \mathrm{O}$ David visitou a mãe em Janeiro.
"the David visited the mother in January"
[temporal location]
David visited his mother in January.
b. ${ }^{\mathrm{OK}} \mathrm{O}$ David visitou a mãe cinco vezes em Janeiro. [circumscription of quantification] "the David visited the mother five times in January"
David visited his mother five times in January.

Temporal circumscription of quantification can be easily characterised within the framework of Discourse Representation Theory (DRT) defined in Kamp \& Reyle (1993). With regard to the data under analysis, the main point to note is that all the grammatical structures with desde-adverbials above involve abstraction over eventualities contained in the time frame set by the temporal adverbial. See the schematic representation, in the language of DRT, in (18), and the two illustrative DRS-representations - for sentences (4) and (6) - in (4') and (6') right afterwards, where Portuguese lexical items are translated for the sake of simplicity (cf. Móia 2000, for details):

\footnotetext{
${ }^{3}$ However, as said in fn. 1, they may provide a frame for durative location. The common fact between durative location and temporal circumscription of quantification is that, in both cases, the whole interval defined by the temporal adverbial is relevant (and this seems to be the requirement imposed by the Romance counterparts of since-adverbials): in sentences with a durative reading (like (i) in fn. 1), the described atelic eventuality is said to hold at all subintervals of the mentioned interval; in sentences with temporally bounded quantification, a reference is made to the sum of all the events of the mentioned type that occur within the relevant interval (whence, the whole interval has to be taken into account). In Móia (2000), I termed this construction fullscanning (inclusive location) in order to underline this idea (since, metaphorically speaking, it is as if the whole interval is scanned in order to gather the relevant events happening within it).
} 




o David visitou a mãe cinco vezes desde Janeiro (David has visited his mother five times since January)

$(4)^{\prime}$

\begin{tabular}{|c|}
$\mathrm{E}=\Sigma \mathrm{e}:{ }^{[\text {since January }[\mathrm{t}]]}$ \\
$\begin{array}{c}\mathrm{e} \subseteq \mathrm{t} \\
\text { e: David visit his mother }\end{array}$ \\
\hline$|\mathrm{E}|=5$ \\
whence: $[\mathrm{E} \subseteq \mathrm{t}]^{4}$
\end{tabular}

cinco ursos morreram no zoo de Lisboa desde Janeiro (five bears have died in the zoo of Lisbon since January)

$(6)^{\prime}$

\begin{tabular}{|c|c|}
\hline \multirow[b]{2}{*}{$\begin{array}{l}\mathrm{Y}=\Sigma \mathrm{y}: \\
\mathrm{E}=\Sigma \mathrm{e}:\end{array}$} & [since January $[\mathrm{t}]]$ \\
\hline & $\begin{array}{c}\mathrm{e} \subseteq \mathrm{t} \\
\mathrm{bear}(\mathrm{y}) \\
\mathrm{e}: \mathrm{y} \text { die in the zoo of Lisbon }\end{array}$ \\
\hline & $|Y|=5$ \\
\hline
\end{tabular}

The representation in (18) evinces the maximality requirement that distinguishes the structures under consideration. In fact, the relevant sentences refer to sets of events (E), more precisely the set of all subevents $\varepsilon$ that, on the one hand, correspond to the descriptive content in the matrix clause $(\Psi)$ and, on the other hand, happen within the time frame defined by the adverbial (t). This representation also evinces the peculiar role of temporal adverbials in these constructions: as can be seen, although they may appear in relatively high syntactic positions, temporal adverbials act here as true event modifiers, inasmuch as inclusion in the time frame set by them (t) is a defining property of the elements assembled in the sum represented by the main clause $(\mathbf{E})$ (witness the presence of the discourse referent $\mathbf{t}$ inside the sub-DRS!).

Temporal circumscription of quantification has several linguistic properties that set it apart from simple inclusive temporal location. Let us consider an outstanding one, by comparing the English sentences in (19) - which involve simple inclusive temporal location - with those in (20) - which involve temporally bounded quantification :

(19)a. David has visited his mother since January.

b. David visited his mother in January.

c. David offered this painting to (exactly) three friends in May 1995. [group reading]

(20)a. David has visited his mother five times since January.

b. David visited his mother five times in January.

c. David wrote (exactly) three essays in May 1995.

First, let us note that in (19), the events described in the main clause (David's visit to his mother or his offering of the mentioned painting) are defined independently of the locating interval. Differently, in the temporally bounded quantification structures of (20), as was underlined, the interval provided by the adverbial plays a role - as a kind of modifier - in defining the (complex) event represented in the main clause. A direct consequence of this

\footnotetext{
${ }^{4}$ Although these temporal adverbials may locate the complex event $(\mathrm{E})$ as a whole $-[\mathrm{E} \subseteq \mathrm{t}]-$ this function is, as it were, subsidiary, since its primary function is (arguably) to provide the frame for temporal quantification over eventualities $-[\ldots . .[\mathrm{e} \subseteq \mathbf{t}] \ldots]$ (cf. Móia 2000).
} 
difference is that, if the temporal frame associated with the adverbial is widened, truth preservation is not guaranteed in temporally bounded quantification structures, though it is caeteris paribus - in (inclusive) temporal location ones. See (22) and (21), where three is to be interpreted in all cases as a non-monotonic exact quantifier:

(21)a. David offered this painting to (exactly) three friends in May 1995. [group reading]

b. David offered this painting to (exactly) three friends in 1995.

(22)a. David wrote (exactly) three essays in May 1995.

b. David wrote (exactly) three essays in 1995.

From (21a), which involves simple inclusive location (in the group reading), it is possible to infer (21b). Conversely, from (22a), which involves temporally bounded quantification, the parallel inference, in (22b), is invalid. Sentences (23) and (24) below contain yet another interesting contrast, distinguishing the duration of telic and atelic eventualities:

(23)a. David prepared this project in (exactly) ten hours last Saturday.

b. David prepared this project in (exactly) ten hours last weekend.

(24)a. David worked on this project for (exactly) ten hours last Saturday.

b. David worked on this project for (exactly) ten hours last weekend.

From (23a) it is possible infer (23b). Conversely, (24a) does not allow the inference (24b). In the first case, the sentence refers to a single episodic event (David preparing the project in a given amount of time) that is located anywhere within the frame provided by last Saturday, i.e. the sentence involves simple inclusive location. In the second case, the sentence refers to the duration of the sum of all the (possibly discontinuous) subevents of David working on the project that happened within the temporal boundaries set by last Saturday, i.e. the sentence involves a "full-scanning" of the interval, or temporal circumscription of quantification. Thus, if the boundaries are different, the sum may be different as well.

Marginally, one may note a particular characteristic of the structures with temporally bounded quantification that possibly constitutes a pragmatic restriction. These structures are somewhat odd, or very odd, if the time boundaries are excessively vague (cf. Alves 2003):

(25) Este rio transbordou cinco vezes \{desde $1980 /$ ?? desde antes de 1980\}.

"this river overflowed five times \{ since 1980 / since before of 1980\}"

This river has overflowed its banks five times \{ since 1980 / since before 1980\}.

Curiously, no parallel contrast in grammaticality is observed (26), where (durative) temporal location is involved:

(26) Este rio está gravemente poluído \{desde 1980 / desde antes de 1980\}.

"this river is gravely polluted \{ since 1980 / since before 1980\}"

This river has been seriously polluted \{ since 1980 / since before 1980\}.

In connection with the type of pragmatic effect observed in (25), it may noted that (non-echo) interrogatives where temporal adverbials - as wh-constituents - are used to define temporal boundaries for quantification are also very odd:

(27) $\quad\{$ ? Quando / *Desde quando $\}$ é que este rio transbordou cinco vezes?

" $\{$ when / since when $\}$ is that this river overflowed five times?

\{When did this river overflow / Since when has this river overflowed \} its banks five times?

At this point, an issue must be stressed: temporally bounded quantification structures may arise with virtually any kind of (so-called) locating adverbial and not only with desdeadverbials. In fact, I assume that the event abstraction which distinguishes this construction 
(cf. (18)) is triggered by quantifying elements in the matrix structure and not by the temporal adverbials. Therefore, whenever these quantifying elements are present - together with an adverbial that identifies a time interval - the temporal circumscription construction may emerge. The specificity of the Portuguese desde-adverbials is thus merely that, when combined with descriptions of telic events, they may set boundaries for quantification, but they may not simply locate, whereas most other temporal adverbials may play both roles. (28) below contains several examples of the construction at stake with different time adjuncts (29) contains parallel examples involving simple (inclusive) temporal location:

(28) Foram descobertas trinta e cinco novas crateras de impacto

\{entre 1980 e 1985 / o ano passado / na década de 80 / desde Janeiro passado\}.

"were found thirty and five new craters of impact

\{between 1980 and 1985 / the year past / in-the decade of 80 / since January past\}"

Thirty five new impact craters were (have been) found

\{between 1980 and 1985 / last year / in the 80's / since last January\}.

(29) Esta cratera de impacto foi descoberta

\{entre 1980 e 1985 / o ano passado / na década de 80 / *desde Janeiro passado\}.

"this crater of impact was found

\{between 1980 and 1985 / the year past / in-the decade of 80 / since January past\}"

This impact crater was (has been) found

\{between 1980 and 1985 / last year / in the 80's / since last January\}.

\section{A broader view of temporal circumscription of quantification}

\subsection{Temporal circumscription of quantification with different types of adverbials}

All the examples given in section 2 contain adverbials that are traditionally classified as temporal locating (or frame) adverbials, since they define intervals of the time axis. Let us consider again two of these cases:

(30) a. O ministro falou com o presidente cinco vezes desde Janeiro.

"the minister spoke with the president five times since January"

The minister has spoken with the president five times since January.

b. O ministro falou com o presidente cinco vezes a semana passada.

"the minister spoke with the president times the week past"

The minister spoke with the president five times last week.

However, adverbials traditionally classified in other classes can also occur in constructions that involve temporally bounded quantification. First, we can mention a subset of adverbials, that might be classified as duration adverbials in some grammars, since they refer to amounts of time rather than to intervals of the time axis - e.g. Portuguese em mês e meio or em menos de três semanas, and its English counterparts in a month and a half or in less than three weeks, respectively:

\footnotetext{
${ }^{5}$ Cf. also the following English examples (involving different adverbials) from the British National Corpus: G2F 9 And, on average, we each do it five times in our life. | CH3 4927 Colin resents the notion that he doesn't carry a big punch and this could be a chance for him to try to prove otherwise as Palacio admits to having been knocked out four times in his 58-fight career. | CB2 1513 Roebuck revealed that his ankle dislocated no less than four times during the World Cup final. ECH 396 I have done the route a dozen or more times since that distant autumn, and (...) I have never set off across that huge ceiling without a feeling of apprehension. | FR5 1234 I only saw Stephen a few times before I went back to prison. | K1U 305 They plan to build another 40 houses over the next 10 years.
} 
(31) a. O ministro falou com o presidente cinco vezes em mês e meio.

"the minister spoke with the president five times in month and half"

The minister spoke with the president five times in a month and a half.

b. Em menos de três semanas, o ministro falou com o presidente cinco vezes ${ }^{6}$.

"in less of three weeks, the minister spoke with the president five times"

In less than three weeks, the minister spoke with the president five times.

These constructions are to be distinguished from those expressing simple duration, like:

O ministro escreveu este livro em mês e meio.

"the minister wrote this book in month and half"

The minister wrote this book in a month and a half.

Secondly, we can mention temporal adverbials that are often classified as frequency adverbials, or as adverbs of temporal quantification (cf. Kamp \& Reyle 1993), like Portuguese todos os fins-de-semana or its English counterpart every weekend:

O ministro falou com o presidente cinco vezes todos os fins-de-semana.

"the minister spoke with the president five times all the weekends"

The minister spoke with the president five times every weekend.

This construction involves temporally bounded quantification over events (expressed in the matrix structure), unlike the following parallel structure (that expresses simple temporal quantification, in the sense of Kamp \& Reyle 1993):

O ministro falou com o presidente todos os fins-de-semana.

"the minister spoke with the president all the weekends"

The minister spoke with the president every weekend.

Finally, we can observe temporally bounded quantification structures - of a comparable nature, I will argue - with adverbials that express pure frequency, like Portuguese cinco vezes por mês or its English counterpart five times a month (or per month):

O ministro falou com o presidente cinco vezes por mês.

"the minister spoke with the president five times per month"

The minister spoke with the president five times per month.

A specificity of constructions like (35) is that they do not have counterparts without quantification over eventualities. In other words, sequences like por mês / per month do not seem to combine with structures that do not involve explicit quantification:

*O ministro falou com o presidente por mês.

"the minister spoke with the president per month"

*The minister spoke with the president per month.

The consideration of all the different examples presented in this section offers a broader view of temporally bounded quantification than the one sketched in section $2^{7}$. My contention is

\footnotetext{
${ }^{6}$ Note that these adverbials, contrary to normal duration adverbials, readily occur in sentence initial-position.

${ }^{7}$ Cf. also the following English examples (involving different adverbials) from the British National Corpus: CM0 109 It is unusual for a major organisation to change its chief executive four times in less than a decade (...). | K3K 1697 Later, experts were divided over whether two horrific attacks in just five days meant more could be expected. | B03 3011 Although the house, originally a simple hall house, has been extended and altered at least five times over nearly 600 years, it still has an overall integrity (...).

GW0 259 There's a man with a Doberman comes around two or three times every night. | C96 2109 The powerheads should draw the whole volume of the tank through the filter bed at least three times each hour. | AS7 1742 Assynt is a good salmon loch with upwards of sixty fish being caught most seasons.
} 
that these structures, and in particular the temporal adverbials that occur in them, should be considered on a par, rather than scattered in independent semantic domains like location, duration, temporal quantification or frequency. Though intimately linked with those domains, these adverbials seem to share linguistic properties, which bring them together as phrases that express temporal circumscription of quantification.

\subsection{Common properties of structures with different types of adverbials}

First, let us start by noting that, formally, all the relevant structures might be considered to involve an abstraction over eventualities similiar to the one already described in section 2 . What happens is that the temporal frame involved in the abstraction may correspond to different temporal entities: (i) intervals of the time axis (in structures traditionally associated with the domain of temporal location or of temporal quantification); (ii) amounts of time (in structures traditionally associated with the domain of duration); (iii) time units (in structures traditionally associated with the domain of pure frequency). Any of this entities can be used as a temporal frame (t) for event-summation. Compare the schematic DRT-representations in (37)-(40).

(37)

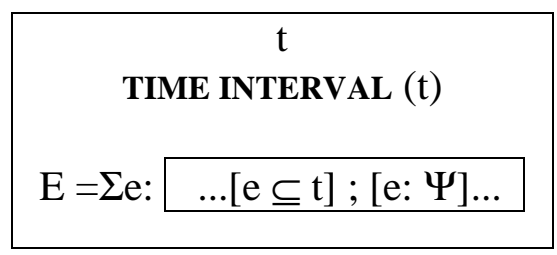

(38)

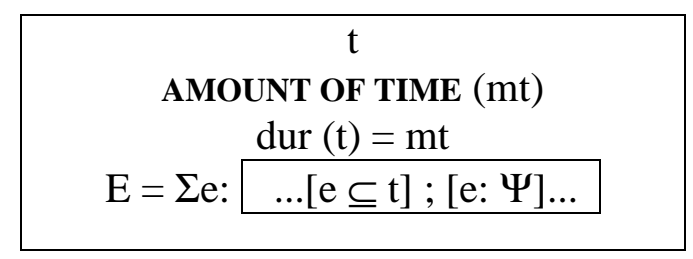



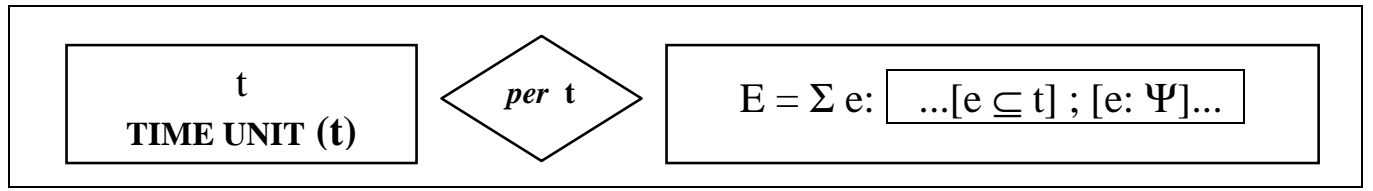

Naturally, structures with temporally bounded quantification can be divided in different subgroups according to the type of temporal frame used. On the one hand, each subgroup may have specific properties that need to be tackled separately (this is outstandingly the case with pure frequency constructions, like five time per month, as we will see later on). However, on the other hand, all these constructions have linguistic properties in common - cf. schemata (37)-(40) -, which call for a parallel analysis. As for these properties, I will only underline here the similarities in distribution, leaving other possible common properties for further research.

As a matter of fact, it should be noted that phrases that identify amounts of time, like in a week and a half, or time units, like per week - just like those that identify intervals of the time

K9J 181 If all goes according to plan, the $£ 60$ million investment will produce around 300,000 tonnes per year of ammonia at the lowest costs in Western Europe. | HL1 499 He also received a three-year period of probation --; during which he would be required to perform 1,800 hours of community service per year --; on a more general conspiracy charge.| G19 1229 The CCLGF meets six or seven times a year and is chaired by the Secretary of State for the Environment. 
axis, as last weekend or since January - may act as temporally binding expressions for indirect quantification over eventualities. They may, for instance occur, with

(i) distributive quantification over discrete objects (cf. (6) above)

(41)a. O David leu três livros no fim-de-semana passado.

"the David read three books in-the weekend past"

David read three books last weekend.

b. O David leu três livros numa semana e meia.

"the David read three books in-a week and half"

David read three books in a week and a half.

c. O David leu três livros por semana.

"the David read three books per week"

David read three books per week.

(ii) temporal measure quantification over atelic eventualities (cf. (10) above)

(42)a. O David trabalhou neste projecto durante mais de 60 horas a semana passada. "the David worked on-this project for more of 60 hours the week past"

David worked on this project for over 60 hours last week.

b. O David trabalhou neste projecto durante mais de 60 horas numa semana e meia.

"the David worked on-this project for more of 60 hours in-a week and half"

David worked on this project for over 60 hours in a week and a half.

c. O David trabalhou neste projecto durante mais de 60 horas por semana.

"the David worked on-this project for more of 60 hours per week"

David worked on this project for over 60 hours per week.

However, structures that express pure frequency (with por-phrases) have a more limited distribution. In particular, they are not licensed with event quantification associated with exclusive operators or with conjunction (cf. (11) and (12) above). This correlates with the fact that (possibly) the event abstraction associated with these operators is not directly asserted (rather being implied at some level).

(43)a. O David só escreveu este artigo \{desde Janeiro / num mês e meio\}.

"the David only wrote this paper \{ since January / in-a month and half\}"

David only wrote (has only written) this paper \{ since January / in a month and a half .

b. *O David só escreveu este artigo por mês.

"the David only wrote this paper per month"

*David only wrote this paper per month.

(44)a. O David visitou Londres, Paris e Berlim \{desde Janeiro / num mês e meio\}.

"the David visited London, Paris and Berlin \{ since January / in-a month and half\}"

David visited (has visited) London, Paris and Berlin \{ since January / in a month and a half\}.

b. *O David visitou Londres, Paris e Berlim por mês.

"the David visited London, Paris and Berlin per month"

*David visited London, Paris and Berlin per month.

It can also be noted that por-phrases exhibit distributional restrictions comparable to those of desde-phrases. More precisely, since por-phrases are only compatible with temporally bounded quantification, requiring event-iteration, the blocking effects resulting from coercion of a single-event reading (observed in (14) and (16), in section 2, apropos desde-phrases) also affect them: 
(45) *O David ofereceu este quadro a três amigos por semana. [group reading]

"the David offered this painting to three friends per week"

*David offered this painting to three friends per week.

(46) *O David comprou cinco descapotáveis ao mesmo tempo por mês.

"the David bought five convertibles at-the same time per month"

*David bought five convertibles at the same time per month.

\subsection{Por-adverbials: frequency and temporal circumscription of quantification}

It is implicit in what was said up to now that por-phrases in sequences like cinco vezes por mês ('five times per month') are being analysed autonomously, i.e. independently of the quantifying phrase (e.g. cinco vezes, 'five times') with which they combine. In fact, these phrases are taken to have a semantic role of its own, as they provide a temporal frame for quantification, along the same lines as adverbials that define time intervals or amounts of time. Given that, traditionally, sequences like cinco vezes por mês ('five times per month') are presented as an unanalysed whole - classified as an adverbial of frequency -, this 'splitting' analysis requires further justification. This is what I will attempt to do now.

The first thing to underline about the por-adverbials under consideration is that they may occur in two rather distinct types of syntactic contexts (just like, for that matter, their English counterparts with per or $a$ ).

O ministro fala/falou com o presidente cinco vezes por mês.

"the minister speaks/spoke with the president five times per month"

The minister speaks with the president five times per month.

O ministro faz/fez cinco discursos por mês.

"the minister makes/made five speeches per month"

The minister makes/made five speeches per month.

In the first sentence, the sequence por mês ('per month') is applied to the quantifier over events cinco vezes ('five times'), which occurs adverbially. In the second case, the same sequence is applied to the NP cinco discursos ('five speeches'), which is the direct object of the verb. In grammar books, only the first case is normally considered. There, as said, sequences like cinco vezes por mês ('five times per month') are normally considered as (unanalysed) units, and classified as adverbials of frequency (cf. e.g. Bennett \& Partee 1978, Quirk et al. 1985, or Huddleston \& Pullum 2002, for the English counterparts). No references are normally made to a possible internal analysis. Huddleston and Pullum (2002: 715), however, classify the counterparts of these por-phrases as "postmodifiers" (a category they oppose to "separate adjuncts") within the overall frequency phrase: "clear postmodifiers are NPs introduced by $a$ or else PPs with per as head".

I will advocate here that, both in adverbial contexts like (47) and in nominal contexts like (48), the sequence [n-times/n-objects por unit-of-time] is a constituent of the whole sentence and that it can have a compositional analysis, distinguishing the sequence [por unit-of-time] as an expression that sets temporal boundaries for event quantification, along the lines defined in the previous sections of this paper (cf. schema (40)).

Among the syntactic properties of the Portuguese sequences [n-times/n-objects por unit-oftime] that justify its analysis as a syntactic constituent - expressing frequency - we might emphasize: the possibility of topicalisation, of focussing, and of anaphoric reference via a relative pronoun (like $o$ que, 'what'), as shown in the following three sentences, respectively:

(49)a. Cinco discursos por mês, o ministro fez muitas vezes.

"five speeches per month, the minister made many times" 
b. Cinco discursos por mês é que o ministro devia fazer!

"five speeches per month [is that] FOCUS STRUCTURE the minister should make!"

c. Cinco discursos por mês é o que um ministro faz normalmente.

"five speeches per month is [the that $]_{=W H A T}$ a minister makes normally"

On the other hand, the por-adverbial alone has considerable syntactic autonomy: it can be topicalised, and it may occur in different positions in the sentence (separate from the quantified NP $n$-times / $n$-objects). Witness its position in the following examples:

(50)a. Por mês, o ministro faz cinco discursos.

b. O ministro faz por mês cinco discursos.

c. O ministro, por mês, faz cinco discursos.

Thus, at least in Portuguese, a compositional analysis of phrases of the type [n-times/n-objects por unit-of-time] seems defensible ${ }^{8}$. According to this analysis, the sequence [por unit-oftime] provides a temporal frame for event quantification along the lines of other temporal adverbials described in this paper. It should be noted however that, despite its relatively embedded syntactic position, this por-phrase often takes scope over the whole predicative content of the sentence (with some exceptions that I will not consider here ${ }^{9}$ ) - cf. DRSrepresentations of (53) and (54) below.

Furthermore, it must be underlined that, as has been often noted in the literature for the English counterparts of por-phrases, this subtype of structures has specific Aktionsart properties (cf. e.g. Moens 1987, or Huddleston and Pullum 2002). Sequences of the form [ntimes por unit-of-time] combine with event descriptions to form complex expressions which behave - as a whole - as atelic expressions (activities). In Portuguese, this explains why these expressions are compatible with (i) verb tenses expressing overlapping to temporal perspective points (e.g. present or imperfective simple past) - cf. (51) -, and (ii) temporal measure phrases headed by durante (the counterpart of English for) - cf. (52):

O ministro fala / falava com o presidente cinco vezes por mês.

"the minister speaks / spoke IMPERFECTIVE SIMPLE PAST with the president five times per month"

The minister speaks / used to speak with the president five times per month.

$\mathrm{O}$ ministro falou com o presidente cinco vezes por mês durante quase um ano.

"the minister spoke with the president five times per month for almost a year"

The minister spoke with the president five times per month for almost a year.

The following DRS-representations illustrate the compositional analysis sketched above ${ }^{10}$ :

\footnotetext{
${ }^{8}$ English per-phrases seem to behave similarly - cf. the following examples from the British National Corpus:

CRA 2668 Adding in refinancing of maturing debt (and allowing for individuals' national savings), that means that $£ 1$ billion of gilt-edged debt must be sold per week. | A7N 981 How much money do you spend on clothes (excluding shoes and lingerie) per month?

${ }^{9}$ The por-adverbial doesn't take scope over the predicative content of the matrix clause in some structures, e.g. when it is embedded in an NP with the counterparts of nouns like rhythm, pace, rate, speed, etc. (Note that, in these cases, it cannot be topicalised.)

(i) O estádio estava a ser evacuado a [NP um ritmo de [duzentas pessoas por minuto]].

"the stadium was to be evacuated at a pace of two-hundred persons per minute"

The stadium was being evacuated at [NP a pace of [two hundred people per minute]].

${ }^{10}$ Two notes about these representations:

(i) I will not attempt to provide here the semantics of the quantifier por. On the one hand, this quantifier is roughly similar to a universal quantifier. On the other hand, however, it often implies an average value (even when the explicit sequence em média ('in average'), is absent).
} 
(53) O ministro fala com o presidente cinco vezes por mês.

"the minister speaks with the president five times per month"

The minister speaks with the president five times a month.



(54) O ministro faz cinco discursos por mês.

"the minister makes five speeches per month"

The minister makes five speeches a month.

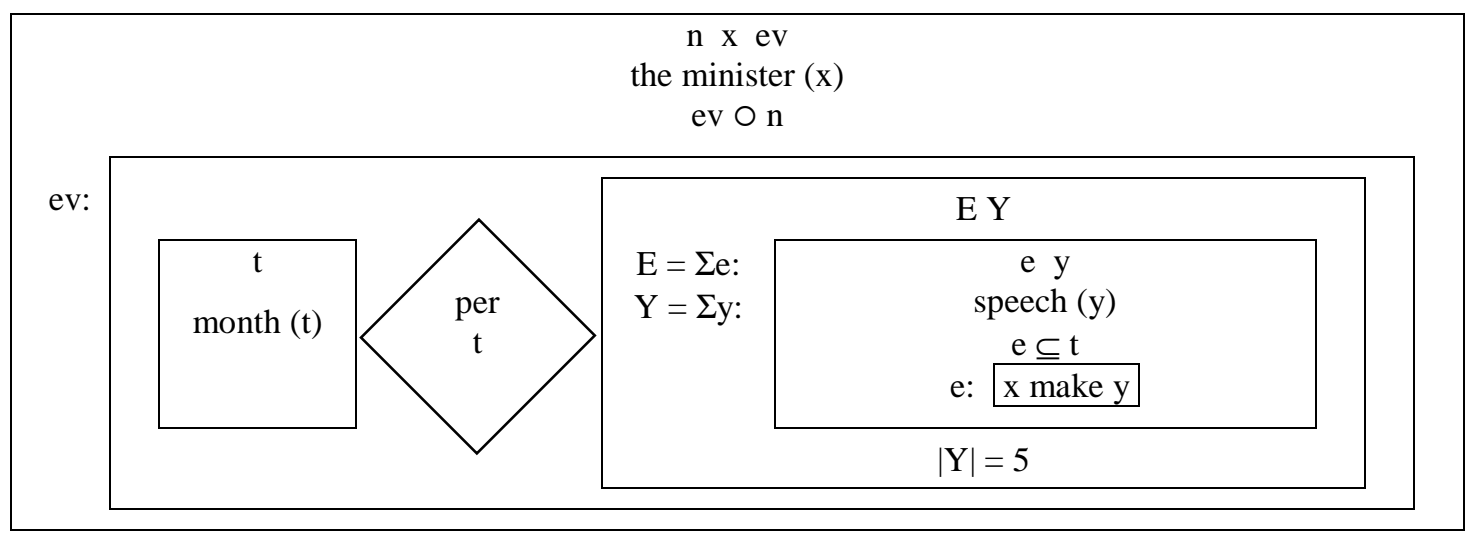

Note that the discourse referent associated with the por-adverbial (t) occurs within the subDRS associated with the event-abstraction (in the condition $[e \subseteq t]$ ). Therefore, considered on its own (irrespective of the fact that it is part of a larger constituent expressing frequency), the por-adverbial defines a temporal frame for event quantification, and is thus comparable to the other temporal adverbials analysed in this paper (e.g. inclusive desde-adverbials).

\section{Conclusion}

In this paper I attempted to identify of a set of constructions where quantification over eventualities expressed in a matrix clause directly depends on a temporal parameter expressed by a temporal adverbial. In constructions with adverbials that identify a time interval or an amount of time (e.g. desde 1995 / since 1995, em 1995 / in 1995 or em menos de dois meses / in less than two months), the main role of the adverbial is, arguably, to provide a frame for event quantification, rather than to locate, or to express duration. In constructions with adverbials that identify time units (e.g. por mês / per month), the main role of the adverbial is to contribute to the expression of a frequency value in combination with a quantified phrase (e.g. cinco vezes / five times or cinco discursos / five speeches). However, a compositional analysis of frequency adjuncts seems defensible, according to which the isolated per-phrase

(ii) The fact that sequences with por-phrases behave as atelic predicates is symbolised in the condition ev: $\alpha$, where $\alpha$ is a duplex condition. The discourse referent ev represents the complex eventuality - an activity - of doing something with a certain frequency (for Aktionsart shift in DRT, cf. Swart 1998). 
has a contribution of its own, viz. to set temporal boundaries for quantification along similar lines as the adverbials that define time intervals or amounts of time.

This paper considered mainly data from Portuguese, although the issue at stake - the evidence for a close interaction between temporal adverbials and event structure in some specific type of structures - has certainly a more general relevance.

\section{References}

Alves, Ana Teresa: 2003, Sobre a Localização Temporal Adverbial Anafórica em Português, Ph.D. thesis, Universidade dos Açores, Ponta Delgada.

Bach, Emmon: 1986, The Algebra of Events, Linguistics and Philosophy 9, 5-16.

Eberle, Kurt: 1998, The Influence of Plural NPs on Aktionsart in DRT, in Fritz Hamm and Erhard Hinrichs (eds.), Plurality and Quantification, Dordrecht: Kluwer Academic Publishers, pp. 55-111.

Huddleston, Rodney \& Geoffrey Pullum: 2002, The Cambridge Grammar of the English Language, Cambridge: C.U.P.

Kamp, Hans \& Uwe Reyle: 1993, From Discourse to Logic. Introduction to Modeltheoretic Semantics of Natural Language, Formal Logic and Discourse Representation Theory, Dordrecht: Kluwer.

Krifka, Manfred: 1990, Four Thousand Ships Passed through the Lock: Object-Induced Measure Functions on Events, Linguistics and Philosophy 13, 487-520.

Moens, Marc: 1987, Tense, Aspect and Temporal Reference, Ph.D. thesis, University of Edinburgh (reproduced by the Centre for Cognitive Science, University of Edinburgh).

Móia, Telmo: 2000, Identifying and Computing Temporal Locating Adverbials with a Particular Focus on Portuguese and English, Ph.D. thesis, University of Lisbon. [available at http://www.fl.ul.pt/dlgr/pessoais/tmoia/index.html]

Móia, Telmo: 2001, Temporal Location of Events and the Distribution of the Romance Counterparts of Since-Adverbials, in Joaquim Camps and Caroline Wiltshire (eds.), Romance Syntax, Semantics and L2 Acquisition, Selected papers from the $30^{\text {th }}$ Linguistic Symposium on Romance Languages, Gainesville, Florida, February 2000, Amsterdam: John Benjamins, pp. 137-152.

Quirk, Randolph et al.: 1985, A Comprehensive Grammar of the English Language, London: Longman.

Rothstein, Susan: 1995, Adverbial Quantification over Events, Natural Language Semantics 3, 1-31.

Schein, Barry: 1993, Plurals and Events, Cambridge, Massachusetts: The MIT Press.

Swart, Henriëtte de: 1998, Aspect Shift and Coercion, Natural Language and Linguistic Theory 16, 347-385.

Vlach, Frank: 1993, Temporal Adverbials, Tenses and the Perfect, Linguistics and Philosophy 16, 231-283. 


\title{
The Present Perfect at the Semantics/Pragmatics Interface: AMERICAN ENGlish ANd BraZILIAN PortugueSE ${ }^{1}$
}

\author{
Karina Veronica Molsing, \\ Pontifícia Universidade Católica, Brazil \\ karinaveronica21@yahoo.com
}

\begin{abstract}
Modern theorists rarely agree on how to represent the categories of tense and aspect, making a consistent analysis for phenomena, such as the present perfect, more difficult to attain. It has been argued in previous analyses that the variable behavior of the present perfect between languages licenses independently motivated treatments, particularly of a morphosyntactic or semanticsyntactic nature (Giorgi \& Pianesi 1997; Schmitt 2001; Ilari 2001). More specifically, the wellknown readings of the American English (AE) present perfect (resultative, experiential, persistent situation, recent past (Comrie 1976)), are at odds with the readings of the corresponding structure in Brazilian Portuguese (BP), the "pretérito perfeito composto" (default iterativity and occasional duration (Ilari 1999)). Despite these variations, the present work, assuming a tense-aspect framework at the semantic-pragmatic interface, will provide a unified analysis for the present perfect in AE and BP, which have traditionally been treated as semantically divergent. The present perfect meaning, in conjunction with the aspectual class of the predicate, can account for the major differences between languages, particularly regarding iterativity and the "present perfect puzzle", regarding adverb compatibility.
\end{abstract}

\section{Introduction}

The present perfects in American English (AE) and Brazilian Portuguese (BP) are often treated as semantically divergent due to the apparent obligatory iteration of the BP variety.

$$
\begin{array}{ll}
\text { a. Mary has sung "Happy Birthday". } & \text { (once) } \\
\text { b. A Maria tem cantado "Parabéns". } & \text { (várias vezes) } \\
\text { The Maria has sung "Congratulations" (many times) }
\end{array}
$$

Sentences like (1a) are most often used to express a single eventuality, although they are compatible with repetition when modified with such adverbs as 'always' or 'many times'. This is contrary to (1b), which cannot refer to a single eventuality, but must express an iteration of singing events. Obligatory iterativity is a phenomenon specific to the present perfect in BP, since the past and future perfects do not force iteration, although they are compatible with repetition as well. Some have characterized the structure's obligatory iterativity, distinguishing it from the AE present perfect, as being due to a covert habitual operator (Giorgi and Pianesi 1997) or to the selectional restrictions of the present tense morphology in BP (Schmitt 2001). The problem with these analyses is that while the present perfect is characteristically iterative, it can also express single, durative situations, as in (2) (Ilari 2001).

(2) a. A Maria tem estado doente.

The Mary has been sick

b. Mary has been sick.

\footnotetext{
${ }^{1}$ This work was funded in part with a grant by CAPES (Coordenação de Aperfeiçoamento de Pessoal de Nível Superior). I would like to thank the audience at Sinn und Bedeutung 10 for their helpful comments, especially Bridget Copley, Patricia Amaral, Telmo Móia and Arnim von Stechow. All remaining errors are mine.
} 
So, besides having the same periphrastic structure (AE, 'have' + past participle and BP, 'ter' + particípio passado), the two varieties also present a semantic overlap as shown in (2a) and (2b), whose meanings are equivalent. However, we still have the different readings to account for. The main readings to be considered for AE are the universal and the existential, reduced from Comrie's (1976) traditional four-way distinction, as shown in (3a) - (3d). Universal readings arise when the eventuality described holds true throughout the entire interval within which it is located. Existential readings arise when the eventuality described occurred at least once within the location interval. The existential subsumes a further distinction between resultative, recent past and experiential readings, which merely reflect contextual variants of the same eventuality. The main readings that arise in BP are that of iterativity and durativity or continuity. Iterativity is understood when the situation repeats throughout the location interval and durativity is similar to the universal reading. Below are some examples of the different readings.
$\mathrm{AE}$
a. Experiential: John has visited Paris. (once/before)
b. Resultative: John has arrived. (and is here)
c. Recent past: I have just graduated from college.
d. Persistent situation: John has lived in New York for 4 years. (Universal)
(Existential)

BP

a. Iterative: $\mathrm{O}$ Bruno tem ido à Disneylândia. (várias vezes)

The Bruno has gone to-the Disneyland

'Bruno has been going to Disneyland'

b. Durative: A Maria tem sido feliz na Europa.

The Maria has been happy in-the Europe

'Mary has been happy in Europe'

In this paper, I will present a unified analysis for the present perfect structures in American English (AE) and Brazilian Portuguese (BP). In section 2, I will review the standard theories on the English present perfect and see how they might work for the BP present perfect, since the very few studies aimed at the BP present perfect have proven to be incomplete. Section 3 will test how the various readings that have been cited in the literature for the English present perfect and those available in the BP present perfect, work in a unified framework. The main property to be reconciled is that of iterativity which will then be tied into adverb restrictions in the next section. Section 4 will discuss the puzzles that arise in both languages regarding adverb compatibility. Section 5 will conclude.

\section{Standard approaches}

\subsection{Extended Now}

Standard approaches to the present perfect make use of variations of Reichenbach's (1947) three-point system of tenses: event time, speech time, and reference time. In the present perfect, the event time is located before speech time and the reference time is simultaneous with speech time. Many theorists favor the Extended Now theory (XN), in which the perfect introduces an interval whose left boundary is unspecified and whose right boundary is fixed at the reference time, in the case of the present perfect, speech time (McCoard 1978; Dowty 1979; Iatridou et al. 2003). The eventuality is located somewhere within this interval. 
(4)

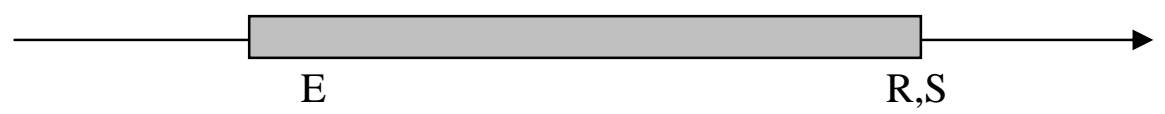

The immediate benefit of the $\mathrm{XN}$ theory is that it explains the present perfect's incompatibility with past-time adverbials, known as the "present perfect puzzle" (Klein 1992, 1994). Since the $\mathrm{XN}$ interval includes speech time, it is inappropriate for it to be modified by an adverb locating the eventuality in the past. This puzzle shows up in BP as well.

$$
\begin{aligned}
& \text { a. *Lena has worked yesterday. } \\
& \text { b. *A Lena tem trabalhado ontem. }
\end{aligned}
$$

Also, $\mathrm{XN}$ theories more aptly account for the universal readings with adverbs such as 'since' and 'for'. The different readings are derived from the semantics of the perfect meaning and the meaning of the particular adverbs. An XN analysis defends that universal readings ( $\mathrm{u}-$ perfects) can only arise with adverbials (Iatridou et al. 2003). While adverbials play an important part in interpreting the present perfect, adverb modification is not a necessary condition for using and understanding it. A resulting drawback of defending the inseparability of u-perfects and adverbs is that one would have to then stipulate ambiguous adverbs to account for ambiguous readings of the u-perfect. Consider the following examples.

a. John has been sick for two weeks.

b. John has been sick since 1990 .

(6a) can be understood as ambiguous between the reading that John is still sick at speech time and the other reading that at some time in the past, John was sick for a period of two weeks. Likewise in (6b), not only can we understand that John's being sick is true for the entire period from 1990 up to and including speech time, it can also be true that at some point between 1990 and speech time, John fell sick and is better now. In situations where no adverb is used, $\mathrm{XN}$ theories often resort to covert adverbs to accommodate the notion that u-perfects can only arise with adverbs. This complicates the derivation of an existential reading, which is equally possible, given contextual information or discourse cues. See (7a).

a. John has been sick.

b. O João tem estado doente.

Theorists consider the BP present perfect to have the particular characteristic of not requiring adverbial modification, as in (7b), setting it apart from other Romance languages (Boléo 1936; Ilari 2001). On the occasions in which the structure is used to express a continuous situation, it is only through adverbial modification that we can get an existential reading, as in (8).

(8) O João tem estado doente muitas vezes.

The John has been sick many times

'John has been sick many times'

However, this varies across dialects, such that both a universal and an existential reading are possible without adverbial modification. This possibility argues against covert adverbs. Finally, $\mathrm{XN}$ analyses generally are not compatible with repetition, not accounting for sentences like (9a), which do not seem to be of the same type as (9b), which are treated as single eventualities of five readings, for example (Iatridou et al. 2003).

a. Bill has read "The Da Vinci Code" many times.

b. Bill has read "The Da Vinci Code" five times. 
Due to these inconsistencies, an XN analysis should be discarded because of its unconvincing cross-linguistic applicability.

\subsection{Anteriority}

Anteriority-type theories defend an interaction between the three temporal points or intervals involved in the present perfect meaning (Klein 1992, 1994). This type of theory claims that there is an interval located before speech time, within which the eventuality is located. The reference time (Klein's 'topic time') is often claimed to include or equal the speech time.

(10) $\mathrm{tt}=$ topic time $\quad \mathrm{tsit}=$ time of situation $\mathrm{tu}=$ time of utterance

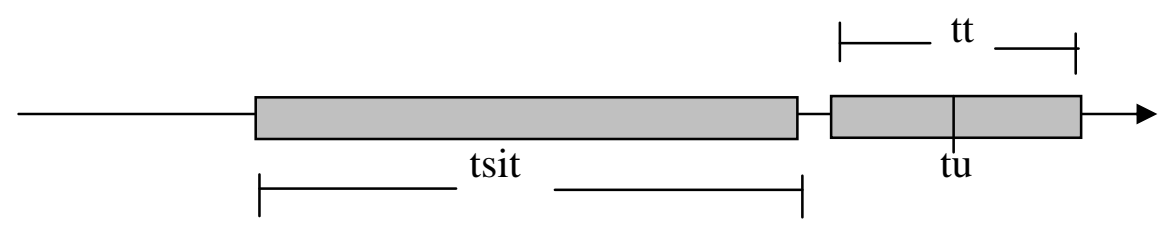

In Klein's version, however, the reference time is given a more explicit role as topic time. While the event time and speech time remain virtually the same (Klein's situation time and utterance time, respectively), the topic time refers to the time for which the claim is made. The notion of topic time can be most easily demonstrated by a question/answer scenario, in which the question sets the topic time. In (11), it is possible that the man is still lying on the ground at speech time, but the question limits the answer to the topic time set by the underlined portion.

\section{Q: What did you see when you walked in the room?}

A: A man was laying on the ground.

The tense relation is given by topic time and speech time while the aspect relation is given by event time and topic time. In the present perfect, the topic time is always fixed at the present, thus including speech time. An interesting byproduct of the present perfect definition given above is that it says nothing about the distance between the eventuality and speech time, nor does it say anything about the frequency of intervals. It is Klein's topic time that distinguishes the present perfect from the simple past and the rest of the perfect system. This means that the ambiguity between the universal and existential readings is to be resolved at the level of pragmatics. However, the role of topic time in the lexical classification of verb phrases is indefeasible as Klein does not apply the traditional aspectual distinctions, making the potential for a formal implementation unclear.

\subsection{Stativizer}

Finally, there are some analyses that treat the perfect as an operator that introduces a state (Kamp and Reyle 1993; de Swart 1998; Nishiyama and Koenig 2004). There are different ways of conceptualizing how the perfect is to introduce the consequent state, but they are conceptually similar to the idea of the eventuality's interval preceding speech time, as in the anteriority theory. The relation between the prior eventuality and the ensuing state can be understood in one of three ways: as one of abutment (Kamp and Reyle 1993; de Swart 1998), causation (Moens and Steedman 1988; Smith 1997), or as introducing a permanent state (ter Meulen 1995).

(12) $n=$ now; speech time $s=$ perfect state ev=eventuality time

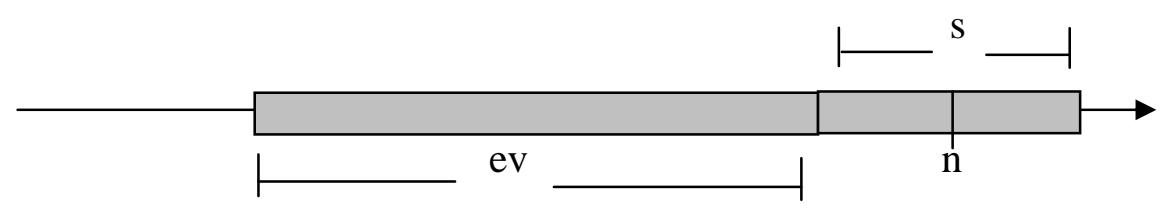


As Nishiyama and Koenig (from here on, NK) attest, all three of these types of stative approaches run into problems when the different types of possible inferences are taken into account. NK's examples below show how a stative approach must account for all of these possible inferences ( $\mathrm{s}=$ perfect state) .

(13) Ken has broken his leg.

a. His leg is broken (s)

b. Ken is behind in his work (s)

c. \#Susan is married (s)

(14) I have seen the key in this room.

a. The key is in this room (s)

(15) I've been in London since last week.

a. I am in London (s)

(13a) and (13b) show that we must account for two types of resultant relations: those entailed lexically and those entailed conversationally. We must also be able to exclude those states which have no causal relation, as in (13c), which would not be excluded in a stative theory with abutment. Also, we must allow for inferences which are not necessarily causal as in (14a) and (15a). NK account for these facts by including a free property variable in the semantics of the perfect meaning, whose value is to be determined at the level of pragmatics, guided primarily by Levinson's I-principle of informativeness.

In a sense, Klein's approach could be seen as a type of perfect state theory, such that the topic time serves as a "posttime" or "poststate" of the eventuality in question. This topic time takes over the role of reference time. In NK's analysis, the corresponding structure to Klein's topic time would be the perfect state. However, in NK's definition for the perfect, the original reference time remains, being that the perfect state is introduced specifically by the perfect. The perfect can take any type of eventuality and map it onto the consequent state, which overlaps speech time and thus, reference time. The category of the consequent state is determined pragmatically. This gives the prior eventuality current relevance via inference processes. How we get the relation between the prior eventuality and the consequent state is what makes the difference between NK's analysis and other treatments of the perfects as stativizers. It is not a relation of abutment, causality nor that which entails permanent consequences. It is a relation of inference that motivates the semantic-pragmatic interface. (16) through (18) are paraphrased from NK (2004: 107-8) and show that the perfect state has a semantic and a pragmatic function.

(16) a. Semantic part: the free variable $X$ is a semantic constraint imposed by the perfect form.

b. Pragmatic part: the value of the free variable $\mathrm{X}$ is determined by pragmatic inferences.

c. Constraint on $\mathrm{X}$ : it is an epistemic variable such that it is inferable from the prior eventuality.

This can be translated as (17), which means that there is some eventuality $e$ and some free property variable $s$ such that $e$ is located before speech time and $s$ overlaps with speech time.

(17) $\exists \mathrm{e} \exists \mathrm{s}[\phi(\mathrm{e}) \wedge \mathrm{X}(\mathrm{s}) \wedge \tau(\mathrm{e})<\mathrm{n} \wedge \tau(\mathrm{s})$ o $\mathrm{n}]$

How $\mathrm{X}$ is determined is guided by Levinson's I-principle of informativeness.

I-principle:

1. Maxim of minimization: the speaker always chooses the least informative utterance. 
2. The hearer enriches the less informative utterance into the most specific interpretation, using world knowledge.

In the following proposal, I will adapt NK's analysis for BP data. To be clear, the following problems that we need to account for are: how to systematize the different readings that arise and how to understand the variable adverb compatibility in AE and BP.

\section{Different readings in $\mathrm{AE}$ and $\mathrm{BP}$}

First, let us get a handle on what types of readings we are trying to account for. As mentioned in the previous section, many theorists defend that the universal reading can only arise in the company of adverbs. We have concluded here that both AE and BP present perfects can be used without adverbial modification. Another point to be made clear regards the fact that the BP present perfect has been cited as having only a universal, and not an existential, reading (Brugger 1978; Squartini and Bertinetto 2000). This conflicts directly with what Amaral and Howe (2005) claim about the BP present perfect, which is that the existential is a subcase of iterativity $^{2}$. This is further proof of the inconsistency of the universal/existential readings in the literature. For these reasons, I propose to abandon the problematic terms 'universal' and 'existential' in favor of 'continuous' and 'noncontinuous'. Continuous readings arise when certain predicates are used to express duration or continuity throughout the interval and whose subevents repeat. Noncontinuous readings arise when certain predicates are used to express iterative situations, repeating whole events.

This way of characterizing noncontinuous readings is compatible with the notion of the presupposition of repeatability that is often associated with the present perfect (Inoue 1979; Smith 1997). That is, the AE present perfect is often used to express one-time occurring eventualities, but there is still some element of repetition that guides its felicitous use. This explains the famous examples in (19) and (20)

a. ??Einstein has visited Princeton.

b. Princeton has been visited by Einstein.

Have you visited the Monet exhibit?

Example (19a) is unacceptable because Einstein is dead and is therefore no longer capable of visiting Princeton again. However, (19b) is more acceptable if we are talking about Nobel Prize winners who have visited Princeton. Moreover, it is only appropriate to ask a question like (20) if: (i) the museum exhibit is still open, so that one can still possibly visit it; and (ii) the person being asked the question is physically capable of visiting the museum exhibit. Hence, the event in question must be repeatable and the referents of the noun phrase must exist at the time of utterance (Smith 1997). This condition of repeatability corroborates the idea that existential-type readings are a subtype of iterative readings. However, this does not mean that the eventuality must repeat at present or any time in the future, as shown by (21a). Even when the eventuality is understood as iterative as in the BP counterpart (21b), continuation can be canceled. So, while the eventualities need not repeat, or continue to repeat, the possibility must be there at speech time.

a. I have visited my parents, but I won't anymore.

b. Eu tenho visitado os meus pais, mas não vou mais.

I have visited the my parents, but no I-go more

How we get the readings from the present perfect meaning works like this. The eventuality described in the $e v$ interval introduces a consequent state $s$, which overlaps speech time $n$, and

\footnotetext{
${ }^{2}$ Amaral and Howe (2005) also deal with subjunctive readings which can have existential readings. This is corroborated by historical data as well.
} 
whose category is determined at the level of pragmatics. So, going back to example (13), an inferable consequent state to Ken's leg being broken are those listed in (13a) and (13b), but not (13c), since it is not inferable from the prior eventuality. Likewise, (14a) and (15a) are appropriate inferences for (14) and (15). Now take a stative predicate as in (22). An appropriate inference is that Bill still be in London at speech time. This means that when the prior eventuality is stative, it may introduce a consequent state of the same nature. This is how we get continuous readings. But this inference is not always necessary with stative predicates since other inferences are possible. For example,

(22) Bill has been in London since last week.

a. $\mathrm{X}(\mathrm{s})$ : Bill is in London.

b. $X(s)$ : Bill is not too familiar with the tube system.

c. X(s): Bill got coverage of the McDonald's bombing.

The first inference is of a lexical nature and the second of a conversational nature. The third inference cancels the continuative nature of the prior eventuality. In this situation, it could be understood that Bill is a field news reporter based in New York. The bombing of a McDonald's in London occurred a week prior to the utterance and some time between the bombing and the utterance, Bill went to London to get coverage of it and has already left. (22) can be uttered felicitously by someone in London ${ }^{3}$. Turning to examples in BP, let us see how the typical readings relate to aspectual class.

Achievements and accomplishments are noncontinuous

A Lúcia tem chegado tarde ao escritório. (iterative events)

The Lucia has arrived late to-the office

'Lucia has been arriving late to the office'

O Paulo tem pintado a casa. (iterative subevents)

The Paulo has painted the house

'Paulo has been painting the house'

(24) means that the target state is not reached at speech time: the house is not completely painted yet.

Activities are noncontinuous

A Ana tem corrido muito. (iterative events or subevents)

The Ana has run a lot

'Ana has been running a lot'

(25) can be understood as repeating subevents if some accomplishment-like reference exists in the context, like if Ana is running a marathon and it is not over yet. Then it would be understood similarly to (24). Otherwise, as a true activity, it would be understood as iterative events of running. For stative predicates, Amaral and Howe (2005) distinguish stage-level and individual level predicates since they behave slightly differently with respect to iterativity and continuity.

Individual-Level Predicates (ILP) are noncontinuous
O João tem sido inteligente.

The João has been intelligent.

'João has been intelligent'

\footnotetext{
${ }^{3}$ To be uttered felicitously by someone not in London, the sentence would have to read 'Bill has been to London since last week'.
} 
This sentence means that João has demonstrated his intelligence on various occasions ${ }^{4}$.

Stage-Level Predicates (SLP) are continuous

A Maria tem estado doente.

The Mary has been sick

'Mary has been sick'

Only these last types of predicates do not force iterativity and continuity holds. An iterative reading is also possible with SLP's, but only with overt adverbial modification (Amaral and Howe 2005), as in (28).

(28) A Maria tem estado doente muitas vezes ultimamente.

The Mary has been sick many times lately

'Mary has been sick a lot lately'

\section{Present perfect puzzles}

While the AE present perfect is compatible with single readings and iterative readings, BP forces iterative readings in most cases. In $\mathrm{AE}$, we often get iterativity through adverb modification or plural NPs. Since these modifications are not necessary in BP, why is iterativity forced? This is what I will call the "frequency puzzle" and, as outlined above, it refers to the fact that the BP present perfect is incompatible with definite frequency adverbs like 'once' ('uma vez') or 'five times' ('cinco vezes'), but is compatible with indefinite frequency adverbs like 'many times' ('muitas vezes') and 'lately' ('ultimamente'). The traditional "present perfect puzzle", the incompatibility with past time adverbials will also be dealt with, in section 4.2.

\subsection{The frequency puzzle}

If a semantic analysis of the present perfect in BP is to stipulate that eventalities described by eventive and ILP predicates must refer to two or more occurrences (instead of 'at least one'), it must also explain why BP speakers cannot specify this number. Ultimately, what one really must explain is why frequency cannot be modified at all, regardless of whether it is one, three or fifty occurrences. It is not false to use the BP present perfect to describe an eventuality that in fact occurred only three times. However, it is infelicitous to specify the three times in the present perfect clause. This leads us to question the generally accepted idea that it is necessarily false to use the present perfect to describe an eventuality that occurs only once. Perhaps it is also just infelicitous. To even begin to answer any of these questions, we must first try to figure out the source of the iterativity.

Many theorists agree that the perfect in English outputs a state regardless of the type of eventuality described by the perfect (Dowty 1979; Kamp and Reyle 1993; Michaelis 1998; de Swart 1998). Let us assume for now that the perfect in BP outputs a state as well. Since the rest of the perfect system behaves similarly in both languages, this is not such an implausible assumption.

There are many ways languages can encode aspect and, taking a hint from Klein (1994), one can expect that some languages focus on certain parts of events while other languages focus on other parts of events. For example, in complex telic events, English tends to focus on the initial state such that the lexical properties of the final state are projected into the "posttime" (Klein 1994). In the case of the present perfect, the posttime is the perfect state. So, for a

\footnotetext{
${ }^{4}$ This seems to reflect some kind of coercion from an individual-level predicate to a stage-level predicate, but the output appears eventive, not stative. I am not sure what the nature of this coercion would be and so I leave it up to future research.
} 
sentence like 'Mary has entered the room', the immediate lexical inference is that she is in the room. Now, given the fact that the BP present perfect has often been characterized as an imperfective, or a perfective with imperfective properties (Squartini and Bertinetto 2000), we can say that BP focuses on ongoing action leading to the final state. This way, the lexical properties to be projected into the "posttime", or the perfect state, are those of continuation.

Therefore, we can maintain that both perfects output a state, but the difference is in what kind of state is introduced. In AE, the perfect most likely introduces some resulting state of the prior eventuality. In BP, the perfect most likely introduces the beginning of a state of continuation, and in the case of eventives, iterativity. More specifically, the lexical inferences that can be derived from the prior eventuality will corroborate the idea that AE outputs a resultant state and $\mathrm{BP}$ outputs an iterative state. While conversational inferences, discourse cues and context can give us an array of other inferences, we are concerned only with the lexical for now. Let us look at some examples. The BP examples and perfect state inferences are direct translations of the AE examples and inferences.

(29) American English

\begin{tabular}{|l|l|l|}
\hline Aspectual Class & Eventuality & Lexical X(s) \\
\hline Achievement & John has arrived late to work. & $\begin{array}{l}\text { John is here and is late. } \\
\# \text { John arrives late }\end{array}$ \\
\hline Accomplishment & John has painted his house. & $\begin{array}{l}\text { The house is painted/complete. } \\
\text { \#John paints his house. }\end{array}$ \\
\hline Activity & John has run. & $\begin{array}{l}\text { John is disposed to run. } \\
\# \text { John runs }\end{array}$ \\
\hline Individual-level & John has been smart. & $\begin{array}{l}\text { ? John is smart. } \\
\text { John is not always smart. }\end{array}$ \\
\hline Stage-level & John has been sick. & $\begin{array}{l}\text { John is sick. } \\
\text { John is not sick. }\end{array}$ \\
\hline
\end{tabular}

Brazilian Portuguese

\begin{tabular}{|l|l|l|}
\hline Aspectual Class & Eventuality & Lexical X(s) \\
\hline Achievement & O João tem chegado tarde. & $\begin{array}{l}\text { \#O João está aqui e está atrasado. } \\
\text { O João chega tarde. }\end{array}$ \\
\hline Accomplishment & O João tem pintado a sua casa. & $\begin{array}{l}\text { \#A casa está pintada/completa. } \\
\text { O João pinta a sua casa. }\end{array}$ \\
\hline Activity & O João tem corrido. & $\begin{array}{l}\text { O João está disposto a correr. } \\
\text { O João corre. }\end{array}$ \\
\hline Individual-level & O João tem sido inteligente. & $\begin{array}{l}\text { ??O João é inteligente. } \\
\text { O João não é sempre inteligente. }\end{array}$ \\
\hline Stage-level & O João tem estado doente. & $\begin{array}{l}\text { O João está doente } \\
\text { O João não está doente. }\end{array}$ \\
\hline
\end{tabular}


The right hand columns show the lexical inferences that can and cannot be derived from the prior eventuality. In achievements and accomplishments, the opposite kinds of perfect states are inferable from the prior eventuality. In AE, the perfect state inferences reflect resultant states and do not allow for a generic or repetitive reading, while BP does. In activities, one can infer in $\mathrm{AE}$ about the general disposition of the agent while in $\mathrm{BP}$, one can infer, again a generic or repetitive reading as well as disposition. The inferences in individual-level and stage level predicates are the same. In BP, the generic or habitual inference is always cancelable with 'mas não mais' ('but not anymore'), to show that the iterative state output by the perfect does not have to be true at speech time. What must still be met, though, is the condition of repeatability as mentioned in section 3. In order to confirm that the consequent state continues or not, it must be possible for it to continue. AE and BP behave similarly with statives because the result of a state and the continuation of a state are the same.

Summing up, both $\mathrm{AE}$ and $\mathrm{BP}$ perfects are compatible with resultative and continuous inferences, but in AE the resultative property is encoded lexically while the continuous is not, and in BP, the continuous property is encoded lexically, while the resultative is not. The AE perfect introduces the end of a perfect state and the BP perfect introduces the beginning of an iterative state ${ }^{5}$.

A common test for whether an eventuality can occur in the present perfect in BP is if it is compatible with 'ultimamente' ('lately'). This ties in well with the analysis here since the iterative perfect state that yields a habitual or generic inference is located at speech time. Since the iterative state only begins after the prior eventuality, the genericity is delimited by the introduction of this state, giving us a sense of 'lately' instead of 'always'. 'Always' ('sempre') is also compatible with the BP present perfect, but must be made explicit.

If the above line of reasoning is true, then we also have an explanation for why the BP present perfect is incompatible with definite frequency adverbs, regardless of whether the frequency refers to one or more. The iterative state is compatible with those adverbs that can iterate with the eventuality and is not compatible with definite frequency adverbs which would have scope over the eventuality. So, while (31) may refer to three particular instances, it was not the speaker's intention to assert this when using the present perfect. Likewise, if the eventuality only refers to one occurrence, it would be inappropriate to use the present perfect since an iterative state is always introduced by eventive predicates in the perfect. Definite frequency adverbs are acceptable when in contexts of indefinite repetition, as in (32).

a. A Brenda tem beijado.

The Brenda has kissed

'Brenda has been kissing (lately)'

b. *A Brenda tem beijado três vezes.

The Brenda has kissed three times

'Brenda has kissed three times

(32) Eles têm nos visitado três vezes por semana.

They have us visited three times per week

'They have visited us three times a week

a. Brenda has kissed.

b. Brenda has kissed three times.

\footnotetext{
${ }^{5}$ The notion of the BP perfect introducing the beginning of an iterative state was first suggested to me informally in a personal communication with Telmo Móia (2005).
} 
In the AE counterparts, (33a) has an 'at least once' reading, given that the lexical property to be projected into the perfect state is that of Brenda being in the poststate of kissing. The nature of the perfect state as a resultative is what allows for modification of frequency as in (33b). Summing up, the frequency puzzle is due to the fact that the perfect in each language introduces states of different categories.

\subsection{The past adverb puzzle}

The original "present perfect puzzle" as dubbed by Klein $(1992,1994)$ refers to the incompatibility of the present perfect with past time adverbs. This puzzle is shared by both $\mathrm{AE}$ and $\mathrm{BP}$.

a. *O Chris tem chegado ontem.

b. *Chris has arrived yesterday.

Positional adverbs can modify either the reference time or the event time for any kind of eventuality. This is more easily demonstrated with the past perfect.

a. Chris had left yesterday. (reference time)

b. Chris wasn't in his hotel room this morning. He had left yesterday. (event time)

Modification of one or the other time interval depends on lexical specification and context. Many XN theories resolve this by the fact that an interval including the speech time, cannot be modified by a past-time adverb. This, however, excludes all positional adverbs (McCoard 1978, Dowty 1979, Pancheva and Stechow 2004). If the positional adverb is indefinite, it is compatible with the present perfect.

a. Chris has worked at 9 o'clock.

b. O Chris tem trabalhado às 9 horas.

a. Chris has worked on Sundays.

b. O Chris tem trabalhado nos domingos.

The incompatibility of the present perfect with definite positional adverbs in the past results from the reference time already being modified in terms of position, by speech time in the present tense. So, positional adverbs cannot modify both the reference time and the eventuality time simultaneously, unless there is some reason to do so. This constraint, known as the present perfect puzzle, disappears once we distinguish definite from indefinite positional adverbs.

\section{Concluding Remarks}

The analysis outlined here, while of an informal nature, argues for a unified analysis of the present perfect in American English and Brazilian Portuguese. Adopting a perfect state framework based on Nishiyama and Koenig (2004), the present perfect meaning in both languages is semantically uniform and their differences are explained by a pragmatic divergence. The sources of both the frequency puzzle and the past adverb puzzle can be derived from the semantics and pragmatics of this present perfect meaning.

\section{References}

Amaral, P. and Howe, C.: 2005, The semantics of the Portuguese present perfect and the grammaticalization of ter/haver, presentation handout, The $8^{\text {th }}$ annual Ohio state university symposium on Hispanic and Luso-Brazilian Literatures, Linguistics and Cultures. 
Boléo, M. de P.: 1936, O pretérito e o perfeito em português, em confronto com as outras linguas românicas, Coimbra, Imprensa da Universidade.

Brugger, G.: 1978, Eventive time properties, in A. Dimitriadis, L. Siegel, C. Sure-Clark, and A. Williams (eds), Proceedings of the 21st Annual Penn Linguistics Colloquium, pp. 5163.

Comrie, B.: 1976. Aspect . Cambridge: Cambridge University Press.

Dowty, D.: 1979, Word meaning and montague semantics: the semantics of verbs and times in generative semantics and in montague's PTQ. Dordrecht: D. Reidel Publishing Co.

Giorgi, A. and Pianesi, F.: 1997, Tense and aspect: from semantics to morphosyntax. New York: Oxford University Press.

Iatridou, S., Anagnostopoulou, E. and Izvorski, R.: 2003, Observations about the form and meaning of the perfect. in A. Alexiadou, M. Rathert and A. von Stechow (eds), Perfect explorations, Berlin: Mouton de Gruyter, pp. 153-205.

Ilari, R.: 2001, Notas para uma semântica do passado composto em português, Revista Letras 55, 129-152.

Inoue, K.: 1979, An analysis of the English present perfect, Linguistics 17, 561-589.

Kamp, H. and Reyle, U.: 1993, From discourse to logic. Dordrecht: Kluwer Academic Press.

Klein, W.: 1992, The present perfect puzzle, Language 68, 525-552.

Klein, W.: 1994, Time in Language. London: Routledge.

McCoard, R.: 1978, The English Perfect: Tense Choice and Pragmatic Inferences. Amsterdam: North-Holland Press.

Michaelis, L.A.: 1998, Aspectual grammar and past-time reference. Routledge: London.

Moens, M. and Steedman, M.: 1998, Temporal ontology and temporal reference, Computational Linguistics 14, 15-29.

Nishiyama, A. and Koenig, J.P.: 2004, What is a perfect state?, in B. Schmeiser, V. Chand, A. Kelleher and A. Rodriguez (eds), WCCFL 23 Proceedings, pp. 101-113, MA: Cascadilla Press.

Pancheva, R. and von Stechow, A.: 2004, On the Present Perfect Puzzle, in K. Moulton and M. Wolf (eds) Proceedings of NELS 34.

Reichenbach, H.: 1947, Elements of Symbolic Logic, New York: The Free Press.

Schmitt, C.: 2001, Cross-linguistic Variation and the Present Perfect: The Case of Portuguese, Natural Language and Linguistic Theory 9, 403-453.

Smith, C.: 1997, The parameter of aspect (second edition). Dordrecht: Kluwer Academic Press.

Squartini, M. and Bertinetto, P.M.: 2000, The simple and compound past in romance languages, in Dahl, Ö., Tense and aspect in the languages of Europe. Berlin; New York: Mouton de Gruyter.

de Swart, H.: 1998, Aspect shift and coercion, Natural Language and Linguistic Theory 16, $347-385$.

ter Meulen, A.: 1995, Representing time in natural language: the dynamic interpretation of tense and aspect. Cambridge: The MIT Press. 